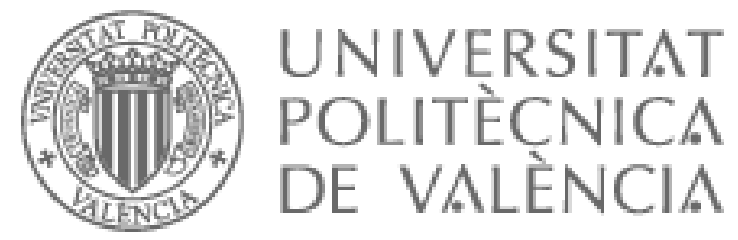

Departamento de Química

\title{
ESTUDIO DE ESTRATEGIAS DE INMOVILIZACIÓN DE BIOMOLÉCULAS SOBRE SOPORTES RÍGIDOS PARA APLICACIÓN EN MICROBIOSENSORES
}

\author{
TESIS \\ que para optar al grado de Doctor en Química presenta \\ MARÍA VICTORIA GONZÁLEZ PEDRO

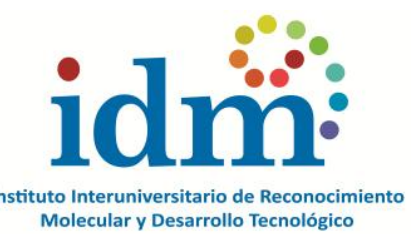

Valencia, Mayo del 2012 


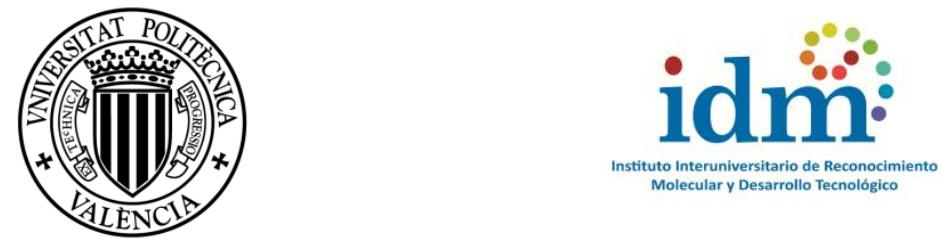

Molecular y Desarrollo Tecnológico

D. Ángel Maquieira Catalá, Catedrático de Universidad del Departamento de Química de la Universidad Politécnica de Valencia.

$D^{a}$. Rosa Puchades Pla, Catedrática de Universidad del Departamento de Química de la Universidad Politécnica de Valencia.

$D^{a}$. María José Bañuls Polo, Profesor Titular de Universidad del Departamento de Química de la Universidad Politécnica de Valencia.

\section{Certifican:}

Que el trabajo que presenta María Victoria González Pedro, en esta memoria, con el título "Estudio de estrategias de inmovilización de biomoléculas sobre soportes rígidos para aplicación en microbiosensores" ha sido realizado bajo nuestra dirección en el Departamento de Química de la Universidad Politécnica de Valencia".

Y para que así conste, a efectos de su presentación para optar al grado de Doctor en Ciencias Químicas, expedimos la presente que firmamos en Valencia, a 25 de Abril de 2012.

Dr. Ángel Maquieira Catalá Dra. Rosa Puchades Pla Dra. María José Bañuls Polo 

A Miguel y a mi familia 



\section{Agradecimientos}

El esfuerzo es una condición necesaria para valorar los objetivos que nos proponemos a lo largo de nuestra vida. Por ello tras un periodo de seis años y medio que ha constituido una etapa de continuo estudio, esfuerzo y aprendizaje, he comprendido que el fruto ha llegado tras el trabajo y la dedicación, y ha sido alimentado gracias a todas las personas que me han acompañado y ayudado sin las que habría resultado imposible completar esta tarea.

En primer lugar quiero agradecer a Ángel y a Rosa, por haberme dado esta oportunidad, porque de ella y de ellos he aprendido mucho. Gracias por confiar en mí así como por el tiempo y esfuerzo dedicado a mi formación.

De un modo especial quiero agradecer a María José. Ha sido un privilegio trabajar codo con codo contigo y, además de una amiga, has sido un referente durante todos los años que he trabajado a tu lado. Muchísimas gracias por tu participación activa en mi tesis doctoral, así como en el legado que has dejado en mi formación investigadora y, por encima de todo, por tu inestimable amistad.

Durante los años de realización de tesis he tenido la suerte de trabajar con un equipo estupendo en lo profesional y lo personal. Por ello a mis queridos compañeros con los que he compartido gran parte de mi tesis Eva, Jesús, Tania, Dolors, Marta, Ester y Sergio, gracias por vuestra inestimable ayuda a pie de laboratorio y por los buenos momentos que he disfrutado con vosotros que serán sin duda el recuerdo más dulce de esta tesis. También quiero agradecer a Sergi y a Luis por su buen consejo, experiencia y disposición a ayudar, y a Raquel, Ana y Álex que aunque su paso por el laboratorio fue más fugaz, también disfruté de su compañía.

Me gustaría agradecer a Carlos su inestimable ayuda durante la breve estancia en el Instituto de Sistemas Optoelectrónicos y Microtecnología en Madrid. Aquellas interminables jornadas fueron sin duda los días más largos pero también los más 
productivos de esta tesis. Y al profesor Gerard Kresbach, por su amabilidad, así como también por el trabajo realizado por la compañía Zeptosens que permitió completar esta tesis con un capítulo inesperado y de gran interés.

También quiero expresar mi gratitud al Departamento de Química y al Instituto de Reconocimiento Molecular y Desarrollo Tecnológico por haberme acogido durante estos años y facilitado llegar a este momento.

Hace dos años comencé una nueva etapa trabajando en el grupo de Dispositivos Fotovoltaicos y Optelectrónicos en la Universidad Jaume I en Castellón. Por ello quiero mencionar a todos mis compañeros de esta nueva aventura, en especial a Juan e Iván, por su comprensión y ayuda, que me ha permitido compaginar los dos trabajos.

En el plano personal no puedo olvidarme de dar las gracias a mi familia por su apoyo totalmente incondicional y su infinita paciencia. A mis padres, por la educación recibida. Y a mi hermana Pili, por tu buen carácter, por "soportarme" a mí y a mis neuras, y transmitirme tu alegría y optimismo.

A Miguel, por el interés que siempre demuestras en todas las empresas que abordo. Por compartir tu vida conmigo y darme tu apoyo durante todo este tiempo, especialmente durante la última etapa de tesis.

Por último quiero mencionar a todas mis amigas que de algún modo u otro me habéis dado la oportunidad de compartir mis motivaciones y por no haber dejado de mostrar interés por "la tesis".

Muchas gracias a todos. 


\section{Resumen}

El desarrollo de nuevos materiales para la mejora de sistemas analíticos basados en receptores moleculares -principalmente proteínas y ácidos nucleicos- altamente sensibles, con gran capacidad de trabajo y de manejo sencillo, tiene un gran potencial frente a los principales retos planteados hoy en día, como asistencia en tiempo real, detección multianalito, selectividad elevada y portabilidad, entre otros.

Los sistemas analíticos desarrollados en la presente tesis, con diferentes grados de aproximación al "ideal", se caracterizan por trabajar a escala micro y nanométrica, requerir la inmovilización controlada del elemento de reconocimiento biológico (biorreceptor o sonda) en la superficie, e incorporar un cierto grado de automatización, siendo el objetivo último y fundamental la aplicación de los desarrollos más prometedores a problemáticas concretas, como la puesta a punto de sistemas para diagnóstico clínico o mejora de la seguridad alimentaria.

En consecuencia, durante la realización del trabajo de tesis, se han planteado metodologías para la modificación química de diferentes materiales (silicio y derivados, óxido de tántalo y polímeros orgánicos) y la inmovilización de sondas de biorreceptores para el desarrollo de sistemas de detección óptica de dianas, en formato con y sin marcaje.

En este sentido, una parte de la tesis aborda la puesta a punto de sistemas de ensayo a escala micrométrica utilizando como plataformas analíticas discos compactos. En este caso, se trata de modificar convenientemente los polímeros que componen ambas caras de los CDs (policarbonato y polimetilmetacrilato) para imprimir micromatrices de reactivos de captura. La lectura de resultados se efectúa a partir de las señales generadas por los trazadores, utilizando un lector de CDs de audio-video estándar. Esta metodología, se ha aplicado a la detección de gripe aviaria en muestras de saliva, así como a la detección de polimorfismos de una sola base (SNPs) para sondas de ADN. 
En otra aproximación se ha trabajo con materiales derivados de silicio y óxido de tántalo. Sus propiedades dieléctricas y su rigidez los hacen ideales para el desarrollo de plataformas que integren nanoestructuras, conformando junto con otros elementos sistemas sensores miniaturizados.

Para materiales silíceos se ha utilizado un dispositivo fotónico, basado en guías de onda tipo slot de nitruro de silicio sobre óxido de silicio, para la detección sin marcaje de los analitos. Estos sistemas permiten la detección de la materia sobre la guía de nitruro y aportan como ventaja la alta sensibilidad de la guía slot. Utilizando estos dispositivos, se han realizado estudios con sistemas biológicos modelo, demostrando la aplicabilidad de estas superficies y su gran potencial para el desarrollo de un dispositivo optoelectrónico integrado multianalito y sensible.

Finalmente, sobre óxido de tántalo, se han investigado las ventajas que presenta la inmovilización covalente de biorreceptores frente a la adsorción. Para ello se ha trabajado con biochips en formato microarray (micromatrices de biorreceptores) de fluorescencia, empleando dispositivos de guía de ondas plana. En estos dispositivos la luz se propaga a través de la superficie de $\mathrm{Ta}_{2} \mathrm{O}_{5}$ (elevado índice de refracción) depositada sobre vidrio, de modo que el campo electromagnético generado como consecuencia del guíado de la luz es aprovechado como fuente de excitación de los fluoróforos. Esta metodología se ha aplicado al desarrollo de ensayos de detección de anticuerpos de hepatitis B en suero sanguíneo. 


\section{Resum}

El desenvolupament de nous materials que permetan la millora dels sistemes analítics fonamentats en receptors moleculars -principalment proteïnes i àcids nucleics- amb elevada sensibilitat, capacitat de treball i maneig senzill, té un alt potencial enfront dels principals reptes plantejats hui en dia, com a assitència en temps real, detecciò multianalito, selectivitat elevada i portabilitat, entre altres.

Els sistemes analitics desenvolupats en la present tesí, amb diferents graus d'aproximació al "ideal", es caracteritzen per treballar a escala micrométrica (o inferior), requerir la immobilització controlada de l'element de reconeiximent biològic (biorreceptor) en la superfície, i incorporar un cert grau d'automatització, especialment a les primeres etapes del procés analític. L'objectiu últim i fonamental d'aquest treball, es l'aplicació dels desenvolupaments més prometedors a problemàtiques concretes, com és l'optimització de sistemes competitius par a diagnòstic clínic o millora de la seguretat alimentària.

De manera que durant la realització del treball de tesi, van ser plantejades diferents metodologies per a la modificació química de diversos materials (polímers orgànics, derivats de silici i òxid de tàntal), que permeteran la immobilització de sondes de bioorreceptors d'interés per al desenrrotllament de sistemes de detecció òptica de dianes moleculars, amb marcatge o sense.

Una de les línies d'investigació va a ser la posada al punt de sistemes d'assaig a escala micrométrica utilitzant com a plataformes analítiques discos compactes. En aquest cas es va tractar de modificar convenientment els polímers principals components dels CDs (policarbonat i polimetilmetacrilat), per a imprimir micromatrius de reactius de captura (biorreceptors). La lectura de resultats es va efectuar a partir dels senyals generades pels traçadors absorbents utilitzats, mitjançant un lector de CDs d'audio-video modificat a l'efecte. Aquesta 
metodologia, es va aplicar a la detecció de grip aviària en mostres de saliva, així com a la detecció d'organismes genéticament modificats.

En una altra aproximació es va treballar amb materials derivats de silici i òxid de tàntal, que a causa de les seues propietats dielèctriques i a la duresa dels mateixos, són ideals per al desenrotllament de plataformes que integren nanoestructuras, conformant junt amb altres elements sistemes sensors miniaturitzats.

Per a materials de silici i derivats es va utilitzar un dispositiu fotónic, basat en anells de guies d'onda slot de nitrur de silici sobre òxid de silici, per a detecció sense marcatge d'anàlits d'interés. Estos sistemes permeten la detecció sense marcatge de la matèria immobilitzada sobre la guia de nitrur i aporten com a avantatge l'alta sensibilitat d'aquest tipus de guía. Amb estos dispositius, es van realitzar estudis amb sistemes biològics model, demostrant l'aplicabilitat d'aquestes superfícies i l'alt potencial per al desenvolupament d'un dispositiu optoelectrònic integrat que permeta la detecció multianalit, amb una alta sensibilitat.

Finalment sobre material òxid de tàntal, es van estudiar els avantatges que presenta la immobilització covalent de biorreceptores enfront d'adsorció, en biochips en format microarray (micromatrius de biorreceptors) de fluorescència emprant dispositius de guia d'onda plana. En estos dispositius la llum es propaga a través d'una superfície de $\mathrm{Ta}_{2} \mathrm{O}_{5}$ (elevat índex de refracció) depositada sobre vidre. De mode que el camp electromagnètic generat com a conseqüència del guiat de la llum, és aprofitat com a font d'excitació dels fluorófors. Aquesta metodologia es va aplicar al desenrotllament d'assajos de detecció de anticossos de hepatitis B en sèrum sanguinio. 


\begin{abstract}
The development of new materials to improve analytical systems based on molecular receptors, mainly proteins and nucleic acids, highly sensitive, hardworking, reliable and easy to use, shows a huge potential and can offer very interesting responses to the addressed challenges today, such as real-time asssitance, multianalyte detection, high selectivity and portability, home health monitoring assays, among others.
\end{abstract}

Analytical systems developed in this work are characterized by micron-scale work (or less), require the controlled immobilization of biological element (biorreceptor) on the surface, and incorporate a degree of automation, especially in the early stages of the analytical process. The last and fundamental aim was the application of the most promising developments in specific issues, as competitive set-up for clinical diagnostic systems or enhancement of food safety.

Thus, in this thesis, methodologies for chemical modification of different materials (organic polymers, derived from silicon and tantalum oxide), which allowed the immobilization of biorreceptors of interest were purposed, for optical detection of molecular targets, with or without labeling.

In this sense, one of the researches was the development of micrometer scale analytical systems using CDs as analytical platforms. In this case it's convenient to modify the polymeric materials CDs are made off (polycarbonate and polymethylmethacrylate), to print microarrays capture reagents. The reading of the results were carried out on the signals generated by absorbing tracers, using a modified CD reader for this purpose. This methodology was applied to the detection of avian influenza in saliva samples and single nucleotide polymorphism (SNPs) .

In other approach we worked with materials derived from silicon and tantalum oxide, which due to their dielectric properties and their hardness, are ideal for the 
development of platforms which incorporate nanostructures, forming together with other elements miniaturized sensor systems.

For silicon materials and derivatives a photonic device based on silicon nitride microrings slot waveguides deposited on silicon oxide substrate, were used for optical label free detection of analytes of interest. These analytical systems allow the detection of the substance immobilized on the nitride waveguide, without any previous labeling step, futhermore provide advantages such as high sensitivity of the slot waveguide. A biological model system (BSA-antiBSA) was studied by this device, showing the successful of these photonic structures applicability and the huge potential for the development of high sensitive integrated optoelectronic device capable of multianalyte detection in real samples.

Finally, on tantalum oxide materials the main advantages of covalent immobilization of biorreceptors face adsorption were studied, for the development of biochips for fluorescence microarrays detection using waveguide devices were studied. In these devices light travels through an area of $\mathrm{Ta}_{2} \mathrm{O}_{5}$ (highe refractive index) deposited on glass. Thus, the electromagnetic field generated as a result of guiding light is used as a source of excitation of the fluorophores. This methodology was applied to setting-up assays to detect hepatitis B antibodies in blood serum. 


\section{ÍNDICE}

\section{INTRODUCCIÓN ................................................................1}

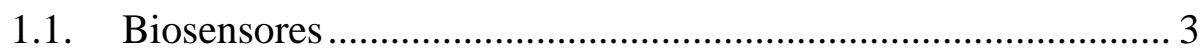

1.2. Clasificación de los biosensores ................................................ 7

1.2.1. Tipo y modo de detección de la interacción....................................8

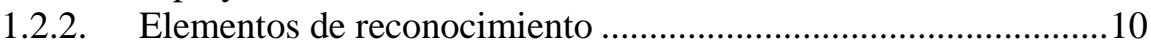

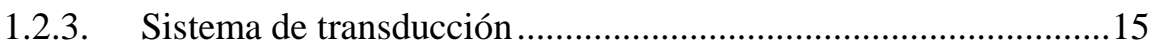

1.3. Técnicas de inmovilización de biomoléculas .............................. 17

1.4. Estudio de soportes sólidos para uso en biosensores ópticos ... 24

1.5. Sistemas biosensores basados en materiales poliméricos..........25

1.5.1. Polímeros orgánicos. Potencial para la fabricación de BioMEMs ...............................................................................

1.5.2. Tecnología de disco compacto: Una herramienta de análisis

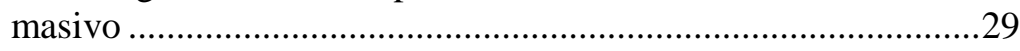

1.5.3. Antecedentes y estado del arte del empleo de discos compactos como plataformas analíticas .........................................34

1.5.4. Funcionalización de superficies poliméricas................................40

1.6. Sistemas ópticos basados en guías de ondas ........................... 44

1.6.1. Sistemas ópticos integrados y detección sin marcaje ....................46

1.6.2. Sistemas ópticos integrados y detección con marcaje...................54

1.6.3. Funcionalización de materiales inorgánicos..................................56

2. OBJETIVOS .................................................................................71

3. MATERIAL Y MÉTODOS.................................................75

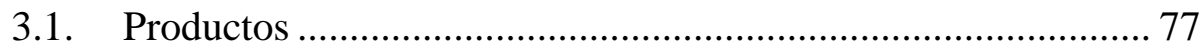

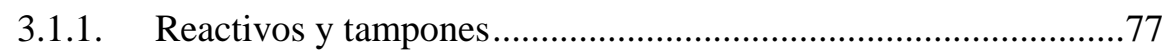

3.1.2. Plataformas de ensayo ..........................................................

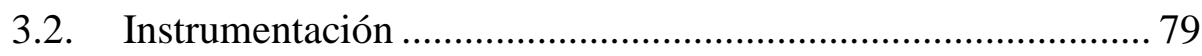


3.3. Estrategias de modificación química de las superficies de

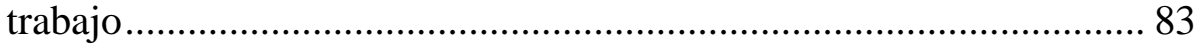

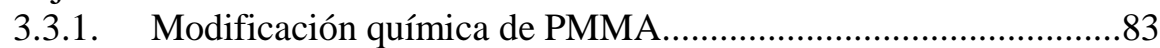

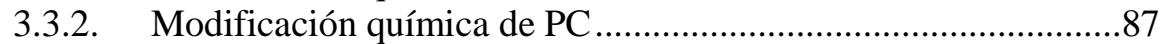

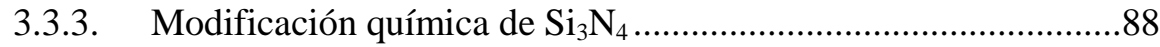

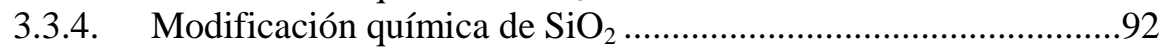

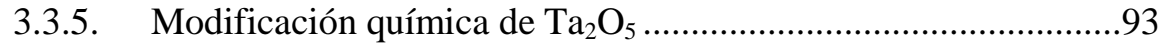

3.4. Desarrollo de ensayos de biorreconocimiento......................... 95

3.4.1. Ensayos de hibridación de sondas de oligonucleótidos................95

3.4.2. Ensayos de reconocimiento con anticuerpos ...............................98

4. RESULTADOS Y DISCUSIÓN.......................................... 103

4.1. Sistemas microanalíticos sobre soportes poliméricos ............ 105

4.1.1. Estrategias de modificación química de superficies

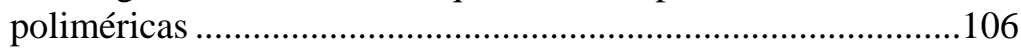

4.1.2. Estudios de inmovilización de sondas biomoleculares ..............120

4.1.3. Estudios de hibridación de sondas de oligonucleótidos .............128

4.1.4. Aplicaciones en inmunoensayo: Detección de gripe aviaria .....141

4.2. Dispositivos ópticos basados en guías de ondas 3D ............... 153

4.2.1. Modificación química selectiva de $\mathrm{Si}_{3} \mathrm{~N}_{4}$ sobre superficies

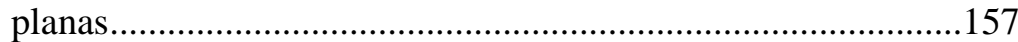

4.2.2. Estudios de inmovilización de biomoléculas sobre las

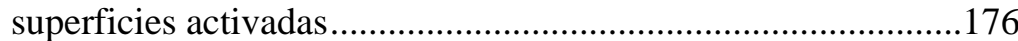

4.2.3. Aplicación en nanoestructuras (3D) ..........................................180

4.3. Dispositivos basados en guía de ondas plana ......................... 188

4.3.1. Modificación química de pentóxido de tántalo ...........................190

4.3.2. Inmovilización de biomoléculas marcadas con Cy5 ...................193

4.3.3. Aplicación a estructuras de guía de ondas plana..........................196

4.4. Estudio comparativo de los sistemas analíticos desarrollados 206

5. CONCLUSIONES 209

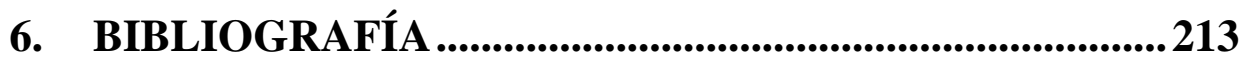

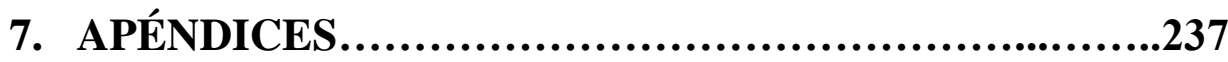





\subsection{Biosensores}

El creciente interés para realizar controles analíticos efectivos, rápidos y económicos, disponiendo de información in situ, y que den respuesta a las necesidades del ámbito sanitario, entre otros, ha dirigido la atención de los investigadores hacía el desarrollo de nuevas técnicas de ensayo y metodologías analíticas. Además, la necesidad de disponer de técnicas rápidas, selectivas, sensibles, portables, con gran capacidad de trabajo y nuevas perspectivas de aplicación, ha propiciado el desarrollo de biosensores.

En el 1996, la IUPAC ${ }^{1}$ definió biosensor como un dispositivo integrado capaz de proporcionar información analítica cuantitativa o semicuantitativa, compuesto por un elemento de reconocimiento biológico (ácido nucleico, anticuerpo, enzima, tejido, etc.) en íntimo contacto con un elemento de transducción, que permite procesar la señal generada por la interacción entre el elemento de reconocimiento y el analito, transformándola en información específica ${ }^{2-4}$. En el funcionamiento básico de un biosensor, el analito es reconocido por un biorreceptor, generando una señal primaria. A continuación, el transductor la convierte en una señal secundaria, generalmente eléctrica, que posteriormente es procesada para ser presentada en forma útil (Figura 1).

Fue en el año 1962, cuando L.C. Clark diseñó el primer biosensor ${ }^{5}$ basado en la inclusión de la enzima glucosa-oxidasa en un electrodo de oxígeno, pudiendo determinar la concentración de glucosa en sangre a partir de la disminución de la concentración de oxígeno. A partir de este momento, han sido muchos los sistemas descritos empleando diferentes tipos de elementos biológicos de reconocimiento (anticuerpos, oligonucleótidos, tejidos, etc.), sistemas de transducción (ópticos, gravimétricos, electroquímicos, etc.) y modos de detección (con o sin marcaje), así 
como los dispositivos biosensores comercializados para detección de glucosa, agentes patógenos, o discriminación de sondas de DNA, entre otros. ${ }^{6-10}$

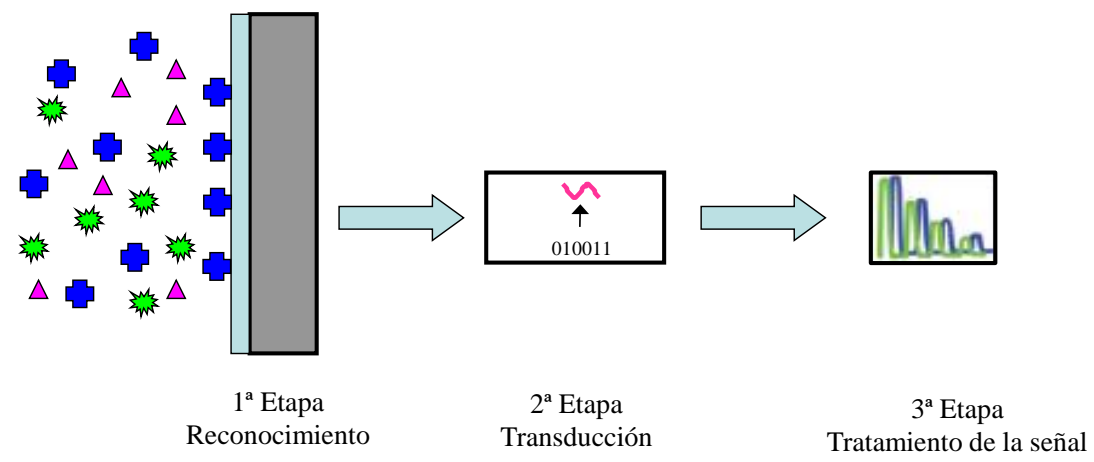

Figura 1. Esquema del funcionamiento básico de un biosensor.

Dentro del campo de los biosensores, resultan de especial interés los sistemas BioElectroMecánicoS (BioMEMs), definidos según -el IV programa Marco de la Unión Europea- como sistemas miniaturizados inteligentes que reúnen funciones sensoras, de procesado y de transducción. Además, integran al menos dos de las siguientes propiedades: eléctricas, mecánicas, ópticas, químicas, magnéticas u otras, en un solo dispositivo ${ }^{11-15}$. En una conferencia celebrada en 1959, R. Feynman ya introdujo el concepto de sistemas miniaturizados ("Hay mucho espacio en lo pequeño"), y el potencial que representaban los dispositivos construidos a escala nanométrica $^{16}$. Sin embargo, es con posterioridad al desarrollo de las tecnologías de microfabricación de semiconductores, normalmente utilizadas en electrónica y microprocesadores, cuando los BioMEMs se convirtieron en una realidad. En general, estos sistemas varían en tamaño, desde micrometros (MEMs) hasta nanómetros (NEMs), tratándose de una escala de trabajo donde las aproximaciones de la física clásica no son siempre aplicables. 
Los biosensores, en cualquier presentación y con diferentes grados de aproximación al ideal, constituyen una herramienta muy útil para el desarrollo de técnicas másivas de ensayo y protocolos de barrido (screening), debido a propiedades tales como:

$\checkmark$ Elevada sensibilidad, incluso en formato sin marcaje.

$\checkmark$ Alta selectividad, interacciona con el compuesto de interés discriminando a otros con propiedades similares.

$\checkmark$ Pretratamiento de muestra reducido, aunque en ciertos protocolos es imprescindible introducir etapas de concentración y purificación.

$\checkmark$ Análisis multimuestra y multianalito, que permite llevar a cabo la determinación simultánea en muestras diferentes o de distintos analitos.

$\checkmark \quad$ Gran capacidad de trabajo.

$\checkmark$ Tiempos de análisis cortos, que posibilitan una medida en pocos minutos.

$\checkmark \quad$ Manejo sencillo, que no requiere de personal cualificado.

$\checkmark$ Portabilidad, permitiendo la realización de análisis in situ.

$\checkmark$ Automatizabilidad, eliminando el control manual y facilitando su integración dentro de otros sistemas.

$\checkmark$ Bajo coste de producción, ya que en general estos sistemas se diseñan para su fabricación en masa.

Otra tecnología de interés, desarrollada a partir de la década de los noventa, es la basada en micromatrices de material biológico, microarrays, ADN arrays o Chips genéticos, Protein Chips y Tissue Chips, en función del tipo de material inmovilizado. Estos dispositivos, también llamados Biochips, constituyen una de las herramientas más recientes para hacer frente a los nuevos desafíos, caracterizados 
por la obtención masiva de información analítica, en un tiempo reducido y al menor coste posible.

Los biochips están constituidos por un soporte sobre el que se sitúa el material biológico formando una matriz ordenada, de manera que cada punto de la matriz esta totalmente identificado, permitiendo su análisis y posterior interpretación (Figura 2). Estos dispositivos miniaturizados permiten trabajar con una elevada densidad de material biológico, y la posibilidad de gestionar y almacenar grandes cantidades de información, derivada de la utilización de herramientas bioinformáticas.

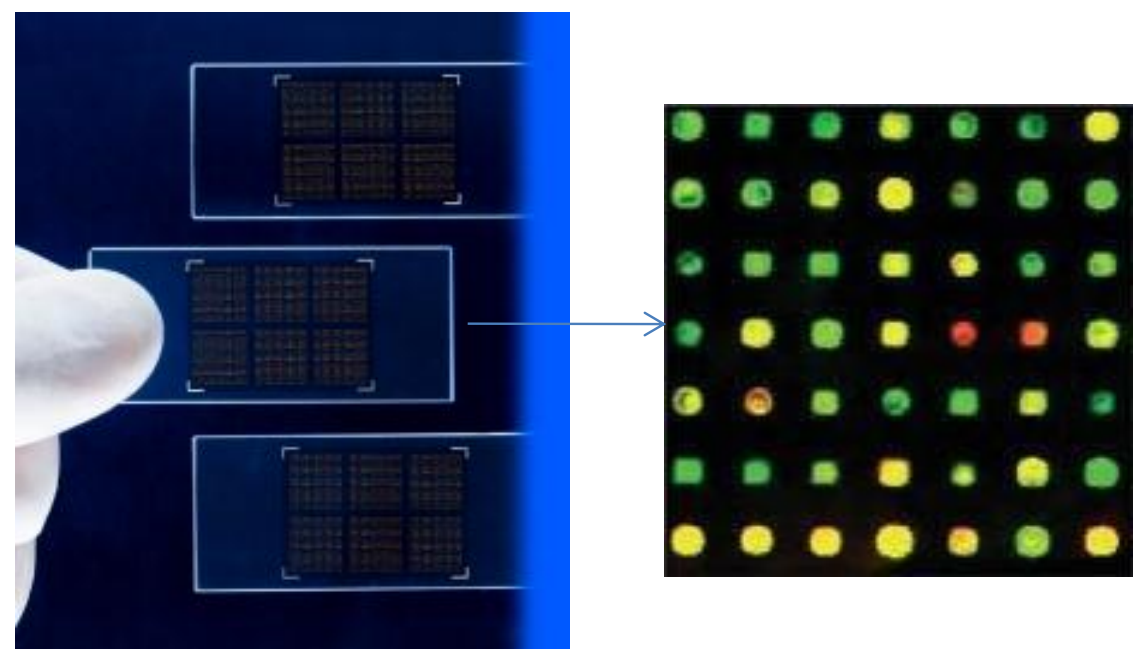

Figura 2. Dispositivos comerciales de micromatrices de sondas.

El primer microarray comercialmente disponible fue producido por la empresa Affymetrix $^{17}$ en el año 1994; con una capacidad de 16.000 sondas, permitía el análisis simultáneo de la expresión de miles de genes. Las generaciones más recientes de microarrays permiten el genotipado de más de 500.000 marcadores de 
polimorfismo de secuencia. Estos nuevos biochips de alta densidad diseñados para el rastreo de enfermedades genéticas han permitido detectar, por ejemplo, el síndrome de la muerte súbita del bebé ${ }^{18}$, el desorden bipolar ${ }^{19}$ y la degeneración macular relacionada con la edad. ${ }^{20}$

Los criterios para sistematizar los microarrays son muy variados pudiendo clasificarlos según el modo de fabricación, el tipo de molécula inmovilizada, el diseño de la matriz o el material soporte empleado.

La tecnología de biosensores ha experimentado un notable avance en los últimos años debido, fundamentalmente, al desarrollo de dispositivos aplicados al área biomédica. Estas investigaciones, en avanzado estado de madurez, han ido transfiriéndose paulatinamente a otros sectores de la industria como el farmaceútico, el medioambiental y el agroalimentario, produciéndose en las dos últimas décadas un avance que ha permitido hacer de los biosensores herramientas analíticas imprescindibles.

\subsection{Clasificación de los biosensores}

Los componentes básicos de una plataforma biosensora son el elemento de reconocimiento y el elemento de transducción, estableciéndose los criterios de clasificación de acuerdo a su naturaleza. De este modo, los sistemas biosensores se han clasificado según el tipo de interacción que se establece entre el elemento de reconocimiento y el analito, el método utilizado para detectar dicha interacción, la naturaleza del elemento de reconocimiento, el formato de ensayo y el sistema de transducción (Tabla 1). 


\subsubsection{Tipo y modo de detección de la interacción}

Los biosensores, según el tipo de interacción, pueden ser biocatalíticos o de bioafinidad. Los sensores biocatalíticos (enzimáticos) se basan en la inmovilización de un elemento que actúa como catalizador, midiendo la aparición o desaparición de las sustancias de interés en el medio de reacción. Por otro lado, los sensores de bioafinidad están basados en la interacción del analito de interés con el elemento de reconocimiento, sin que exista transformación catalítica, formándose el complejo analito-receptor.

En este último caso, para le detección de la interacción y la estimación de su magnitud -ya que no existe consumo de sustrato ni generación de productos- puede utilizarse un sistema de detección directa de la interacción receptor analito, basada en los cambios de masa que tienen lugar en la superficie receptora, o bien en los cambios de las propiedades ópticas o electroquímicas producidos por dicha unión. Alternativamente, se recurre al marcaje de alguno de los elementos de reconocimiento o de alguna molécula que compita con el analito por su unión con el receptor. En consecuencia, podemos diferenciar entre detección directa -sin necesidad de marcaje-, y detección indirecta -cuando es necesario marcar alguno de los elementos de reconocimiento con fluoróforos, enzimas, partículas metálicas, etc.-.

El protocolo de sensado más sencillo es la detección directa, basada en la unión del analito sin marcar y el biorreceptor previamente anclado sobre la plataforma de ensayo $^{21-28}$, siendo las más utilizadas las basadas en fenómenos de interferometría y de resonancia de plasmón de superficie (SPR). 


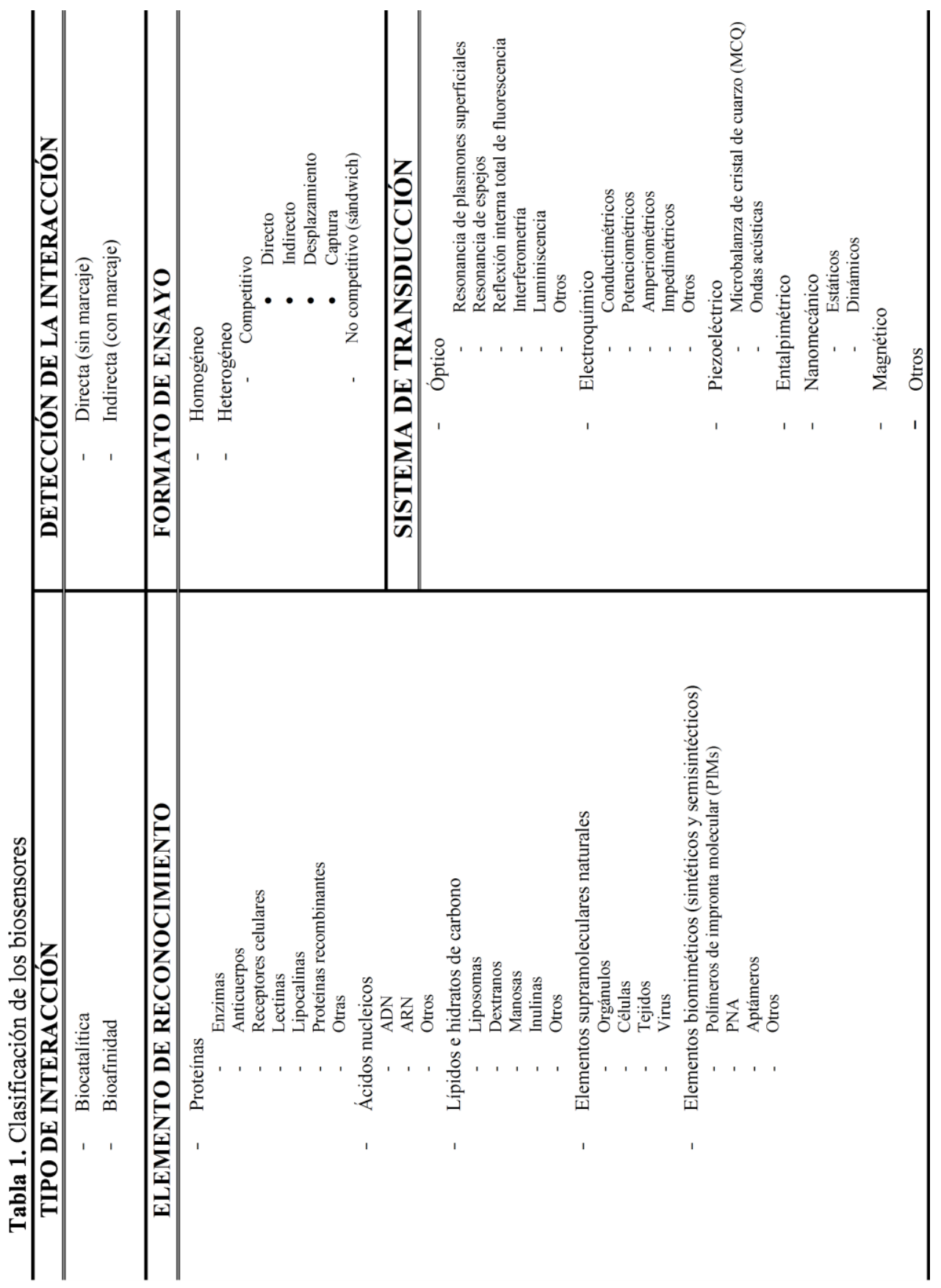


En los métodos de detección indirecta es necesario el marcaje de alguno de los elementos de reconocimiento; en función del marcaje utilizado los ensayos pueden clasificarse como (i) enzimáticos, cuando utilizan una enzima, (ii) radioactivos (RIAs), si las medidas son radioquímicas, y (iii) fluoroinmunoensayos, si el marcador es un fluoróforo o una molécula quimioluminiscente ${ }^{29}$. Además, existen otros tipos de marcadores cuyo uso es más restringido, como los particulados (látex, oro, puntos cuánticos o nanocristales), complejos metálicos $\left(\mathrm{Tb}^{3+}, \mathrm{Eu}^{3+}\right), \mathrm{y}$ cofactores enzimáticos (FAD), entre otros.

\subsubsection{Elementos de reconocimiento}

La capacidad de reconocer un analito en una matriz heterogénea es un aspecto crucial en el desarrollo de biosensores, por lo que la elección del biorreceptor es una de las etapas más críticas. Las moléculas utilizadas en los biosensores como elementos de reconocimiento deberán cumplir ciertos criterios fundamentales para poder ser empleadas como unidades sensoras. Así, deben tener afinidad hacia el elemento objeto del reconocimiento y ser suficientemente selectivas para reconocer a éste en presencia de otros compuestos, además de permanecer estables a lo largo del tiempo. En función del elemento de reconocimiento (proteínas, ácido nucleico, etc.), pueden diferenciarse varias categorías de biosensores (Tabla 1).

A continuación se describen con más detalle los elementos de reconocimento utilizados en el presente trabajo, anticuerpos y ácidos nucleicos.

\section{Anticuerpos}

La mayoría de los biosensores de afinidad se basan en este tipo de reconocimiento. Un anticuerpo es una proteína producida por el organismo como respuesta inmunológica a un "invasor" extraño, mientras que el antígeno es la sustancia que el cuerpo está tratando de eliminar o bloquear mediante la respuesta 
inmunológica. Los anticuerpos poseen una alta capacidad de interacción con el antígeno y, por tanto, es la unión específica de un anticuerpo a un antígeno lo que permite la detección sensible de analitos utilizando diferentes técnicas de inmunoensayo.

Los anticuerpos pueden ser policlonales, monoclonales o recombinantes. Los primeros son poblaciones heterogéneas de inmunoglobulinas que reconocen distintas regiones del antígeno, mientras que los monoclonales son anticuerpos idénticos producidos "in vitro" a través de la clonación de un solo tipo de célula del sistema inmune; es decir todos los anticuerpos proceden de una única célula y, por tanto, manifiestan un comportamiento idéntico. La afinidad y selectividad de la interacción antígeno-anticuerpo determinan la sensibilidad de un inmunosensor, así como su posible regeneración mediante la aplicación de agentes que favorezcan la disociación del complejo ${ }^{30,31}$. Por otro lado, los anticuerpos recombinantes o de segunda generación, son moléculas producidas en el laboratorio mediante el empleo de técnicas de biología molecular, con capacidad de reconocimiento del agente inmunógeno. La producción de este tipo de anticuerpos no requiere inmunización de animales.

Dada la amplitud del concepto de inmunoensayo, el número posible de formatos que puede adoptar un inmunoanálisis es enorme ${ }^{2,32,33}$. Según el desarrollo de la interacción antígeno -anticuerpo, pueden ser homogéneos -cuando la reacción inmunoquímica se produce en el seno de una disolución sin que haya separación física entre el analito y el resto de componentes de la matriz-, o heterogéneos cuando la interacción tiene lugar en la interfase entre un soporte sólido y una disolución, permitiendo la separación del analito y del resto de la matriz-. En la Figura 3 se muestra un esquema de los formatos de inmunoensayo más representativos. 


\section{A- Formato heterogéneo competitivo}

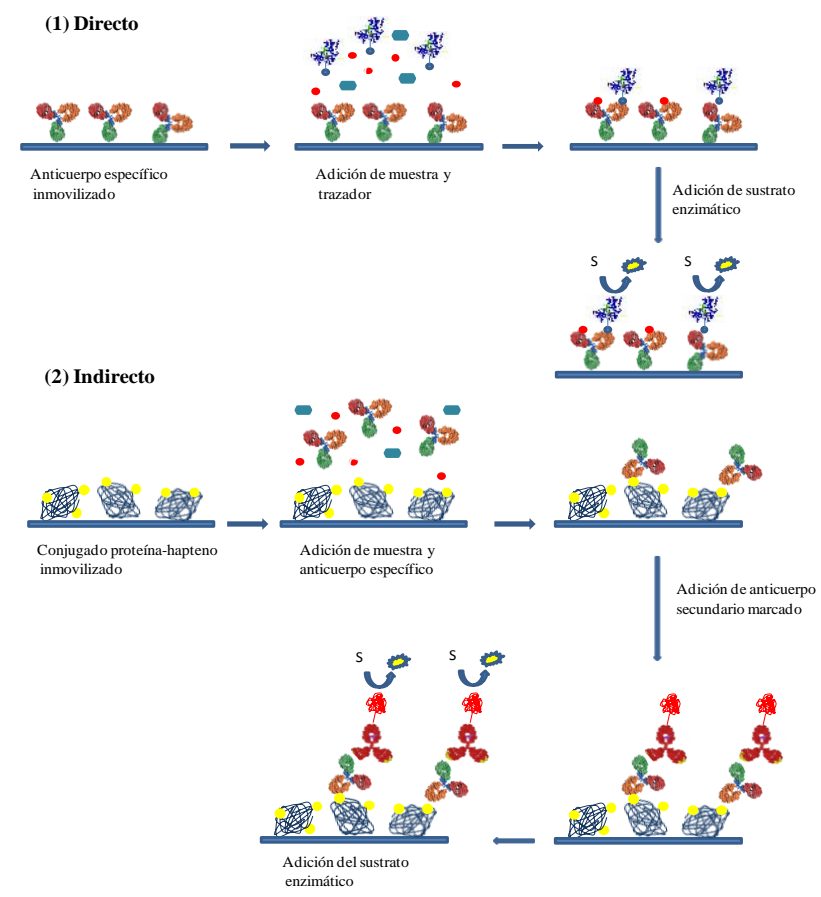

B- Formato heterogéneo no competitivo (sandwich)

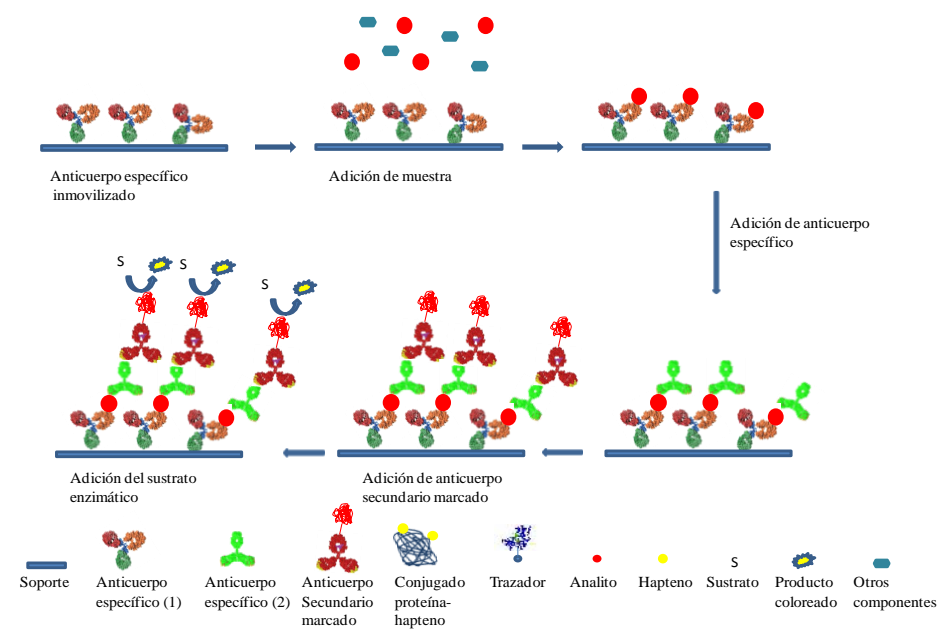

Figura 3. Esquema de los formatos de inmunoensayo más representativos. 
En funcion del diseño, los inmunoensayos pueden ser $\operatorname{competitivos}^{34-40}$ (o de reactivo limitado) -cuando el analito rivaliza con un homólogo marcado por los sitios específicos del anticuerpo, que se encuentra en cantidad limitante-, por desplazamiento -cuando el antígeno marcado se incuba con el anticuerpo (reactivo limitante) y después es desplazado por su homólogo marcado-. Según el desarrollo del formato competitivo, los inmunoensayos pueden ser directos -de anticuerpo inmovilizado (Figura 3A-1)- o indirectos -de conjugado inmovilizado (Figura 3A2)-.

En los formatos no competitivos (o de reactivo en exceso) el analito o diana molecular es capturado por anticuerpos sin marcar previamente inmovilizados sobre el soporte, y el complejo es detectado por la adición de anticuerpos específicos marcados que se unen a la proteína formando un sándwich ${ }^{40,41-46}$ (Figura 3B). Esta configuración solo puede utilizarse cuando el analito de interés posee al menos dos sitios de unión y, por tanto, no será apropiado para moléculas de bajo peso molecular.

\section{Ácidos nucleicos (ANs)}

Los biosensores que utilizan ácidos nucleicos se basan en el fenómeno de hibridación de sondas. Mediante este proceso se combinan las cadenas de ácidos nucleicos con alto grado de complementariedad, en una única molécula de doble cadena.

Los biosensores conocidos como genechips, consisten en matrices bidimensionales de moléculas de AN ordenadas sobre un sustrato sólido, a las que se les denomina "sondas". Estos fragmentos de material genético pueden ser secuencias cortas monocatenarias (oligonucleótidos), o bien productos de PCR (replicación "in vitro" de secuencias de ADN mediante la reacción en cadena de la polimerasa). Por otro lado, los ácidos nucleicos de las muestras a analizar se 
marcan, generalmente con fluoróforos, y se incuban sobre el panel de sondas permitiendo la hibridación (reconocimiento y unión entre cadenas complementarias). Durante la hibridación, las muestras de material genético marcadas se unen a sus complementarias inmovilizadas en un soporte, permitiendo la identificación y cuantificación del ADN presente en la muestra mediante el empleo de un escáner de fluorescencia, y de las herramientas informáticas adecuadas para cuantificar e interpretar los datos obtenidos.

Los genechips se usan para el reconocimiento y cuantificación de ANs y poseen gran cantidad de aplicaciones prácticas, por ejemplo, la identificación de organismos modificados genéticamente y de agentes patógenos. La sensibilidad de este tipo de sensores es elevada, permitiendo en algunos casos eliminar etapas previas de amplificación ${ }^{47-50}$.

Como alternativa al uso de sondas de ANs naturales se pueden desarrollar biosensores de ANs utilizando aptámeros como elemento de reconocimiento y ácidos peptidonucleicos (APNs). Un aptámero es una secuencia de oligonucleótidos sintetizada artificialmente, capaz de reconocer diversas moléculas diana con una afinidad y especificidad elevada, mientras los APNs son moléculas sintéticas que tienen la capacidad de almacenar información (como el ADN) y una estabilidad química semejante a las proteínas. Estas moléculas presentan ventajas en cuanto al diseño, si bien su aplicación práctica poseen serios inconvenientes. En el caso de los aptámeros, especialmente, su falta de estabilidad en fluídos biológicos (son necesarias etapas de modificación química para conferirle estabilidad biológica); además, suelen poseer constantes de afinidad inferiores a las alcanzadas cuando el elemento de reconocimiento es una proteína ${ }^{51}$. A pesar de todo ello, están demostrando poseer un gran potencial. 


\subsubsection{Sistema de transducción}

El sistema de transducción es el elemento que convierte las variaciones de las propiedades físico-químicas producidas por la interacción entre el elemento de reconocimiento y el analito en una señal que puede ser amplificada, almacenada y registrada. Existen distintos tipos de transductores en función de las propiedades físicas en las que se fundamenta la medida: electroquímicos ${ }^{52-56}$, ópticos, piezoelectricos $^{47,57}$ (másicos, acústicos), entalpimétricos ${ }^{58,59}$ y mecánicos ${ }^{60,61}$. Además, todos ellos pueden trabajar tanto a escala micrométrica como nanométrica. En la Tabla 2 se describen las principales ventajas e inconvenientes de los sistemas de transducción de mayor uso.

Los transductores ópticos están basados en la medición de las variaciones que se producen en las propiedades de la radiación electromagnética; son los más utilizados debido a su gran campo de aplicación, ya que incorporan técnicas de espectrometría y, por tanto, presentan un gran número de subcategorías en función del tipo de espectroscopia empleada (absorción, dispersión, reflexión, luminiscencia, fluorescencia, fosforescencia, quimioluminiscencia, infrarrojo, RAMAN, refracción, resonancia, interferencia, etc. $)^{62-64}$. En algunos casos permiten la detección directa del analito en la muestra, sin utilizar marcaje.

Dentro de los transductores ópticos, los sistemas elementales más establecidos consisten en una fuente de luz, una plataforma sensora (bien de vidrio, plástico, o metal) donde se encuentran los biorreceptores, y un sistema de detección basado en medidas espectroscópicas (fluorescencia, absorbancia, etc.).

Además, en las últimas décadas los dispositivos de óptica integrada han adquirido gran importancia debido a su alta sensibilidad, estabilidad mecánica, posibilidad de miniaturización e integración en microsistemas, y fabricación a gran escala. 


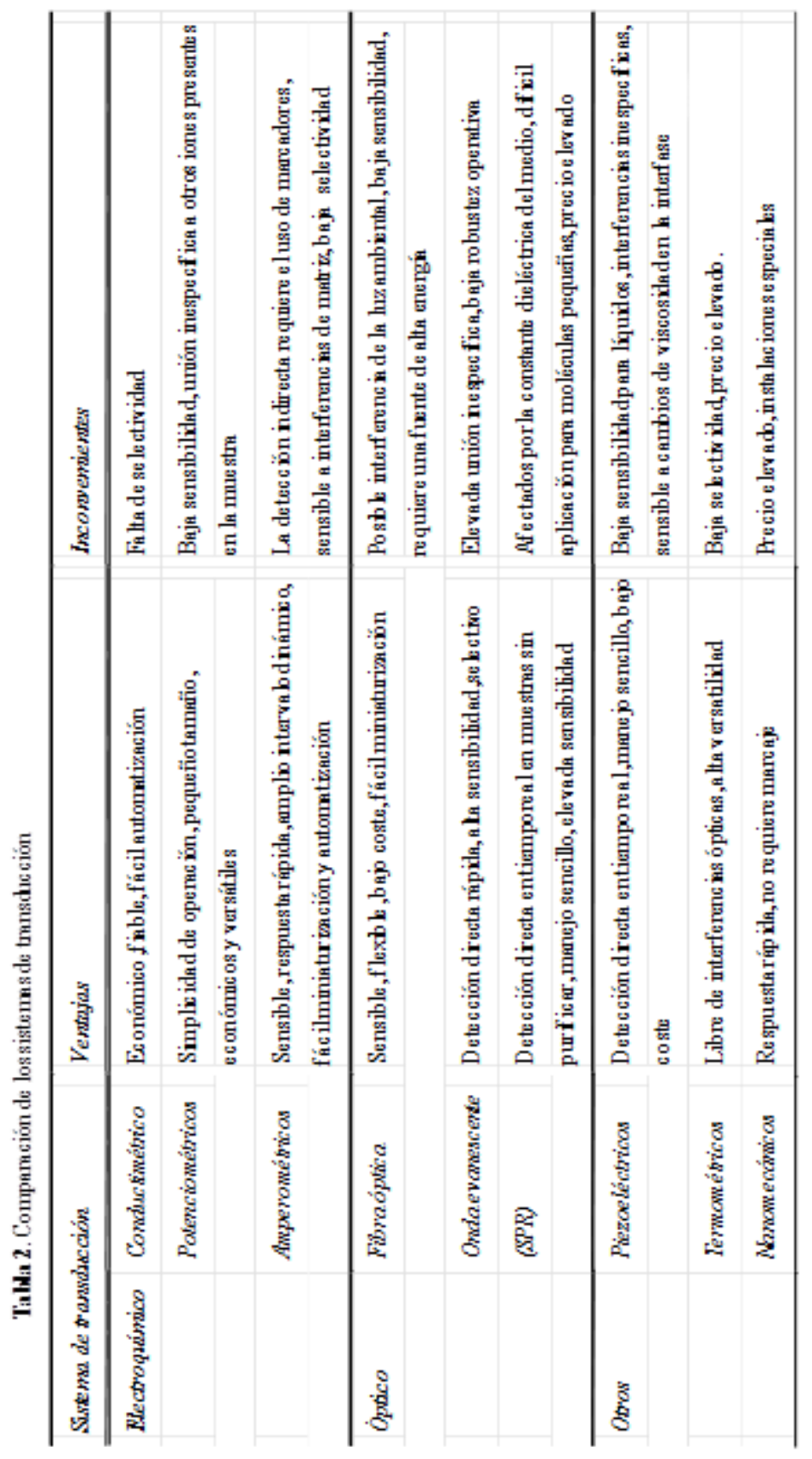


Todo ello ha dado lugar al desarrollo de transductores ópticos más complejos basados en el principio de modulación del campo evanescente. En una guía de ondas la luz se transmite en condiciones de reflexión total interna; no obstante, el campo electromagnético asociado a la guía de ondas no queda estrictamente confinado al interior del núcleo de la guía, sino que presenta un decaimiento exponencial en las zonas que envuelven al núcleo, dando lugar al denominado campo evanescente. Cualquier interacción molecular (analito-receptor) que se produzca dentro de este campo producirá cambios en las características de la luz que se propaga por la guía de ondas.

Varios son los biosensores que se basan en este principio de transducción: resonancia de plasmón de superficie (SPR), resonancia de espejos, interferómetros ${ }^{65-68}$, sensores de fibra óptica capilar ${ }^{69-71}$ o reflexión interna total de fluorescencia, entre otros. Se caracterizan por ser dispositivos con un alto potencial, que permiten la detección del analito de manera selectiva, rápida (de segundos a minutos) y, en ocasiones, directa. Algunos de ellos y sus principales aplicaciones se describen posteriormente con más detalle.

\subsection{Técnicas de inmovilización de biomoléculas}

Una de las etapas clave en la construcción de un biosensor es la inmovilización del elemento de reconocimiento sobre el soporte de interés. En la mayoría de casos, se requiere una fijación ordenada de biorreceptores al material base (soporte) del sistema sensor (formando una capa uniforme y orientada), de modo que se facilite el reconocimiento molecular de los analitos. Por ello, la inmovilización de biomoléculas sobre soportes rígidos es, desde el punto de vista químico, uno de los problemas fundamentales para el desarrollo de biosensores. 
La inmovilización es un proceso en el que se confina o localiza la biomolécula en una región definida del espacio, para dar lugar a formas insolubles que retienen su actividad biológica y que, en ocasiones, pueden ser reutilizadas repetidamente ${ }^{72}$; posteriormente, esta definición se ha ampliado a aquel proceso por el cual se restringen, completa o parcialmente, los grados de libertad del biorreceptor, por su unión al soporte ${ }^{73}$.

Las principales ventajas del empleo de biomoléculas fijadas sobre soportes sólidos, $\operatorname{son}^{74}$ :
$\checkmark$ Aumento de la estabilidad del biorreceptor
$\checkmark$ Orientación del biorreceptor
$\checkmark$ Disposición en zonas críticas del biosensor
$\checkmark$ Reutilización
$\checkmark$ Diseño de dispositivos biosensores de fácil manejo y alta sensibilidad, adaptados a diferentes escenarios

Sin embargo, los principales inconvenientes atribuibles a dicho proceso $\operatorname{son}^{75}$ :
$\checkmark$ Alteración de la conformación de la biomolécula respecto a su estado nativo y pérdida de biodisponibilidad de la molécula inmovilizada.
$\checkmark$ Heterogeneidad del sistema biorreceptor-soporte, al inmovilizar fracciones con distinta capacidad de reconocimiento.
$\checkmark$ Localización del biorreceptor, lo que condiciona el acceso del analito al mismo. En muchos casos, los factores de difusión limitan las prestaciones del sistema sensor, lo que se traduce en mayores tiempos de ensayo y menor sensibilidad.


Las técnicas de inmovilización se clasifican en dos grandes categorías, retención física y unión química, tal y como se muestra en la Figura 4.

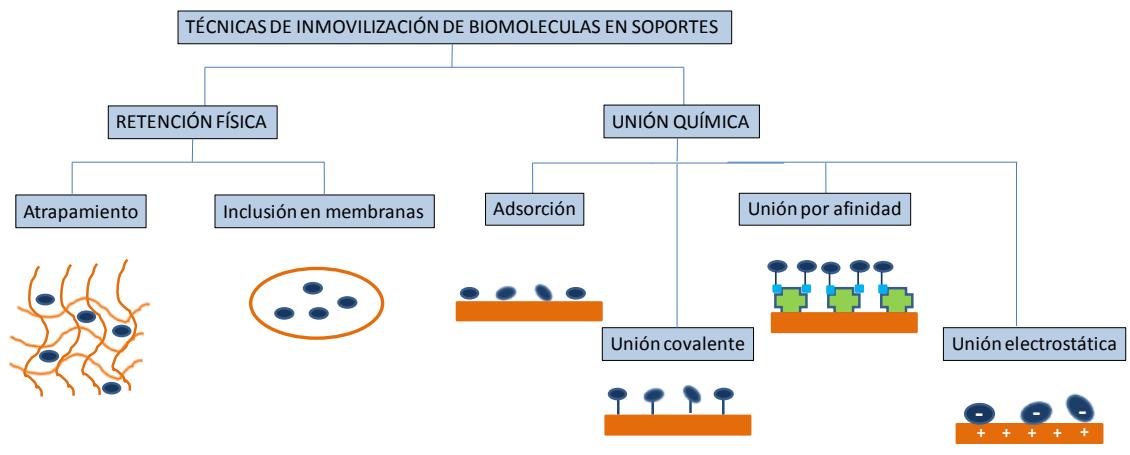

Figura 4. Esquema de las diferentes técnicas de inmovilización de biomoléculas.

\section{Métodos de inmovilización por retención física}

$\checkmark$ Atrapamiento, consiste en la retención física de la biomolécula en las cavidades interiores de una matriz sólida porosa, generalmente constituida por polímeros tipo poliacrilamida, colágeno, alginatos, carragenatos o resinas de poliuretano. El proceso de inmovilización más empleado recurre a la suspensión del elemento biológico en una disolución de monómero, seguido de polimerización, bien mediante cambios de temperatura o mediante adición de reactivos.

$\checkmark$ Inclusión en membranas. En esta metodología, las biomoléculas son insertadas en membranas semipermeables. 


\section{Métodos de inmovilización por unión química}

$\checkmark$ Adsorción, implica la unión del elemento de reconocimiento al soporte mediante interacciones débiles: puentes de hidrógeno, fuerzas de Van der Waals, interacción electrostática, etc.

$\checkmark$ Enlace covalente, significa la formación de uniones entre un grupo funcional del biorreceptor y grupos del soporte sólido.

$\checkmark$ Unión mediante afinidad, consiste en el uso de moléculas características (avidina, proteína A, lectinas, etc.), con elevadas constantes de equilibrio y selectividad hacia una molécula o familia (biotina, $\operatorname{IgGs}$ ), que permiten inmovilizar otras mediante su intermediación.

$\checkmark$ Electrostática, este tipo de unión es posible realizarla cuando la superficie del soporte está provista de grupos cargados, aniónicos o catiónicos, capaces de enlazar iónes de carga opuesta. Los soportes más empleados son vidrios y resinas interciambadoras del tipo estirenodivinil-benceno, con grupos iónicos sustituibles.

La elección de un procedimiento u otro depende principalmente del diseño del biosensor, de la naturaleza del elemento biológico (dimensiones, composición, dominios hidrofílicos e hidrofóbicos), del tipo de soporte sólido ${ }^{30,54,76}$ y del sistema de transducción elegido, teniendo en cuenta que la técnica de inmovilización seleccionada debe mantener la actividad biológica del biorreceptor y favorecer (o al menos no alterar) la cinética de la misma. En la Tabla 3 se presentan las distintas propiedades de los métodos de inmovilización descritos.

A continuación se describen las dos estrategias de inmovilización que presentan mayor interés en el ámbito de la presente investigación. 
Tabla 3. Comparación de los diferentes métodos de inmovilización ${ }^{77}$

\begin{tabular}{l|cccccc}
\hline & $(1)$ & $(2)$ & $(3)$ & $(4)$ & $(5)$ & (6) \\
\hline \hline Preparación & Sencilla & Intermedia & Sencilla & Sencilla & Laboriosa & Intermedia \\
Unión & Media & Débil & Fuerte & Media & Fuerte & Fuerte \\
Estabilidad & Alta & Media & Baja & Baja & Alta & Alta \\
Reusabilidad & Posible & Posible & Sí & Sí & Posible & No \\
Precio & Medio & Medio/Alto & Medio & Bajo & Alto & Medio \\
\hline
\end{tabular}

(1) Atrapamiento, (2) Inclusión en mebranas, (3) Electrostática, (4) Adsorción química, (5) Unión covalente y (6) Unión por bioafinidad

\section{Adsorción}

Es la metodología más simple para la inmovilización de biomoléculas, puesto que no son necesarios reactivos especiales. En la adsorción, la biomolécula se une a un soporte sin funcionalizar mediante interacciones polares, fuerzas de Van der Waals, enlaces de hidrógeno etc., todas ellas de carácter débil. Como principales ventajas de este método destacan ${ }^{78,79}$ :

$\checkmark \quad$ Preparación sencilla

$\checkmark \quad$ Aplicación general a multitud de sustancias

$\checkmark \quad$ Las sondas inmovilizadas son estables durante largos periodos

$\checkmark$ Coste reducido

Pero la adsorción presenta también algunos inconvenientes:

$\checkmark$ Procesos lentos, se requieren tiempos de inmovilización largos

$\checkmark \quad$ Posible desorción de la biomolécula

$\checkmark \quad$ Aleatoriedad de la inmovilización 


\section{Unión covalente}

La metodología de unión covalente se basa en la reacción entre grupos químicos del soporte con determinados grupos residuales de las biomoléculas. Se pueden diferenciar dos grandes grupos de sustancias: aquellas en las que los grupos enlazados corresponden a proteínas (anticuerpos, enzimas, receptores, tejidos, etc.) y las basadas en ácidos nucleicos, en las que la unión al soporte se efectúa generalmente a través de grupos funcionales situados en los extremos 3' o 5'.

En el caso de las proteínas, de entre los 20 aminoácidos naturales que se encuentran en la estructura de las mismas, los más empleados para la formación de enlaces con el soporte son principalmente lisina, cisteína, tirosina e histidina, y en menor medida metionina, triptófano, arginina, y los ácidos aspártico y glutámico (que contienen residuos amino, carboxilato, sulfihidrilo y fenol). El resto de aminoácidos, debido a su carácter hidrófobo no se encuentran expuestos al exterior de la superficie proteica y no pueden intervenir en la unión covalente, salvo que se produzca un despliegue de la proteína a consecuencia de la desnaturalización, o se hidrolice y se obtengan fragmentos.

Otras sustancias (aunque minoritarias) interesantes son los hidratos de carbono. La inmovilización covalente se puede realizar en soportes previamente activados, principalmente, mediante grupos tiol, maleimida y benzoquinona.

La inmovilización covalente presenta las siguientes ventajas ${ }^{79,80}$ :

$\checkmark$ Manipulación sencilla de los derivados inmovilizados.

$\checkmark \quad$ Unión fuerte y estable.

$\checkmark$ Control del proceso de inmovilización.

$\checkmark$ Direccionalidad (orientación del biorreceptor anclado). 
$\checkmark$ Resistencia a la desactivación por el efecto de la temperatura, disolventes orgánicos o $\mathrm{pH}$, al tener estabilizada su estructura terciaria.

$\checkmark \quad$ Robustez de las superficies de ensayo.

$\checkmark \quad$ Versatilidad de los derivados obtenidos.

En cambio, presenta una serie de inconvenientes:

$\checkmark$ Es una técnica que, en general, requiere la activación o derivatización previa del soporte sólido $\mathrm{y}$, además, no garantiza una orientación correcta de las moléculas biológicas.

$\checkmark \quad$ Es necesario conocer la densidad de grupos activos por unidad de superficie, ya que condiciona el número de uniones biorreceptor-soporte y su geometría, que puede ser distorsionante y conducir a derivados inactivos.

$\checkmark$ Posible pérdida de actividad del elemento de reconocimiento.

Considerando todo lo expuesto, se puede concluir que el tipo de enlace recomendado es el covalente, especialmente si se quiere controlar al máximo la respuesta del sistema y se tiene en cuenta la reproducibilidad, reusabilidad y fabricación de dispositivos. En este sentido, la unión covalente ofrece respuestas adecuadas a las exigencias en cuanto a sensibilidad y reproducibilidad de resultados.

También está muy explotada la vía de utilizar "intermedios" como, por ejemplo, tapizar la superficie con avidina o estreptavidina y fijar sobre ella sondas biotiniladas. No obstante, esta estrategia no siempre es viable o recomendable, ya que requiere la biotinilización y purificación de reactivos o analitos, aumenta el espesor de la capa de biomoléculas y no resuelve el problema básico de controlar la orientación de los biorreceptores. 


\subsection{Estudio de soportes sólidos para uso en biosensores ópticos}

El éxito en el desarrollo de un biosensor sensible y selectivo depende, en gran medida, de las características de la superficie de trabajo elegida y de la disponibilidad de los materiales adecuados. Por ello, es importante sistematizar el tipo de soporte y sus características.

Así, para los biosensores ópticos se pueden diferenciar dos tipos de soportes: pasivos y activos. Los soportes pasivos son aquellos cuya única finalidad es actuar como material sobre el que se inmovilizan los biorreceptores. Para este tipo de sistemas se utilizan materiales en función de sus propiedades ópticas (índice de refracción, transparencia), mecánicas (dureza, rugosidad) y funcionales (derivatización, adaptación a producción en masa). En general se utiliza vidrio, otros silicatos, silicio, polímeros sintéticos (como por ejemplo, policarbonatos), metales y carbono (grafito, fullerenos, diamante, etc.), entre otros.

Los soportes activos son aquellos que, además de actuar como superficie de anclaje del biorreceptor, posibilitan el guiado de la luz y juegan, por tanto, un papel activo en la transducción y generación de la señal (guías de onda, fibras ópticas, cristales fotónicos, sistemas interferométricos, etc.). En estos sistemas los materiales son seleccionados en función de sus propiedades dieléctricas (silicio y derivados, $\mathrm{Ta}_{2} \mathrm{O}_{5}, \mathrm{TiO}_{2}, \mathrm{CdSe}$, etc.), magnéticas y químicas.

En el presente trabajo hemos estructurado el estudio en dos bloques principales: el primero centrado en sistemas biosensores basados en materiales poliméricos -más concretamente chips de policarbonato (PC), polimetilmetacrilato (PMMA), poliestireno (PS), y componentes de dispositivos ópticos de audio-video (discos compactos)-, y el segundo centrado en dispositivos micronanofotónicos y materiales en base silicio y $\mathrm{Ta}_{2} \mathrm{O}_{5}$ para fabricación de guías de onda. 


\subsection{Sistemas biosensores basados en materiales poliméricos}

Los materiales poliméricos de síntesis surgieron como una alternativa a los soportes de materiales más establecidos como vidrio, silicio y óxido de silicio. El desarrollo de las técnicas de microfabricación de polímeros, junto con sus propiedades físico-químicas y bajo coste, han propiciado su uso en sistemas sensores.

Una de las primeras aplicaciones de los materiales poliméricos en sistemas analíticos fue el desarrollo de dispositivos tipo biochip de ANs, proteínas y tejidos. Los biochips son sistemas de análisis masivo que permiten estudiar, en formato microarray y en un solo experimento, miles de muestras o diferentes sustancias en una misma muestra, mediante el empleo de micromatrices bidimensionales de moléculas (generalmente biomoléculas) ordenadas sobre un sustrato sólido, en posiciones preestablecidas. Aunque el vidrio es el soporte convencional sobre el que generalmente se desarrollan microarrays, debido a su baja fluorescencia de fondo, transparencia y resistencia térmica, en los últimos años se ha extendido el uso de sustratos poliméricos. Estos materiales, con propiedades comparables al vidrio, ofrecen una gran variedad de vías de inmovilización química y, además, se adaptan muy bien a la fabricación en masa con costes muy competitivos.

Los materiales poliméricos también constituyen excelentes plataformas para el desarrollo de BioMEMs. Además, ofrecen la ventaja de poder transformarse fácil y económicamente en dispositivos que integran operaciones de tratamiento de muestra, manejo de fluidos y detección. Una de las propuestas más representativas es la conocida como Lab-on-a-chip ${ }^{81}$.

Por otro lado, el concepto de análisis molecular a través de la interacción entre moléculas y dígitos, o sistemas híbridos, se ha convertido en un tema de investigación de gran interés durante la última década. En estos sistemas, el análisis molecular se produce debido a la habilidad de las moléculas de alterar la 
transmisión de una corriente de datos, de manera que se consigue una interacción real entre sistema molecular y sistema digital. ${ }^{82-84}$

Dentro de este tipo de sistemas, los discos compactos de audio-video (CDs) son plataformas constituidas por polímeros sintéticos (PMMA y PC) con un elevado potencial, especialmente cuando se incorpora el lector de discos como detector ${ }^{85-87}$. En este sentido, diferentes grupos de investigación han desarrollado tecnologías basadas en la utilización de discos compactos como soportes sobre los que efectuar ensayos químicos.

Antes de profundizar en los fundamentos de esta metodología, comentaremos brevemente las características y el papel de los polímeros en el desarrollo de BioMEMs, así como en las prestaciones que ofrecen frente a otros materiales como vidrio o silicio.

\subsubsection{Polímeros orgánicos. Potencial para la fabricación de BioMEMs}

Aunque menos estudiados que los materiales inorgánicos, los polímeros (elastómeros, plásticos, fibras) presentan un gran interés dadas sus características físicas (Tabla 4) y procedimientos de fabricación. ${ }^{88-91}$

Un polímero está formado por una estructura en dos o tres dimensiones, resultado de la unión covalente de varias unidades básicas, monómeros. Se diferencia entre homopolímeros -cuando el polímero está formado por unidades básicas idénticas-, y copolímeros -cuando lo forman dos tipos de monómeros diferentes-.

Dependiendo de sus aplicaciones industriales, se clasifican en termoplásticos que comprende la familia de los polietilenos, poliestirenos, policarbonatos, polimetilmetacrilatos y poliimidas-, termoestables -dentro de este grupo se encuentran los poliuretanos y siliconas-, y elastómeros -como el 
polidimetilsiloxano-. En la Figura 5 se muestran algunos de los polímeros más utilizados en biosensores.

Las principales ventajas ${ }^{88,90}$ que ofrece el uso de materiales poliméricos en el desarrollo de BioMEMs son:

$\checkmark$ Buenas propiedades mecánicas, superiores al vidrio y derivados. ${ }^{92,93}$

$\checkmark \quad$ Transparencia apropiada y señales reducidas ${ }^{94}$ para para su aplicación en sistemas con detección óptica (fluorescencia, absorbancia, etc.).

Tabla 4. Comparación de las propiedades físico-químicas de diversos polímeros orgánicos y $\mathrm{SiO}_{2} .{ }^{95}$

\begin{tabular}{|c|c|c|c|c|c|}
\hline & $P M M A^{\mathrm{a}}$ & $P C^{\mathbf{b}}$ & $P S^{\mathrm{c}}$ & $P D M S^{\mathrm{d}}$ & $\mathrm{SiO}_{2}$ \\
\hline Tipo de polímero & Termoplástico & Termoplástico & Termoplástico & Elastómero & -- \\
\hline Densidad $\left(\mathrm{g} / \mathrm{L} \times 10^{3}\right)$ & 1,16 & 1,2 & 1,05 & 1,227 & 525 \\
\hline $\operatorname{Tg}\left({ }^{\circ} \mathrm{C}\right)$ & 106 & 150 & 100 & -120 & \\
\hline $\begin{array}{c}\text { Conductividad } \\
\text { térmica }(\mathrm{W} / \mathrm{mK})\end{array}$ & 0,186 & 0,21 & 0,18 & $0,17-0,3$ & 1,2 \\
\hline$\%$ T de luz visible & 92 & 89 & 90 & 91 & $>90$ \\
\hline \multicolumn{6}{|l|}{ Resistencia química } \\
\hline$\checkmark$ Ácidos & Buena & Buena & Buena & Muy buena & Excelente \\
\hline$\checkmark$ Bases & Excelente & Pobre & Buena & Muy pobre & Pobre \\
\hline$\checkmark$ Disolventes & Pobre & Pobre & Pobre & Pobre & Excelente \\
\hline
\end{tabular}

$*^{\mathrm{a}}$ Polimetilmetacrilato, ${ }^{\mathrm{b}}$ Policarbonato, ${ }^{\mathrm{c}}$ Poliestireno, ${ }^{\mathrm{d}}$ Polidimetilsiloxano. 


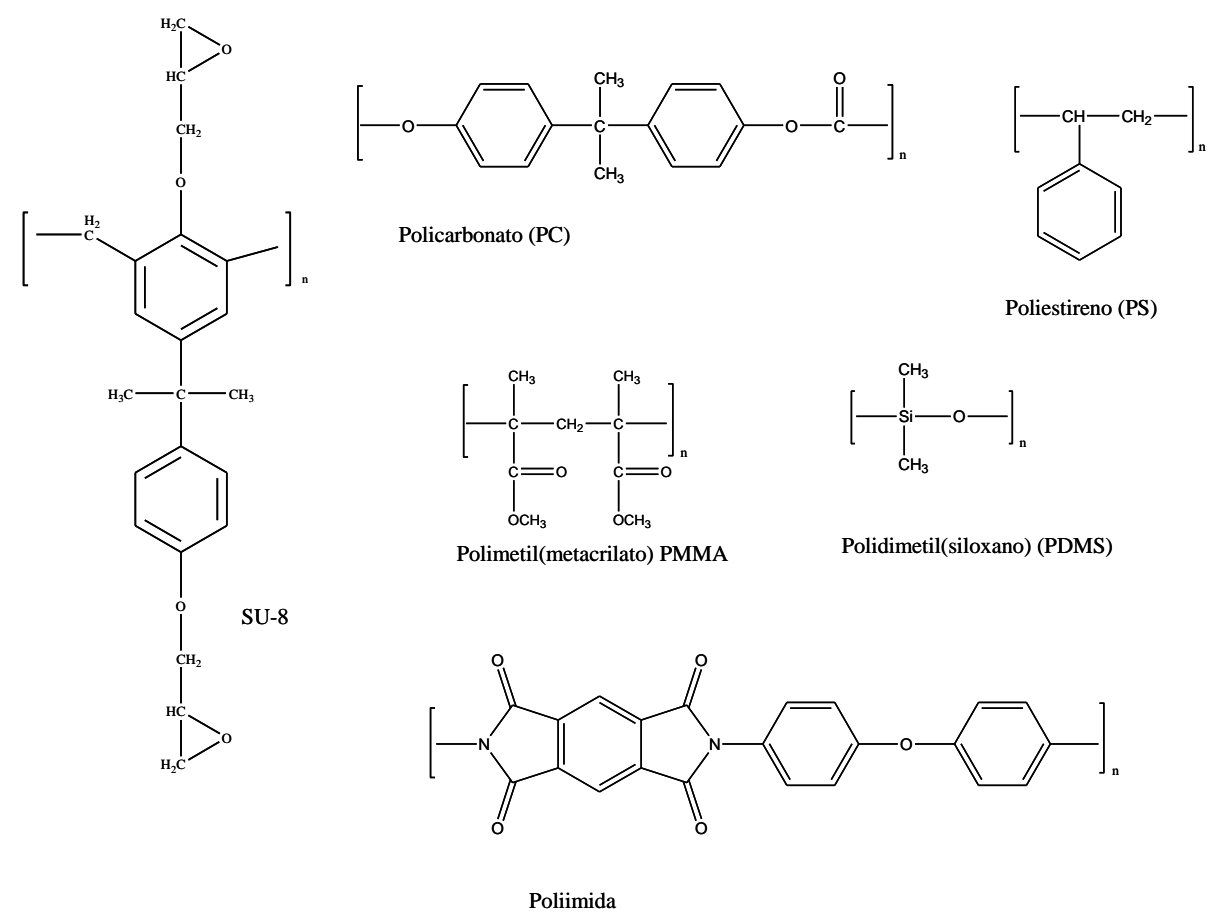

Figura 5. Estructura de algunos de los polímeros orgánicos más utilizados en biosensores

$\checkmark \quad$ La mayoría de los polímeros son relativamente económicos; además, su procesado no exige en general sala limpia, abaratando significativamente los costes de fabricación.

$\checkmark \quad$ La microfabricación sobre silicio es una técnica relativamente limitada. El empleo de materiales poliméricos incrementa enormemente las posibilidades de microfabricación (low temperature chemical vapor deposition ${ }^{96,97}$, embossing, spraying, screen printing, thick film procesing $^{98}$, stereo lithography ${ }^{99}$ ).

$\checkmark$ Los conocimientos en electrónica y optoelectrónica han avanzado extraordinariamente en el campo de los polímeros ${ }^{100,101}$ (dispositivos 
fotovoltaicos, memorias, transistores, etc.), de modo que los sensores complementados con MEMs basados en polímeros están permitiendo desarrollar sistemas completamente integrados.

$\checkmark$ En comparación con los compuestos inorgáncos, los polímeros orgánicos ofrecen una química mucho más versátil.

\subsubsection{Tecnología de disco compacto: Una herramienta de análisis masivo}

Un disco compacto (CD) es un soporte digital óptico utilizado para almacenar información. Fue desarrollado en 1980 por Sony y Philips, y a pesar de que cada productor utiliza pequeñas variaciones en la composición de los materiales empleados en la fabricación de los discos, todos siguen unas especificaciones comunes $^{102}$. La información es almacenada en un sustrato de plástico transparente, generalmente de policarbonato (PC), sobre el que se aplica una película metálica de aluminio, oro, níquel etc., recubierta de una laca protectora, generalmente de polimetilmetacrilato (PMMA), y opcionalmente una etiqueta (Figura 6A). Tanto el PC como el PMMA son materiales transparentes a la radiación visible, presentan baja distorsión óptica, alta resistencia mecánica, buena estabilidad térmica y elevada exactitud dimensional, además de gran hidrofobicidad.

En los denominados genéricamente CDs, la información está almacenada en forma de pits que se imprimen durante el proceso de fabricación del disco de policarbonato. Cada pit tiene una profundidad de aproximadamente $125 \mathrm{~nm}$, una anchura de $500 \mathrm{~nm}$, y una longitud que oscila entre 830 y 3500 nm. Los pits están ordenados en el disco a lo largo de una única espiral contínua y extremadamente larga que constituye la pista de datos (data track), que será barrida por el haz láser desde el interior hasta el exterior del CD, en sentido levógiro. El espacio entre pistas (distancia radial entre una revolución de la espiral y la siguiente) es de 1600 
$\mathrm{nm}$. Los espacios entre pits a lo largo de la misma pista de datos se conocen como lands (Figura 6B).

(A)

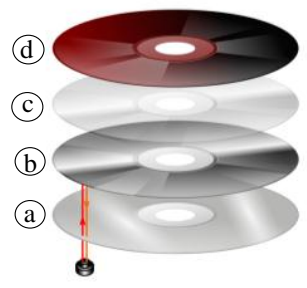

(B)

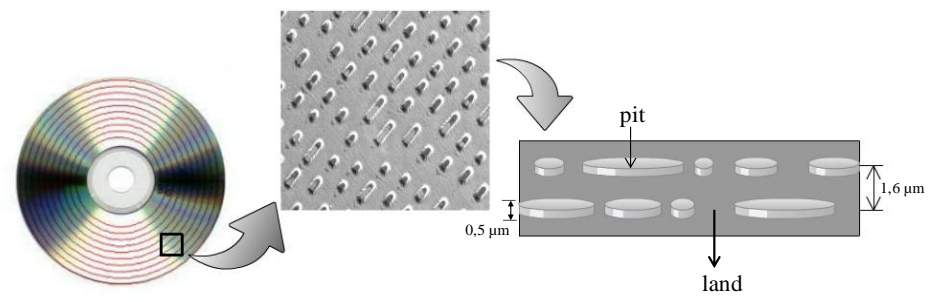

Figura 6. (A) esquema de la composición de un CD, (a) PC, (b) película metálica (Al, $\mathrm{Au}$ ), (c) laca protectora de PMMA, (d) etiqueta. (B) Esquema de la espiral contínua que constituye la pista de datos.

La información almacenada en forma de pits y lands es leída empleando un lector de discos compactos.Como puede apreciarse en la Figura 7, un lector de CDs consta básicamente de tres piezas:

$\checkmark$ Motor de arrastre del disco (Disc Drive Motor), motor que hace girar el disco. Este motor se controla de forma precisa para que gire a una velocidad dada $\left(\mathrm{v}_{\max }=1000 \mathrm{rpm}\right)$, en función del tipo de disco utilizado y de la situación de la pista leida.

$\checkmark$ Cabezal óptico (Laser Pickup Assembly), sistema compuesto por un láser que emite a $780 \mathrm{~nm}$ ( o 640 en el caso de discos DVD) y una lente que lo focaliza a fin de ajustar la distancia donde se encuentra la pista de datos. Lleva incorporado un sensor opto-electrónico que es capaz de detectar la luz reflejada en la película metálica del disco. 
$\checkmark$ Mecanismo rastreador (Tracking mechanism), sistema compuesto por un motor que mueve el dispositivo láser a lo largo de un eje radial fijo, de modo que el haz de luz puede seguir la pista de datos en espiral mientras el disco gira. Este sistema mueve el láser con una resolución de micrometros.

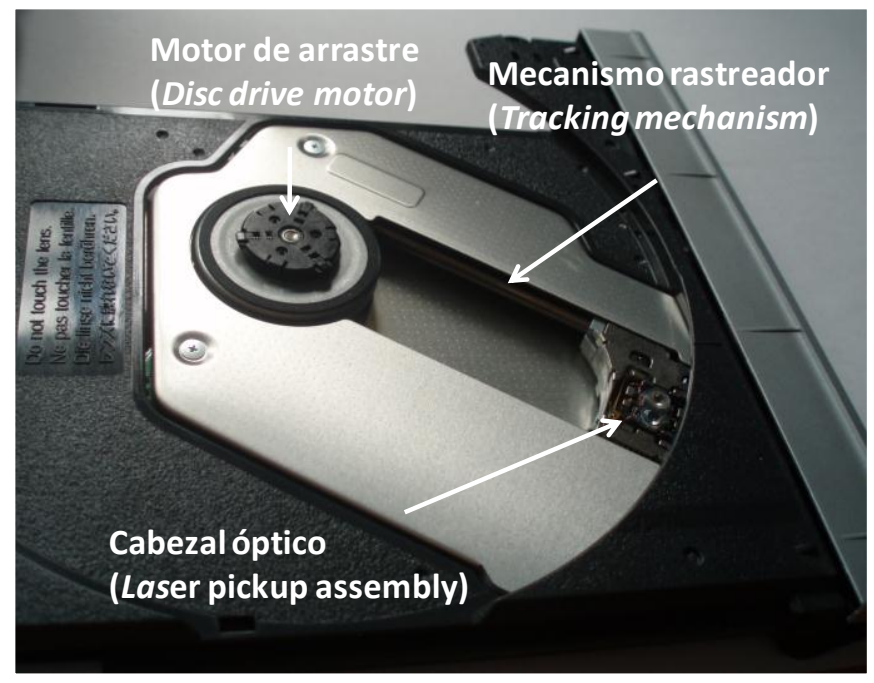

Figura 7. Foto del sistema lector de discos compactos. ${ }^{\mathbf{1 0 3}}$

La lectura de la información grabada en un disco se efectúa a partir de la modificación de la señal del haz láser reflejado. El lector utiliza el fenómeno de interferencia con la finalidad de proporcionar información binaria. Hay que tener en cuenta que las regiones land reflejan la luz de modo diferente que las pits, y que los sensores ópticos del lector detectan los cambios en la reflectividad como una señal digital (on/off ó 1/0). La profundidad de los pits es seleccionada de modo que coincide con la cuarta parte de la longitud de onda del láser $(780 \mathrm{~nm})$. Por ello, el haz del láser reflejado desde una región land estará en oposición de fase respecto al 
reflejado desde una región pit, tal y como se muestra en la Figura 8. De este modo, cada pit actúa como un micro-interferómetro a través del cual los datos detectados pueden ser digitalizados.

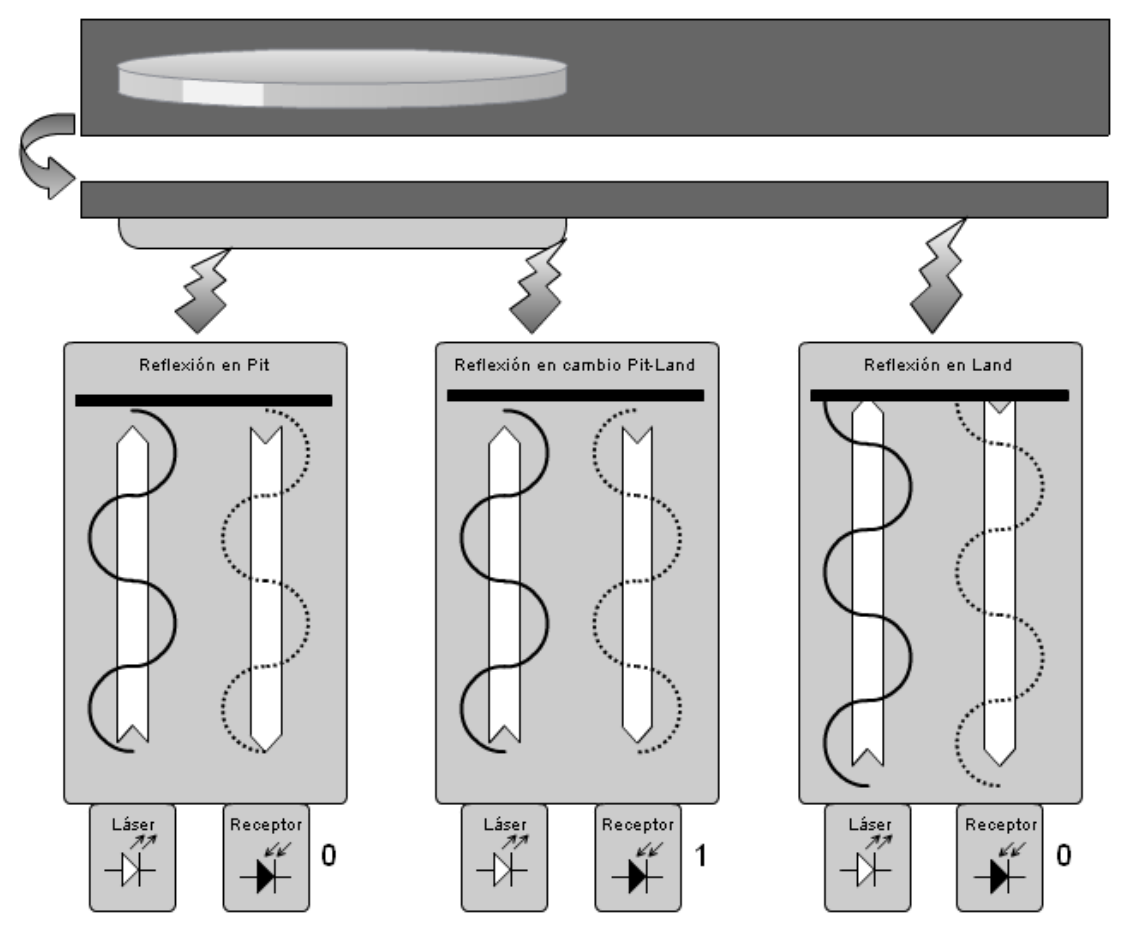

Figura 8. Esquema del fenómeno de interferencia destructiva en el que se basa el sistema de detección del lector de CDs. 
En la década de los noventa fue desarrollado el denominado Disco Digital Versátil (DVD), soporte óptico de alta densidad con prestaciones superiores a las del CD. La principal ventaja del DVD frente al CD es la mayor velocidad de lectura y capacidad de almacenamiento de datos; esto se consigue incorporando un láser de mayor resolución que emite en el rojo $(650 \mathrm{~nm})$, lo que permite disminuir las dimensiones de los pits y los lands. Otra ventaja de los DVDs es la posibilidad de almacenar información en ambas caras del disco; además, cada cara puede estar constituida por dos capas, lo que multiplica por cuatro la capacidad de almacenamiento del dispositivo óptico.

Finalmente, existen otros formatos de disco compacto más avanzados como el Blue Ray -que trabaja con un láser de mayor resolución (405 nm)- o el Light-Scribe, que mejoran las prestaciones bien por su capacidad de trabajo o por sus particulares características. Además, existen otros dispositivos en fase de desarrollo (no comercializados) que podrían presentar mejores propiedades. En la Tabla 5 se comparan las principales características de varios de los dispositivos ópticos comentados.

Desde el punto de vista del presente trabajo, un punto clave para el desarrollo de biosensores empleando la tecnología de disco compacto es el estudio del material base de los dispositivos ópticos descritos, así como la posibilidad de aplicar películas poliméricas sobre éstos mediante diferentes técnicas (spin-coating, sputtering, etc.), ya que serán el soporte de anclaje de los biorreceptores y, por tanto, condicionarán la etapa de inmovilización y el formato de ensayo. Por otro lado, las propiedades del sistema lector empleado determinarán las prestaciones de las metodologías desarrolladas, ya que actuará como elemento de detección. 
Tabla 5. Comparación de las características de diferentes tipos de disco compacto de audio-video.

\begin{tabular}{|c|c|c|c|}
\hline & $C D$ & $D V D$ & Blue Ray \\
\hline Alm. de $\operatorname{datos}^{I}(G B)$ & 0,7 & 4,7 & 27 \\
\hline Estructura & $1,2 \mathrm{~mm}$ & $0,6 \mathrm{~mm} \times 2$ sustratos & $0,6 \mathrm{~mm} \times 2$ sustratos \\
\hline Tasa de bits ${ }^{2}$ (Mbps) & 0,15 & 11,1 & 36 \\
\hline$\lambda_{\text {láser }}(\mathrm{nm})$ & 780 & 650 & 405 \\
\hline Ancho de pista (um) & 1,6 & 0,74 & 0,32 \\
\hline Materiales base & Policarbonato & Policarbonato & Durabis ${ }^{104-106}$ \\
\hline Dureza & Baja & Baja & Alta \\
\hline
\end{tabular}

${ }^{1}$ Capacidad de almacenamiento de datos (1 lado 1 capa), ${ }^{2}$ tasa de transferencia de datos

\subsubsection{Antecedentes y estado del arte del empleo de discos compactos como plataformas analíticas}

De acuerdo a la bibliografía, existen dos grandes planteamientos a la hora de utilizar discos compactos como soportes de ensayo. El primero se basa en el concepto de Lab-on-a-chip, dispositivos de tamaño del orden micro o nanométrico que integran sistemas de tratamiento de muestra, manejo de fluídos y detección, pero adaptados a la morfología de un CD. Este planteamiento utiliza los discos como plataformas analíticas que se ayudan de la fuerza centrífuga para mover los fluidos y desarrollar los ensayos, pudiendo denominarse como Lab-on-a-Disk. El segundo planteamiento utiliza discos compactos estándar, introduciendo modificaciones mínimas para aprovechar al máximo la tecnología de audio-video, tanto durante el ensayo como durante su lectura. 
Dentro del primer planteamiento, Madou et al. ${ }^{107-110}$ son los más proactivos y han publicado una revisión muy completa sobre este tipo de sistemas. Algunas compañías como Gyros $\mathrm{AB}^{111}$ y Gamera ${ }^{112}$ han llegado a comercializar este tipo de dispositivos integrados. Estos sistemas están constituidos por discos de PC, PS, etc., de varios milímetros de espesor, con una red de microcanales, depósitos y válvulas, que permiten su empleo tanto para el tratamiento de muestra como para efectuar reacciones de identificación. El resultado es medido utilizando detectores convencionales como densímetros, fotómetros, fluorímetros, etc., adaptados a una geometría circular. Ninguno de ellos utiliza el principio de lectura de los escáneres de CDs. En la Figura 9A se muestra un ejemplo de esta modalidad de dispositivo.

En el segundo planteamiento, LaClair et $a .^{83,84}$ usan las rutinas de determinación de errores que incorporan los lectores de CDs como base para desarrollar ensayos en discos para detección cuantitativa y directa de los analitos, si bien, el principal problema es que cada fabricante aplica un modo distinto de corrección de errores, lo que afecta a la sensibilidad del ensayo.

Alexandre et al. ${ }^{13,114}$ desarrollaron un disco compacto dividido en dos secciones; en una se efectuan los ensayos de detección de ácidos nucleicos y en la otra es grabada la información numérica simultáneamente al proceso de lectura (Figura 9B). Utilizan parcialmente la tecnología de $\mathrm{CD}$, aunque incorporan un sistema de detección formado por un fotodiodo situado perpendicularmente al emisor láser. Requiere discos de baja reflectividad, habiendo efectuado aplicaciones para la discriminación de cepas de estafilococos.

Más recientemente, Potyrailo et al. ${ }^{115}$ han utilizado CDs y DVDs como plataformas sobre las que depositan películas reactivas para la detección de aniones y cationes en aguas, orina y suero sanguíneo. El resultado obtenido con lectores de CD y DVD, es una imagen que se relaciona con la concentración de analito en la muestra, previa calibración. En estudios posteriores han desarrollado dispositivos 
Lab on a Disk, que aprovechan las tres longitudes de onda de trabajo de los dispositivos de lectura $(780,650$ y $450 \mathrm{~nm})$ para la detección de residuos de plaguicidas en aguas ${ }^{116}$.

Información numérica

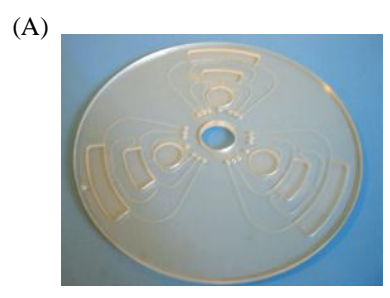

(B)

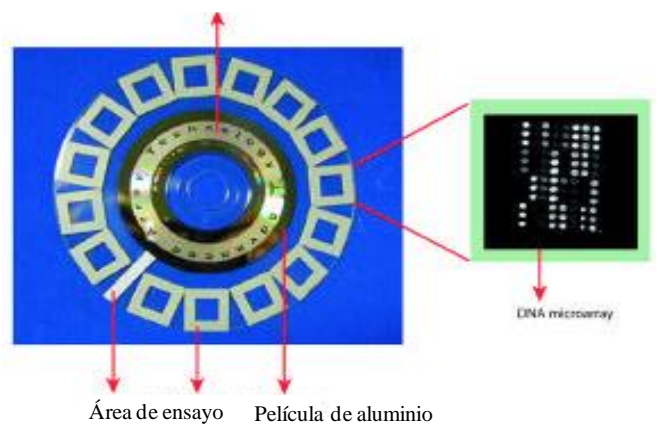

Figura 9. Ejemplos de discos con aplicaciones biosensoras. (a) Disco con sistema de microfluídica automatizado desarrollado por Madou et al. ${ }^{110}$. (b) Disco compacto dividido en zonas de trabajo desarrollado por Alexandre et al. ${ }^{113}$

Existen también otros planteamientos, como los propuestos por Lange et al. ${ }^{117}$ basados en el empleo del pick-up del cabezal lector de CDs y una lente de aumento para la adquisición de imágenes de microscopia de alta resolución. Nolte et al. ${ }^{118-122}$ introducen el concepto BioCD, si bien utilizan discos de silicio y detectan el reconocimiento biológico mediante un sistema basado en fenómenos de interferometría, mientras que Singh y Hillier ${ }^{123}$ han estudiado fenómenos de resonancia de plasmón de superficies en disco compacto.

En los últimos años, el grupo de investigación donde se ha desarrollado la presente trabajo ha sido muy activo en el planteamiento que utiliza discos compactos como plataformas analíticas, aprovechando la tecnología audio-video para la lectura de los ensayos. 
Estudios previos han demostrado, por primera vez, que un dispositivo de lectura /grabación óptico (lector/grabador de CDs) integrado en un ordenador personal convencional puede tener un alto potencial analítico, utilizando el láser del lector de CDs como fuente de barrido. ${ }^{48,85,124-128}$ Además, se ha demostrado la utilidad de la tecnología de CDs para la generación de señales inmunoquímicas in situ sin interrumpir la lectura normal del disco.

Con tal finalidad, se han empleado discos de baja reflectividad constituidos por policarbonato y una película de oro, de modo que parte del haz láser del lector de CDs es transmitido, siendo detectado mediante un fotodiodo plano colocado en la cara interior opuesta del lector de CDs (Figura 10A). En lo que respecta al modo de detección, se ha utilizado un amplio espectro de productos de reacción absorbentes que pueden ser detectados por el lector de CDs trabajando con el diodo láser estándar $\left(\lambda_{\text {emisión }} 780 \mathrm{~nm}\right)$. En lo que respecta a la capacidad de procesado de muestras, un disco estándar tiene $12 \mathrm{~cm}$ de diámetro; teniendo en cuenta que se trabaja en formato de micromatriz y con microgotas de un diámetro medio de 300 $\mu \mathrm{m}$ y un espaciado de $100 \mu \mathrm{m}$, significaría que se pueden imprimir 70.800 puntos/disco. Estos datos pueden dar una idea de la capacidad de trabajo y del potencial de las metodologías basadas en disco compacto desarrolladas en nuestro grupo de investigación.

En cuanto a la elección de la superficie de trabajo, los mejores resultados (mayor resolución óptica) se obtienen trabajando sobre la superficie superior del CD (cara de oro), dadas las características del propio soporte y del dispositivo de lectura. Ello es debido a la diferencia entre los índices de refracción del aire y del policarbonato, de modo que la luz incidente del láser del dispositivo óptico se refracta en la superficie del policarbonato con un ángulo mayor y, por tanto, el punto de luz incidente original (unos $800 \mu \mathrm{m}$ sobre PC) se focaliza hasta un tamaño de $1,7 \mu \mathrm{m}$ sobre la superficie metalizada (Figura 10B). Una mejor resolución óptica permite que el detector resuelva spots de menor tamaño y, por tanto, trabajar con 
microarrays de mayor densidad, permitiendo el análisis de un mayor número de muestras por unidad de superficie.

También se ha estudiado la posibilidad de aplicar sobre el disco (mediante técnicas de spin-coating, sputering, adhesión, etc.) disoluciones de otros polímeros -poliestireno u otros plásticos químicamente modificados-, lo que permite disponer de una película delgada y uniforme de polímero sobre la capa del oro con el objeto de mejorar las prestaciones del ensayo. ${ }^{129-131}$

Otra línea de investigación más reciente que muestra gran interés por su sencillez y buenos resultados, es utilizar el propio haz láser y el pick-up del lector de CDs como guía y como detector, respectivamente, relacionando la atenuación de la señal con la extensión de la reacción analítica (Figura 10C). Esta aproximación, que también utiliza discos estándar y un lector de CDs comercial sin modificaciones, se está mostrándo como el planteamiento más interesante. Los resultados obtenidos hasta la fecha (sensibilidad $\mathrm{IC}_{50} 1 \mu \mathrm{g} / \mathrm{L}$ en inmunoensayos competitivos) junto a la elevada capacidad de trabajo, indican que este planteamiento puede ser muy interesante en ensayos tanto de receptores proteínicos como de ácidos nucleicos. ${ }^{128}$

El desarrollo de la metodología de CDs para la detección de una señal inmunoquímica in situ, pasa por el estudio y la optimización de las etapas de inmovilización de biorreceptores. La mayoría de las estrategias de inmovilización sobre CD se basan en técnicas de adsorción (unión por puentes de hidrógeno, fuerzas de Van der Waals) o unión covalente de la biomolécula al soporte previamente activado, siendo necesario en este caso modificar químicamente la superficie de los polímeros. 
(A) Detección por transmisión

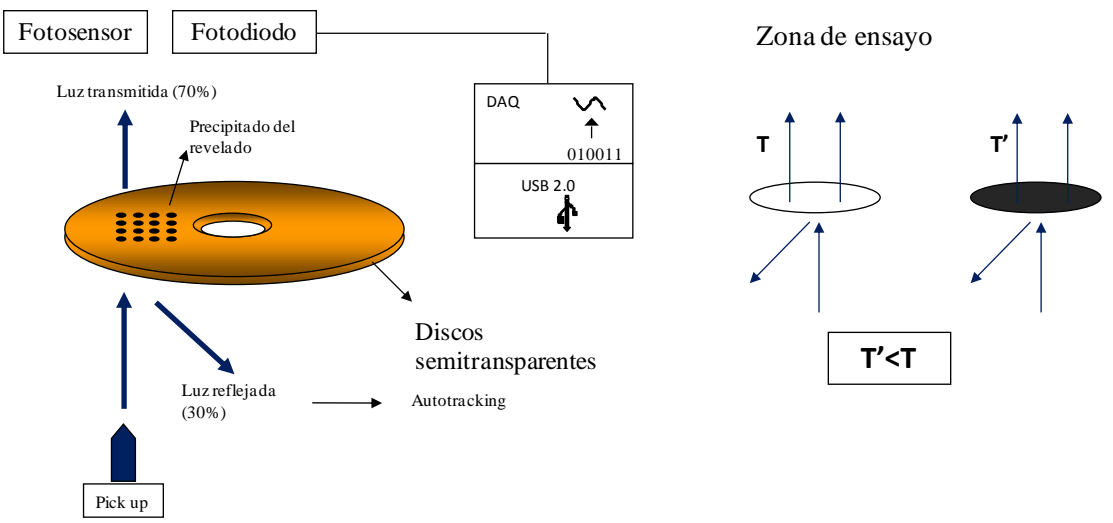

(B) Focalización del haz del láser

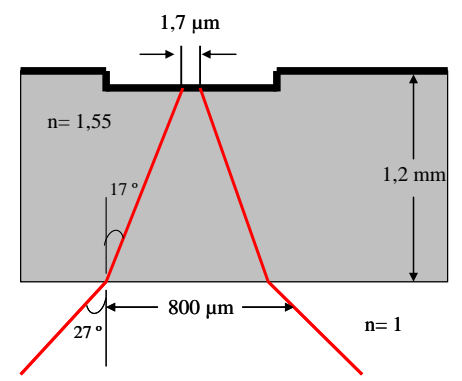

(C) Detección por reflexión

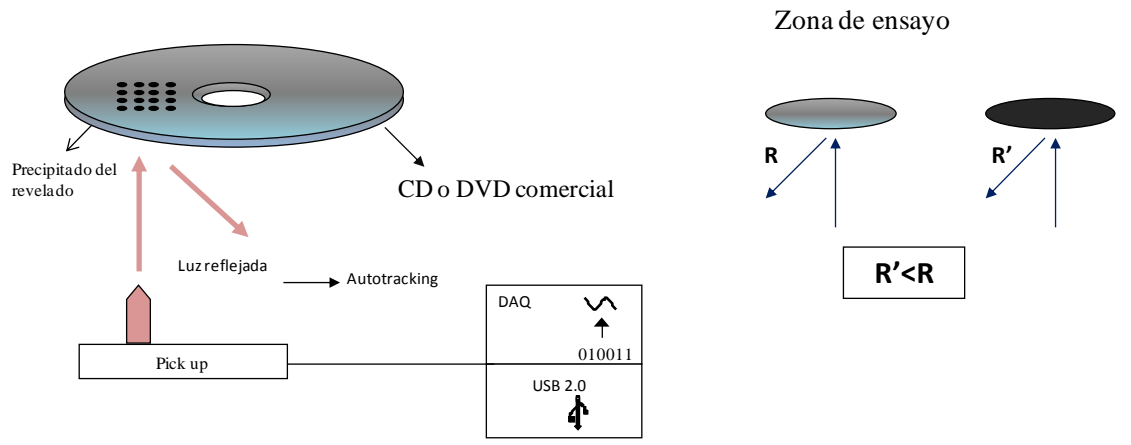

Figura 10. Modos de medida empleando la tecnología de CDs. 


\subsubsection{Funcionalización de superficies poliméricas}

La inmovilización covalente de biorreceptores en un $\mathrm{CD}$ requiere la activación previa de la superficie del disco, constituido principalmente por PC y PMMA, la deposición de una película de polímero (PS, PMMA, etc.) y el posterior tratamiento de la superficie.

Este trabajo se centra, fundamentalmente, en el estudio de la modificación química de PMMA y PC. Ambos son polímeros termoplásticos que presentan ventajas para su aplicación en biosensores debido a sus propiedades ópticas y baja temperatura de transición vítrea, aspectos que los hace fácilmente moldeables y que ha permitido desarrollar de técnicas de fabricación y producción en masa a bajo coste. Para su utilización en dispositivos analíticos y, en particular, en CDs, es de gran importancia que la modificación de la superficie llevada a cabo mantenga las propiedades ópticas (transparencia, índice de refracción,etc.) y físicas del polímero base, garantizando la calidad de la medida final, además de poder emplear las superficies modificadas en medio acuoso.

Los Esquemas 1 y 2 muestran las diferentes estrategias de modificación química de PMMA y PC descritas hasta el momento. En lo que respecta al PMMA, se ha utilizado para la inmovilización de enzimas ${ }^{132-134}$, fabricación de dispositivos microfluídicos, deposición de metales, e inmovilización de proteínas y ácidos nucleicos. Waddell et al. ${ }^{135}$ han desarrollado superficies de PMMA aminadas como sustrato para la inmovilización de oligonucleótidos e hibridación en formato microarray, basando su estrategia en la aminolisis del éster metílico con amiduro de litio de la etilendiamina y posterior unión de un brazo espaciador (Esquema 1A).

Christensen et al. ${ }^{136}$ proponen un procedimiento químico más sencillo, basado en la unión directa de la diamina bajo condiciones básicas de $\mathrm{pH}$, sin necesidad de formar la sal de litio como intermedio de reacción. La posterior unión del agente de 
entrecruzamiento o crosslinker adecuado permite el anclaje de oligonucleótidos a través de sus grupos amino o tiol (Esquema 1B).

(A)
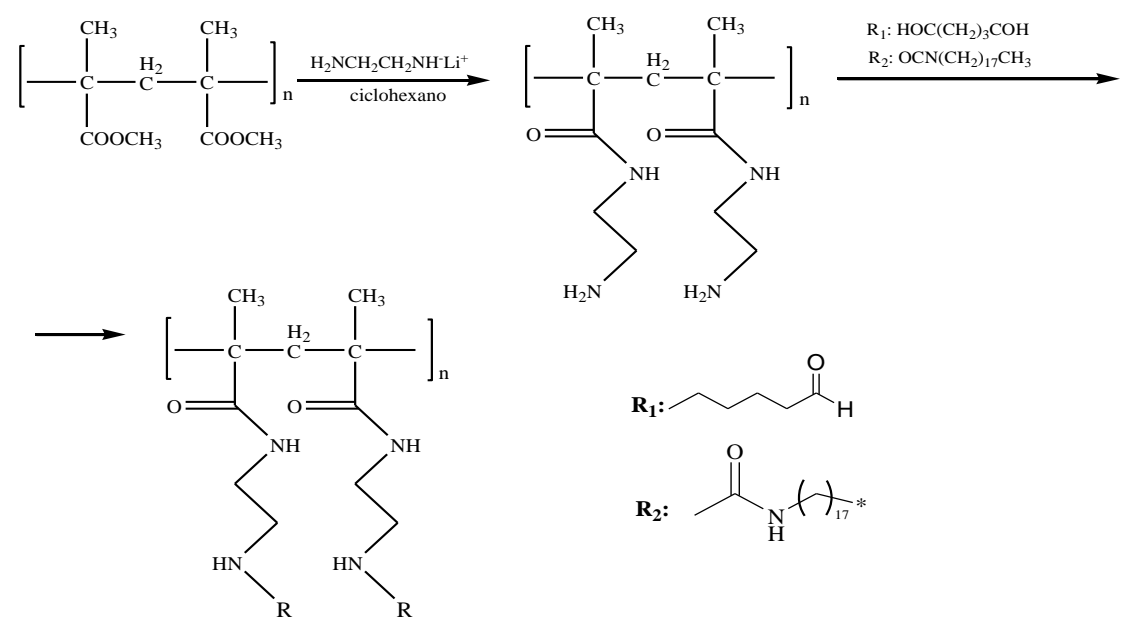

(B)
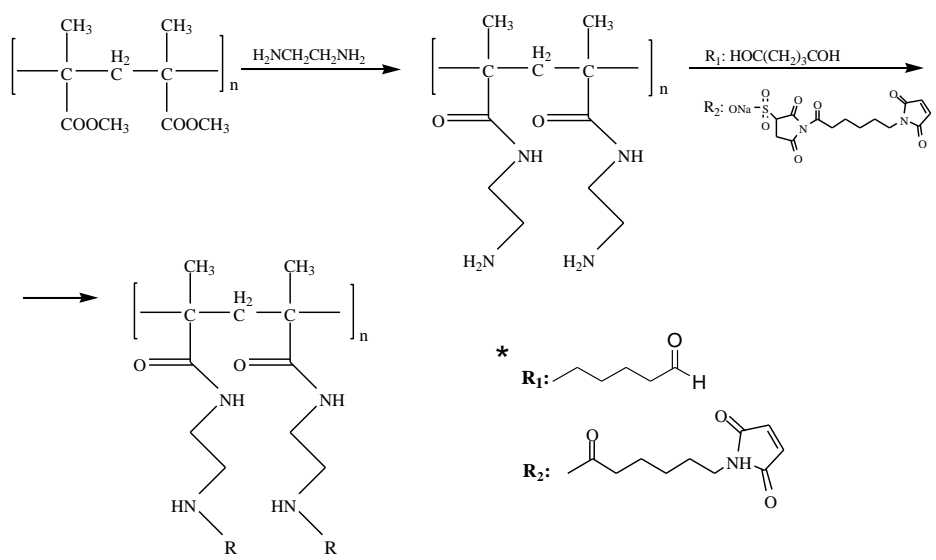

*Crosslinker, molécula homo- o heterobifuncional, que se une al soporte y al elemento de reconocimiento.

Esquema 1. Estrategias de modificación química de PMMA. 
(C)
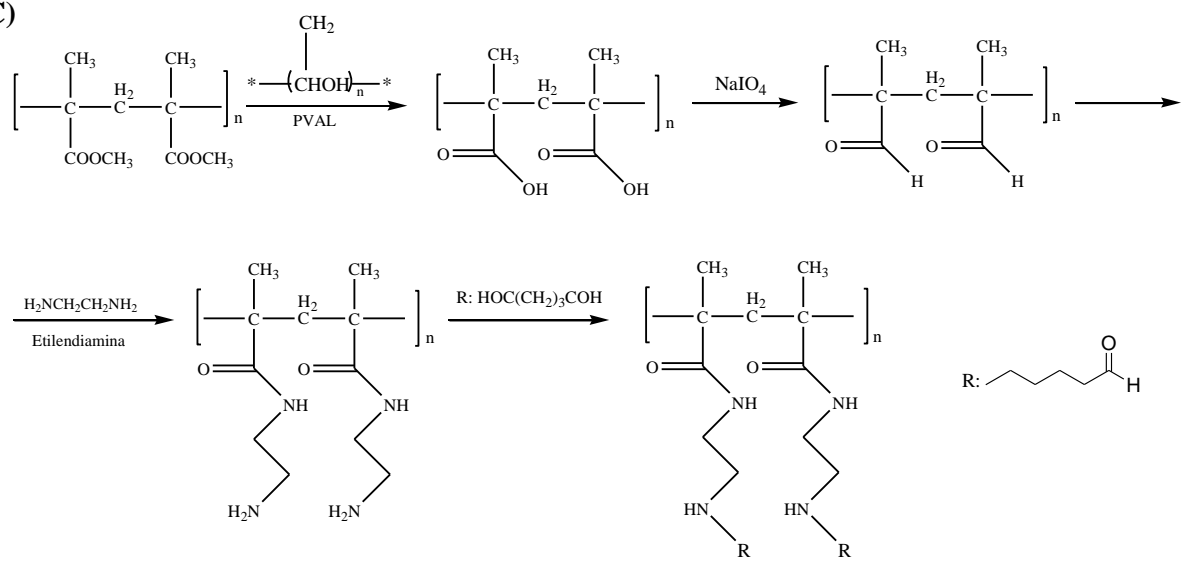

(D)

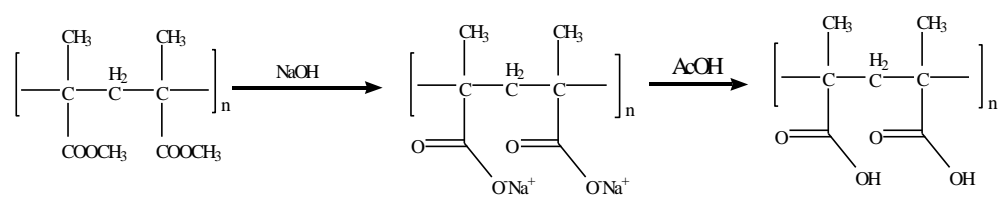

Esquema 1 (cont). Estrategias de modificación química de PMMA.

Por otro lado, Bulmus et al. ${ }^{137}$ (Esquema 1C) utilizan superficies previamente aldehizadas para la inmovilización de la enzima glucosa-oxidasa, estudiando la actividad de la misma en función del brazo espaciador empleado. Díaz-Quijada et $a l .^{138}$ han desarrollado un método para la inmovilización de oligonucleótidos basado en la hidrólisis básica de los residuos éster del polimetilmetacrilato (Esquema 1D). Finalmente, $\mathrm{Xu}$ et al. $^{139}$ han activado las superficies de PMMA con grupos carboxílicos, mediante irradiación con plasma de oxígeno.

En lo que se refiere al policarbonato, La Clair et al. ${ }^{83}$ proponen un método de barrido para el reconocimiento de pequeñas moléculas y macromoléculas. Este 
método consiste en la activación con grupos fosfato de las superficies de PC (Esquema 2).

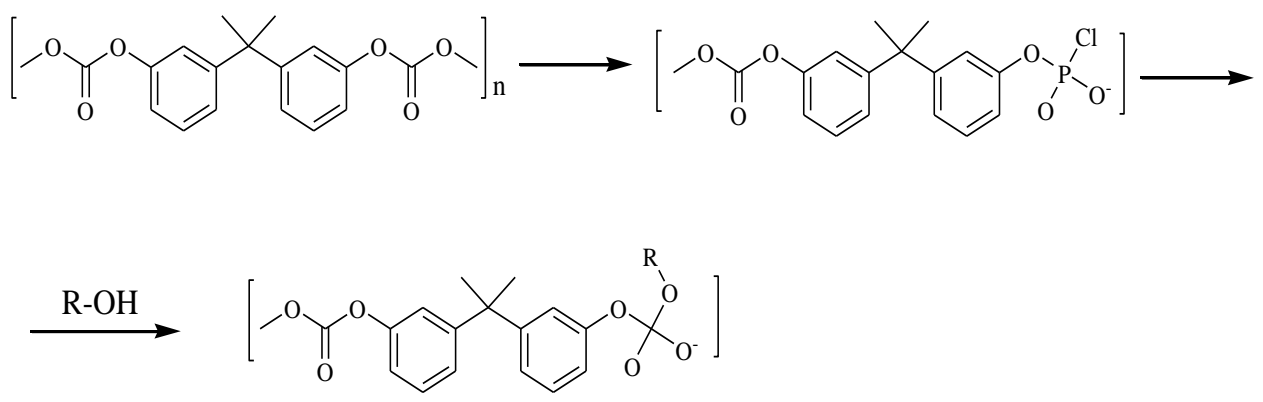

Esquema 2. Estrategia de modificación de PC

Otros autores como Remacle et al. ${ }^{114}$, han desarrollado microarrays de ADN sobre discos compactos mediante activación del PC por hidrólisis básica. Los grupos ácidos generados con esta metodología, después del tratamiento con una diamina, conducen a la unión de la sonda de ADN por adsorción. Finalmente, Li et al. ${ }^{140}$ y Pallapa et al. ${ }^{141}$, han llevado a cabo la inmovilización covalente de sondas de ácidos nucleicos y proteínas sobre discos compactos previamente activados con grupos carboxílicos, mediante irradiación UV (254-300 nm) en una atmósfera rica en ozono. 


\subsection{Sistemas ópticos basados en guías de ondas}

Los sistemas ópticos integrados compuestos por materiales inorgánicos, que emplean elementos de transducción basados en fenómenos de onda evanescente para la detección de la interacción analito-receptor, han surgido como una alternativa prometedora de cara al desarrollo de sistemas biosensores de alta sensibilidad, miniaturizados e integrados.

Previamente a la revisión del estado del arte de este tipo de sistemas sensores, se introducen los materiales inorgánicos más utilizados, las aplicaciones y propiedades de los mismos (Tabla 6), así como sus antecedentes en óptica integrada.

La óptica integrada se inició como línea de investigación aplicada a finales de los años 60, y su objetivo fue la miniaturización de dispositivos ópticos de manera análoga a lo que sucedía en los circuitos integrados en microelectrónica ${ }^{142}$. Más tarde, la meta fue poder integrar dispositivos ópticos y electrónicos en un mismo sustrato, obteniendo así los circuitos opto-electrónicos.

En este sentido, y gracias a sus características ópticas, mecánicas y eléctricas, así como a su abundancia, el silicio y el óxido de silicio han sido los materiales utilizados mayoritariamente como sustratos en la fabricación de sistemas microopto-electromecánicos (MEMs) ${ }^{143-146}$. Estos materiales son los primeros para los que se desarrollaron técnicas de microfabricación, y la base de los primeros dispositivos comerciales. Desde entonces, se han desarrollado un gran número de técnicas de microfabricación para estos sustratos, siendo los materiales más comunes en sistemas ópticos integrados con funciones sensoras.

El vidrio también presenta propiedades dieléctricas y ópticas atractivas para su empleo en sistemas nanobiosensores. Diferentes técnicas de microfabricación han sido desarrolladas sobre este tipo de sustratos, que son suministrados en forma de obleas de diferentes composiciones (cuarzo, sílice fundida, vidrio borosilicado) y 
diámetros. Su transparencia óptica, junto a su inercia química y resistencia a altas temperaturas, los hace especialmente adecuados para la fabricación de dispositivos con principio de transducción óptica.

Algo menos estudiado que los anteriores, pero con un gran potencial de aplicación en óptica integrada debido a sus propiedades dieléctricas, es el nitruro de silicio. Este material posee un elevado índice de refracción, que lo hace candidato óptimo para la construcción de nuevos dispositivos que integren estructuras con propiedades ópticas de gran interés, como por ejemplo, las guías de onda. Desde un punto de vista químico, este material aporta ventajas como la presencia de oxinitruro superficial, que permite su modificación tanto a través de la química del nitrógeno como de los grupos hidroxilos superficiales.

Por otro lado, existen otros materiales con propiedades dieléctricas adecuadas como $\mathrm{Ta}_{2} \mathrm{O}_{5}, \mathrm{TiO}_{2}$, etc. Estos óxidos son dúctiles y maleables, además de presentar una elevada resistencia a la corrosión, comparable a la del grafito y los fluoropolímeros (Teflón), lo que permitió que en la década de los 90 se desarrollaran técnicas de microfabricación apropiadas y se aplicaran a la construcción de BioMEMs. La principal ventaja de estos óxidos es que son materiales altamente refractarios, lo que los hace muy interesantes en la construcción de dispositivos optoelectrónicos.

Existen algunos trabajos sobre biosensores con transducción óptica que utilizan otro tipo de materiales como $\mathrm{ZnO}, \mathrm{GaO}$, InO y nanotubos de carbono. Estos materiales tienen un uso más extendido en biosensores electroquímicos y optoelectroquímicos, ya que sus propiedades electrónicas y su conductividad son muy adecuadas para la fabricación de electrodos. 
Tabla 6. Propiedades ópticas y químicas de algunos materiales inorgánicos ${ }^{147}$

\begin{tabular}{l|cccc}
\hline & $\mathbf{S i}$ & $\mathbf{S i O}_{2}$ & $\mathbf{S i}_{3} \boldsymbol{N}_{4}$ & $\mathbf{T a}_{2} \boldsymbol{O}_{5}$ \\
\hline \hline Densidad $\left(\mathbf{g} / \mathbf{c m}^{3}\right)$ & 2,33 & 2,2 & 3,1 & 8,2 \\
Índice de refracción & 3,73 & 1,46 & 2,05 & 2,15 \\
Constante dieléctrica $(\boldsymbol{p F} / \boldsymbol{m})$ & 13 & 3,9 & 7,5 & 25 \\
Resistencia química* & Excelente & Excelente & Excelente & Excelente \\
\hline
\end{tabular}

* Frente ácidos, bases y disolventes orgánicos

En las secciones siguientes se describen varios tipos de sistemas ópticos integrados para la detección directa sin marcaje de la interacción analito-receptor, basados en diferentes principios de transducción óptica (interferometría, generación de plasmones de superficie, guías de onda). También presentan los sensores de onda evanescente que aprovechan el campo magnético asociado al guiado de la luz para la detección luminiscente, selectiva y sensible, utilizando marcaje.

\subsubsection{Sistemas ópticos integrados y detección sin marcaje}

Las tecnologías de detección y cuantificación de analitos mediante transductores ópticos sin marcaje son de gran interés debido a su capacidad de sensar directamente interacciones biomoleculares (label-free), simplificar el ensayo y, en algunos casos, conocer la cinética del proceso a medida que ocurran estas interacciones. Entre los diferentes tipos de biosensores ópticos integrados sin marcaje distinguiremos: los de resonancia de plasmones de superficie (SPR, SPRI), interferometros (Mach-Zehnder ${ }^{23}$, Young's, Hartman), guías de onda, anillos resonadores y cristales fotónicos. A continuación vamos a describir los desarrollos más interesantes de este tipo de sistemas, así como sus aplicaciones y las prestaciones alcanzadas. 
En la Figura 11 se representan diferentes esquemas para el sensado de la interacción analito-receptor en dispositivos optoelectrónicos. En la Tabla 7 se resumen algunos ejemplos del estado del arte de los distintos sistemas de detección sin marcaje descritos.

(A)

Resonancia de plasmón de superficie(SPR)
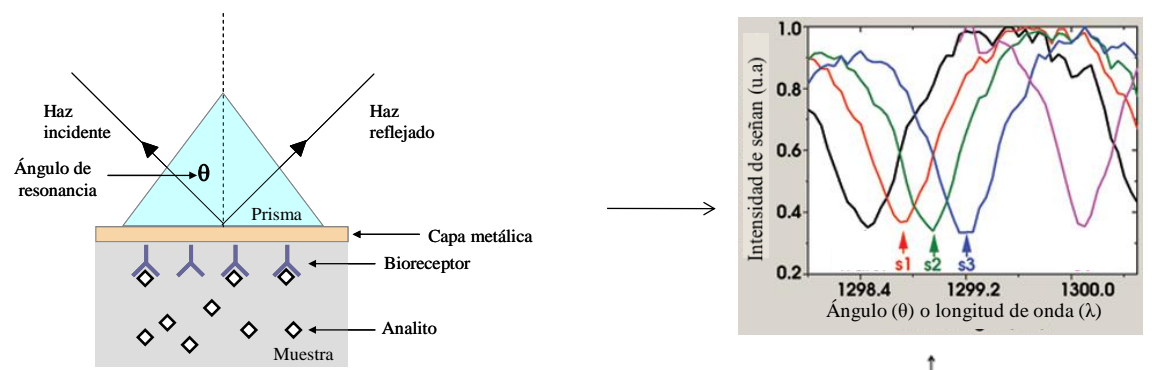

(B)

(C)

Microanillos resonadores

Guía de referencia
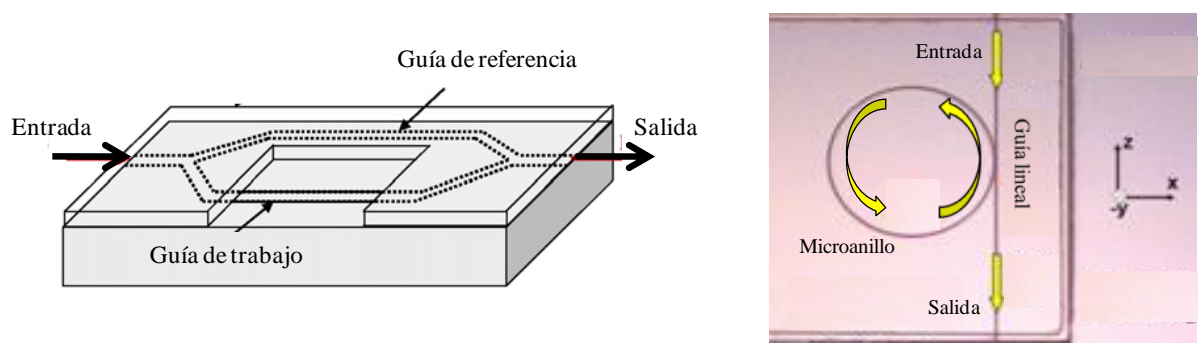

Figura 11. Esquema de dispositivos de detección sin marcaje. 


\section{Resonancia de plasmones de superficie (SPR)}

Es un proceso de detección óptico que se produce cuando incide luz polarizada sobre la superficie de un prisma cubierto por una película metálica. Bajo ciertas condiciones (longitud de onda, polarización y ángulo de incidencia) los electrones de la banda de conducción del metal absorben fotones del haz incidente y los convierten en ondas de plasmones de superficie, generándose un máximo en la intensidad del haz reflejado en la superficie metálica (condiciones de resonancia). De este modo, las perturbaciones originadas por las moléculas sobre la superficie metálica inducen una modificación de las condiciones de resonancia, que puede ser monitorizada como un desplazamiento en la reflectividad de la luz o en el ángulo de resonancia, siendo esta la base para las mediciones de SPR. En la Tabla 7 se muestran algunos trabajos, de los muchos publicados que utilizan esta metodología, por ejemplo, para la detección de marcadores tumorales y Salmonella, alcanzando límites de detección de $0,7 \mathrm{nM}$ y $100 \mathrm{cfu} / \mathrm{mL}$, respectivamente; usando equipos comerciales que emplean esta configuración, se han alcanzando límites de detección de $5 \mathrm{nM}$ para plaguicidas y $25 \mathrm{cfu} / \mathrm{mL}$ para la bacteria E. Coli. ${ }^{148-150}$

Otra modalidad son los sistemas SPR integrados con guías de onda, que ofrecen una buena alternativa a los prismas, son robustos, y permiten la integración con otros componentes ópticos y eléctricos. Slavik et al. ${ }^{151,152}$ han alcanzando límites de detección de $1 \mathrm{ng} / \mathrm{mL}$ para la proteína $\mathrm{IgG}$ mediante este tipo de sistemas, mientras que Piliarik et al. ${ }^{153,154}$ lograron límites de detección de $10 \mathrm{nM}$ para antibióticos mediante esta configuración.

A pesar de que los dispositivos basados en SPR son muy competitivos, existen varios problemas que limitan su aplicación. En primer lugar, en estos sistemas el campo evanescente solo penetra en el medio adyacente unos $100 \mathrm{~nm}$, dificultando por tanto la detección de moléculas de gran tamaño (células, bacterias, etc.). En segundo lugar, no es posible diferenciar los cambios de índice de refracción 
producidos en la superficie y en el seno de la disolución, disminuyendo el rendimiento de detección en el caso de muestras complejas como sangre.

La SPR tiene una capacidad de trabajo reducida, aunque puede aumentarse sensiblemente con la tecnología SPR de imagen (SPRI). Un sensor SPRI integra una cámara con un sistema de iluminación por LEDs para la visualización de la luz reflejada. Esta técnica trabaja en formato microarray y permite la detección multianalito con sensibilidades de 1 a $10 \mathrm{nM}^{155,156}$

\section{Interferometría}

En esta categoría se agrupan los interferómetros Mach-Zender, Young y Hartman, principalmente, que aunque difieren en el diseño se rigen por el mismo principio de medida.

Los biosensores interferométricos se basan en la detección del desplazamiento de fase en la luz guiada, entre una guía de referencia y una guía de ensayo en contacto con la muestra, de modo que la magnitud del desplazamiento se puede correlacionar con la cantidad de materia inmovilizada sobre la guía de ensayo. En la Tabla 7 se muestran algunos estudios para estos sistemas, como los de Heidenman et al. ${ }^{157}$, que desarrollaron un interferómetro Mach-Zender para detección de marcadores tumorales; Ymeti et al. ${ }^{158,159}$, que utilizaron un interferómetro de Young para la detección del virus del Herpes, alcanzando límites de detección de $10^{5}$ partículas/mL; o Schneider et al. ${ }^{160-162}$, que diseñaron un protopipo de trabajo con la configuración de Hartman para la detección del virus de la influenza A y Salmonella. Algunos de estos dispositivos se han comercializado, como por ejemplo el biosensor Analight, desarrollado por Farfield Group Ltd. (Manchester, U.K.). ${ }^{163}$

Existe una variante denominada interferometría de barrido inverso (backscattering interferometry) que ha llegado a alcanzar resultados competitivos 
con los sistemas clásicos. En esta modalidad el área de ensayo se reduce significativamente al utilizar un haz colimado, midiéndo los desplazamientos de fase de la luz reflejada. En aquellas zonas o puntos donde se ha inmovilizado materia, se detecta un desplazamiento de fase que puede correlacionarse con la cantidad de sonda inmovilizada. Varios trabajos ${ }^{164-166}$ demuestran la aplicabilidad de estos sistemas para la detección de sondas de oligonucleótidos hasta concentraciones de $2 \mathrm{pM}$.

\section{Microanillos resonadores}

Dentro del campo de los dispositivos fotónicos integrados, los microanillos resonadores son estructuras con un gran potencial como plataformas biosensoras sin marcaje, altamente sensibles y con capacidad de análisis multianalito -un chip de pequeño tamaño puede incluir varios microanillos-. Estas plataformas presentan una estructura de guía de ondas fabricadas con materiales de alto índice de refracción $\left(\mathrm{Si}_{3} \mathrm{~N}_{4}, \mathrm{TiO}_{2}\right.$, etc.) en forma de anillo, ópticamente acopladas a una o varias guías de ondas lineales, sobre una superficie plana mediante fotolitografía ${ }^{167}$, si bien existen varios diseños. 
Tabla 7. Límites de detección para algunos sistemas ópticos sin marcaje.

\begin{tabular}{|c|c|c|c|}
\hline Dispositivos & Analito & $L D D$ & Referencia \\
\hline \multirow[t]{2}{*}{ SPR/ Prisma } & $\alpha$-fetoproteína & $0,7 \mathrm{nM}$ & Teramura $^{168}$ et al. \\
\hline & Salmonella & $100 \mathrm{cfu} / \mathrm{mL}$ & Oh et al. ${ }^{169}$ \\
\hline \multirow[t]{2}{*}{ SPR/ Guía de onda } & Proteína (IgG) & $2,5 \mathrm{nM}$ & Slavik et al. ${ }^{151,152}$ \\
\hline & Sulfonamidas & $10 \mathrm{nM}$ & Piliarik et al. ${ }^{153,154}$ \\
\hline \multirow[t]{2}{*}{ SPRI } & $\beta_{2}$-microglobulina & $1 \mathrm{nM}$ & Lee et $a l . .^{170}$ \\
\hline & $\mathrm{ADN}$ & $10 \mathrm{nM}$ & Nelson et al. ${ }^{156}$ \\
\hline \multirow[t]{2}{*}{ SPR comerciales } & E. Coli,Salmonella & $25 \mathrm{cfu} / \mathrm{mL}$ & Biacore $2000^{171}$ \\
\hline & Plaguicidas (Carbamatos) & $5 \mathrm{nM}$ & $\beta$-Sensia ${ }^{148-150}$ \\
\hline I. Mach-Zender & Gonadotropina humana & $50 \mathrm{pM}$ & Heideman et al. ${ }^{157}$ \\
\hline \multirow[t]{2}{*}{ I. Hartman } & RNA & $0,3 \mathrm{nM}$ & Schneider et al $^{160-162}$ \\
\hline & Salmonella & $5 \times 10^{5} \mathrm{cfu} / \mathrm{mL}$ & \\
\hline \multirow[t]{2}{*}{ I. Young } & Virus del herpes (HSV-1) & $1000 \mathrm{part} / \mathrm{mL}$ & Ymeti et al ${ }^{158,159}$ \\
\hline & Estreptavidina & $1 \mathrm{pM}$ & Analight $2000^{163}$ \\
\hline I. barrido inverso & $\mathrm{ADN}$ & $2 \mathrm{pM}$ & Lin et al. ${ }^{164}$ \\
\hline \multirow{4}{*}{$\begin{array}{l}\text { Microanillos } \\
\text { resonadores }\end{array}$} & $\mathrm{ADN}$ & $100 \mathrm{nM}$ & Little et al. ${ }^{66,67}$ Abraham et al. ${ }^{172}$ \\
\hline & ARN & $4 \mathrm{nM}$ & Ramachandran et al. ${ }^{66}$ \\
\hline & Bacteria (E. Coli) & $10^{5} \mathrm{cfu} / \mathrm{mL}$ & Ksendov. et al. ${ }^{173,174}$ \\
\hline & Avidina & $0,1 \mathrm{nM}$ & Vos et al..$^{175}$ \\
\hline
\end{tabular}


Tabla 7 (cont). Límites de detección para algunos sistemas ópticos sin marcaje.

\begin{tabular}{llll}
\hline Dispositivo & Analito & LDD & Referencia \\
\hline \hline Cristales fotónicos & Proteína (IgG) & $0,15 \mathrm{nM}$ & Skivesen et al. ${ }^{176}$ \\
& ADN & $20 \mathrm{nM}$ & ${\text { Toccafondo } \text { et al. }{ }^{177}}$ \\
& Influenza A & $1 \mathrm{ng} / \mathrm{mL}$ & Endo et al. ${ }^{178}$ \\
\hline
\end{tabular}

La propagación de la luz a través de las guías de onda genera un campo evanescente, que se extiende a una distancia de 100-300 $\mathrm{nm}$ sobre la superficie de la guía de ondas y cuya intensidad decae exponencialmente con la distancia a la misma. Los anillos y las nanoguías lineales están posicionados de modo que se consigue un acoplamiento del campo evanescente y la luz que proviene de la nanoguía de entrada se propaga a través del anillo. De este modo, cuando se alcanza la longitud de onda de resonancia se consigue el acoplamiento con el anillo y la recirculación continua de la luz dentro del mismo. La intensidad de luz dentro del anillo se incrementa significativamente debido a la continua entrada de luz desde la nanoguía lineal, generándose una amplificación del campo evanescente que puede ser explotada para aplicaciones sensoras.

De este modo, cuando un analito se deposita cerca de la superficie del anillo cambia el índice de refracción efectivo de la superficie, alterando las propiedades de resonancia del microanillo y produciendo un desplazamiento en la longitud de onda de resonancia que puede ser determinado monitorizando el espectro óptico a la salida de la nanoguía lineal. Existen estudios que emplean estos dispositivos para la detección cuantitativa y cualitativa de biomoléculas (Tabla 7). Chao et al. ${ }^{68,179,180}$ desarrollaron un dispositivo de anillos poliméricos y demostraron su aplicabilidad detectando proteína $\mathrm{G}$ hasta concentraciones $250 \mathrm{pg} / \mathrm{mm}^{2}$. Mediante un sistema de anillos resonadores de $\mathrm{Si}_{3} \mathrm{~N}_{4} / \mathrm{SiO}_{2}$, Vos et al. ${ }^{175}$ describen la detección de avidina 
hasta $10 \mathrm{ng} / \mathrm{mL}$. Más recientemente, Abraham et al. ${ }^{172}$ han desarrollado un estructura fotónica compuesta por varios anillos resonadores, demostrando su utilidad para la detección simultánea y múltiple de sondas de ARN.

\section{Cristales fotónicos}

Los cristales fotónicos han surgido como un campo de interés creciente en biosensores. Se basan en estructuras dieléctricas altamente ordenadas en los que la introducción de defectos permite la propagación de la luz, generándose un pico en el espectro de transmisión o reflexión. La inmovilización de materia generará una variación de la luz transmitida o reflejada, que puede relacionarse con la cantidad inmovilizada. Así, Toccafondo et al. ${ }^{177}$ han desarrollado un dispositivo basado en guías de ondas de cristales fotónicos (Figura 12) con el que han alcanzado una gran sensibilidad (límites de detección de 20 nM para ensayos de hibridación de oligonucleótidos), como consecuencia del fenómeno de confinamiento del campo electromagnético en la guía.

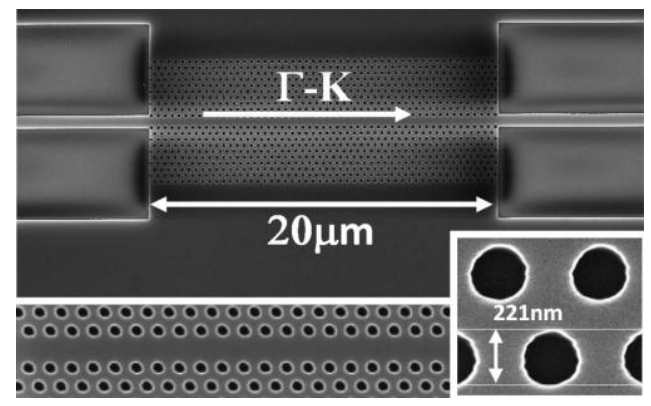

Figura 12. Imagen de SEM de dispositivo de medida para la detección de sondas de ADN basado en guías de ondas de cristales fotónicos. ${ }^{177}$ 


\subsubsection{Sistemas ópticos integrados y detección con marcaje}

Estos sistemas utilizan el campo evanescente generado cuando una radiación viaja a través de una guía de ondas para la detección de cualquier interacción molecular que se produzca en este campo, como la unión del analito a un receptor inmovilizado en la superficie de las guía de ondas; requieren el marcaje con moléculas fluorescentes, aportando ventajas como una elevada sensibilidad, detección rápida y selectiva del analito, y bajo ruido de fondo. Además, las medidas pueden llevarse a cabo en medios con alta turbidez, aspecto muy interesante en el caso de la mayoría de las disoluciones biológicas.

Un tipo interesante de sistemas de detección luminiscente basado en fenómenos de campo evanescente son los que utilizan guías de onda planas. Consisten en una película de un material de alto índice de refracción depositada sobre un soporte transparente de bajo índice de refracción. En esta modalidad cuando un haz láser incide sobre las guías de entrada (gratings) la luz se propaga por reflexión interna total a través de la superficie del material con mayor índice de refracción, generando un campo evanescente. La intensidad del campo generado, que depende de la diferencia de índices de refracción de ambos medios y del grosor de la capa del material depositado, puede ser aprovechada para la detección fluorimétrica de microarrays de ADN y proteínas, con alta sensibilidad y selectividad ${ }^{75,76,181-183}$, así como para la adquisición de imágenes de microscopia de alta resolución. ${ }^{184}$

En el desarrollo de estos sistemas generalmente se emplean chips de vidrio sobre los que se deposita una capa de dióxido de titanio o pentóxido de tántalo, materiales con propiedades óptimas para el guiado de la luz debido a su transparencia y elevado índice de refracción.

Diferentes estudios $^{74}$ han demostrado que el espesor óptimo de película para aplicaciones sensoras oscila entre 100-200 nm, con un índice de refracción alrededor de 2, alcanzándo en estas condiciones las mayores intensidades de campo. 
Una de las aplicaciones más interesantes de la tecnología descrita es la basada en formato de arrays de ADN y proteínas. En este sentido, frente a las principales desventajas que presentan las técnicas convencionales, los sensores de guías de onda planas surgieron como una alternativa muy prometedora para detección fluorescente, altamente sensible, y selectiva de dianas, utilizando formato de microarrays. La principal ventaja de esta metodología es que la detección de fluorescencia se limita a nivel superficial, permitiendo la discriminación entre las interacciones que se producen en la proximidad de la superficie de ensayo y las que se dan en la matriz de reacción (muestra). Además, debido a la intensidad del campo evanescente, pueden detectarse concentraciones muy bajas (picomolar) ${ }^{76,185}$, pudiendo eliminar alguna de las etapas de ensayo como, por ejemplo, la amplificación mediante PCR.

Ehrat et al. han patentado y comercializado un dispositivo de medida basado en la tecnología de guía de ondas plana denominado Zeptochip, muy versátil, con capacidad de detección multianalito, y con aplicaciones en genómica, proteómica y análisis clínico ${ }^{181-183,185,186}$. Tal y como muestra la Figura 13, el dispositivo esta formado por una película de $\mathrm{Ta}_{2} \mathrm{O}_{5}$ depositada sobre un sustrato de vidrio. El principio óptico de detección consiste en una fuente de excitación láser que, a una determinada longitud de onda coincidente con la geometría de la guía de entrada, se propagará por la película de $\mathrm{Ta}_{2} \mathrm{O}_{5}$. Como consecuencia de este fenómeno, se genera un campo evanescente de alta intensidad en dirección perpendicular a la superficie, con una profundidad de alrededor de $200 \mathrm{~nm}$ en el medio adyacente. De este modo, los microarrays de sondas previamente depositadas sobre la superficie son excitados simultáneamente y la señal de fluorescencia registrada con una cámara CCD. Esta discriminación espacial, junto a la alta intensidad de los campos de excitación, incrementa considerablemente la relación señal/ruido en comparación con los métodos convencionales. 
A continuación, se aborda el estado del arte de la química de superficies de compuestos silíceos y pentóxido de tántalo en el campo de la óptica integrada, teniendo en cuenta los dos tipos de plataformas con las que se ha trabajado en esta investigación -un sistema fotónico integrado basado en microanillos resonadores de nitruro de silicio sobre una plataforma de óxido de silicio ${ }^{187,188}$, y guías de ondas plana de $\mathrm{Ta}_{2} \mathrm{O}_{5}$ depositado sobre un soporte transparente (vidrio) de bajo índice de refracción $^{185,189}$-.

(A)

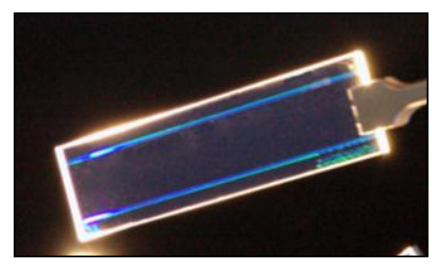

(B)

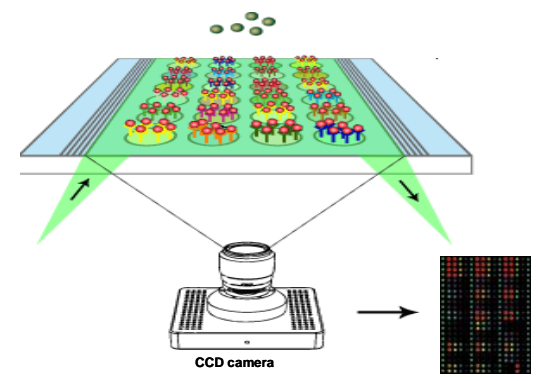

Figura 13. (A) Imagen del dispositivo sensor comercial de $\mathrm{Ta}_{2} \mathrm{O}_{5}$ desarrollado por Zeptosens ${ }^{190}$. (B) Principio de lectura de la técnica basada en guía de ondas plana.

\subsubsection{Funcionalización de materiales inorgánicos}

\subsubsection{Estrategias de modificación química de compuestos silíceos}

El silicio y los materiales derivados de éste como el óxido y el nitruro de silicio, entre otros, presentan importantes ventajas para utilizarse como componentes base de los biosensores. Entre ellas destacan sus propiedades físicas, que permiten 
emplear técnicas muy establecidas en la fabricación de dispositivos miniaturizados que integran sistemas sensores y electromecánicos a escala micro y nano. Por otro lado, sus propiedades químicas facilitan su funcionalización y recubrimiento con monocapas biomoleculares.

La estructura fotónica base del dispositivo analítico empleado en la presente tesis se compone de un conjunto de microanillos resonadores de nitruro de silicio sobre un sustrato de óxido de silicio. Por ello, es crucial que la modificación química realizada sea altamente selectiva para el nitruro de silicio, ya que la materia inmovilizada sobre la guía será detectada, mientras que aquella inmovilizada fuera de la guía no lo será, lo que conllevará una caída drástica de las prestaciones del sistema sensor.

Los tratamientos más aplicados en este tipo de materiales se basan en la derivatización de las superficies con organosilanos, haciendo uso de los silanoles siempre presentes en el silicio y nitruro de silicio de forma nativa, de modo que tras el empleo de un crosslinker adecuado permita el anclaje covalente de ácidos nucleicos o proteínas a través de sus grupos amino o tiol ${ }^{191-195}$. Otros tratamientos utilizan plasma para la oxidación previa y controlada de la superficie, o procesos de deposición en fase vapor ${ }^{196}$.

En todos los casos se requiere que la funcionalización de la superficie sea efectiva, homogénea, reproducible y con el mayor número posible de puntos de anclaje. A continuación se describen las estrategias más interesantes para la modificación de estos materiales.

\section{Modificación superficial de Si}

En los últimos años, la derivatización química de las superficies de silicio se ha convertido en un área de creciente interés por su impacto en la química fundamental, la ciencia de superficies y la electrónica molecular. La 
funcionalización química puede ser abordada utilizando diferentes vías de actuación: (i) aprovechando la reactividad del silicio, (ii) a través de los grupos $\mathrm{OH}$ generados tras la oxidación superficial por contacto directo con la atmósfera y (iii) aprovechando la reactividad de los $\mathrm{Si}-\mathrm{H}$ generados tras una etapa de etching con HF.

Entre las diferentes estrategias posibles ${ }^{197-202}$ mostradas en el Esquema 3, destacan:

$\checkmark$ Cicloadición del silicio con grupos alqueno o alquino.

$\checkmark$ Condensación de alcoholes a los silanoles del silicio.

$\checkmark$ Silanización de las superficies hidroxiladas o de las superficies Si-H, por reacción con un clorosilano o un alcoxisilano.

$\checkmark$ Silanización de las superficies Si-H por reacción con azanos, eliminando $\mathrm{NH}_{3}$.

$\checkmark$ Arilación de superficies con grupos terminales Si-H utilizando sales de diazonio.

$\checkmark$ Arilación con nitrobenceno de las superficies con terminación Si-H, eliminando $\mathrm{H}_{2} \mathrm{O}$.

$\checkmark$ Hidrosilación de alquenos en superficies terminadas con $\mathrm{Si}-\mathrm{H}$.

Zuilhof $e t$ al. ${ }^{203-206}$ han demostrado la activación de silicio con distintos grupos funcionales a partir de la reacción de hidrosilación con cadenas que contienen un grupo alqueno terminal. No sólo han estudiado los mecanismos de reacción y demostrado la formación de monocapas, si no que además -en trabajos recienteshan demostrado la utilidad de estas superficies en el desarrollo de biosensores para detección de sondas de oligonucleótidos. ${ }^{207}$ 


\section{Silicio (100)}

Cicloadición

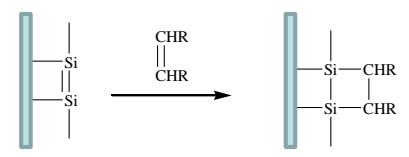

Silicio hidroxilado (Si-OH)

Condensación

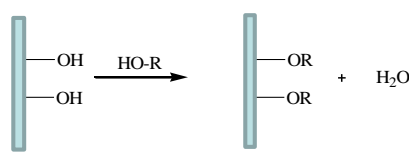

Silanización

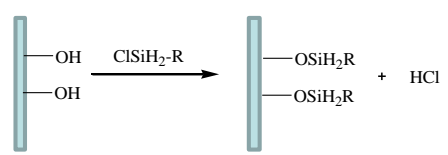

Silicio hidrogenado (Si-H)

Silanización

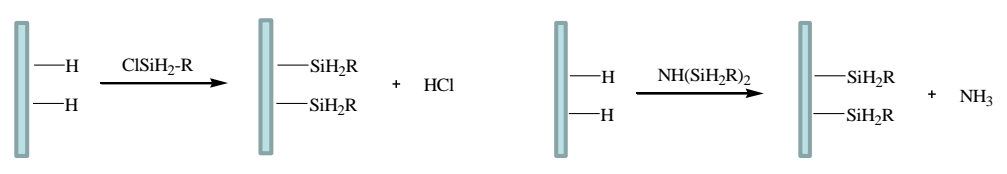

Hidrosilación

Arilación
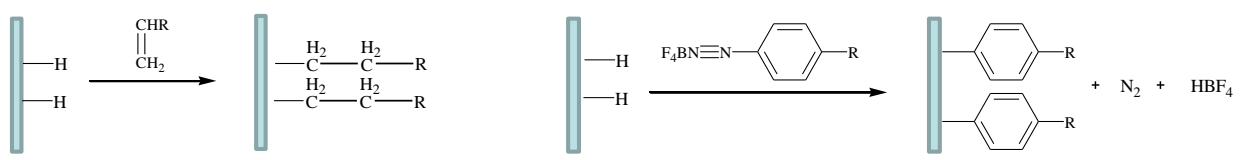

Esquema 3. Estrategias de modificación química de las superficies de silicio.

Balasubramanian et al. ${ }^{208}$ desarrollaron una metodología para la activación de nanoguías de silicio con grupos amino mediante una reacción de hidrosilación con una molécula que contenía un grupo alqueno terminal, utilizando la superficie activada para la puesta a punto de ensayos de hibridación de sondas de oligonucleótidos. 
En otra aproximación, Zhang et $a .^{209}$ utilizaron la capa de óxido nativo remanente en las superficies de silicio para la silanización con alcoxilinos. Finalmente obtuvieron superficies aldehizadas que fueron empleadas para la detección del virus del dengue.

\section{Modificación superficial de $\mathrm{SiO}_{2}$}

El dióxido de silicio es el material más estudiado y de mayor uso como soporte inerte en el campo de los biosensores. Su química, bien establecida, es compatible con gran cantidad de disolventes y estable a altas temperaturas. El dióxido de silicio es un polímero inorgánico cuya unidad básica es un tetraedro, en el que una molécula de silicio está unida a cuatro oxígenos y cada oxígeno a dos átomos de silicio; estos tetraedros se distribuyen de forma no ordenada, confiriendo al silicato la propiedad de ser un sólido amorfo. El elevado punto de fusión y la alta temperatura de transición vítrea de este material son debidos a la estabilidad de los enlaces Si-O. El dióxido de silicio es, junto con el silicio, uno de los materiales preferidos en sistemas miniaturizados, debido a que las técnicas de microfabricación (fotolitografía, ablación, etc.) están ampliamente estudiadas y establecidas.

En cuanto a la modificación química superficial del $\mathrm{SiO}_{2}$, la bibliografía recoge numerosas referencias para la formación de SAMs de organosilanos en la superficie de este material, mediante la generación de siloxanos entre los grupos hidroxilo superficiales y el organosilano (Esquema 4). Estas reacciones de silanización tienen lugar a bajas temperaturas y no requieren condiciones específicas, consiguiéndose una homogeneidad y densidad aceptable en la monocapa formada, si bien los siloxanos pueden ser hidrolíticamente inestables bajo condiciones fisiológicas, perdiendo su actividad $^{210-214}$. 


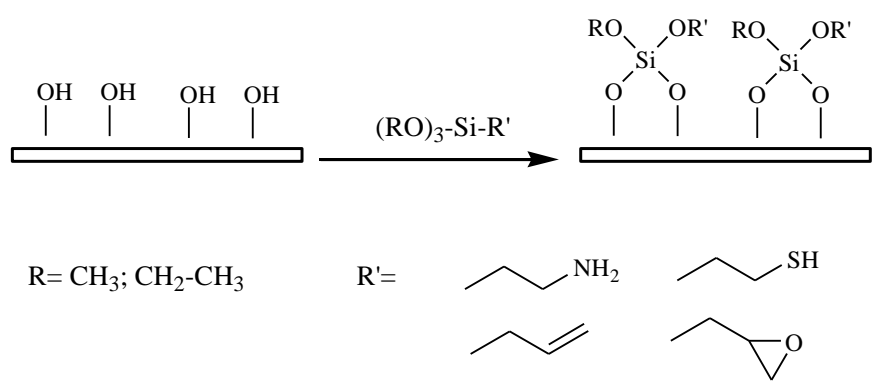

Esquema 4. Estrategias de modificación de óxido de silicio mediante la química de los organosilanos.

\section{Modificación superficial del $\mathrm{Si}_{3} \mathbf{N}_{4}$}

El nitruro de silicio es el material menos estudiado de los aquí tratados, a pesar de que sus propiedades dieléctricas, dureza mecánica y estabilidad a altas temperaturas, lo convierten en un soporte con un elevado potencial en el campo de los nanobiosensores.

Su química está menos desarrollada que la de otros derivados siliceos, siendo escasos los trabajos de caracterización de capas orgánicas en superficies de nitruro.

La mayoría de las estrategias descritas se limitan a la funcionalización de la capa nativa de $\mathrm{SiO}_{2}{ }^{194,215-218}$ presente en las superficies de nitruro de silicio. Sin embargo, estas metodologías no son válidas en sistemas que requieren funcionalizar un material $\left(\mathrm{Si}_{3} \mathrm{~N}_{4}\right)$ en presencia de otro $\left(\mathrm{SiO}_{2}\right)$, como es el caso de los dispositivos utilizados en esta tesis; además, presentan la problemática adicional de falta de reproducibilidad, consecuencia de la heterogeneidad de la capa nativa preexistente sobre la superficie del nitruro ${ }^{219,220}$.

En los últimos años se han desarrollado diferentes metodologías de modificación a través de la química del enlace Si-H (Esquema 5A), utilizando procesos térmicos o fotoquímicos ${ }^{204-206}$. La mayoría de estos métodos están ampliamente estudiados 
en superficies de silicio, siendo más escasos los resultados para $\mathrm{Si}_{3} \mathrm{~N}_{4}$. Entre los diferentes trabajos publicados, Pignataro et al. ${ }^{221}$ hidrosilaron superficies de nitruro de silicio, previamente activadas con grupos $\mathrm{Si}-\mathrm{H}$, mediante tratamiento con un alqueno (Esquema 5A.1). Los principales inconvenientes de esta estrategia aplicada al $\mathrm{Si}_{3} \mathrm{~N}_{4}$ se deben a los menores rendimientos de funcionalización respecto al silicio y la baja homogeneidad de la capa formada.

Arafat et al. $^{222}$ (Esquema 5A.2) alcanzaron buenos rendimientos de inmovilización para la hidrosilación con alquenos o alquinos, mediante el uso de superficies de nitruro de silicio enriquecidas, es decir, con una mayor relación estequiométrica de silicio. Activaron las superficies con grupos carboxilados, realizando varios estudios de inmovilización de péptidos. Más recientemente, han desarrollado superficies activadas con grupos NHS-ester, con aplicaciones para ensayos de hibridación de sondas de ADN. Los principales inconvenientes de esta estrategia se deben a que las capas formadas sobre el nitruro continúan siendo de peor calidad en relación al silicio y a que las condiciones de reacción son agresivas.

Otra alternativa plantea el uso de precursores protegidos (ésteres para ácidos, amidas para aminas, etc.) capaces de resistir las condiciones de reacción establecidas $y$, tras un proceso de desprotección, generar una superficie químicamente activa. Por ejemplo, Coffinier et al. ${ }^{223}$ utilizaron como precursor tertbutil 2-[(alilamino)carbonil]hydrazina-carboxilato, que resiste las condiciones de hidrosilación, para producir una monocapa orgánica a través de la formación de enlaces Si-C. Posteriormente, tras un tratamiento ácido, generan superficies activadas con grupos semicarbazida (Esquema 5A.3). 
A. ESTRATEGIAS DE MODIFICACIÓN A TRAVÉS DEL ENLACE Si-H

A.1

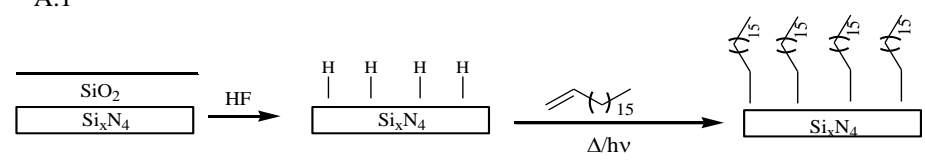

A. 2

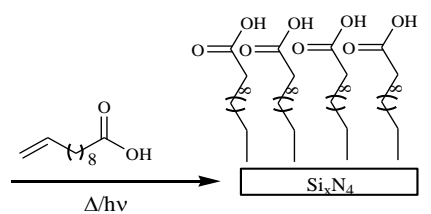

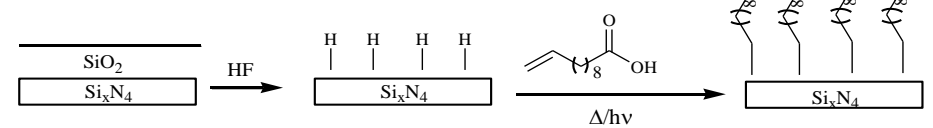
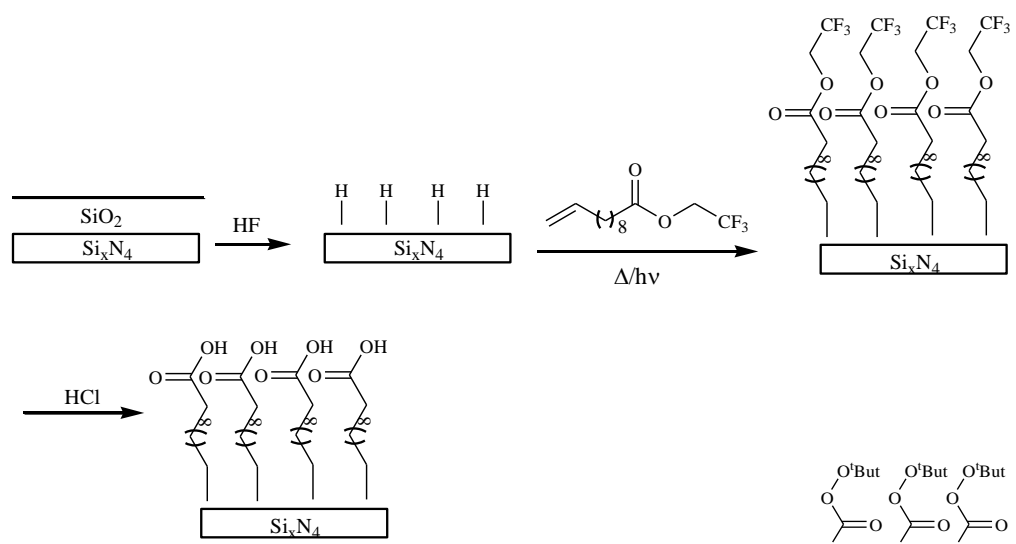

A. 3
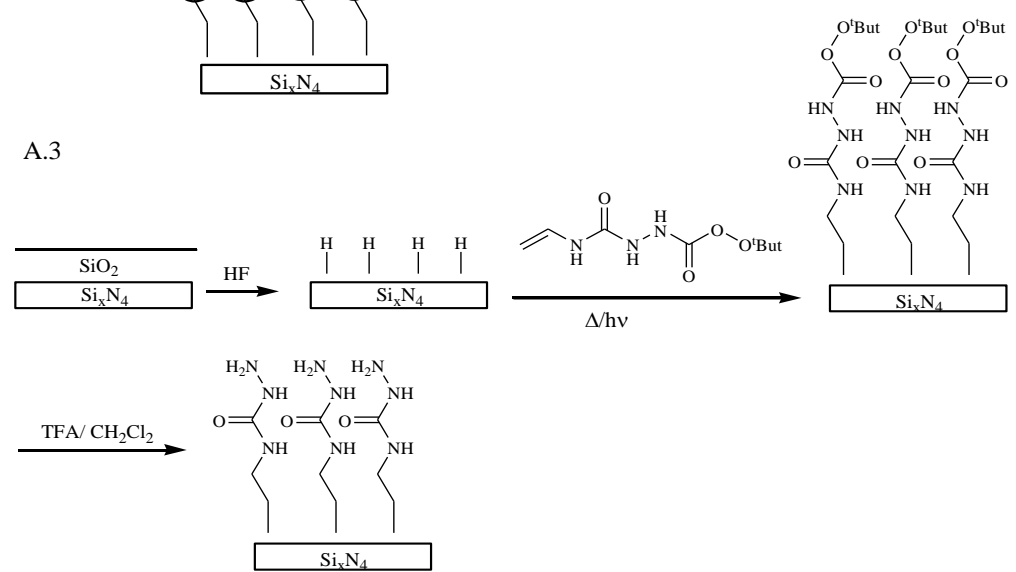

Esquema 5. Estrategias de modificación química del $\mathrm{Si}_{3} \mathrm{~N}_{4}$. 


\section{B. ESTRATEGIAS DE MODIFICACIÓN A TRAVÉS DEL ENLACE Si-N}

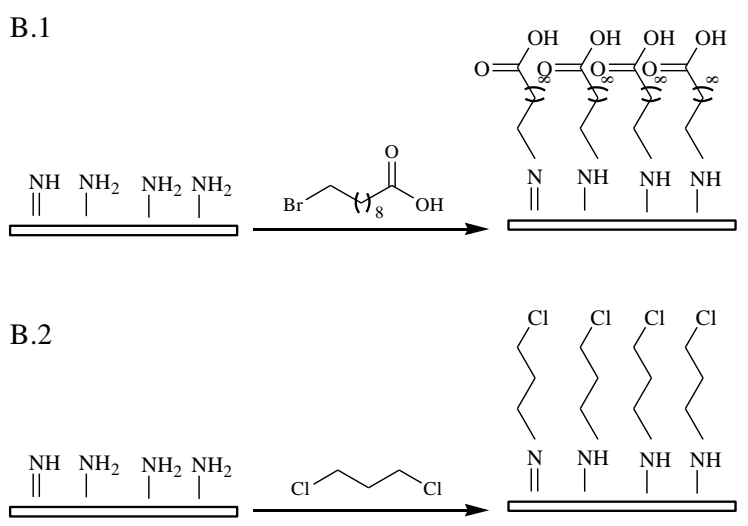

Esquema 5 (cont.). Estrategias de modificación química del $\mathrm{Si}_{3} \mathrm{~N}_{4}$.

Finalmente, existen algunos estudios basados en la reactividad de los grupos amino. Estas estrategias (Esquema 5B) son de gran interés, ya que ofrecen la ventaja de su selectividad química sin necesidad de pasivado de las superficies de óxido de silicio. En esta aproximación, Cattaruzza et al. ${ }^{224}$ han descrito la formación de una capa de ácidos carboxílicos mediante tratamiento - térmico o fotoquímico- con un bromoácido (Esquema 5B.1). El mecanismo de la reacción consiste en una sustitución nucleófila del grupo halogenado con los grupos amino de la superficie, generando así una superficie activada con grupos carboxílicos. Otra estrategia es la desarrollada por Karymov et al. ${ }^{225}$ (Esquema 5B.2), que proponen la inmovilización de sondas de ácidos nucleicos sobre superficies previamente halogenadas mediante derivados homobifuncionales de etano o propano $\left(\mathrm{X}-\left(\mathrm{CH}_{2}\right)_{\mathrm{n}^{-}}\right.$ $\mathrm{X}) ; \mathrm{X}=\mathrm{Br}, \mathrm{Cl}, \mathrm{n}=2$ ó 3). 


\subsubsection{Modificación química superficial del pentóxido de tántalo $\left(\mathrm{Ta}_{2} \mathrm{O}_{5}\right)$}

El pentóxido de tántalo se emplea en la fabricación de guías de onda planas, consistentes en una película de $\mathrm{Ta}_{2} \mathrm{O}_{5}$ depositado sobre un soporte transparente (vidrio) de bajo índice de refracción. En este y en otros casos se necesitan protocolos de modificación química superficial bien definidos, simples y reproducibles, que no alteren las propiedades ópticas y mecánicas de los dispositivos.

En el Esquema 6 se muestran diferentes estrategias de modifiación de óxido de tántalo, basadas en la interacción de un compuesto organosilano o un clorosilano ${ }^{226}$ con los grupos - OH terminales de la superficie del óxido, así como en la generación de monocapas a través de la química de los alquilfosfonatos.

Polzius et $a{ }^{227}$ han desarrollado varios métodos de modificación química superficial de $\mathrm{Ta}_{2} \mathrm{O}_{5}$ basados en la química de los alcoxisilanos. En sus estudios han comparado diversas estrategias de inmovilización, covalente y por adsorción, mediante el uso de proteína $\mathrm{G}$ como molécula de captura de inmunoglobulinas. De todas las estrategias desarrolladas (Esquema 6A), los mejores resultados se obtuvieron para la inmovilización de proteínas sobre una matriz de dextrano activada con grupos carboxílicos tras un tratamiento con ácido bromoacético. Los peores resultados se obtuvieron para la metodología basada en la inmovilización directa de proteína sobre la superficie de $\mathrm{Ta}_{2} \mathrm{O}_{5}$.

Otros autores como De Palma et al. ${ }^{228}$, han estudiado y caracterizado mediante diversas técnicas (XPS, voltamperometría cíclica, elipsometría) la formación de una monocapa, por acoplamiento de un clorosilano con los grupos - $\mathrm{OH}$ de la superficie de óxido de tántalo (Esquema 6B). 
A

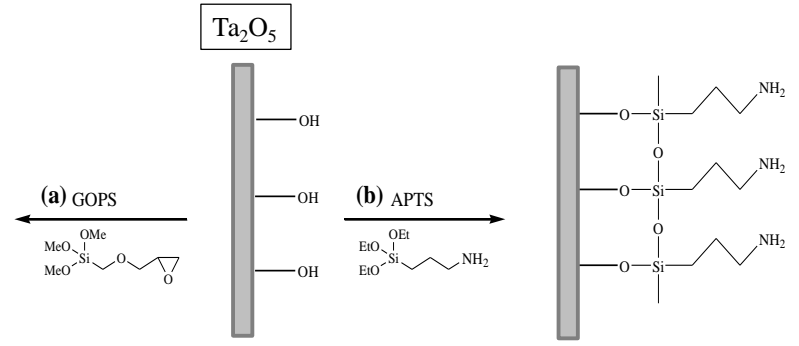

A.2

A.1

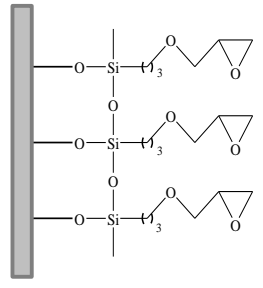

$\mathrm{Ta}_{2} \mathrm{O}_{5}$

A.1.1
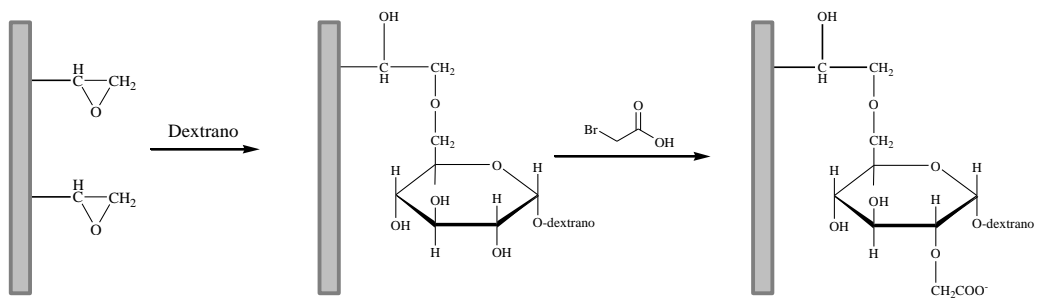

A.1.2

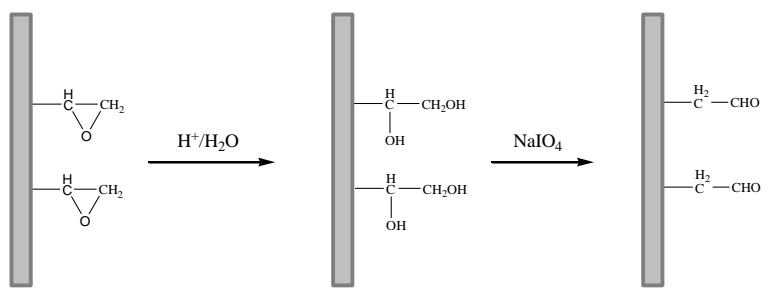

A.2.1

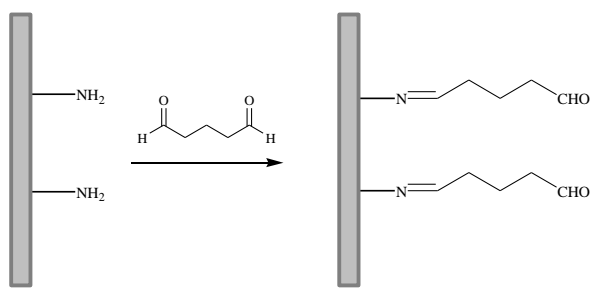

A.2.2
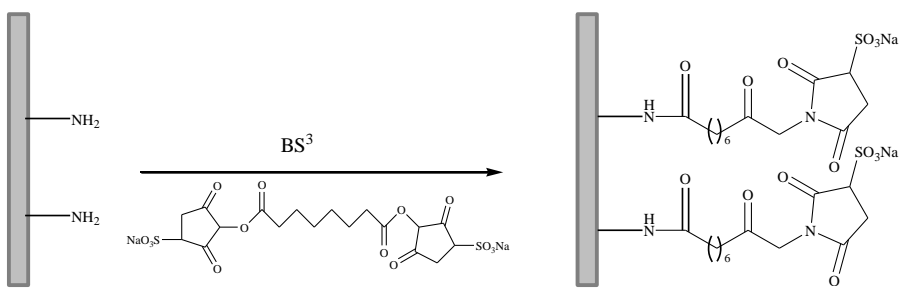

Esquema 6. Estrategias de modificación química de superficies de $\mathrm{Ta}_{2} \mathrm{O}_{5}$. 
(B)

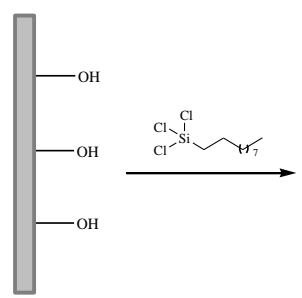

(C)

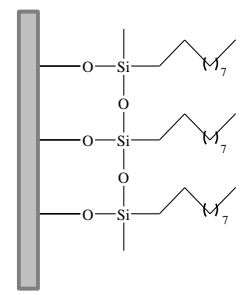

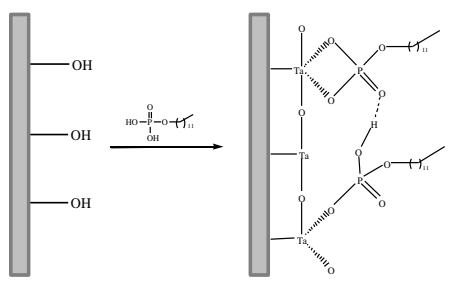

Esquema 6 (cont.). Estrategias de modificación química de superficies de $\mathrm{Ta}_{2} \mathrm{O}_{5}$.

Finalmente, Textor et al. y Brovelli et al. ${ }^{229,230}$ han demostrado la formación de monocapas orientadas sobre superficies de $\mathrm{Ta}_{2} \mathrm{O}_{5}$ por tratamiento químico con diferentes ésteres de alquilfosfonatos (Esquema 6C). Estas superficies altamente hidrofóbicas, han sido empleadas por Pawlak et al. ${ }^{231,232}$ para la inmovilización por adsorción de anticuerpos y el desarrollo de inmunoensayos de detección de interleukinas.

\section{Recapitulación}

A modo de resumen, en la presente tesis se aborda la modificación química de superficies de distintos materiales (polímeros, compuestos silíceos y óxido de tántalo) para el anclaje covalente de biomoléculas en condiciones simples y su empleo en el desarrollo de biosensores ópticos.

Desde el punto de vista de esta investigación, un punto clave para el desarrollo de biosensores es el estudio del material base de los dispositivos ópticos, ya que serán el soporte de los biorreceptores, condicionando la etapa de inmovilización, el formato de ensayo y las propiedades del sistema de detección, lo que determinará las prestaciones de los biosensores desarrollados. 
Estudios previos realizados en nuestro grupo de investigación han demostrado la aplicación de la tecnología de CDs para la generación de una señal inmunoquímica in situ sin interrumpir la lectura normal del disco. La inmovilización covalente de biorrecepetores en $\mathrm{CD}$ requiere la activación previa de la superficie del disco, constituido principalmente por PC y PMMA, bien por tratamiento químico directo del mismo, o mediante la deposición de una película de polímero en la superficie del disco compacto y posterior tratamiento de la misma.

Existen muchos trabajos sobre biosensores que utilizan materiales poliméricos, en su mayoría basados en la inmovilización de sondas por adsorción y, más recientemente, por unión covalente sobre superficies activadas. Muchas de las estrategias de activación descritas modifican las propiedades ópticas o mecánicas del material, no siendo adecuadas para su aplicación a discos compactos, chips, etc., lo que plantea la necesidad de estudiar métodos alternativos.

En segundo lugar, para la puesta a punto de un sistema nanobiosensor basado en una estructura fotónica de microanillos resonadores de guías de onda slot de $\mathrm{Si}_{3} \mathrm{~N}_{4}$, sobre un sustrato de $\mathrm{SiO}_{2}$ y detección sin marcaje, es necesaria la modificación química selectiva de las guías de onda de nitruro de silicio.

Las aportaciones en el campo de materiales nanoestructurados para compuestos silíceos $\left(\mathrm{Si}, \mathrm{SiO}_{2}, \mathrm{Si}_{3} \mathrm{~N}_{4}\right)$ son escasas; además, en el caso del nitruro de silicio su química esta algo menos explotada. La mayoría de las estrategias descritas utilizan la química de los enlaces $\mathrm{Si}-\mathrm{H}$ y del óxido de silicio presente en el silicio y en el nitruro de silicio. Todo ello evidencia que la activación química selectiva de nitruro de silicio esta muy poco estudiada.

Finalmente, uno de los retos más importantes es demostrar la utilidad de la propuesta en su aplicación a casos reales. Los resultados de las investigaciones pueden permitir la puesta a punto de sistemas multiparamétricos basados, por ejemplo, en la utilización de anticuerpos y fragmentos de ácidos nucleicos como 
biorreceptores. En general, el número de aplicaciones y problemas a resolver es muy elevado, tanto en sanidad -detección de infecciones o tumores-, como en seguridad alimentaria o microbiología -diferenciación de tipos de carnes, micotoxinas, alérgenos, etc.-, y sistemas de uso personal (point of care).

En resumen, en la presente tesis se persigue el desarrollo de estrategias para el tratamiento de distintos materiales (PC, PMMA, $\mathrm{Si}, \mathrm{Si}_{3} \mathrm{~N}_{4}, \mathrm{SiO}_{2}, \mathrm{Ta}_{2} \mathrm{O}_{5}$ ) que empleen una química simple y reproducible, y que permitan el anclaje selectivo de biorreceptores para el desarrollo de biosensores ópticos portables y económicamente competitivos. 

2. OBJETIVOS 

El presente trabajo se enmarca dentro de la línea de investigación que el grupo Señal y Medida (SYM), del Centro de Reconocimiento Molecular y Desarrollo Tecnológico de la Universidad Politécnica de Valencia, viene desarrollando sobre la modificación química de materiales.

El objetivo general es el estudio de estrategias de funcionalización de soportes rígidos (polímeros orgánicos, derivados del silicio y pentóxido de tántalo) para el anclaje covalente de receptores moleculares específicos, útiles en el desarrollo de micro y nanobiosensores aplicables en diferentes sectores: clínico, veterinario, genómico, proteómico, alimentario y medio ambiental.

Con esta finalidad se plantearon los siguientes objetivos concretos:

1. Estudio de la modificación química de superficies de polímeros sintéticos (PMMA y PC) para anclaje covalente de biomoléculas, empleando metodologías simples y reproducibles que no alteren las propiedades ópticas y mecánicas de los sustratos, permitiendo su empleo en sensores ópticos.

2. Funcionalización selectiva de nitruro frente a óxido de silicio, con grupos terminales capaces de fijar proteínas y ácidos nucleicos de modo orientado manteniendo su actividad.

3. Estudio de estrategias de modificación de pentóxido de tántalo empleando alcóxidos para el anclaje covalente de biorreceptores.

4. Optimización de ensayos de hibridación en soportes de PC y PMMA empleando marcadores fluorescentes.

5. Desarrollo de ensayos de demostración sobre disco compacto: discriminación de polimorfismos de una sola base (SNPs) y detección de gripe aviaria.

6. Desarrollo de ensayos sin marcaje empleando microanillos resonadores de guía de $\mathrm{Si}_{3} \mathrm{~N}_{4}$ sobre un sustrato de $\mathrm{SiO}_{2}$.

7. Estudio de las características de un biosensor de guía de ondas plana de pentóxido de tántalo activado con grupos aldehído. 




\subsection{Productos}

\subsubsection{Reactivos y tampones}

Reactivos: Etanolamina, (3-isocianatopropil)trietoxisilano (3-ICPTS), hidruro de litio y aluminio $\left(\mathrm{LiAlH}_{4}\right)$, borohidruro de sodio $\left(\mathrm{NaBH}_{4}\right)$, glutaraldehido, ácido 10undecanoico, ácido 11-bromoundecanoico, tert-butóxido sódico, N-etil-N'-[3(dimetilamino)propil]carbodiimida (EDC), N-hidroxisuccinimida (NHS), estreptavidina marcada con oro (estreptavidina-Au) con tamaño de partícula de 5-12 $\mathrm{nm}$, estreptavidina marcada con peroxidada de rábano picante (estrepavidina-HRP), tetrametilbencidina (TMB), kit de revelado de plata (Disolución A y B), albúmina de suero bovino (BSA), anticuerpo antialbúmina de suero bovino (anti-BSA) y ovoalbúmina (OVA), fueron adquiridos a Sigma-Aldrich (Madrid, España). N-[3(trimetoxisilil)propil]etilendiamina

(3-TMSPED), (3-mercaptopropil) trimetoxisilano y 2,2,2 trifluoroetanol fueron suministrados por Acros (Barcelona, España). El alcoxisilano 2-[metoxi(polietilenoxi)propil]trimetoxisilano (PEGorganosilano) fue adquirido a Gelest (Avilés, España).

Los oligonucleótidos denominados SYM8, SYM22, SYM23, SYM25 y SYM26 (Tabla 8), fueron suministrados por Sigma-Genosis (Suffolk, Reino Unido). SYM8 y SYM23 fueron empleados para los ensayos de inmovilización; SYM8, SYM22, SYM25 y SYM26 se utilizaron para los ensayos de hibridación. Los anticuerpos monoclonales de ratón del virus de la gripe aviaria $\left(\mathrm{mAb}\left(\mathrm{H}_{1} \mathrm{~N}_{1}\right)\right)$, así como los virus inactivos de gripe aviaria, fueron cedidos por Certest Biotec (Zaragoza, España). 
Tabla 8. Secuencias de los oligonucleótidos empleados en los ensayos de inmovilización e hibridación.

\begin{tabular}{l|ccc}
\hline Nombre & Secuencia (5'to 3') & Extremo 5, & Extremo 3' \\
\hline \hline SYM8 & AATGCTAGCTAATCAATCGGG & Cy5 & -- \\
SYM22 & $\left(\right.$ T ${ }_{15}$ CCCGATTGATTAGCTAGCATT & $-\mathrm{NH}_{2}$ & -- \\
SYM23 & TTACGATCGATTAGTTAGCCC(T) $)_{15}$ & Cy5 & $-\mathrm{NH}_{2}$ \\
$\boldsymbol{S Y M 2 5}$ & AATGCTAGCTAATCAATCGGG & Biotina & -- \\
$\boldsymbol{S Y M 2 6}$ & AATGCTAGATAATCAATCGGG & Biotina & -- \\
\hline
\end{tabular}

El reactivo de marcaje fluorescente Cy5 y el anticuerpo de cabra anticonejo marcado con Cy5 (GAR-Cy5), fueron adquiridos a Amersham (Madrid, España).

Todos los disolventes orgánicos, ácidos y sales utilizadas para la preparación de tampones fueron suministrados por Scharlau (Barcelona, España).

Tampones: Tampón citrato sódico salino, $\operatorname{SSC10\times (0,9~M~cloruro~de~sodio;~0,09~}$ M citrato sódico, pH 7); Tampón carbonato, TC10× (15 mM carbonato sódico, 35 mM hidrógenocarbonato sódico, pH 9,6); Tampón fosfato, PBS10× (8 mM hidrógenofosfato sódico, $2 \mathrm{mM}$ dihidrógeno fosfato sódico, $137 \mathrm{mM}$ cloruro sódico, 2,7 mM de cloruro potásico, $\mathrm{pH}$ 11); Tampón MES (0,1 M 2-(Nmorfolino)etanosulfonato, $\mathrm{pH} 3,5)$.

\subsubsection{Plataformas de ensayo}

Los discos compactos regrabables con capa de oro (reflectividad del 30\%), así como discos de PC transparentes $(0,6 \mathrm{~mm}$ de espesor) fueron adquiridos a Media Corp. (Tau-Yuan Shien, China) y cortados, cuando fue necesario, en chips de $55 \times 25$ 
mm. El PMMA (Ref. 99530, $1 \mathrm{~mm}$ de espesor) fue proporcionado por Röhm (Darmstad, Alemania), y cortado para los ensayos en chips de $55 \times 25 \mathrm{~mm}$.

Las superficies planas de $\mathrm{Si}_{3} \mathrm{~N}_{4}$ y de $\mathrm{SiO}_{2}$ fueron proporcionadas por el Centro de Tecnología Nanofotónica (NTC) de la Universidad Politécnica de Valencia. Las estructuras fotónicas basadas en guía de ondas de $\mathrm{Si}_{3} \mathrm{~N}_{4}$ sobre un sustrato de $\mathrm{SiO}_{2}$ (chips patrón, Figura 14a, y microanillos sensores, Figura 14b), fueron fabricados por el NTC y el Royal Institute of Technology (KTH, Estocolmo, Suecia).

Los chips de vidrio recubiertos con una película de $\mathrm{Ta}_{2} \mathrm{O}_{5}$ de 57x 14 mm (Figura 14c) fueron cedidos por Zeptosens, A.G. ( A Division of Bayer, Witterswil, Suiza).

\subsection{Instrumentación}

Para la impresión de las sondas de proteínas y ácidos nucleicos inicialmente se empleó un sistema manual de contacto (6x4 pins) adquirido a V\&P Scientific, Inc. (San Diego, CA, EE.UU) y, posteriormente, el robot AD1500 de Biodot. Inc. (Irvine, CA), con sistema de impresión sin contacto y aguja de material cerámico.

La señal de fluorescencia fue registrada usando un escáner de fluorescencia (EF) Genepix 4000B (Axon Instruments; Union City, CA, EE.UU.) a una longitud de onda de excitación de $635 \mathrm{~nm}$, o con un lector de fluorescencia de superficie (LFS) desarrollado por el grupo de investigación, basado en la excitación de sondas fluorescentes con LEDs monocromátricos $\left(\lambda_{\text {exc }}=633 \mathrm{~nm}\right)$ y lectura de la fluorescencia con una cámara CCD situada ortogonalmente. ${ }^{233}$

Las medidas de fluorescencia mediante tecnología de guía de ondas plana se efectuaron con un equipo Zeptoreader (Zeptosens, Witerswill, Schitzerland), compuesto de un láser y una cámara $\mathrm{CCD}$ que registra la fluorescencia de las sondas inmovilizadas $\left(\lambda_{\text {exc }}=532, \lambda_{\text {emisión }}=635 \mathrm{~nm}\right)$. 
(a)

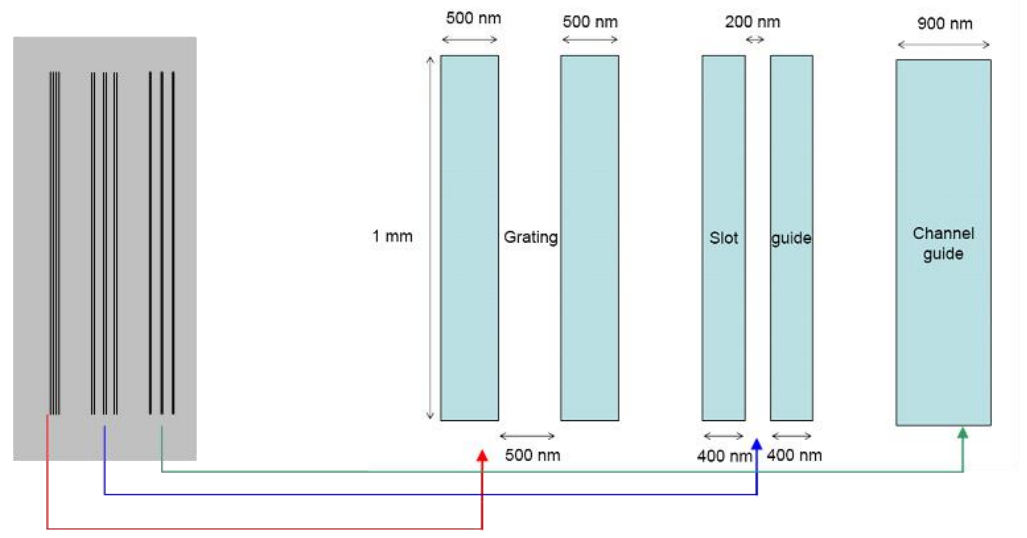

(b)
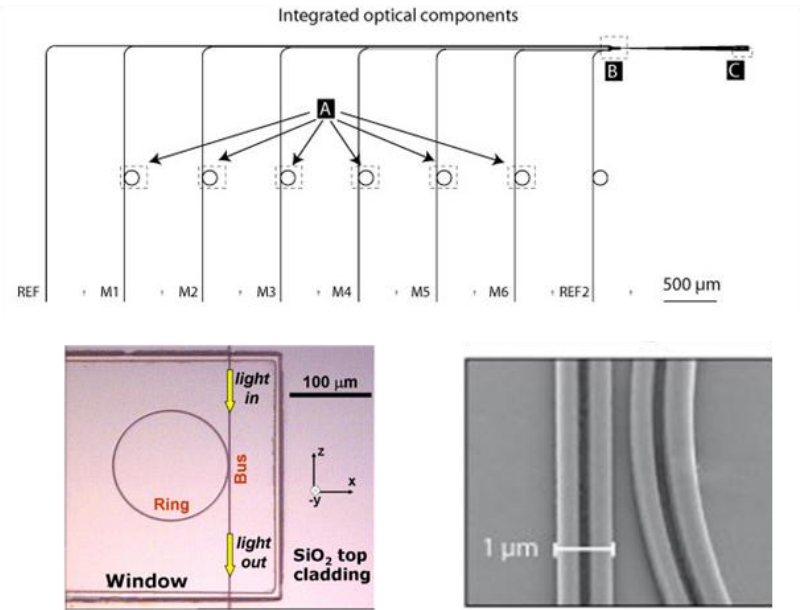

(c)

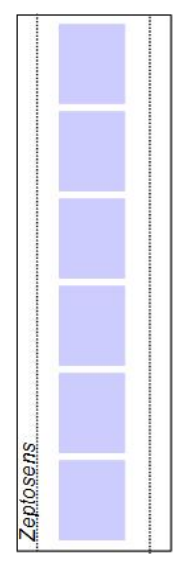

Figura 14. (a) Estructuras patrón constituidas por diferentes tipos de guías de $\mathrm{Si}_{3} \mathrm{~N}_{4}$ con distintas morfologías, (b) Estructura de un anillo sensor de guías slot acoplado a una guía de ondas lineal e integrado en una muestra que contiene varios anillos sensores, (c) Chip de vidrio recubierto por una película de $\mathrm{Ta}_{2} \mathrm{O}_{5}$ (57x14 mm). 
Las medidas de ángulo de contacto se llevaron a cabo con un sistema OCA20 equipado con el programa informático SCA2O (Dataphysics Instruments $\mathrm{GmbH}$, Raiffeisenstraße, Alemania).

Los espectros de infrarrojo de reflectancia total atenuada con transformada de Fourier (ATR-FTIR) se obtuvieron utilizando un equipo de infrarrojo con celda dotada de ventana de ZnSe, Nicolet Nexus de Thermo Electro Corporation (Waltham, Massachussets, EE.UU.).

Para la lectura de los discos se utilizó un lector/grabador de CDs comercial (Premium, Plextor America, Fremont, CA, EE.UU.), que emplea como fuente la luz emitida por un diodo láser $\left(\lambda_{\text {emisión }}=780 \mathrm{~nm}\right)$ enfocado a la cara de policarbonato del CD. El sistema de lectura incorpora también un fotodiodo plano (SLSD-71N6, Silanex, Montreal, Canadá) situado en el interior del dispositivo a lo largo de la línea que barre el haz láser durante el proceso de lectura/grabación. El intervalo espectral del fotodiodo se encuentra entre 400 y $1100 \mathrm{~nm}$, tiene una longitud de $25,4 \mathrm{~mm}$ y cubre un área de $55 \mathrm{~cm}^{2}$ de los $90 \mathrm{~cm}^{2}$ totales del disco.

Una vez desarrollados los ensayos, y a medida que el láser barre la superficie del disco durante el proceso de lectura/grabación, los spots (de la micromatriz) absorben la luz que, de otra manera, se hubiera transmitido y hubiera sido detectada por el fotodiodo. Así, se genera una señal electrónica distintiva del ruido de fondo, que será más o menos intensa en función de la extensión de la reacción de amplificación producida en cada punto de la superficie. La luz absorbida se transforma en una señal eléctrica que se digitaliza mediante la tarjeta de adquisición de datos de 12 bits integrada en el ordenador personal. Las áreas de ensayo se seleccionan mediante marcas "de disparo" situadas sobre el borde exterior del disco, de modo que en cada proceso de lectura/grabación el ordenador solo recoge la información existente en dicha área. El tamaño de cada área es aproximadamente de $5 \mathrm{~cm}^{2}$, produciendo una información bruta de $120 \mathrm{MB}$. Con los discos empleados 
en los ensayos, la máxima velocidad lineal de lectura es de $13 \mathrm{~m} / \mathrm{s}$ (10x), por lo que la lectura de un disco se realiza en 6 ó $7 \mathrm{~min}$. El sistema proporciona una señal de radiofrecuencia $(\mathrm{RF})$ con un ancho de banda de $150 \mathrm{kHz}$. En este trabajo se utiliza una velocidad de muestreo de $10^{6}$ bits por segundo, lo que permite una identificación mejor de la señal RF; dado el tamaño de los spots (diámetro de 450 $\mu \mathrm{m})$, la velocidad de muestreo es apropiada para la detección de los mismos con una resolución adecuada.

La lectura de los ensayos en disco compacto se realizó con el software de grabación de discos compactos Easy CD Creator (Roxio Inc., Santa Clara, CA, EE.UU.), mediante simulación de la escritura de un archivo de 70 MB. Un programa de adquisición de datos de Ultraview Corporation (Orinda, CA, EE.UU.) configura la tarjeta capturadora de datos integrada en un ordenador personal. Esta aplicación selecciona el canal analógico de entrada, la velocidad de muestreo y el tamaño del archivo, además de recoger los datos resultantes en el disco duro del ordenador en formato binario descomprimido, produciendo una imagen del sector medido.

Para el tratamiento de imagen se empleó el software gráfico DiscImage, programado con Visual $\mathrm{C}++$, que representa los datos digitales como imagen en escala de grises. Este programa permite, además, exportar la imagen en formato tif o como mapa de bits. Debido a la diferencia espacial entre los datos tomados horizontalmente (cada $13 \mu \mathrm{m}$ ) y verticalmente (cada 1,6 $\mu \mathrm{m}$ ), debe llevarse a cabo un ajuste gráfico que origine una imagen proporcional en dos dimensiones, por lo que las imágenes se procesan con el programa Photoshop 7.0 de Adobe Sytems Inc. (San José, CA, EE.UU.). Finalmente, se realiza un análisis cuantitativo de la imagen mediante el programa Genepix 6.0 (Axon Inst., Union City, CA, EE.UU.). Todo el software empleado trabaja en un ordenador personal con entorno Windows. 
La caracterización de superficies mediante espectroscopía fotoelectrónica de rayos X (XPS) se llevó a cabo con un equipo SAGE 150 (SPECS GmbH-Surface Analysis; Berlín, Alemania) en el Instituto de Tecnología Cerámica (ITC, Castellón, España). Las medidas de elipsometría se realizaron utilizando un equipo Thermawave Optiprobe 5200 (QT Solutech GmbH, Munich, Alemania).

Las imágenes de microscopía electrónica de barrido se obtuvieron con un equipo S-4500 de Hitachi High-Technologies (Krefeld, Alemania). Y las medidas de microscopía confocal de fluorescencia (MCF) se efectuaron en el Centro de Investigación Príncipe Felipe (CIPF, Valencia, España) utilizando un microscopio LEICA AOBS-TCS-SP2 (Barcelona, España), dotado de ocho líneas de láser (458, 476, 488, 496, 514, 543, 594, $633 \mathrm{~nm}$ ), diodo (405 nm), detector para Contraste Interferencial (DIC), platina motorizada, y cámara de incubación regulada para temperatura y $\mathrm{CO}_{2}$.

Los ensayos de detección sin marcaje se llevaron a cabo en el Instituto de Sistemas Optoelectrónicos y Microtecnología (ISOM) de la Universidad Politécnica de Madrid, mediante el uso de un lector óptico (SO) de fabricación propia. ${ }^{187}$

\subsection{Estrategias de modificación química de las superficies de trabajo}

\subsubsection{Modificación química de PMMA}

\subsubsection{Estudios en chip}

\section{$\underline{\text { Reducción de PMMA (PMMA1) }}$}

Los chips de PMMA $(55 \times 25 \mathrm{~mm})$ fueron previamente lavados con etanol y secados. Tras introducirlos en una mezcla de $\mathrm{LiAlH}_{4}(1,5 \mathrm{~g}, 40 \mathrm{mmol})$ disuelto en 
ciclohexano anhidro $(30 \mathrm{~mL})$, se agitaron a temperatura ambiente y en condiciones anhidras durante 30 minutos. El exceso de hidruro fue cuidadosamente hidrolizado con metanol y las superficies se lavaron con $\mathrm{HCl}$ acuoso al 10\%, agua y etanol, y se secaron con aire a presión (PMMA1).

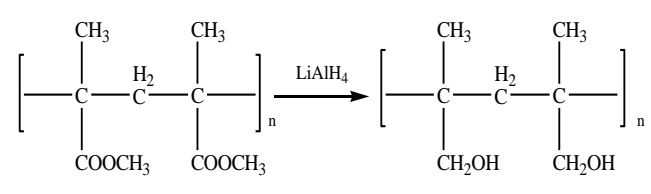

PMMA

PMMA 1

Introducción de grupos isocianato (PMMA2)

Para la incorporación del organosilano, las superficies de PMMA1 se introdujeron en una disolución de ICPTS $(0,2 \mathrm{~mL} ; 0,8 \mathrm{mmol})$ en 2-propanol (20 $\mathrm{mL}$ ) durante 10 minutos. Posteriormente, se incubaron en estufa a $62{ }^{\circ} \mathrm{C}$ durante 20 minutos, se lavaron con 2-propanol y se secaron con aire a presión (PMMA2).

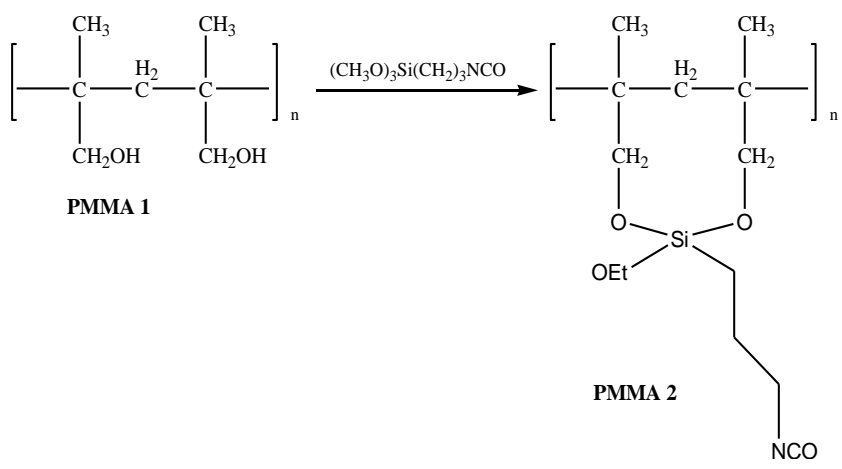

Introducción de grupos amino (PMMA3)

Las placas de PMMA previamente hidroxiladas (PMMA1) se introdujeron en una disolución de TMSPED (0,2 mL; 0,9 mmol) en 2-propanol (20 mL) durante 10 
minutos. A continuación, las superficies se lavaron con agua y etanol, y se secaron en estufa a $62{ }^{\circ} \mathrm{C}$ durante 20 minutos (PMMA3).

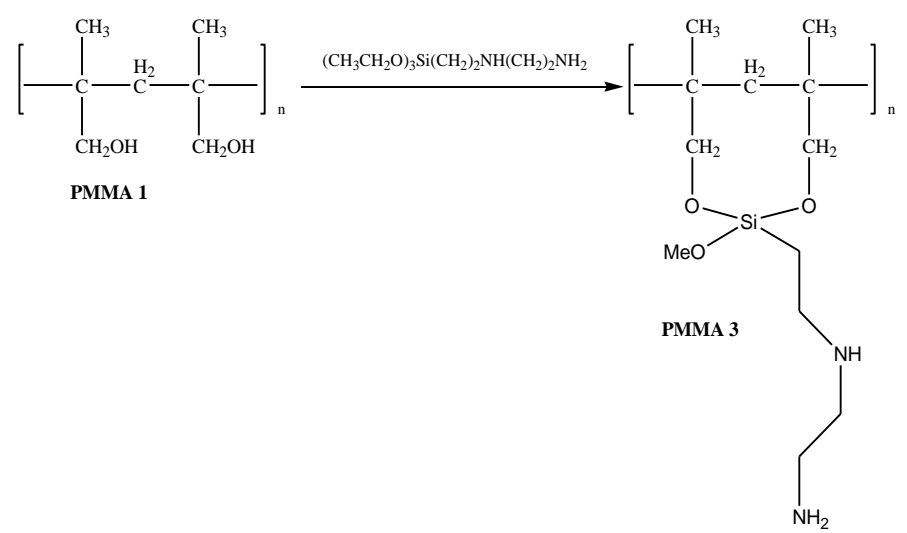

\section{$\underline{\text { Introducción de grupos aldehído (PMMA4) }}$}

Los chips de PMMA previamente aminados (PMMA3) se introdujeron en una disolución de glutaraldehído (0,75 mL, $2 \mathrm{mmol})$ en PBS1x, pH 8 (20 mL), durante 2 h. Después se lavaron con agua, etanol y se secaron con aire a presión (PMMA4).
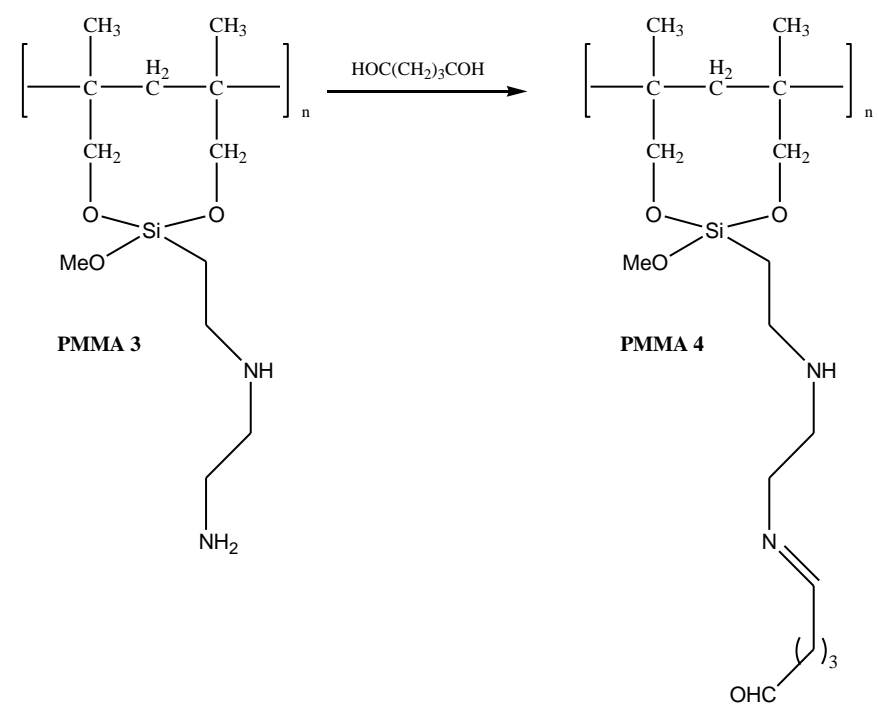


\subsubsection{Estudios en disco compacto (CD)}

\section{$\underline{\text { Reacción de transaminación del PMMA (PMMA5) }}$}

A una disolución de PMMA (310 mg) en THF (3 mL) se adicionó etanolamina ( $0,1 \mathrm{~g}, 1,6 \mathrm{mmol})$ y se llevó a reflujo durante $2 \mathrm{~h}$. Tras eliminar el THF a vacío, el residuo fue redisuelto en diclorometano. La fase orgánica se lavó varias veces con $\mathrm{HCl}$ (1 M) hasta la eliminación total de la etanolamina. Posteriormente, se secó con $\mathrm{MgSO}_{4}$, se filtró, y tras la evaporación del disolvente en rotavapor, se obtuvo el polímero transaminado como un sólido incoloro, con un rendimiento del $70 \%$ (PMMA5).

RMN- ${ }^{1} \mathrm{H}\left(\mathrm{CDCl}_{3}\right): \delta(\mathrm{ppm}) 3,79\left(\mathrm{t}, \mathrm{CH}_{2}-\mathrm{OH}\right), 3,57\left(\mathrm{~s}+\mathrm{m}, \mathrm{CH}_{3}-\mathrm{O}\right.$ and $\mathrm{CH}_{2^{-}}$ NHCO), 1,87-1,78 (m, $\left.\mathrm{CH}_{2}\right), 0,091$ (s, $\left.\mathrm{CH}_{3}\right), 0,806\left(\mathrm{~s}, \mathrm{CH}_{3}\right)$.

El recubrimiento polimérico de los CDs se efectuó utilizando una centrífuga marca Selecta (Barcelona, España). Para ello, los discos se centrifugaron a 840 rpm durante 1 minuto y, mediante una pipeta automática, se aplicó $1 \mathrm{~mL}$ de PMMA5 ( $1 \%$ en Dowanol) en la zona central del disco. Durante el giro, la disolución de polímero se distribuye uniformemente a lo largo de toda la superficie por efecto de la fuerza centrífuga. Finalmente, el CD se mantuvo en estufa a $60{ }^{\circ} \mathrm{C}$ durante 30 minutos para eliminar el disolvente.

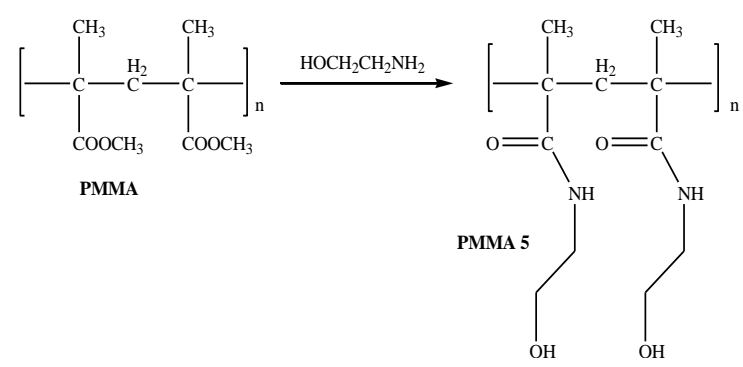




\section{$\underline{\text { Introducción de grupos isocianato (PMMA6) }}$}

Los CDs recubiertos con una película de polímero se introdujeron en una disolución de ICPTS $(0.2 \mathrm{~mL}, 0,8 \mathrm{mmol})$ en 2-propanol $(20 \mathrm{~mL})$ durante 10 minutos y se incubaron en estufa a $62{ }^{\circ} \mathrm{C}$, durante 5 minutos. Finalmente se lavaron con 2- propanol y se secaron con aire a presión (PMMA6).
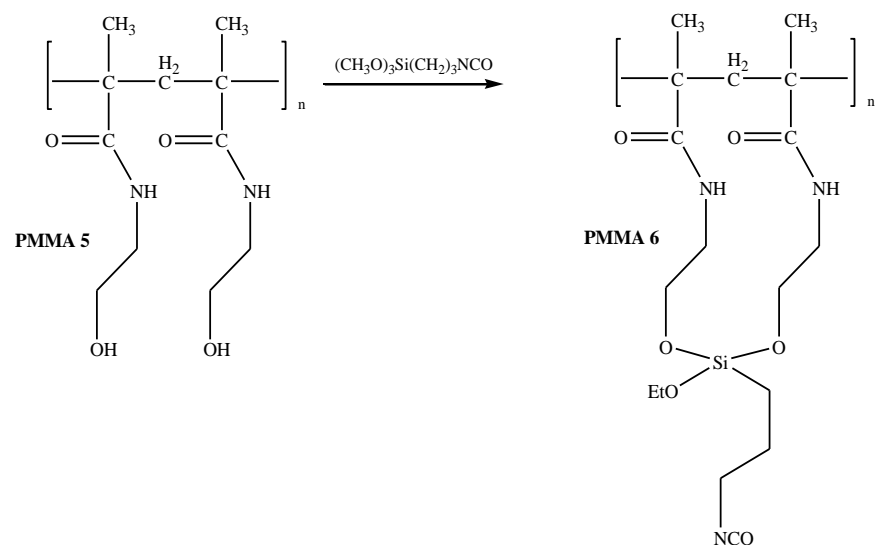

\subsubsection{Modificación química de PC}

\section{Introducción de grupos amino en PC (PC2)}

Los discos transparentes de PC de 0,6 mm de espesor se trataron con una mezcla de $\mathrm{HNO}_{3}$ acuoso al $30 \%(90 \mathrm{~mL})$ y $\mathrm{H}_{2} \mathrm{SO}_{4}$ concentrado $(5 \mathrm{~mL})$. Tras calentar durante 10 minutos a $65^{\circ} \mathrm{C}$, estos se lavaron con agua destilada (PC1). Para la reducción de los grupos nitro introducidos, los discos se trataron con una disolución de $\mathrm{NaBH}_{4}(10 \mathrm{~g}, 0,26 \mathrm{mmol})$ en $100 \mathrm{~mL}$ de PBS1x a temperatura ambiente durante 4 horas. Finalmente se lavaron con PBS1x y después con agua destilada (PC2). 


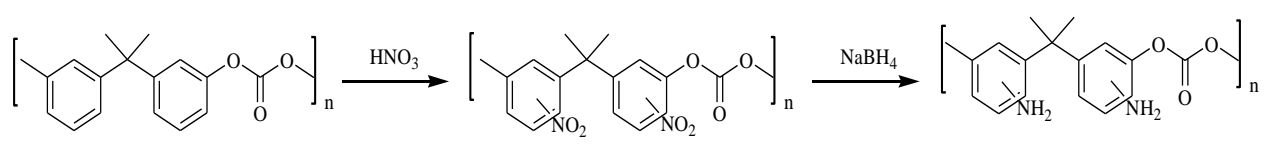

PC

PC 1

PC 2

Introducción del crosslinker glutaraldehido en PC2 (PC3)

Los discos de PC2 se sumergieron en una disolución acuosa de glutaraldehído (20 mL, $53 \mathrm{mmol}$ ) en $100 \mathrm{~mL}$ PBS1x, pH 8, durante 2 horas a temperatura ambiente. Posteriormente se lavaron con PBS1x, agua, y se secaron con aire a presión (PC3).

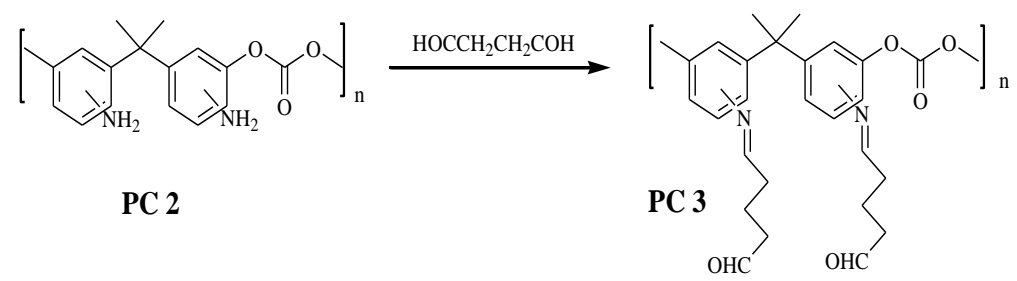

\subsubsection{Modificación química de $\mathrm{Si}_{3} \mathrm{~N}_{4}$}

\subsubsection{Reactividad a través de los enlaces $\mathrm{Si}-\mathrm{H}$}

$\underline{\text { Síntesis del 10-undecenoato de 2,2,2, trifluoroetilo }}$

A una disolución de 2,2,2-trifluoroetanol (5M en $40 \mathrm{~mL}$ de tolueno) se adicionaron $30 \mathrm{~mL}$ de ácido 10-undecilénico y $1 \mathrm{~mL}$ de $\mathrm{H}_{2} \mathrm{SO}_{4}$ concentrado, calentando a $140{ }^{\circ} \mathrm{C}$ durante $5 \mathrm{~h}$. El crudo de reacción se lavó con una disolución saturada de carbonato sódico, agua y salmuera. Posteriormente, se secó con $\mathrm{MgSO}_{4}$, se evaporó el disolvente en rotavapor y, tras purificación mediante columna 
cromatográfica (hexano/acetato de etilo, 99:1), se obtuvo el producto deseado en forma de aceite incoloro, con un rendimiento del $68 \%$.

$\mathrm{RMN}^{1}{ }^{1} \mathrm{H}\left(\mathrm{CDCl}_{3}\right): \delta(\mathrm{ppm})$ 5,70-5,90 (m, 1H), 4,86-5,06 (m, 2H), 4,38-4,51 (q, $2 \mathrm{H}), 2,35-2,45(\mathrm{t}, 2 \mathrm{H}), 1,98-2,1(\mathrm{~m}, 2 \mathrm{H}), 1,55-1,75(\mathrm{~m}, 2 \mathrm{H}), 1,20-1,50(\mathrm{~m}, 10 \mathrm{H})$.

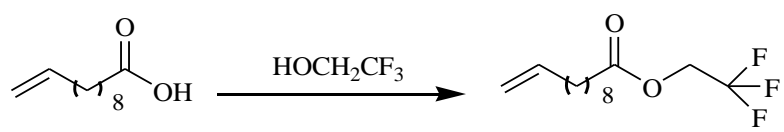

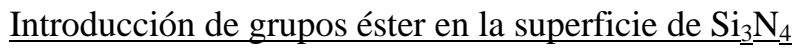

Los chips de $\mathrm{Si}_{3} \mathrm{~N}_{4}(55 \times 25 \mathrm{~mm})$, previamente lavados con diclorometano y etanol, se trataron con $\mathrm{HF}(0,08 \mathrm{~mL}$ en $2 \mathrm{~mL}$ de agua) durante 2 minutos bajo atmosfera de argón, con la finalidad de eliminar la capa de óxido nativo presente en las superficies de $\mathrm{Si}_{3} \mathrm{~N}_{4}$. Posteriormente, las superficies se lavaron con 2-propanol y se secaron bajo atmósfera de argon. Finalmente, la unión del derivado éster se realizó por vía térmica (a) y fotoquímica (b).

(a) Método térmico. Una disolución del éster del 2,2,2-trifluoroetanol (0,2 M en $10 \mathrm{~mL}$ de mesitileno), se llevó a reflujo durante 20 minutos bajo atmósfera inerte. Posteriormente, los chips -previamente tratados con HF- se adicionaron a la disolución y se mantuvieron a reflujo durante 24 h bajo atmósfera de argon.

(b) Método fotoquímico. En una cubeta de cuarzo se introdujo una disolución del éster del 2,2,2-trifluoroetanol (0,2 M en $2 \mathrm{~mL}$ de mesitileno), y se burbujeó argon durante 10 minutos. Las superficies previamente activadas se introdujeron en la disolución irradiando a $254 \mathrm{~nm}$ durante $48 \mathrm{~h}$ con una lámpara ultravioleta (Vilber Lourmat, VL-4 LC, 4 W) situada a $0,5 \mathrm{~cm}$ de la cubeta. Finalmente, los chips se lavaron con hexano, etanol y diclorometano, y se secaron bajo aire a presión. 


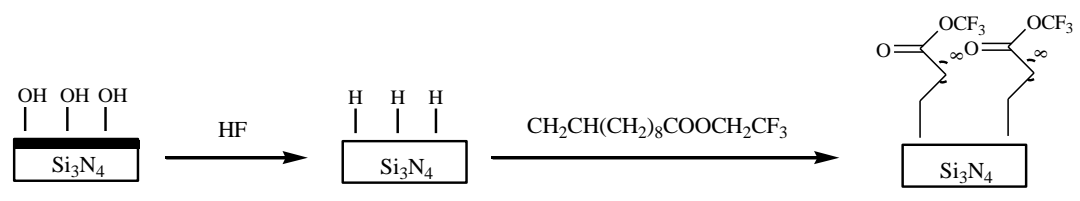

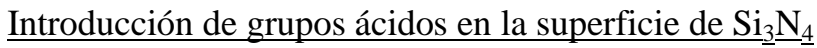

Para obtener una superficie activada con grupos ácido carboxílico, se procedió a las desprotección del éster del trifluoroetanol. Para ello, las muestras derivatizadas tal y como se ha descrito anteriormente, se introdujeron en una disolución de tertbutóxido potásico (0,15 g, 1,3 mmoles) en $5 \mathrm{~mL}$ de DMSO durante 10 minutos y, posteriormente, se trataron con $\mathrm{HCl} 0,1 \mathrm{M}$ durante 10 minutos.

La unión covalente de las grupos amino de las biomoléculas y los grupos ácido de la superficie, se llevó a cabo mediante la activación de los ácidos carboxílicos por inmersión en una disolución conteniendo EDC (2 mg, 13 nmoles) y NHS (3 mg, 26 nmoles) en $5 \mathrm{~mL}$ de PBS1x, durante $2 \mathrm{~h}$ a temperatura ambiente.

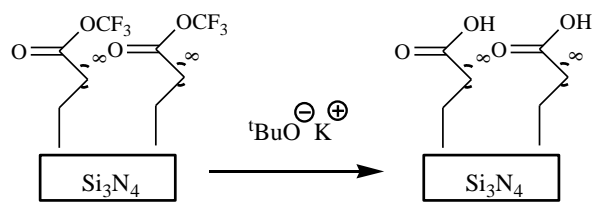




\subsubsection{Reactividad a través de los enlaces Si-N}

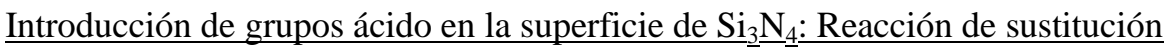
nucleofílica con un bromoácido

Las placas de $\mathrm{Si}_{3} \mathrm{~N}_{4}$ tratadas con $\mathrm{HF}$, tal y como es descrito en el apartado anterior, se introdujeron en un matraz conteniendo una disolución de ácido 11bromoundecanoico $(0,21 \mathrm{~g}, 0,8$ mmoles $)$ en $5 \mathrm{~mL}$ de tolueno, y se llevo a reflujo bajo atmósfera de argon durante $5 \mathrm{~h}$. Transcurrido el tiempo de reacción, los chips se lavaron con diclorometano y etanol, y se secaron bajo aire a presión.

Finalmente, los grupos ácido de la superficie fueron activados para la conjugación con biorreceptores a través de los grupos amino de las mismos, por inmersión en una disolución conteniendo EDC (2 mg, 13 nmoles) y NHS (3 mg, 26 nmoles) en $5 \mathrm{~mL}$ de PBS1x, durante $2 \mathrm{~h}$ a temperatura ambiente.

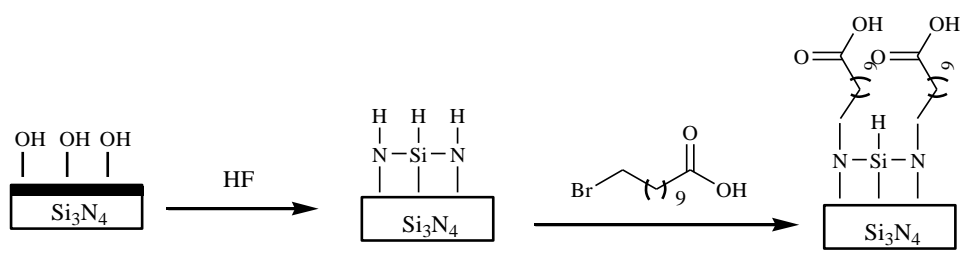

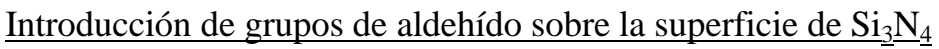

Los chips, tratados con HF (apartado 3.3.3.1), se introdujeron en una disolución previamente desoxigenada de glutaraldehído ( $2 \mathrm{~mL}, 5,3$ mmoles) disuelto en $10 \mathrm{~mL}$ de PBS1x, durante $2 \mathrm{~h}$ a temperatura ambiente y bajo atmósfera de argon. Posteriormente, se lavaron con PBS-T y agua, y se secaron bajo aire a presión. 


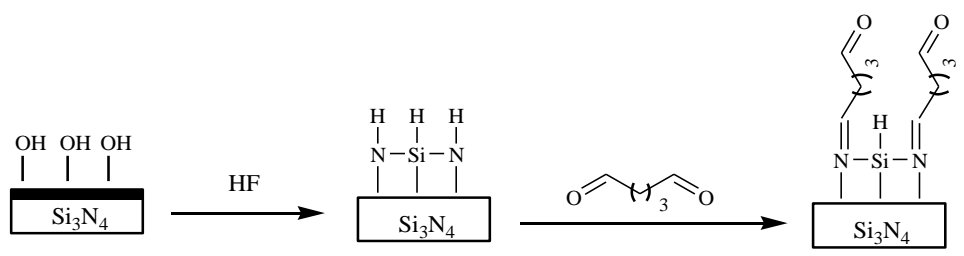

\subsubsection{Modificación química de $\mathrm{SiO}_{2}$}

\section{$\underline{\text { Bloqueo de } \mathrm{SiO}_{2}}$}

Las superficies de $\mathrm{SiO}_{2}$ fueron lavadas previamente con diclorometano y etanol, y posteriormente tratadas con un organosilano derivado del polietilenglicol (PEGorganosilano, 0,2 mL, 0,66 mmoles) en $10 \mathrm{~mL}$ de metanol (0,15 M AcOH), durante 30 minutos. Finalmente, se lavaron con metanol y se secaron bajo aire a presión.

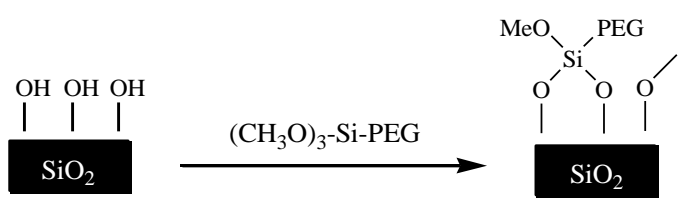

$\underline{\text { Activación de la superficie de } \mathrm{SiO}_{2}}$

Los materiales se sumergieron en una mezcla de ICPTS $(0,2 \mathrm{~mL}, 0,8$ mmoles $)$ disuelta en $10 \mathrm{~mL}$ de disolución metanólica de $\mathrm{AcOH} 0,15 \mathrm{M}$, durante 30 minutos y bajo atmósfera de argon. Transcurrido este tiempo, las superficies se lavaron con metanol y se secaron en corriente de aire. 


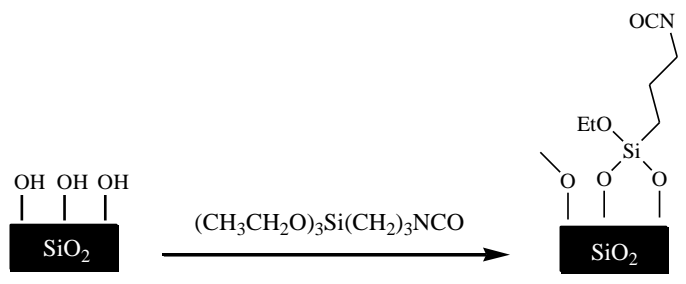

\subsubsection{Modificación química de $\mathrm{Ta}_{2} \mathrm{O}_{5}$}

\section{Activación con grupos aldehído (-CHO)}

Los chips de $\mathrm{Ta}_{2} \mathrm{O}_{5}$ previamente lavados con metanol, se sumergieron en una mezcla que contenía TMSPED $(0,46 \mathrm{~mL}, 2 \mathrm{mmol})$ y agua $(0,74 \mathrm{~mL}, 40$ mmoles $)$ en $20 \mathrm{~mL}$ de disolución metanólica de $\mathrm{AcOH} 0,15 \mathrm{M}$, durante 1,5 horas a $25{ }^{\circ} \mathrm{C}$. Posteriormente, se lavaron con metanol y se secaron bajo aire a presión. Los chips aminados, se trataron con glutaraldehído $(0,8 \mathrm{~mL}, 8,5$ mmoles $)$ disuelto en $20 \mathrm{~mL}$ de PBS 1x, durante 2 horas a $25^{\circ} \mathrm{C}$. Tras los lavados con PBS-T (10 min) y agua destilada (5 $\mathrm{min})$, se secaron con aire a presión y se almacenaron bajo atmósfera de argon.
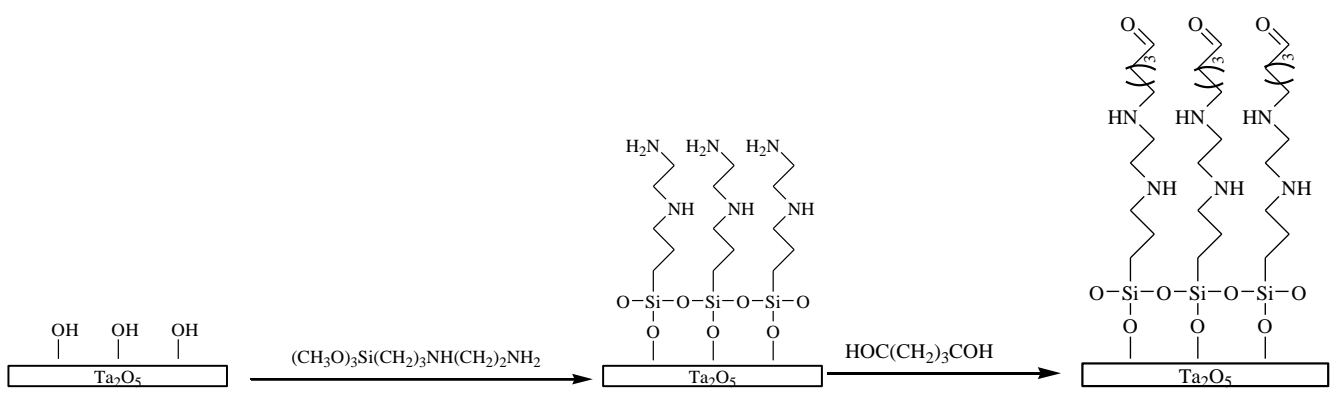


\section{Activación con grupos isocianato (-NCO)}

Las chips de $\mathrm{Ta}_{2} \mathrm{O}_{5}$ se sumergieron en una disolución de ICPTS $(0,46 \mathrm{~mL}, 1,8$ mmoles) y agua (10 $\mu \mathrm{L}, 40$ nmoles) en $20 \mathrm{~mL}$ de hexano, durante $1 \mathrm{~h}$. Después se lavaron con hexano, se secaron y almacenaron bajo atmósfera de argon.

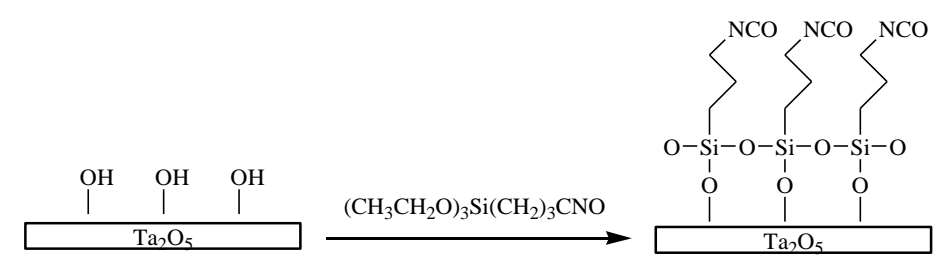

\section{$\underline{\text { Activación con grupos tiol (-SH) }}$}

Los chips de $\mathrm{Ta}_{2} \mathrm{O}_{5}$ se trataron con (3-mercaptopropil)trimetoxisilano $(0,37 \mathrm{~mL}$, 2 mmoles) y agua ( $0,74 \mathrm{~mL}, 40$ mmoles) en $20 \mathrm{~mL}$ de disolución metanólica de $\mathrm{AcOH} 0,15 \mathrm{M}$, durante 1,5 horas a $25^{\circ} \mathrm{C}$. Finalmente, se lavaron con PBS-T (10 min) y agua destilada (5 min), y se secaron con aire a presión.

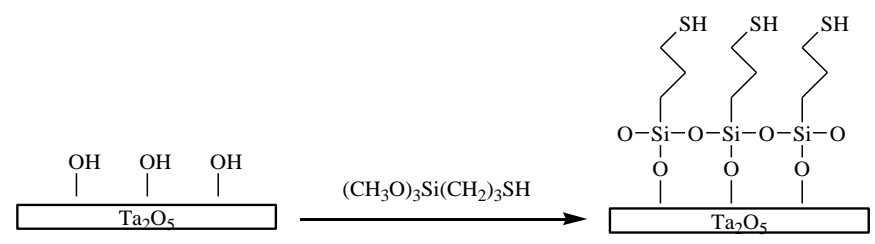




\subsection{Desarrollo de ensayos de biorreconocimiento}

\subsubsection{Ensayos de hibridación de sondas de oligonucleótidos}

Diferentes oligonucleótidos marcados con Cy5 en el extremo 5', y/o terminados en grupos amino en el extremo 3', fueron empleados para los ensayos de hibridación de hebras de ADN. El denominado SYM23 fue el empleado para la estimación del porcentaje de oligonucleótido inmovilizado, mientras que SYM8, SYM22, SYM25 y SYM26 fueron usados para los ensayos de hibridación (Tabla 8, apartados 3.1.1).

\subsubsection{Calibrado}

Para los calibrados, fueron preparadas diluciones seriadas del oligonucleótido SYM23 aminado y marcado con Cy5. Dieciocho réplicas (2 matrices de 3x3 puntos) de cada una de las disoluciones fueron impresas sobre las superficies químicamente activadas $\left(\varphi_{\text {punto }}=400 \mu \mathrm{m}, \mathrm{V}_{\text {gota }}=50 \mathrm{~nL}\right)$. La intensidad de fluorescencia de las matrices impresas fue registrada con el escáner de fluorescencia (EF) o con el lector de fluorescencia de superficie (LFS), y cuantificada con el software Genepix 6.0, para finalmente obtener una curva de calibrado.

De forma similar se procedió para obtener la curva de calibrado del oligonucleótido complementario a la sonda SYM8. De este modo, la señal de fluorescencia de los puntos fue cuantificada y la cantidad de oligonucleótido inmovilizado e hibridado se calculó por interpolación en las respectivas curvas de calibrado. 


\subsubsection{Ensayos de inmovilización}

Para el estudio de la inmovilización sobre las superficies tratadas, se prepararon seis disoluciones del oligo SYM23 a concentraciones comprendidas entre 1 y 10 $\mu \mathrm{M}$, empleando diferentes tampones: $\mathrm{SSC} 1 \times \mathrm{pH} 7, \mathrm{SSC} 10 \times \mathrm{pH} 7, \mathrm{TC} 1 \times \mathrm{pH} 9,6$, TC10× $\mathrm{pH} 9,6$, TC1 $\times \mathrm{pH} 11$ y TC10× $\mathrm{pH} 11$. Se imprimieron micromatrices de $3 \times 3$ de cada una de las disoluciones, incubando los chips en cámara oscura y húmeda durante 1 hora a $37^{\circ} \mathrm{C}$; finalmente, éstos se lavaron con PBS-T y se secaron. Los resultados fueron leídos con el escáner de fluorescencia y cuantificados con el software Genepix 6.0.

\subsubsection{Ensayos de hibridación en chip de SYM8}

Siguiendo el procedimiento descrito en el apartado 3.4.1.2 se inmovilizó covalentemente el oligonucleótido SYM22 a diferentes concentraciones $(1,5,10 \mathrm{y}$ $20 \mu \mathrm{M})$ en $\mathrm{TC} 1 \times, \mathrm{pH} 11)$ sobre las superficies previamente activadas. Para el bloqueo de los grupos activos residuales se depositaron $35 \mu \mathrm{L}$ de OVA (1\% en TC $1 \times \mathrm{pH} 9,6)$ sobre el área impresa, se extendieron con ayuda de un cubreobjetos y se dejaron incubar durante 30 minutos en cámara húmeda a temperatura ambiente. Los chips se lavaron durante 5 minutos con PBS-T, 5 minutos con agua y se secaron. Por otro lado, se prepararon varias disoluciones de oligonucleótido complementario SYM8 marcado con Cy5 (0,1-1 $\mu \mathrm{M})$, en un medio que contenía SSC6 $\times, 0,6 \%$ SDS, $0,1 \%$ ADN de esperma de salmón y $2 \%$ de BSA, depositando $100 \mu \mathrm{L}$ de cada disolución de hibridación sobre las superficies impresas. La hibridación tuvo lugar en cámara húmeda, a $37^{\circ} \mathrm{C}$ durante $1 \mathrm{~h}$. Después se realizaron varios lavados, primero con SSC 0,1×, SDS 0,5\% durante 15 minutos, y después con SSC 0,1× durante 5 minutos. Finalmente, los chips se lavaron con agua y se secaron con aire a presión. La señal de fluorescencia se registró mediante EF o LFS, calculando el porcentaje de hibridación a partir de los datos de calibrado (ver Apéndice I). 


\subsubsection{Ensayos de hibridación en CDs}

Para los ensayos de hibridación en $\mathrm{CD}$, los discos fueron divididos en ocho zonas sobre las que se inmovilizó covalentemente el oligonucleótido SYM22 (matrices $3 \times 3)$ a diferentes concentraciones $(1,5,10,20 \mu \mathrm{M})$. A continuación, se bloqueó la superficie, tal y como se describe en el apartado anterior. Posteriormente, se depositaron $35 \mu \mathrm{L}$ de distintas concentraciones de una disolución del oligonucleótido complementario biotinilado (SYM25) de 0,2 a $10^{-4}$ $\mu \mathrm{M}$-SSC6×, 0,6\% SDS, 0,1\% ADN de esperma de salmón y $2 \%$ de BSA-, extendiéndolos con ayuda de un cubreobjetos sobre las áreas impresas. La hibridación se efectuó en cámara húmeda a $37^{\circ} \mathrm{C}$ durante $1 \mathrm{~h}$. Los CDs se lavaron durante 5 min con PBS-T y 5 min con agua, y se secaron por centrifugación. Siguiendo el mismo procedimiento utilizado por Cao et al. ${ }^{234}$, en cada zona de ensayo se depositaron $35 \mu \mathrm{L}$ de estreptavidina-Au ( $10 \mu \mathrm{g} / \mathrm{mL}$ en PBS1x), dejando incubar durante 40 min en cámara húmeda a $37^{\circ} \mathrm{C}$, tras lo cual se lavaron 5 min con PBS-T, 5 min con agua y se secaron. Finalmente, se depositaron $20 \mu \mathrm{L}$ de revelador de plata sobre cada una de las zonas, observándose un precipitado oscuro en las matrices que produjeron ensayo positivo transcurridos $12 \mathrm{~min}$. Alternativamente, también se empleó estreptavidina-HRP y TMB como revelador. Se siguió el mismo procedimiento, observándose un precipitado azul oscuro a los 3 min de revelado. Tras retirar los cubreobjetos y lavar con agua, los ensayos fueron leídos empleando un lector de CDs, obteniendo una imagen en escala de grises que, tras su procesado con Photoshop 7.0, permite el análisis cuantitativo mediante el programa Genepix 6.0 .

\subsubsection{Ensayos de detección de SNPs en CDs}

Para realizar los ensayos de detección de polimorfismos de un solo nucleótido, el oligo SYM22 $(0,1 ; 0,5 ; 1$ y $5 \mu \mathrm{M})$ fue covalentemente inmovilizado sobre las 
superficies activadas de los discos, tal y como se ha descrito en el apartado 3.4.1.2. Después de bloquear con OVA, fueron depositadas $(35 \mu \mathrm{L})$ diferentes concentraciones $\left(0,05-5 \cdot 10^{-4} \mu \mathrm{M}\right)$ de SYM25 y SYM26, preparadas en tampón SSC6× 0,6\% SDS, 0,1\% ADN de esperma de salmón 2\% BSA y 25\% formamida-, sobre cada una de las zonas impresas. Los discos se dejaron incubar durante $1 \mathrm{~h} \mathrm{a}$ $37^{\circ} \mathrm{C}$ en cámara oscura y húmeda, se lavaron con PBS-T y agua, y se secaron. Finalmente, el ensayo se reveló con estreptavidina-Au y plata, tal y como se ha descrito en el apartado 3.4.1.4. Los resultados se leyeron con el reproductor de CDs.

\subsubsection{Ensayos de reconocimiento con anticuerpos}

\subsubsection{Calibrado}

Para el calibrado, se prepararon disoluciones del anticuerpo GAR-Cy5 en un intervalo de concentraciones comprendido entre 1 y $50 \mu \mathrm{g} / \mathrm{mL}$ en PBS $1 \times$. Nueve réplicas ( 1 matriz de $3 \times 3$ puntos) de cada una de las disoluciones fueron impresas sobre las superficies de los chips, activadas mediante distintas metodologías. La intensidad de fluorescencia de los puntos impresos se registró utilizando el detector LFS, y la imagen obtenida se analizó con el software Genepix 6.0 para obtener la curva de calibrado.

\subsubsection{Ensayos de inmovilización}

Para el estudio de inmovilización fueron impresas en formato microarray $(3 \times 3)$ diferentes disoluciones de GAR-Cy5, con concentraciones comprendidas entre 5 y $200 \mu \mathrm{g} / \mathrm{mL}$ en PBS1×, incubando los chips en cámara oscura y húmeda durante 1 hora a $37^{\circ} \mathrm{C}$. Finalmente, se realizaron varios lavados con tampón MES, agua y 
una disolución acuosa de $\mathrm{AcOH}$ 0,15 M. Los resultados de la inmovilización fueron leídos mediante LFS y cuantificados con el programa Genepix 6.0.

\subsubsection{Inmunoensayo para detección de BSA}

Para este ensayo el anticuerpo antialbúmina de suero bovino $(0,2 \mathrm{mg} / \mathrm{mL}$ en PBS1×) fue impreso en los chips mixtos $\mathrm{Si}_{3} \mathrm{~N}_{4} / \mathrm{SiO}_{2}$ previamente activados siguiendo las metodologías descritas anteriormente. Las muestras se incubaron durante $2 \mathrm{~h}$ a $37^{\circ} \mathrm{C}$, y se lavaron con PBS-T y agua. Posteriormente, se depositaron $20 \mu \mathrm{L}$ de OVA $1 \%$ en PBS1x a fin de bloquear los grupos activos residuales, se incubaron durante 30 minutos a temperatura ambiente, y se lavaron con PBS-T y agua. Tras el bloqueo, se depositaron $20 \mu \mathrm{L}$ de diferentes diluciones de BSA-Cy5 (0,1-100 mg/mL en PBS1x) sobre los chips. El marcaje de BSA con Cy5 se realizó de acuerdo al protocolo proporcionado por el proveedor ${ }^{235}$. Tras 1 h de incubación en cámara húmeda a $37^{\circ} \mathrm{C}$, los chips se lavaron con PBS-T. La señal de fluorescencia se leyó mediante LFS y se cuantificó con el software del equipo.

\subsubsection{Aplicación de los ensayos a la detección del virus $\mathrm{H}_{1} \mathrm{~N}_{1}$ de la gripe aviaria en muestras de fluido oral sobre DVD}

\section{Protocolo del inmunoensayo para la detección del virus $\mathbf{H}_{1} \mathbf{N}_{1}$}

Los inmunoensayos de detección del virus de la gripe aviaria fueron desarrollados en formato sandwich no competitivo. Para ello, las superficies de los DVDs químicamente activadas fueron divididas en 8 zonas, imprimiendo 8 matrices $(2 \times 8$ puntos $)$ de anticuerpo $\mathrm{mAb}\left(\mathrm{H}_{1} \mathrm{~N}_{1}\right)(40 \mathrm{mg} / \mathrm{mL}$ en $\mathrm{TC} 1 \times)$ sobre cada una de las zonas. En cada matriz se imprimieron además dos filas de ocho puntos de anticuerpo marcado con biotina, ${ }^{236}$ como control positivo $\left(\mathrm{mAb}\left(\mathrm{H}_{1} \mathrm{~N}_{1}\right)-\mathrm{BT}\right)$, y otra de anticuerpo GAR a modo de control negativo (Figura 15). Después de $2 \mathrm{~h}$ de 
incubación en cámara oscura y húmeda a temperatura ambiente, los discos fueron lavados con PBS-T y agua, y secados por centrifugación a $800 \mathrm{rpm}$.

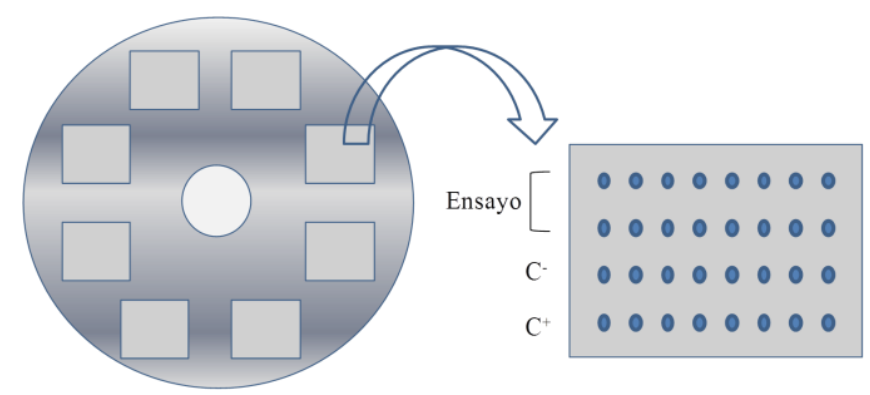

Figura 15. Esquema de ensayo de detección del virus de la gripe aviaria.

Por otro lado, disoluciones de virus fraccionados $\left(\mathrm{H}_{1} \mathrm{~N}_{1}\right)$ fueron preparadas en un intervalo comprendido entre $0-1 \mu \mathrm{g} / \mathrm{mL}$ en PBS1×. $35 \mu \mathrm{L}$ de cada una de las disoluciones se depositaron y extendieron con ayuda de un cubreobjetos sobre las áreas impresas. Tras $15 \mathrm{~min}$ de incubación a temperatura ambiente, los discos fueron lavados con PBS-T y agua. A continuación, $800 \mu \mathrm{L}$ de anticuerpo $\left[\mathrm{mAb}\left(\mathrm{H}_{1} \mathrm{~N}_{1}\right)\right.$-BT $(5 \mu \mathrm{g} / \mathrm{mL}$ en $\mathrm{PBS} 1 \times)$ ] fueron depositados sobre los DVDs y extendidos homogéneamente con ayuda de un disco de PC de 0,6 $\mathrm{mm}$ de espesor. Tras incubar 15 min en cámara oscura y húmeda a temperatura ambiente, los discos se lavaron con PBS-T y agua, y se incubaron con estreptavidina-HRP $(10 \mu \mathrm{g} / \mathrm{mL}$ en PBS1 $\times$ ) durante 15 min a temperatura ambiente. Tras lavar el disco con PBS-T y agua, se dispensaron $800 \mu \mathrm{L}$ de disolución de revelado (TMB), apareciendo un precipitado azul oscuro en aquellas zonas en las que se produce la detección del virus de la gripe aviaria, transcurridos $8 \mathrm{~min}$. La intensidad del precipitado fue medida y cuantificada mediante el lector de CDs y el software Genepix 6.0. 
Los resultados obtenidos se representan en una curva de saturación, a partir de cuyo intervalo lineal pueden estimarse las concentraciones de las muestras.

\section{Detección del virus $\mathrm{H}_{1} \mathrm{~N}_{1}$ en muestras de saliva}

(a) Toma de muestra. Un total de ocho voluntarios sanos, cuatro hombres y cuatro mujeres, con una edad media de 30 años, participaron en el estudio. Todos ellos cumplían con los requisitos establecidos de no tener infección bacteriana en amígdalas y faringe, así como no haber tenido exposición conocida al virus de la gripe aviaria (por infección o por vacunación) durante el último año, con el fin de que no se produjeran interferencias en los resultados del ensayo. Las muestras de fluido oral fueron tomadas según el protocolo de $\operatorname{Binax}^{237}$ y almacenadas en nevera a $4{ }^{\circ} \mathrm{C}$, hasta un máximo de $24 \mathrm{~h}$ antes de la prueba.

(b) Protocolo de ensayo. Para la detección del virus de la gripe aviaria en fluido oral, las muestras fueron dopadas a diferentes concentraciones comprendidas dentro del intervalo lineal de la curva de saturación. Para cada muestra se realizaron 6 réplicas en diferentes discos ( 2 matrices $3 \times 8,48$ puntos muestra/réplica), y se procedió tal y como se ha descrito en el protocolo de ensayo (apartado 3.4.2.4). Paralelamente, se realizó una réplica para cada una de las muestras sin dopar, con la finalidad de evaluar el efecto matriz y comprobar que estaban exentas de virus. Finalmente, se calcularon los porcentajes de recuperación a partir de los valores interpolados en la curva de saturación.

\subsubsection{Aplicación a ensayos para detección de (mAb-HBsAg) mediante tecnología de guía de ondas plana}

Para la detección de anticuerpos contra la hepatitis B, marcador de recuperación o inmunidad frente a la enfermedad, se empleó un formato indirecto. El ensayo se desarrolló según protocolo de trabajo patentado por Zeptosens ${ }^{238}$. Para ello, sobre 
los dispositivos de guía de ondas plana se depositaron matrices $2 \times 4$ conteniendo diferentes diluciones del antígeno de superficie (HBsAg) comprendidas entre 0,5-2 $\mu \mathrm{g} / \mathrm{mL}$. En cada una de las matrices se adicionaron dos columnas patrón que contenían anticuerpo GAR marcado con Alexa-647. Tras incubación durante 2 h y bloqueo con caseína, las superficies se trataron con el anticuerpo monoclonal de ratón del antígeno de superficie del virus de la hepatitis $\mathrm{B}$, en un intervalo 0,00013$130 \mu \mathrm{g} / \mathrm{mL}$ en suero humano diluido (1:300). Después se trató con anticuerpo mAbAlexa-647, y se procedió a la lectura de fluorescencia mediante el Zeptoreader®. 


\section{RESULTADOS Y DISCUSIÓN}





\subsection{Sistemas microanalíticos sobre soportes poliméricos}

El desarrollo de sistemas analíticos sobre soportes poliméricos basados en la unión covalente de receptores moleculares -proteínas o ácidos nucleicos, principalmente-, pasa por la aplicación de una química de superficies simple y reproducible, que dote a los materiales en estudio de la capacidad de anclaje de receptores específicos, sin modificar sus propiedades ópticas y físico-químicas, manteniendo inalterada la capacidad de reconocimiento del receptor.

Para la puesta a punto de sistemas de ensayo a escala micrométrica sobre sustratos poliméricos se abordó, en primer lugar, el estudio de estrategias de modificación química de los plásticos que componen un disco compacto (PMMA y PC), y se procedió a la caracterización de las superficies obtenidas mediante diversas técnicas: ángulo de contacto, infrarrojo de reflectancia total atenuada con transformada de Fourier (ATR-FTIR), espectroscopia de dispersión de energía (EDS) y resonancia magnética nuclear (RMN). Posteriormente, se optimizaron los procesos de inmovilización covalente de micromatrices de biorreceptores sobre las superficies activadas. Finalmente, se realizó la puesta a punto de ensayos de screening como demostración de las aproximaciones estudiadas. Los ensayos incluyeron la discriminación de SNPs, útil para el análisis de organismos modificados genéticamente, y la detección del virus de la gripe aviaria.

El estudio sobre soportes poliméricos se desarrolló utilizando dos vías claramente diferenciadas, tanto por las plataformas analíticas empleadas como por el sistema de detección. En la primera metodología estudiada se trabajó sobre chips de PMMA y PC de $55 \times 25 \mathrm{~mm}$, empleando para la detección lectores de fluorescencia de superficie -detallados en material y métodos (EF y LFS)- y reactivos marcados con el fluoróforo Cy5. En segundo lugar, se utilizaron discos compactos como soportes de ensayo, empleando un lector de CDs como detector. 


\subsubsection{Estrategias de modificación química de superficies poliméricas}

Se ensayaron diferentes estrategias de modificación química superficial de PMMA y PC, basadas en la introducción de grupos funcionales electrófilos adecuados (aldehído e isocianato) para el anclaje covalente de biomoléculas a través de grupos amino libres. El objetivo fue obtener un alto grado de derivatización química superficial, utilizando una química sencilla y reproducible, que permita la unión covalente de biomoléculas en condiciones suaves de $\mathrm{pH}$, temperatura y fuerza iónica, de modo que no se altere la actividad de los biorreceptores. Además, el soporte modificado debe mantener sus propiedades ópticas y mecánicas, posibilitando la lectura de los resultados mediante los sistemas ópticos descritos. En el Esquema 7 se muestran las rutas de derivatización química desarrolladas.

\subsubsection{Estudios de solubilidad de los polímeros en disolventes orgánicos}

Con el fin de desarrollar procedimientos de modificación química adecuados se realizó, en primer lugar, un estudio de la solubilidad de los polímeros -PMMA y PC- en diferentes medios orgánicos. Para ello, se seleccionaron aquellos disolventes que no alterasen las superficies de trabajo y no afectasen a las propiedades ópticas de los materiales, requisito necesario dado que el principio de detección de los dispositivos de medida se basa en fenómenos de transmisión o reflexión de la luz.

Para ello se emplearon chips de PMMA y PC $(55 \times 25 \mathrm{~mm})$, que se sumergieron durante tres días en distintos disolventes orgánicos: dietil éter, diclorometano, ciclohexano, metanol, 2-propanol y agua, seleccionados en base a la compatibilidad con la química de los organosilanos, ya que gran parte de las metodologías propuestas emplean la química de estos compuestos. Transcurrido dicho periodo, se observó que el dietil éter y el diclorometano disolvían totalmente el PMMA y el PC. Con el metanol se produjo un ablandamiento y una disminución de la transparencia, 
mientras que en ciclohexano, 2-propanol y agua, aparentemente las propiedades ópticas y mecánicas quedaban inalteradas.

Para conocer si se habían producido alteraciones superficiales significativas, se realizaron medidas de ángulo de contacto empleando agua como disolvente. Los ángulos fueron medidos inmediatamente después de la deposición de la gota sobre las dos superficies tratadas con 2-propanol, ciclohexano y agua, y curadas en estufa a $62{ }^{\circ} \mathrm{C}$ durante $6 \mathrm{~h}$, así como para los chips de PMMA y PC sin tratar. La reproducibilidad de los resultados obtenidos en todos los casos mostró la homogeneidad de las superficies tras ser expuestas a los distintos disolventes seleccionados. Por otro lado, la variación de las medidas respecto a las muestras sin tratar, 4\% para agua, 9\% para 2-propanol y 12\% para ciclohexano en el caso del PMMA, y 6\%, 14\% y 17\%, respectivamente, para el PC, indicó que no se producían alteraciones superficiales significativas, pudiendo llevar a cabo las modificaciones en dichos medios. 


\section{R.1. Modificación del PMMA}

R.1.1. Aplicación en chip

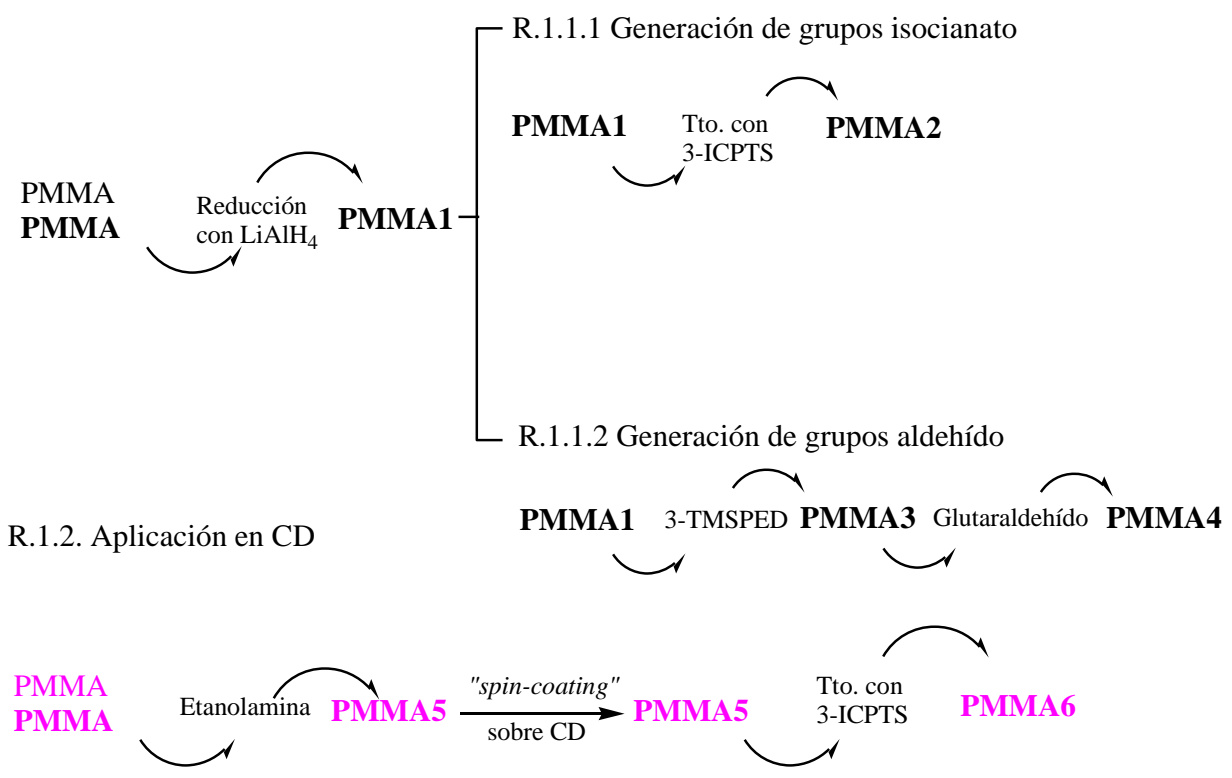

\section{R.2. Modificación del PC}

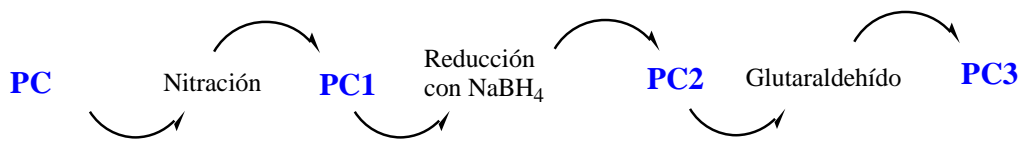

Esquema 7. Esquema de las rutas (R.1 y R.2) de derivatización química desarrolladas para PMMA y PC. 


\subsubsection{Estudios de modificación superficial de PMMA: Aplicación en chip}

La primera ruta de derivatización consistió en la reducción de los grupos éster del PMMA utilizando $\mathrm{LiAlH}_{4}$, que proporcionó grupos hidroxilo en la superficie del polímero, y posterior unión con el correspondiente organosilano por condensación con los hidroxilos generados (Esquema 8). Para ello se empleó ciclohexano, puesto que de los disolventes seleccionados en el apartado 4.1.1.1. (agua, 2-propanol y ciclohexano) es el único compatible con $\mathrm{LiAlH}_{4}$.

Para ello, fueron estudiados tiempos de reacción entre 10 min y 12 h, y distintas concentraciones de reductor, concluyendo que los mejores resultados se obtenían para 30 minutos y $5 \%$ de $\mathrm{LiAlH}_{4}$, respectivamente.

Por otro lado, para el tratamiento de silanización, y obtención de las superficies PMMA2 y PMMA3, se utilizó 2-propanol como disolvente. Para optimizar esta etapa se ensayaron diferentes concentraciones de entre 0,1 y $5 \%$ de los organosilanos (3-isocianatopropil)trietoxisilano (3-ICPTS) y $\mathrm{N}$ [trimetoxilsilil)propil] etilendiamina (TMSPED). Así mismo, se estudiaron tiempos de reacción entre 10 minutos y 2 horas. Las condiciones óptimas de reacción conICPTS y TMSPED fueron: tratamiento de 10 min con una disolución al $1 \%$ en 2propanol y secado de los chips durante 20 minutos a $62{ }^{\circ} \mathrm{C}$.

Para la obtención de PMMA4, la superficie aminada de PMMA3, fue tratada con glutaraldehído al 5\% en PBS1x, pH 8. La optimización del pH fue crucial, ya que a $\mathrm{pH}$ inferiores a 7 la mayoría de los grupos amino se encuentran en forma de sal amónica, impidiendo el ataque del nucleófilo y la unión del glutaraldehido mediante la formación de una base de Schiff, mientras que a valores de $\mathrm{pH}$ superiores a 9 el glutaraldehído tiende a polimerizar. Las superficies resultantes se caracterizaron mediante ángulo de contacto, ATR-FTIR y EDS. 


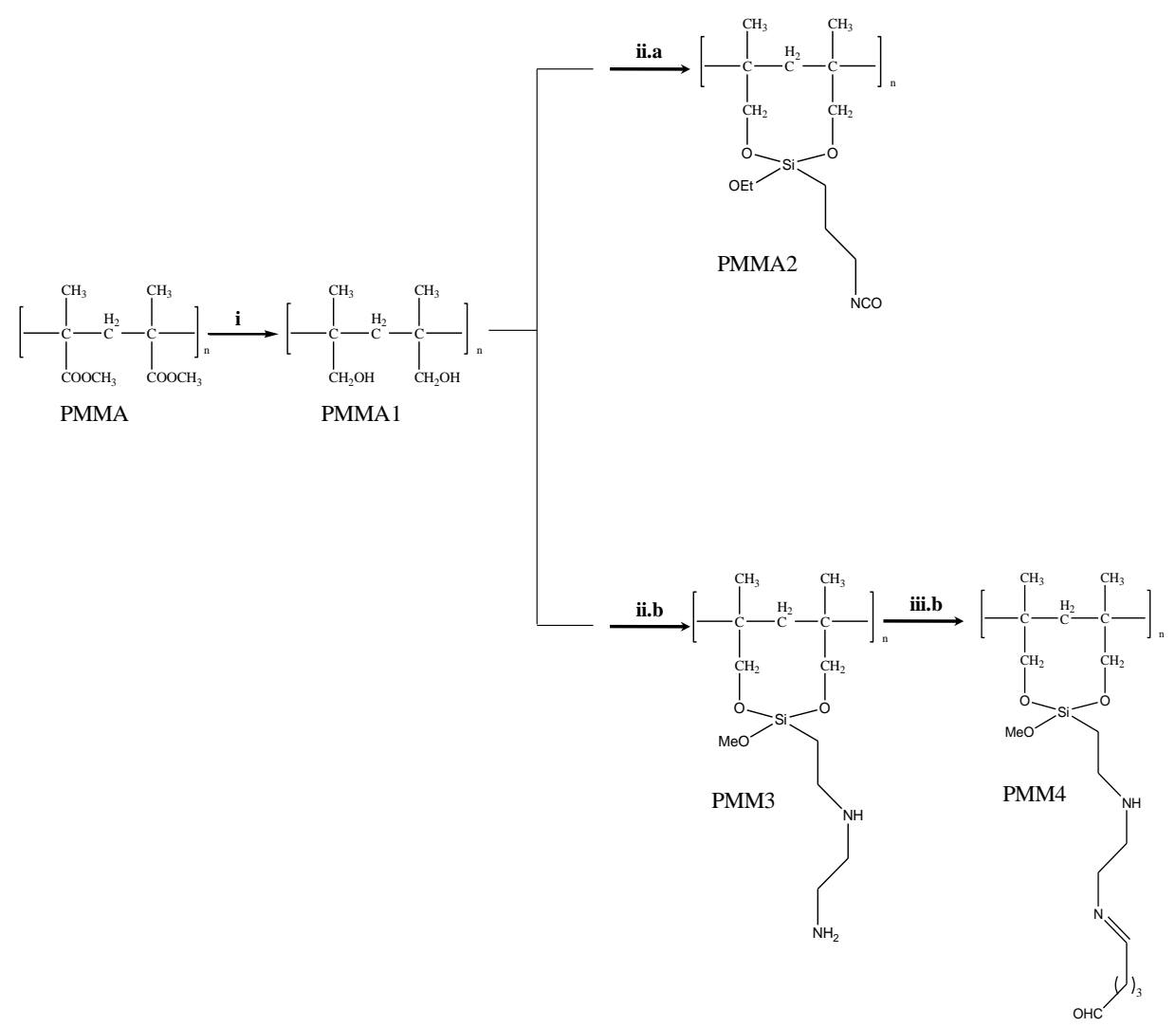

Esquema 8. Vías de modificación química del PMMA (R.1.1). i. $\mathrm{LiAlH}_{4}$ (5\% en ciclohexano), 30 min; ii.a. $\left(\mathrm{CH}_{3} \mathrm{O}\right)_{3} \mathrm{Si}\left(\mathrm{CH}_{2}\right)_{3} \mathrm{NCO}$ (1\% en 2-propanol), 10 min; i.b. $\left(\mathrm{CH}_{3} \mathrm{CH}_{2} \mathrm{O}\right)_{3} \mathrm{Si}\left(\mathrm{CH}_{2}\right)_{2} \mathrm{NH}\left(\mathrm{CH}_{2}\right)_{2} \mathrm{NH}_{2}$ (1\% en 2-propanol), 10 min; iii.b. $\mathrm{OHC}\left(\mathrm{CH}_{2}\right)_{3} \mathrm{CHO}(5 \%$ en PBS1×, pH 8), 2 h. 


\section{Ángulo de contacto}

Las medidas de ángulo de contacto se llevaron a cabo con agua y glicerol. Sobre cada sustrato y para cada disolvente se realizaron 5 medidas, cuya media y error relativo se muestran en la Tabla 9.

Los resultados indican que los ángulos de contacto estimados para PMMA1 correlacionan bien con los encontrados en la literatura ${ }^{239}$. Las medidas de ángulo de contacto proporcionan información sobre la hidrofilia de la superficie, de modo que para disolventes polares, a mayor hidrofilia superficial menores valores de ángulo de contacto (Figura 16). Esta tendencia se producirá para agua y en menor magnitud para glicerol, debido al carácter polar de ambos disolventes.

Los resultados mostrados en la Tabla 9 indican un incremento de la hidrofilia al aumentar la proporción de oxígeno en la superficie y, por tanto, una disminución de los ángulos de contacto (PMMA1 y PMMA4). Ello es debido a un aumento de la polaridad de las superficies, así como a la posibilidad de formar enlaces de hidrógeno con las moléculas de agua. Por la misma razón, también se observó un incremento de la hidrofilia tras la introducción de grupos isocianato y amino (PMMA2 y PMMA3), aunque de menor magnitud.

Tabla 9. Ángulos de contacto $(\theta)$ para distintas superficies.

\begin{tabular}{c|cc}
\hline Superficie & $\boldsymbol{\theta}_{\text {agua }}$ & $\boldsymbol{\theta}_{\text {glicerol }}$ \\
\hline \hline PMMA & $76 \pm 1$ & $78 \pm 1$ \\
PMMA1 & $45 \pm 2$ & $40 \pm 2$ \\
PMMA2 & $72 \pm 3$ & $77 \pm 3$ \\
PMMA3 & $74 \pm 1$ & $78 \pm 1$ \\
PMMA4 & $43.5 \pm 3$ & $66 \pm 1$ \\
\hline
\end{tabular}




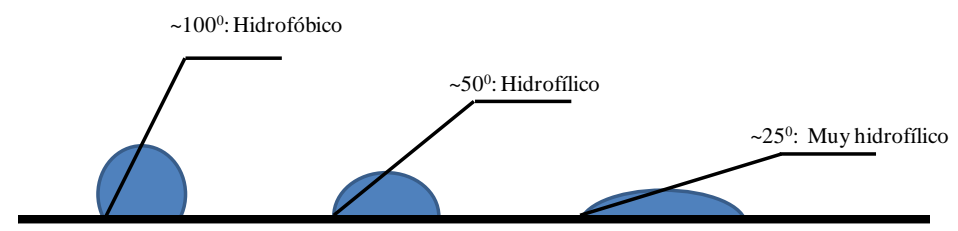

Figura 16. Clasificación de la hidrofilia de la superficie en función del ángulo de contacto.

Espectroscopía infrarroja de reflectancia total atenuada con transformada de Fourier (ATR-FTIR)

La Figura 17 muestra los espectros de infrarrojo con transformada de Fourier de las superficies de PMMA, PMMA1 y PMMA3. Para el PMMA1, se observa un pico característico del -OH alrededor de 3200-3400 $\mathrm{cm}^{-1}$; para el PMMA3 la banda a $3300-3500 \mathrm{~cm}^{-1}$ indica la presencia del grupo $-\mathrm{NH}_{2}$. Hay que señalar que las superficies fueron incubadas en estufa a $40-50{ }^{\circ} \mathrm{C}$ durante toda la noche, antes de obtener el espectro, para descartar que estas señales fuesen debidas a humedad o residuos volátiles. 

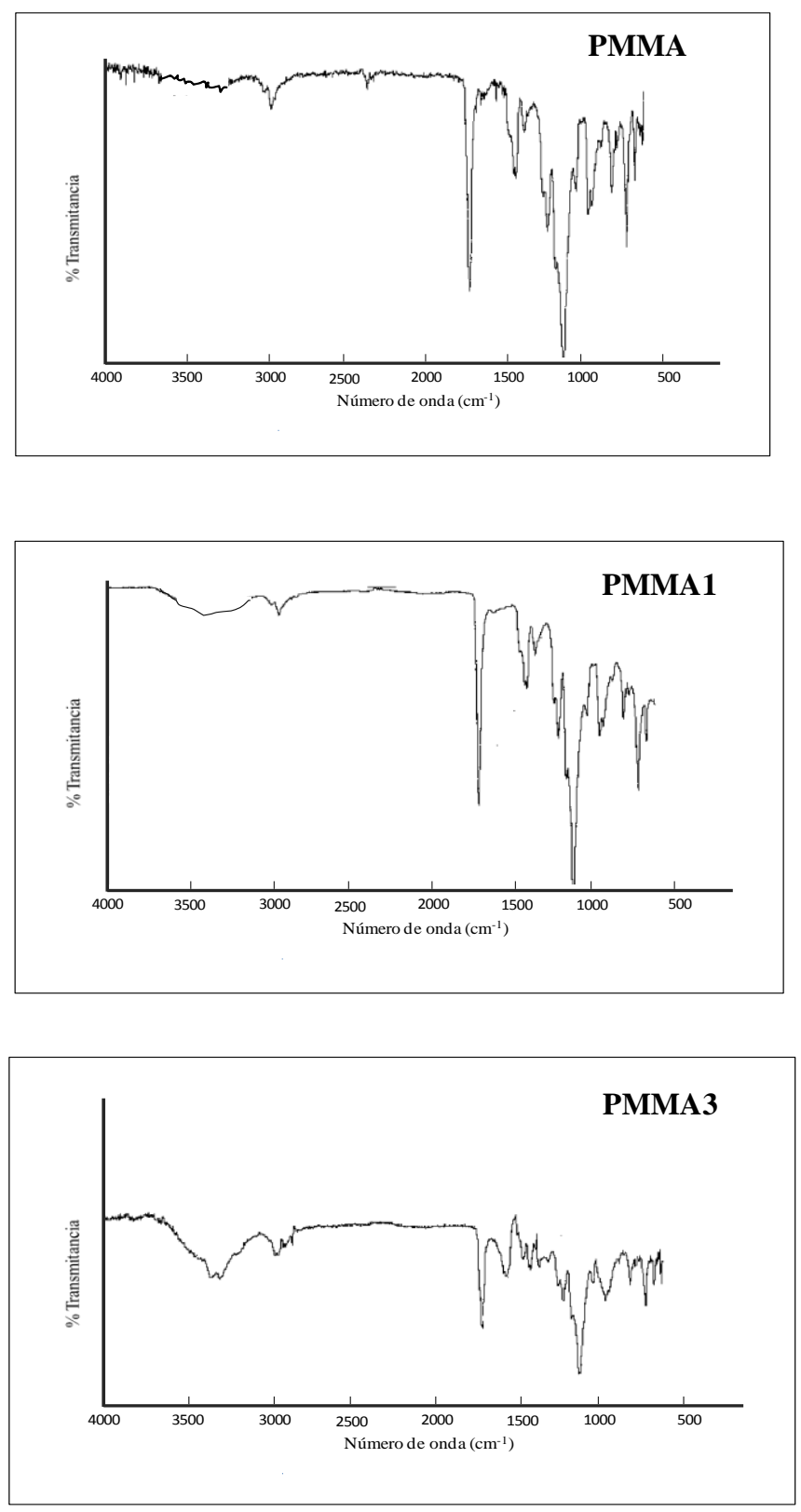

Figura 17. Espectros ATR-FTIR de PMMA, PMMA1, PMMA3 


\section{Espectroscopía de dispersiónde energía (EDS)}

Para comprobar la efectividad de la unión del organosilano sobre las superficies de los chips se registraron los espectros de dispersión de energía de PMMA2 y PMMA3. Mediante esta técnica se puede llevar a cabo la detección cualitativa y cuantitativa de los elementos que constituyen la muestra, aprovechando la emisión de rayos $\mathrm{X}$ generados por la excitación de los átomos de la muestra en un microscopio de barrido electrónico. En la Figura 18 se observa la aparición del pico correspondiente al Si para PMMA2 como consecuencia del proceso de silanización.

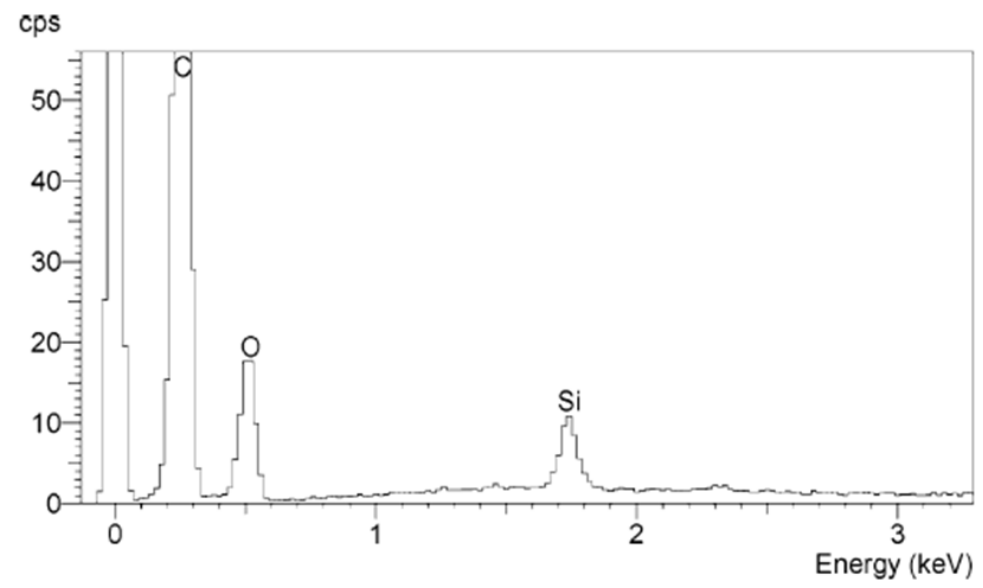

Figura 18. Espectro de dispersión de energía de PMMA2

\subsubsection{Estudios de modificación superficial de PMMA: Aplicación en CD}

Para lograr la unión covalente de biomoléculas sobre discos compactos semitransparentes $(\mathrm{CD}-\mathrm{Au})$ químicamente activados con grupos isocianato, se realizaron las siguientes etapas: (1) Introducción de grupos hidroxilo en el PMMA mediante tratamiento con etanolamina en THF, (2) lacado (o spin-coating) del CDAu con PMMA hidroxilado (PMMA5), y (3) introducción del grupo isocianato por 
reacción de condensación de los grupos hidroxilo del PMMA5 con 3-ICPTS, PMMA6 (Figura 19).

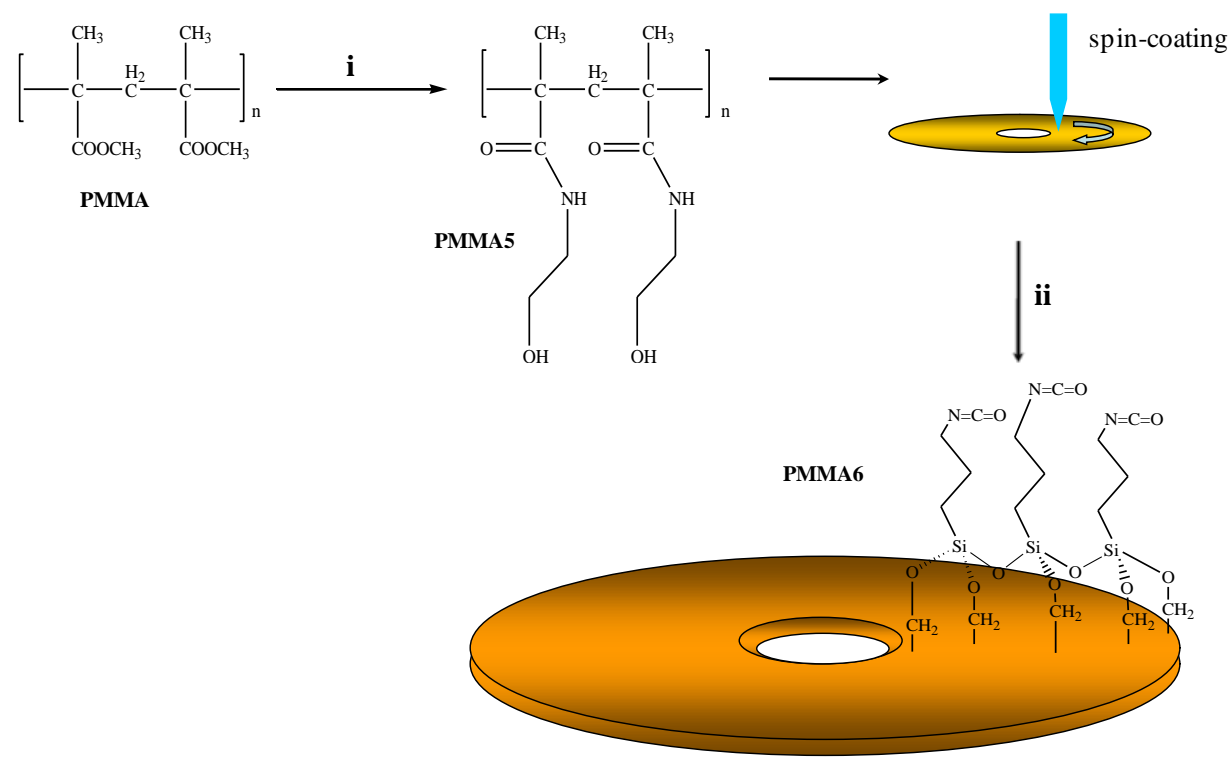

Figura 19. Vía de modificación química del PMMA (R.1.2). i. $\mathrm{HO}\left(\mathrm{CH}_{2}\right)_{2} \mathrm{NH}_{2}$ (0,5 M en THF), $2 \mathrm{~h}$; ii. $\left(\mathrm{CH}_{3} \mathrm{O}\right)_{3} \mathrm{Si}\left(\mathrm{CH}_{2}\right)_{3} \mathrm{NCO}$ (1\% en 2-propanol), $10 \mathrm{~min}$

En la primera etapa, se llevó a cabo la reducción de PMMA en fase líquida disolviendo el polímero en una disolución de $\mathrm{LiAlH}_{4}$ en tetrahidrofurano (THF), tal y como se muestra en la primera ruta de derivatización (Ruta R.1.1). Sin embargo, los resultados no fueron satisfactorios, por lo que se diseñó una estrategia alternativa de funcionalización (Ruta R.1.2). Esta vía, esquematizada en la Figura 19, consistió en la reacción de PMMA con exceso de etanolamina en THF para producir la aminólisis del éster metílico, generándose una superficie de PMMA 
hidroxilado (PMMA5) con un rendimiento aproximado del 50\% determinado por RMN- ${ }^{1} \mathrm{H}$.

Para el cálculo del rendimiento, se relacionó el valor obtenido para la integración de un protón perteneciente a un grupo $-\mathrm{CH}_{2}$ del derivado de etanolamina, con la correspondiente a un protón procedente del éster metílico del PMMA, lo que proporciona una idea del número de grupos hidroxilo introducidos.

Posteriormente, el polímero PMMA5, se disolvió en acetato de (1-metil, 2metoxi)etilo (Dowanol) al $1 \%$ y se aplicó sobre la cara superior del CD-Au por spin-coating. A continuación, se secó, tal y como se describe en el apartado 3.3.1.2., obteniéndose una película homogénea de $60 \mathrm{~nm}$ de espesor (medido por AFM y elipsometria), con un alto grado de homogeneidad y reproducibilidad (medido AFM, elipsometría y SEM).

Para la silanización de la superficie de PMMA5 se utilizó 2-propanol como disolvente, al igual que en la derivatización del PMMA en formato chip. Se optó por emplear 3-ICPTS por permitir el acoplamiento directo con los grupos aminos de la biomolécula formando un enlace urea, mientras el 3-TMSPED requiere un paso adicional para la introducción del crosslinker adecuado. Para optimizar el proceso, fueron ensayadas concentraciones de organosilano comprendidas entre 0,1 y $5 \%$, y tiempos de reacción entre 10 minutos y 2 horas. Tratamientos superiores a $1 \mathrm{~h}$ provocaban un ataque parcial de la película de polímero depositada, afectando a las propiedades de transparencia y uniformidad de las superficies. Las condiciones óptimas fueron tratamiento con 3-ICPTS al $1 \%$ durante 10 minutos y secado de los chips en estufa a $62{ }^{\circ} \mathrm{C}$ durante 20 minutos. 


\section{Ángulos de contacto}

Los valores de los ángulos de contacto obtenidos para las superficies modificadas en cada una de las etapas empleando agua como disolvente (Tabla 10), mostraron una disminución de los ángulos de contacto para las superficies de PMMA5, debida al aumento de la polaridad tras la introducción de grupos hidroxilo y, en menor medida, para PMMA6 con grupos isocianato. La tendencia observada correlaciona bien con los resultados obtenidos para la ruta R.1.1.1.

Tabla 10. Ángulos de contacto $(\theta)$ para distintas superficies

\begin{tabular}{c|cc}
\hline Superficie & $\boldsymbol{\theta}_{\text {agua }}$ & $\boldsymbol{\theta}_{\text {glicerol }}$ \\
\hline \hline PMMA & $76 \pm 1$ & $78 \pm 1$ \\
PMMA5 & $63 \pm 2$ & $65 \pm 2$ \\
PMMA6 & $70 \pm 1$ & $75 \pm 1$ \\
\hline
\end{tabular}

\subsubsection{Estudios de modificación superficial del PC}

La ruta de modificación química desarrollada para PC se aplicó tanto a discos transparentes, como a CDs y DVDs comerciales. El procedimiento de activación química del PC (Figura 20) implica: (1) nitración de los anillos bencénicos del PC1, (2) reducción de los grupo nitro del PC1 a amino (PC2), e (3) introducción de grupos aldehído por reacción con glutaraldehído (PC3). 


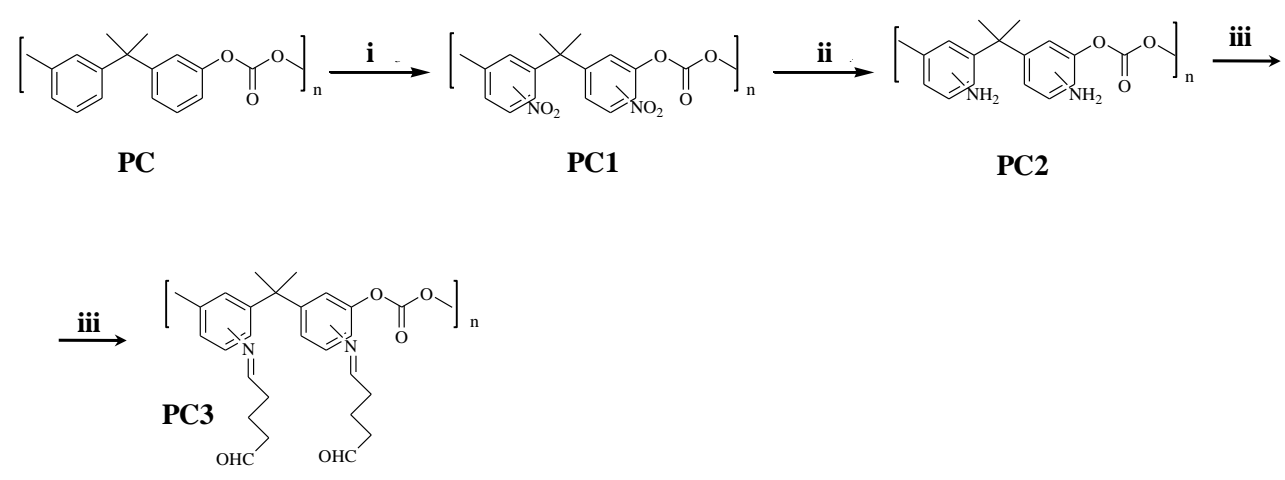

Figura 20. Vía de modificación química del PC (R.2). i. $\mathrm{HNO}_{3}(0,4 \mathrm{M}) ; \mathrm{H}_{2} \mathrm{SO}_{4}(1$ $\mathrm{mM})$ en agua, $10 \mathrm{~min}, 65^{\circ} \mathrm{C}$; ii. $\mathrm{NaBH}_{4}(1 \mathrm{M}), \mathrm{NaOH}(0,1 \mathrm{M})$ en agua, $4 \mathrm{~h}$; iii. $\mathrm{OHC}\left(\mathrm{CH}_{2}\right)_{3} \mathrm{CHO}$ (5\% en PBS1x), pH 8, 2 h.

La nitración de los anillos bencénicos se llevó a cabo en una disolución de ácido nítrico ( $0,4 \mathrm{M}$ en agua) que contenía ácido sulfúrico $(1 \mathrm{mM})$, durante 10 minutos. Se observó que tiempos superiores a 10 minutos producen una degradación de las superficies y pérdida de transparencia, mientras que con tiempos inferiores la nitración resultó insuficiente. La aminación se llevó a cabo por reducción de los grupos nitro mediante $\mathrm{NaBH}_{4}$ al $5 \%$ en agua $(0,1 \mathrm{M}$ de $\mathrm{NaOH})$ durante $4 \mathrm{~h}$.

Finalmente, las superficies aminadas (PC2) se trataron con glutaraldehído al 5\% en PBS 1×, pH 8, durante $2 \mathrm{~h}$, para generar grupos aldehído con los que inmovilizar biomoléculas a través de sus grupos amino por la formación de una imina. Al igual que en el apartado anterior, las superficies fueron caracterizadas por ángulo de contacto y ATR-FTIR. 


\section{Ángulos de contacto}

Los resultados obtenidos para las superficies de PC1 (sin tratar) correlacionan bien con los encontrados en la literatura para $\mathrm{PC}^{90}$.

Tal y como cabía esperar, la disminución de los valores de ángulo de contacto de las diferentes superficies de policarbonato, empleando agua y glicerol como disolventes (Tabla 11), indica un aumento de la hidrofilia de las superficies como consecuencia de la introducción de grupos $-\mathrm{OH}, \mathrm{NH}_{2}$ y $-\mathrm{CHO}$.

Tabla 11. Ángulos de contacto $(\theta)$ para distintas superficies

\begin{tabular}{c|cc}
\hline Superficie & $\boldsymbol{\theta}_{\text {agua }}$ & $\boldsymbol{\theta}_{\text {glicerol }}$ \\
\hline \hline PC & $78 \pm 2$ & $71 \pm 0,9$ \\
PC1 & $57 \pm 2$ & $58 \pm 2$ \\
PC2 & $66 \pm 2$ & $69 \pm 1$ \\
PC3 & $59 \pm 2$ & $61,7 \pm 0,9$ \\
\hline
\end{tabular}

\section{Espectroscopía infrarroja de reflectancia total atenuada con transformada} de Fourier (ATR-FTIR)

Los espectros de IR con transformada de Fourier obtenidos de PC y PC2 (Figura 21), corroboran la presencia del grupo $-\mathrm{NH}_{2}$ en PC2, al observarse el estrechamiento característico del amino en el intervalo $3200-3600 \mathrm{~cm}^{-1}$. 

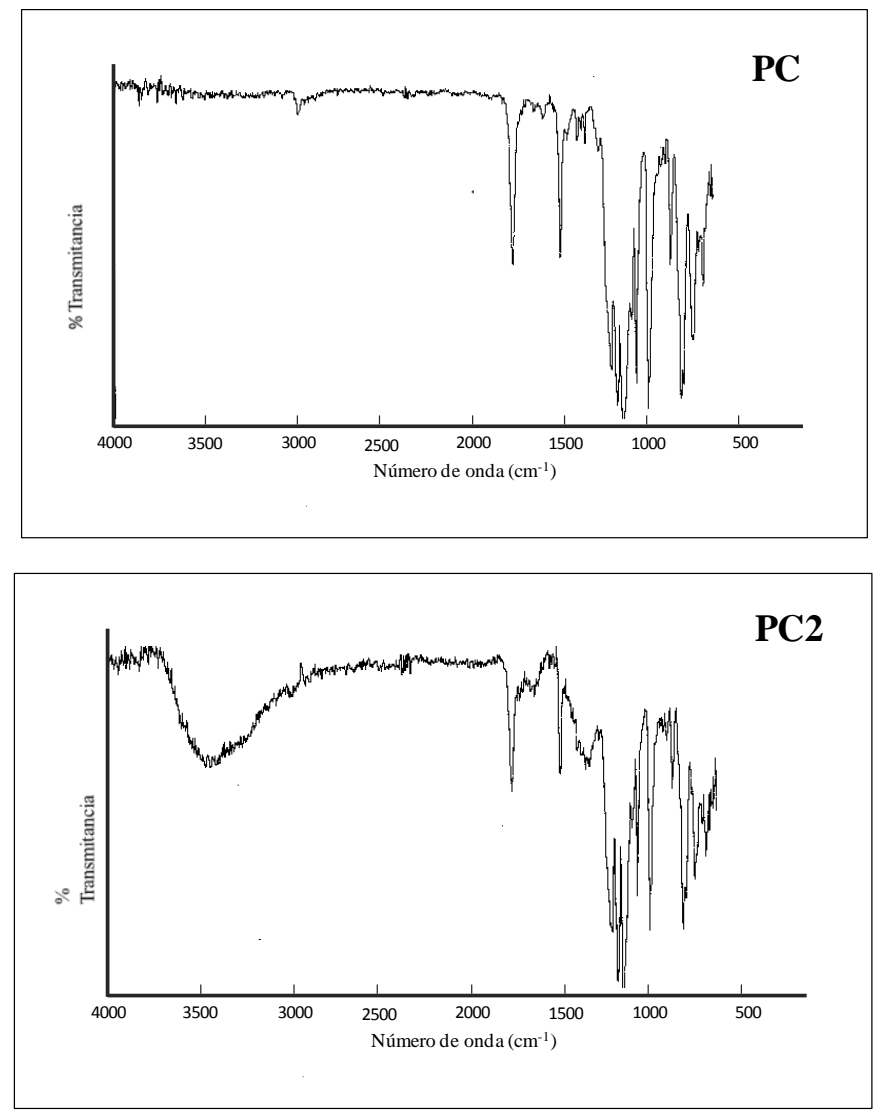

Figura 21. Espectro ATR-FTIR de PC y PC2.

\subsubsection{Estudios de inmovilización de sondas biomoleculares}

Para el estudio de la inmovilización de biorreceptores sobre las superficies poliméricas químicamente modificadas, se imprimieron micromatrices de oligonucleótidos (Tabla 12).

Las sondas denominadas SYM8 y SYM23 estaban marcadas con Cy5 en el extremo 5'. Además, SYM23 contiene un grupo amino en el extremo 3' que permite discriminar cuando la unión es covalente o por adsorción. 
Las metodologías de inmovilización de sondas marcadas, junto con las técnicas de caracterización de superficie empleadas, proporcionan información respecto al grado de activación química alcanzado tras las respectivas modificaciones.

Tabla 12. Sondas de oligonucleótidos empleadas en los ensayos de inmovilización.

\begin{tabular}{c|ccc}
\hline Sonda & Secuencia (5'to 3') & Extremo 5, & Extremo 3' \\
\hline \hline SYM8 & AATGCTAGCTAATCAATCGGG & Cy5 & Ninguno \\
\hline SYM23 & TTACGATCGATTAGTTAGCCC $(\mathrm{T})_{15}$ & $\mathrm{Cy} 5$ & $\mathrm{C}_{7}-\mathrm{NH}_{2}$ \\
\hline
\end{tabular}

\subsubsection{Estudios de inmovilización sobre PMMA}

Los ensayos de inmovilización se llevaron a cabo tal y como se ha descrito en el apartado 3.4.1. Así, sobre las diferentes superficies de PMMA (PMMA-PMMA6) se imprimieron micromatrices $(3 \times 3)$ del oligonucleótido SYM23 a varias concentraciones $(1-10 \mu \mathrm{M})$, en diferentes medios y condiciones de $\mathrm{pH}$ y fuerza iónica. Tras un tiempo de incubación de 1 h a $37^{\circ} \mathrm{C}$, se llevó a cabo un lavado con PBS-T con el fin de eliminar los restos de sonda no inmovilizada. Después se midió la intensidad de fluorescencia.

En la Figura 22 se representa la intensidad de fluorescencia para la inmovilización de SYM23 sobre los derivados de la ruta R.1.1. (PMMA-PMMA4), en distintos medios ( $\mathrm{pH}$ y fuerza iónica). Los mayores rendimientos de inmovilización de SYM23 se alcanzaron sobre PMMA2 y PMMA4 en TC1× pH 11, al producirse la unión covalente del oligonucleótido a los grupos isocianato y aldehído, respectivamente.

El resto de las superfices (PMMA, PMMA1 y PMMA3) presentaron valores de fluorescencia despreciables respecto a PMMA2 y PMMA4, a excepción de 
PMMA3, debido a las interacciones entre el grupo amino en su forma protonada $\left(\mathrm{pk}_{\mathrm{b}}=3-4\right)$ y los grupos fosfato cargados negativamente que contienen los oligos $\left(\mathrm{pK}_{\mathrm{a} 1}=2,1, \mathrm{pK}_{\mathrm{a} 2}=7,12, \mathrm{pK}_{\mathrm{a} 3}=12,7\right.$, valores relativos al ácido fosfórico $\left.{ }^{240,241}\right)$. Para comprobar la naturaleza de la unión se realizó un lavado con $\mathrm{HCl}$ diluído, tras el cual se observó la desaparición total de la señal para el PMMA3, corroborando que la unión de oligonuclétido es debida a interacciones de carácter débil (Figura 23).

En cuanto a la optimización de las condiciones de inmovilización, los mejores resultados se obtuvieron en $\mathrm{TC} 1 \times$ a $\mathrm{pH} 11$. Cuando se trabaja a valores de $\mathrm{pH}$ elevados todos los grupos amino del oligonucleótido se encuentran en forma de aminas libres $\left(\mathrm{pK}_{\mathrm{b}}=3-4\right)$, por lo que el ataque nucleofílico del grupo amino es muy efectivo. Por otro lado, trabajando a pHs inferiores a 7 , una parte de los grupos amino están en forma de sal amónica, impidiendo el ataque nucleofílico y la unión covalente. También se observó que al aumentar la fuerza iónica disminuía ligeramente el rendimiento de la inmovilización.

De manera análoga, se estudió la inmovilización de SYM23 sobre la superficie de los discos (estrategia R.1.2). Para ello, se utilizaron discos compactos lacados con PMMA sin tratar, activados con grupos hidroxilo y con grupos aldehido (PMMA, PMMA5 y PMMA6), empleando distintas condiciones de trabajo (pH y fuerza iónica). Se observó que el mayor rendimiento de inmovilización de la sonda se obtenía sobre PMMA6, consecuencia de la unión covalente del oligonucleótido a los grupos isocianato superficiales. Sin embargo, la señal obtenida para PMMA y PMMA5 resultó despreciable ( $<10 \%$ respecto al PMMA6). Los mejores resultados (Figura 24a) se obtuvieron al utilizar TC1× a pH 11. 


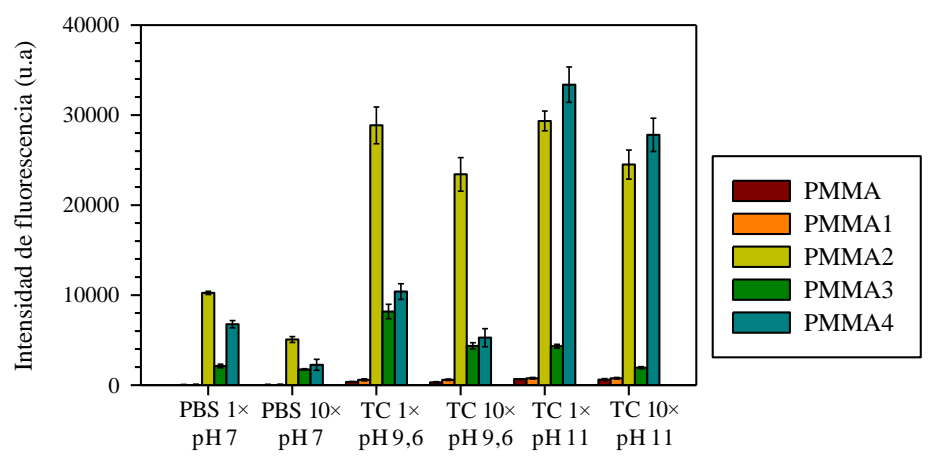

Figura 22. Comparación de las intensidades de fluorescencia de PMMA (sin tratar), PMMA1 (-OH), PMMA2 (-NCO), PMMA3 ($\mathrm{NH}_{2}$ ) y PMMA4 ( $-\mathrm{CHO}$ ) en diferentes tampones.

(a)

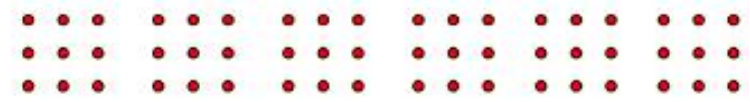

PBS $1 \times \quad$ PBS $10 \times \quad$ TC $1 \times \quad$ TC $10 \times \quad$ TC $1 \times \quad$ TC $10 \times$ $\begin{array}{llllll}\mathrm{pH} 7 & \mathrm{pH} 7 & \mathrm{pH} 9,6 & \mathrm{pH} 9,6 & \mathrm{pH} 11 & \mathrm{pH} 11\end{array}$

(b)

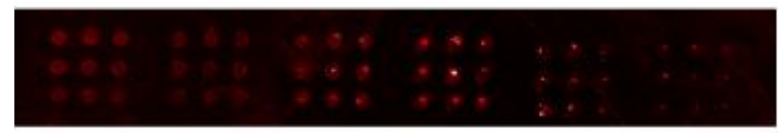

(c)

(d)
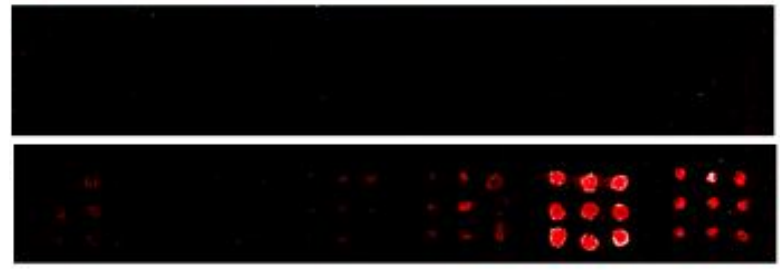

Figura 23. (a) Imagen de las matrices impresas sobre los chips, (b) oligo SYM23 (10 $\mu \mathrm{M})$ inmovilizado sobre PMMA3 antes de los lavados, (c) después de los lavados en medio ácido, (d) oligo SYM23 inmovilizado sobre PMMA4 después de los lavados en medio ácido. 
Paralelamente, con la finalidad de descartar la inmovilización pasiva por simple adsorción, se realizaron ensayos con el oligonucleótido SYM8 (marcado con Cy5 y sin grupo amino) sobre las superficies PMMA2, PMM4 y PMMA6. Los resultados mostraron que para los tiempos de incubación del ensayo la señal de fluorescencia resultó despreciable, concluyendo que no se produce la inmovilización pasiva de la sonda.

Las densidades de inmovilización estimadas (Apéndice I), fueron 1,6 pmol/ $\mathrm{cm}^{2}$ para PMMA2, $1,1 \mathrm{pmol} / \mathrm{cm}^{2}$ para PMMA4 y $2 \mathrm{pmol} / \mathrm{cm}^{2}$ para PMMA6, para una concentración de sonda $5 \mu \mathrm{M}$. Estos datos correlacionan bien con los encontrados en la literatura para vidrio ${ }^{242}\left(2 \mathrm{pmol} / \mathrm{cm}^{2}\right), \mathrm{PMMA}^{136}\left(4 \mathrm{pmol} / \mathrm{cm}^{2}\right)$ y oro ${ }^{243}(3$ $\mathrm{pmol} / \mathrm{cm}^{2}$ ).

Al comparar los resultados de inmovilización para la activación de PMMA con grupos isocianato, obtenidos sobre chips y sobre discos compactos (Figura 24b), se observó que para ambas rutas los resultados siguen la misma tendencia, siendo los valores obtenidos para las superficies de PMMA6 significativamente mejores. Este resultado era de esperar, teniendo en cuenta que la efectividad de una reacción llevada a cabo en fase líquida (homogénea) normalmente es mayor que trabajando en fase heterogénea. Así, la mayor densidad de grupos hidroxilo introducida tras la reacción de transaminación (R.1.2) respecto a la reducción con hidruro de litio y aluminio (R.1.1.), facilitó la formación de una capa más ordenada y compacta de organosilano, generándose un mayor número de grupos isocianato en las superficies y, por tanto, una mayor capacidad de inmovilización de sonda. 
(a)

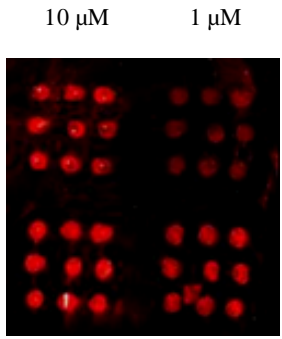

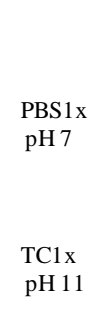

(b)

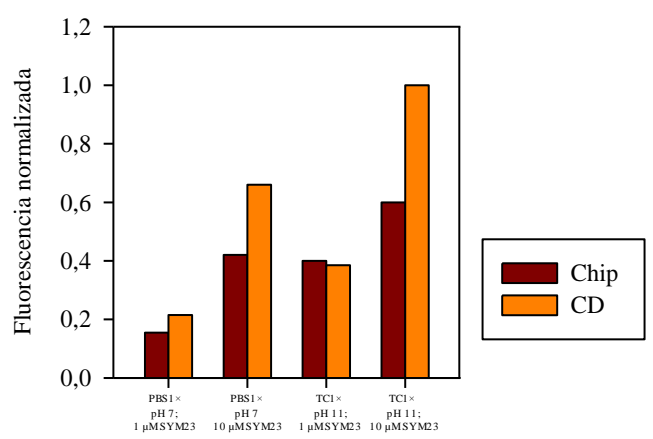

Figura 24. (a) imagen del oligo SYM23 inmovilizado sobre PMMA7 en distintos tampones y concentraciones. (b) Gráfica comparativa de la fluorescencia de las superficies de PMMA3 (formato chip) y PMMA7 (formato $\mathrm{CD}$ ), empleando distintos medios y concentraciones de oligonucleótido.

Por último, se procedió a lalectura con los discos químicamente activados y tapizados con oligonucleótidos con el lector de CDs, observándose que ésta tuvo lugar sin presentar errores internos de lectura. Así pues, puede concluirse que la activación química del PMMA no produce alteración significativa de las propiedades ópticas de la superficie, y que los discos tratados pueden ser empleados como plataformas analíticas empleando el lector de CDs como detector. Esta demostración abre el camino para la aplicación de la metodología de disco compacto utilizando CDs activados químicamente. Además, el uso de la química de los alcoxisilanos posibilita la introducción de un gran número de grupos funcionales (-SH, - $\mathrm{NCO},-\mathrm{NH}_{2}$, etc.), lo que hace muy versátil el anclaje de sondas sobre este material. 


\subsubsection{Estudios de inmovilización sobre PC}

Los ensayos de inmovilización de sondas sobre PC se llevaron a cabo en las condiciones descritas en el apartado 3.4.1. Para ello, se imprimieron micromatrices $3 \times 3$ del oligonucleótido SYM23 sobre los discos de PC activados con grupos aldehído (PC3), y sobre los soportes intermedios de la ruta R.2. (PC-PC2). En todos los casos fueron ensayadas diferentes concentraciones $(1-10 \mu \mathrm{M})$ y medios de reacción ( $\mathrm{pH}$ y fuerza iónica).

Tras la incubación durante $1 \mathrm{~h}$ a $37{ }^{\circ} \mathrm{C}$ y posterior lavado con PBS-T para eliminar los residuos de sonda no inmovilizada, se llevó a cabo la lectura de fluorescencia mediante EF. Los resultados indicaron que los controles PC y PC1 no mostraron ninguna señal, mientras que para PC2 se observó señal de fluorescencia residual (Figura 25a). Sin embargo, la señal es muy inferior a la obtenida en PC3 (Figura 25b), probablemente debido a que el oligonucleótido marcado se queda retenido mediante interacciones débiles (a través de los grupos fosfatos cargados negativamente del oligo sobre la superficie protonada de los grupos amino ${ }^{240,241}$, a diferencia de PC3 donde se produce la unión covalente entre el grupo amino del oligo y los grupos aldehído de la superficie mediante la formación de una base de Schiff.

En la Figura 25b se compara la intensidad de fluorescencia para PC2 y PC3, en distintas condiciones de $\mathrm{pH}$ y fuerza iónica. De forma análoga a lo observado sobre las superficies tratadas de PMMA, los resultados indicaron que el incremento de la fuerza iónica del medio produce una disminución del rendimiento en la inmovilización, y que a valores de $\mathrm{pH}$ alrededor de 11 se produce el máximo rendimiento de inmovilización, hecho que concuerda con que a $\mathrm{pH}$ más básico existe un equilibrio entre los grupos amino libre y los protonados $\left(\mathrm{pK}_{\mathrm{b}} \sim 3-4\right)$, mientras que a $\mathrm{pH}<10$ los grupos amino estarán en su mayoría protonados impidiendo el ataque nucleófilo, lo que hace imposible la unión covalente. 
(a)

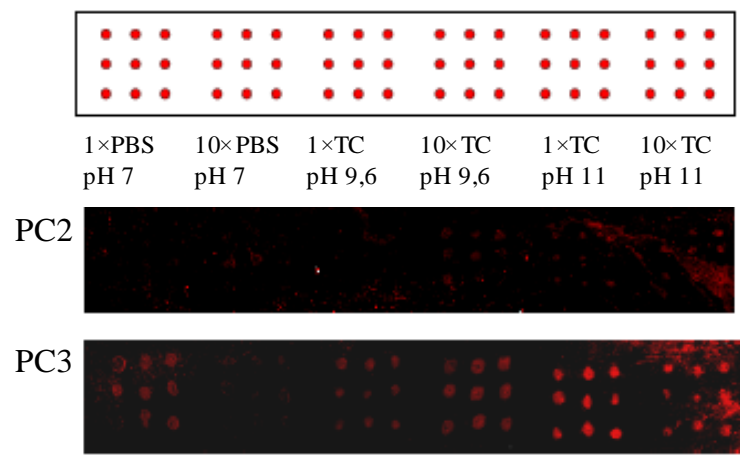

(b)

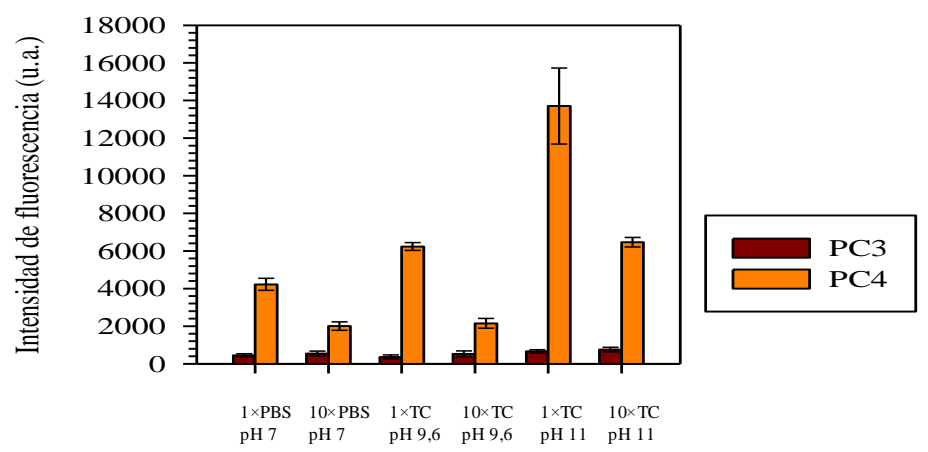

Figura 25. (a) Resultados de la inmovilización de SYM23 (10 $\mu \mathrm{M}$ ) sobre PC2 y PC3. (b) Gráfica comparativa de las intensidades de fluorescencia de PC2 y PC3 en diferentes medios. 
Paralelamente, se realizaron controles de inmovilización de SYM8 (oligonucleótido sin grupo amino) sobre PC3. Los resultados obtenidos demostraron que no se detecta adsorción pasiva del oligo sobre la superficie aldehizada, confirmando la unión covalente del oligonucleótido SYM23.

Otro aspecto clave a tener en cuenta se debe a que, aunque conceptualmente se forma un enlace imina, la reacción no es reversible, como cabría esperar en este tipo de enlace. Este hecho se debe a que el glutaraldehído tiende a polimerizar, y a valores de $\mathrm{pH}$ básicos tendremos una mezcla de derivados poliméricos con diferentes longitudes, conteniendo grupos aldehído $\alpha, \beta$-insaturados susceptibles de sufrir una adición nucleofílica por parte de la amina al $\mathrm{C}_{\beta}$. El resultado de esta unión es un enlace tipo amino, confiriendo por tanto irreversibilidad a la unión. $^{244,245}$

Los rendimientos de inmovilización, estimados a partir de la interpolación en las curvas de calibrado de SYM23 (Apéndice I) para una concentración de sonda inmovilizada de $5 \mu \mathrm{M}$, se estimaron en $2,2 \mathrm{pmol} / \mathrm{cm}^{2}$, similar a los encontrados en la literatura para este tipo de superficies $\left(5,3 \mathrm{pmol} / \mathrm{cm}^{2}\right)^{246}$.

\subsubsection{Estudios de hibridación de sondas de oligonucleótidos}

Una vez optimizados los procesos de inmovilización de sondas de oligonucleótidos, se procedió a estudiar la aplicabilidad de los materiales preparados para el desarrollo de genechips, que -como se ha comentado anteriormente- consisten en un gran número de fragmentos de ADN de una sola hebra ordenados en un sustrato sólido de manera que formen una matriz de secuencias en dos dimensiones. Durante el proceso de hibridación, las muestras de material genético marcadas se unirán a sus complementarias inmovilizadas, permitiendo la identificación y cuantificación del ADN presente en la muestra. 
En este trabajo, las metodologías desarrolladas basadas en materiales poliméricos se han clasificado en dos tipos, en función del soporte de ensayo: chip o disco compacto. Los distintos oligonucleótidos empleados se muestran en la Tabla 13.

Para la detección y cuantificación de sondas de ADN en chip se utilizaron los oligos, SYM22 y SYM8, marcados con Cy5; para los ensayos de hibridación en formato CD se usaron los oligos SYM22 y SYM25; mientras que para la discriminación de SNPs se utilizó el oligo SYM26, análogo a SYM25 en todas menos en una de las bases nitrogenadas situada en el centro de la cadena. Para la detección y cuantificación sobre disco compacto, se optó por el par biotinaestreptavidina. Mediante este sistema la molécula biotina conjugada al oligo reconoce específicamente a la estreptavidina. El marcaje de esta última con la especie adecuada permitirá la detección mediante el lector de CDs.

Tabla 13. Sondas de oligonucleótidos empleadas en los ensayos de hibridación.

\begin{tabular}{c|ccc}
\hline Nombre & Secuencia (5'to 3') & Extremo 5, & Extremo 3' \\
\hline \hline SYM8 & AATGCTAGCTAATCAATCGGG & Cy5 & Ninguno \\
SYM22 & $\left(\right.$ T) ${ }_{15}$ CCCGATTGATTAGCTAGCATT & $-\mathrm{NH}_{2}$ & Ninguno \\
SYM25 & AATGCTAGCTAATCAATCGGG & Biotina & Ninguno \\
SYM26 & AATGCTAGATAATCAATCGGG & Biotina & Ninguno \\
\hline
\end{tabular}

\subsubsection{Ensayos de hibridación en genechips: Detección fluorimétrica}

Para los ensayos de hibridación se empleó PMMA derivatizado con grupo isocianato (PMMA2) según la ruta R.1.1.1 descrita en el apartado 3.4.1.3. Para ello, se imprimieron dieciocho réplicas ( 2 matrices, $3 \times 3$ puntos) del oligo sonda $S Y M 22$ en TC $1 \times$, en un amplio intervalo de concentraciones $(1,5,10$ y $20 \mu \mathrm{M})$, utilizando 
un sistema manual de impresión por contacto. Tras el bloqueo de los grupos residuales activos (-CNO ó - $\mathrm{CHO}$ ) con OVA, se llevaron a cabo los ensayos de hibridación del oligo de cadena complementaria SYM8 marcado con Cy5, ensayando diferentes concentraciones $(0,1 ; 0,2 ; 0,5$ y $1 \mu \mathrm{M})$. La lectura del resultado del ensayo se realizó con un escáner de fluorescencia tratando los datos con el software Genepix 6.0.

Para la estimación del rendimiento total de hibridación, detallado en el Apéndice I, fue necesario conocer la cantidad de sonda SYM22 inmovilizada. Por ello, además de los calibrados llevados a cabo con SYM8, se realizaron calibrados con el oligonucleótido SYM23, de cadena análoga a SYM22 pero marcado con Cy5. Para la estimación de las densidades de inmovilización $\left(\mathrm{pmol} / \mathrm{cm}^{2}\right.$ ) e hibridación a partir de las respectivas curvas de calibrado, se tuvo en cuenta el radio medio de cada matriz, considerando un volumen medio de gota de $50 \mathrm{~nL}$.

En la Figura 26a se esquematiza el ensayo, mientras que en la 26b se muestran los valores de señal obtenida para diferentes concentraciones de SYM22 y SYM8. Los mejores resultados se obtuvieron para concentraciones $5 \mu \mathrm{M}$ de SYM22, no observando ninguna mejora significativa en la eficiencia de la hibridación a concentraciones superiores. Además, experimentalmente se observó que para concentraciones superiores a $20 \mu \mathrm{M}$, los puntos presentan un halo de fluorescencia y una oquedad negra en el centro, además de una menor reproducibilidad. Probablemente, ello se debe a que una alta densidad de oligonucleótido inmovilizado provoca un impedimento estérico (dificultando el acceso del oligonucleótido de cadena complementaria) y un aumento de las interacciones electrostáticas, lo que puede incrementar la adsorción inespecífica alrededor de la zona de ensayo $^{240,247}$. 
(a)

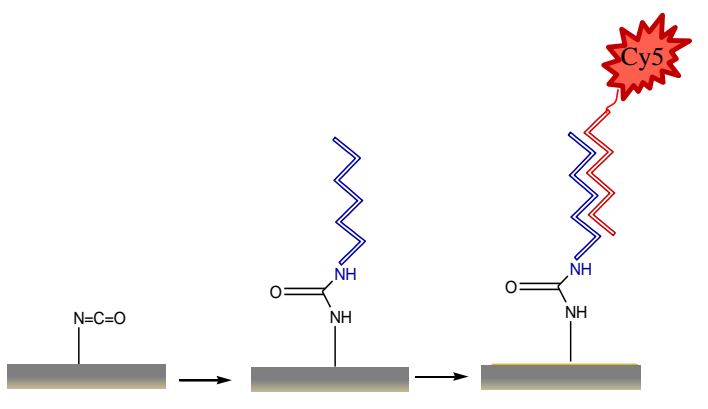

(b)

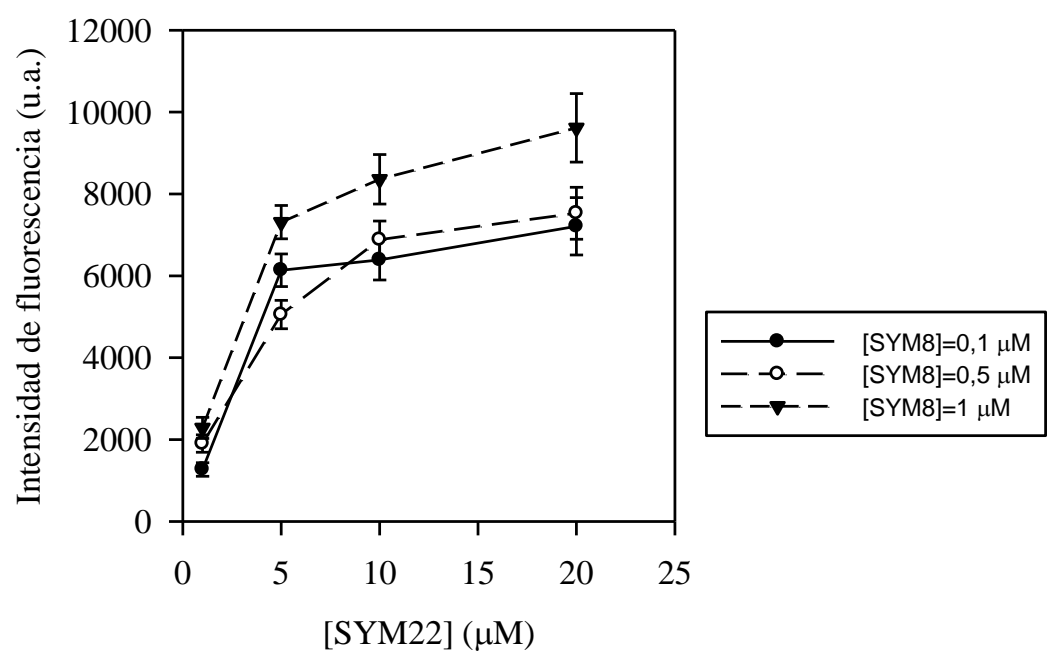

Figura 26. (a) Esquema del ensayo de hibridación, (b) intensidad de la señal para diferentes concentraciones de oligonucleótido SYM22 y SYM8.

Las densidades de hibridación obtenidas para una concentración $5 \mu \mathrm{M}$ de sonda SYM22 y 0,1 $\mu \mathrm{M}$ de oligonucleótido complementario SYM8 oscilaron entre 0,3$0,4 \mathrm{pmol} / \mathrm{cm}^{2}$, resultado que concuerda con estudios previos realizados sobre superficies de PMMA químicamente $\operatorname{modificadas}^{136}$. Estos valores suponen un 
rendimiento de hibridación del $20 \%$. Las desviaciones estándar relativas intrachip, para una media de dieciocho réplicas ( 2 matrices de $3 \times 3$ ) oscilaron entre 7 y $18 \%$, mientras que para 6 réplicas realizadas en diferentes días se obtuvieron desviaciones estándar relativas interchip del 12\%. Estos valores dan una idea de la elevada reproducibilidad de la metodología desarrollada. En la Tabla 14 se muestran los valores de densidad de inmovilización obtenidos para SYM22 y el rendimiento de hibridación de SYM8 sobre superficies de PMMA activadas con grupo isocianato (PMMA2), siendo comparables con los resultados recogidos en la bibliografía para distintos materiales.

Finalmente se quiso comprobar la eficacia de la hibridación realizando diferentes controles eliminando alguno de los pasos del ensayo. En un primer control se omitió el tratamiento de derivatización química, en el segundo la inmovilización de SYM22, en el tercero el bloqueo con OVA y, en el cuarto, la hibridación con la cadena complementaria. Tal y como cabía esperar, no se observó señal significativa en ningún caso, a excepción del control en el que se eliminó la etapa de bloqueo con OVA, para el que se registró un elevado ruido de fondo como consecuencia de la unión inespecífica del oligonucleótido.

Tabla 14. Estudio comparativo de los resultados obtenidos sobre PMMA6 con los recogidos en la literatura para distintos materiales.

\begin{tabular}{|c|c|c|c|}
\hline Sonda & $\begin{array}{c}\text { Densidad } \\
\text { inmovilización } \\
\text { pmol/cm }\end{array}$ & $\begin{array}{c}\text { Rendimiento de } \\
\text { hibridación } \\
\%\end{array}$ & Referencias \\
\hline SYM 22 & 1,6 & -- & $\begin{array}{l}\left(\mathrm{pmol} / \mathrm{cm}^{2}\right) \\
2(\text { vidrio })^{242} ; 2-4(\text { PMMA })^{248,136} \\
; 3(\text { Gold })^{243} ; 5(\mathrm{PC})^{246}\end{array}$ \\
\hline SYM 8 & $0.3-0.4$ & $\sim 20$ & $\begin{array}{l}\text { \% Rendimiento de hibridación } \\
7.5-10 \%(\mathrm{PMMA})^{48,136}, 43 \% \\
(\mathrm{PC})^{48}, 32-56 \%\left(\mathrm{SiO}_{2}\right)^{249}\end{array}$ \\
\hline
\end{tabular}




\subsubsection{Ensayos de hibridación en disco: Detección mediante tecnología de CDs}

Para el desarrollo de ensayos de hibridación utilizando tecnología de CDs para la lectura del ensayo, diferenciamos dos formatos de trabajo diferentes. En ambos la lectura del ensayo se efectuó mediante transmisión (ver apartado 1.5.3), utilizando el propio haz láser del lector de CDs como fuente y un fotodiodo anexionado en la cara interior opuesta del lector como detector. Ello permite la lectura de la señal inmunoquímica a partir de la variación de la intensidad de la luz transmitida.

En una primera aproximación las hibridaciones se desarrollaron directamente sobre la cara superior de discos semitransparentes, previa deposición de una película de PMMA activada con grupos isocianato (PMMA6) según la Ruta 1.2. Mientras que en la segunda metodología, intermedia entre formato tipo chip y basados en tecnología CD, se emplearon como plataformas de ensayo discos de PC aldehizados (PC3) mediante la Ruta 2 que fueron acoplados a CDs semitransparentes para la lectura del ensayo.

Los ensayos de hibridación en disco se llevaron a cabo tal y como se describe en el apartado 3.4.1.4. de la Parte Experimental. El oligonucleótido SYM22 se inmovilizó covalentemente sobre los discos a diferentes concentraciones $(1$ a 20 $\mu \mathrm{M})$ en TC $1 \times \mathrm{pH} 11$. Cada disco, tal y como muestra la Figura 27a, fue dividido en 8 zonas y en cada una se imprimieron 8 micromatrices de $3 \times 3$. Tras una etapa de bloqueo de los grupos activos residuales de la superficie mediante OVA, se procedió a la hibridación con SYM25 (oligonucleótido biotinilado de cadena complementaria a SYM22). Para ello, cada zona fue tratada con diferentes concentraciones de oligonucleótido (de 0,2 a $0,001 \mu \mathrm{M}$ ) y, tras una hora a $37^{\circ} \mathrm{C}$, se incubaron $30 \mathrm{~min}$ con estreptavidina-HRP. Finalmente, se efectuó el revelado con TMB durante 6 minutos. La aparición de un precipitado azul oscuro fue indicativo de la presencia de HRP y, por tanto, de la efectividad en la hibridación, pudiendo 
relacionar la mayor o menor abundancia de precipitado con la extensión de la hibridación. Los discos fueron escaneados con el lector de CDs, de modo que el precipitado formado se relaciona con la disminución en la transmitancia del haz láser del lector en aquellas micromatrices donde se produce hibridación. En el caso del soporte PC3, tras la realización de los ensayos éste fue acoplado a la cara superior de un CD-Au para su lectura (Figura 27b).

El empleo de oligonucleótidos biotinilados permitió determinar la eficacia de hibridación, correlacionando la intensidad de la señal con la cantidad de precipitado formado $\mathrm{y}$, por tanto, con el número de cadenas biotiniladas hibridadas. Alternativamente, se empleó como trazador estreptavidina marcada con Au, que tras el revelado con una mezcla de $\mathrm{Ag}^{+}$e hidroquinona, genera un precipitado negro consecuencia de la reacción de reducción de $\mathrm{Ag}^{+} \mathrm{a} \mathrm{Ag}^{0}$, catalizada por la presencia de Au.

En la elección del marcador, aunque debe ser optimizada sobre cada superficie y para cada sistema, se observó que, en general, utilizando Au como marcador se obtenían precipitados más estables que no perdían intensidad tras los lavados, así como fondos más bajos y mejor relación señal/ruido, y por tanto mayor exactitud. Sin embargo, usando HRP se alcanza mejor sensibilidad, ya que se trata de una reacción enzimática que rinde mayor amplificación de la señal. En este caso se empleó estreptavidina-HRP para el revelado de los ensayos desarrollados sobre las superficies de PMMA6, mientras que para PC3 se optó por el sistema Au/Ag debido elevado ruido de fondo que se obtuvo usando HRP. 
(a)

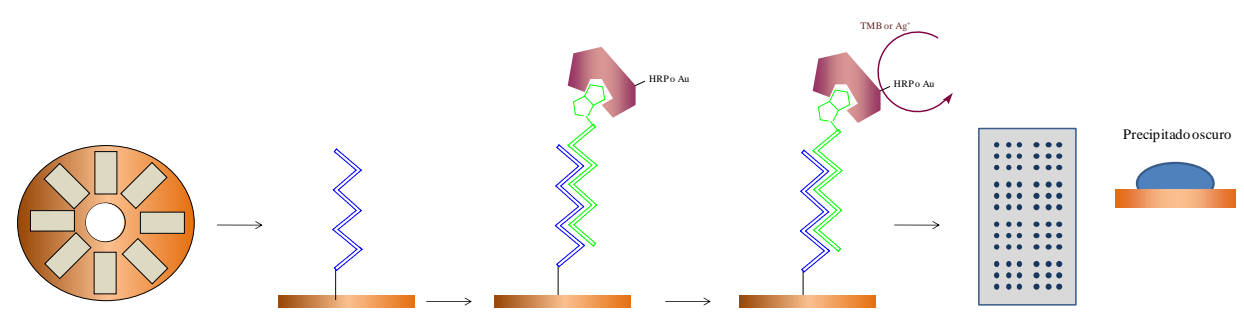

(b)
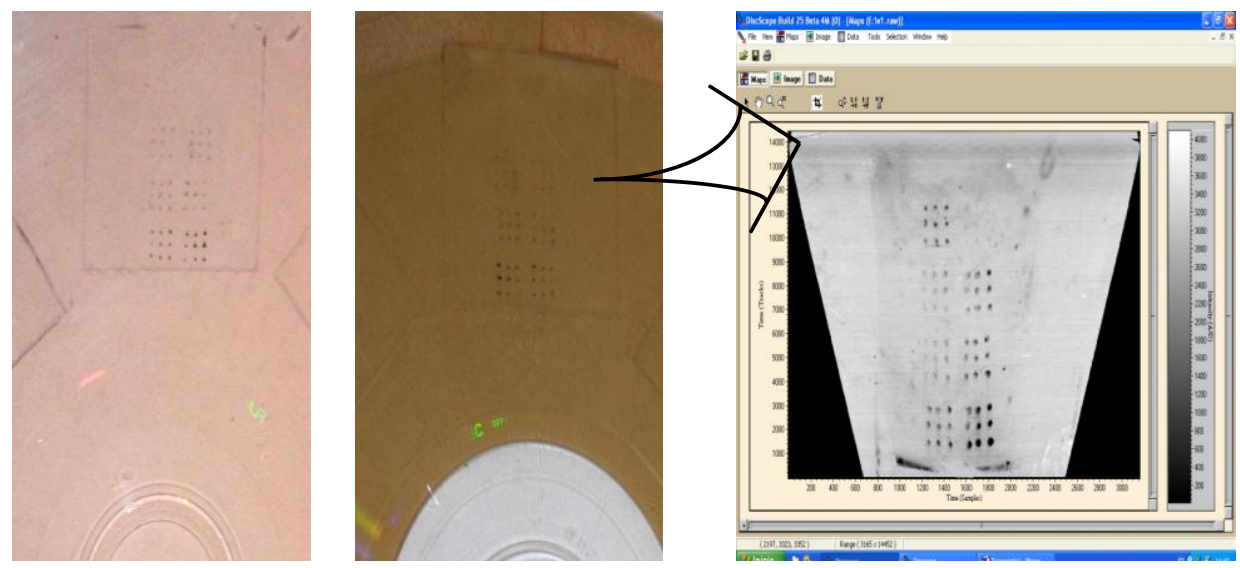

Figura 27. (a) Esquema del ensayo de hibridación sobre disco compacto. (b) Imagen de los resultados obtenidos para PC3.

Para comprobar la especificidad de la hibridación se realizaron diferentes controles omitiendo alguna de las etapas del proceso: tratamiento químico (control 1), inmovilización de SYM22 (control 2), bloqueo con OVA (control 3) y, finalmente, tratamiento con la cadena complementaria (control 4). Tal y como cabía esperar, todos los controles dieron negativos, a excepción del control 3. Sin embargo, el elevado ruido de fondo para este último debido a la ausencia de bloqueo, dificultó la lectura del ensayo. 
En la Figura 28, se representa la variación de la señal de hibridación empleando distintas concentraciones de SYM22 y SYM25 sobre superficies de PMMA6 (Figura 28a) y PC3 (Figura 28b). En ellas se observa que para ambos materiales los mejores resultados se obtuvieron para una concentración $5 \mu \mathrm{M}$ de sonda inmovilizada SYM22. Concentraciones superiores de SYM22 no producen ninguna mejora significativa en la hibridación, probablemente debido a que una alta densidad de oligonucleótido inmovilizado puede generar un aumento de las interacciones eletrostáticas y estéricas, dificultando el acceso del oligonucleótido de cadena complementaria. Los límites de detección alcanzados fueron $5 \mathrm{nM}$ para PMMA y 2,5 nM para PC.

Para evaluar la reproducibilidad de los tratamientos efectuados sobre las superficies de disco compacto, se calculó la desviación estándar relativa intradisco tomando una media de 108 réplicas (puntos por disco), para una concentración 5 $\mu \mathrm{M}$ de sonda SYM 22 y $0,05 \mu \mathrm{M}$ de SYM25, obteniéndose valores de $22-29 \%$ en PMMA y de 11-13\% en PC. La desviación estándar relativa interdisco, para un total de 9 réplicas realizadas en diferentes días, fue del 27\% para PMMA y 19\% para PC. Los datos obtenidos permiten concluir que se alcanza una mayor reproducibilidad y sensibilidad con la metodología desarrollada para superficies de policarbonato.

En la Figura 29 se compara la intensidad de la señal de hibridación para diferentes concentraciones de oligo sonda obtenida para los soportes estudiados (PMMA2, PMMA6 y PC3). Los mejores resultados se observan a partir de una concentración de sonda $5 \mu \mathrm{M}$, sin mostrar mejoras significativas a mayores concentraciones de sonda inmovilizada. En esta gráfica solo debemos considerar las tendencias a nivel cualitativo, ya que para cada una de las superficies se ha empleado un marcaje distinto.

Los resultados presentados en la Tabla 15 muestran las sensibilidades (usando como criterio los límites de detección alcanzados) para los distintos soportes. En 
ella se observa que los mejores límites de detección fueron obtenidos para PMM6 y PC3, lo que da una idea de las buenas prestaciones de las metodologías basadas en tecnología de CD.

(a)

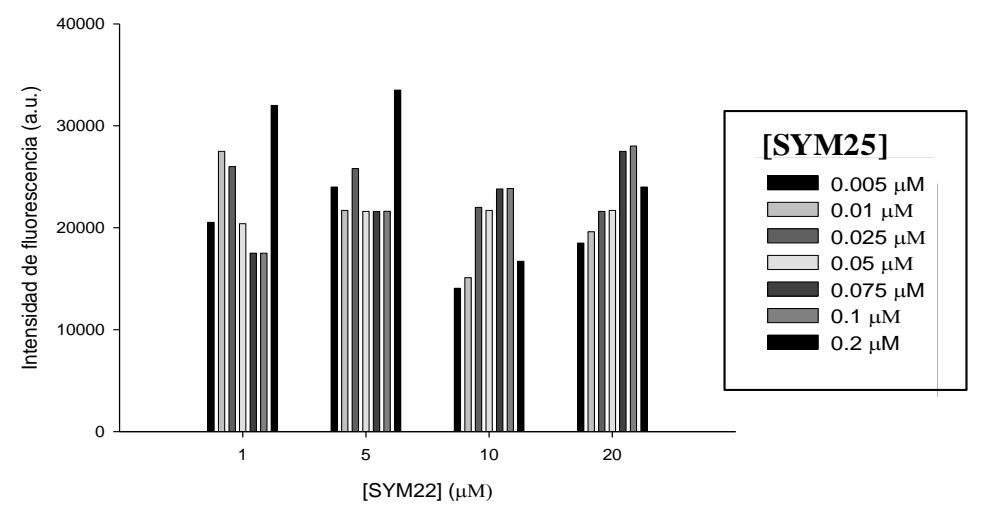

(b)

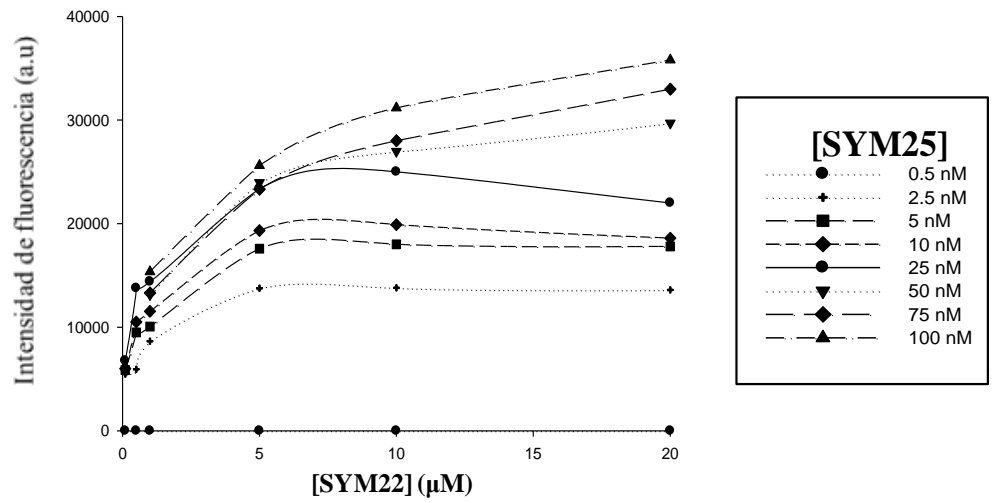

Figura 28. Extensión de la hibridación (intensidad de la fluorescencia) efectuada sobre superficies de PMMA6 (a) y PC3 (b) a diferentes concentraciones de oligo SYM22 y SYM25. 


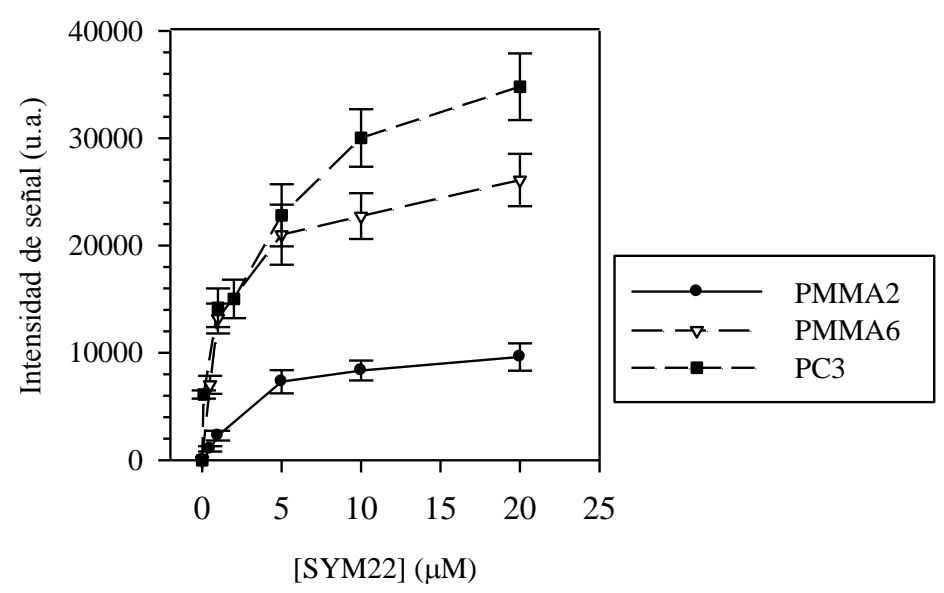

Figura 29. Intensidad de la señal de hibridación para diferentes concentraciones de oligonucleótido sonda (SYM22) y distintos soportes (PMMA2, PMMA6 y PC3). [SYM8] y [SYM25]= 0,1 $\mu$ M.

Tabla 15. Límite de detección (LDD) y desviación estándar relativa (DER) de los ensayos desarrollados en chip (PMMA2), disco (PC3) y disco compacto (PMMA6)

\begin{tabular}{c|ccc||}
\hline & $\boldsymbol{L D D}(\boldsymbol{n M})$ & $\boldsymbol{D E R}_{\text {intra }}(\boldsymbol{\%})$ & $\boldsymbol{D E R}_{\text {inter }}(\boldsymbol{\%})$ \\
\hline \hline PMMA2 & 10 & $7-18$ & 12 \\
PMMA6 & 5 & $22-29$ & 27 \\
PC3 & 2,5 & $11-13$ & 19 \\
\hline
\end{tabular}




\subsubsection{Ensayos de detección de polimorfismos de una sola base (SNPs) sobre discos de PC}

Tras la optimización de los procesos de hibridación, se estudió la aplicabilidad de la metodología para la discriminación de polimorfismos de una sola base (SNPs). Esta técnica, de gran utilidad en el campo de la genómica, tiene aplicaciones en la detección de organismos genéticamente modificados (GMOs), o la diferenciación de virus o bacterias procedentes de distintas cepas, entre otras.

Para los ensayos de discriminación de SNPs se emplearon los oligos SYM22 y SYM25, así como el oligo SYM26 que difiere de SYM25 en la base nitrogenada número nueve (se ha sustituido citosina por adenina). Los ensayos se efectuaron sobre superficies de PC3 activadas con grupos aldehído según la ruta R.2, dada la robustez, reproducibilidad y elevada sensibilidad alcanzada en los ensayos de hibridación.

Los ensayos de discriminación de SNPs, se llevaron a cabo en las condiciones descritas en el apartado 3.4.1.5. Para ello, los discos se dividieron en 8 zonas sobre las que se inmovilizó la sonda SYM22 (matrices $3 \times 3$ de 0,1 a $5 \mu \mathrm{M}$ ). Tras un bloqueo de los grupos activos residuales con OVA, las diferentes zonas impresas se incubaron con SYM25 y SYM26 $\left(0,05-5 \cdot 10^{-4} \mu \mathrm{M}\right)$ en tampón SSC6×, 0,6\% SDS, $0,1 \%$ ADN de esperma de salmón, $2 \%$ de BSA y $25 \%$ de formamida. Finalmente, se añadió estreptavidina-Au y se reveló con plata. Los resultados obtenidos se registraron con ayuda del lector de CDs. Para la puesta a punto del ensayo se optimizaron diferentes variables, como la concentración de formamida en la matriz de hibridación, la temperatura y el tiempo de hibridación.

La formamida es un agente que permite mejorar la selectividad de los ensayos de SNPs. Ello es debido a que este compuesto dificulta la formación de puentes de hidrógeno, que son los responsables del enlace entre las cadenas. Por lo tanto, para obtener una hibridación en presencia de formamida ambos oligonucleótidos han de 
ser totalmente complementarios. Con esta finalidad, se ensayaron concentraciones de formamida comprendidas entre 0 y $25 \%$, observando que al aumentar la concentración la discriminación era mayor, siendo total para un 25\% de formamida.

La temperatura es un factor determinante en la hibridación. A temperaturas demasiado elevadas, no tiene lugar, mientras que temperaturas demasiado bajas tienden a favorecer hibridaciones inespecíficas, alterando la especificidad de la reacción. La temperatura óptima tiene que ser lo suficientemente baja para permitir la hibridación específica entre la sonda inmovilizada y su secuencia complementaria, pero no demasiado para evitar hibridaciones no específicas. Por ello, se realizaron varios ensayos entre 25 y $60^{\circ} \mathrm{C}$ con el fin de establecer la temperatura óptima de discriminación de SNPs, observando que ésta era máxima en el intervalo entre 40 y $50{ }^{\circ} \mathrm{C}$. Estos resultados correlacionan con lo esperado, teniendo en cuenta que la temperatura óptima de hibridación debe ser $5-8{ }^{\circ} \mathrm{C}$ más baja que la de fusión $\left(\mathrm{T}_{\mathrm{m}}\right)$, cuyo valor puede estimarse a partir de la ecuación de Wallace $\left(\mathrm{T}_{\mathrm{m}}=2(\mathrm{~A}+\mathrm{T})+4(\mathrm{G}+\mathrm{C})\right.$; siendo $\mathrm{A}, \mathrm{T}, \mathrm{G}$ y $\mathrm{C}$ el número de oligonucleótidos de cada tipo $)^{250}$. Teniendo en cuenta que los resultados no son exactos, ya que la validez de la ecuación de Wallace es exclusivamente para oligonucleótidos cuyo número de bases nitrogenadas oscile entre 18 y 26 , el valor aproximado de $\mathrm{T}_{\mathrm{m}}$ para la sonda SYM 22 fue de $60^{\circ} \mathrm{C}$.

Paralelamente se ensayaron distintos tiempos de incubación comprendidos entre 30 minutos y 4 horas, observando que para valores inferiores a $1 \mathrm{~h}$ la señal de hibridación era débil. Las condiciones óptimas seleccionadas para la discriminación de SNPs fueron tiempos de incubación de 1 hora a $40{ }^{\circ} \mathrm{C}$, empleando una concentración de formamida en la disolución de hibridación del 25\%. En estas condiciones fue posible discriminar entre los oligonucleótidos SYM25 y SYM26 hasta concentraciones de $0,0025 \mu \mathrm{M}$, resultados comparables a los obtenidos mediante las técnicas de referencia ${ }^{48}$. 
Estos resultados avalan el principal objetivo de este trabajo mostrando el potencial de la tecnología de disco compacto para el desarrollo de sistemas de análisis competitivos.

\subsubsection{Aplicaciones en inmunoensayo: Detección de gripe aviaria}

\subsubsection{Ensayos de detección de gripe aviaria utilizando tecnología de DVD}

Los virus de la gripe aviaria pertenecen al género Influenza, familia Orthomyxoviridae. Esta familia incluye tres tipos de virus (A, B y C) en función del carácter antigénico de una nucleoproteína interna. Los virus tipo A son los patógenos más agresivos de los tres géneros que pueden provocar la enfermedad, y aunque los huéspedes naturales de los diferentes subtipos son las aves, en ocasiones pueden transmitirse a humanos.

Todos los virus influenza A están clasificados de acuerdo con las dos proteínas que se encuentran en su cápside: Hemaglutinina $(\mathrm{H})$ y Neuraminidasa $(\mathrm{N})$. Todos contienen ambas proteínas, pero la estructura de las mismas difiere cepa a cepa debido a una rápida mutación del genoma viral. Las cepas tienen asignada una nomenclatura basada en la estructura H-número N-número, según las variantes de las dos proteínas que contienen. Hay dieciséis subtipos $\mathrm{H}$ y nueve $\mathrm{N}$ conocidos en aves, pero únicamente tres subtipos $\mathrm{H}$ y dos $\mathrm{N}$ han sido confirmados en humanos, siendo los más frecuentes $\mathrm{H}_{1} \mathrm{~N}_{1}, \mathrm{H}_{3} \mathrm{~N}_{2}$ y $\mathrm{H}_{5} \mathrm{~N}_{1}$.

Los métodos de detección viral incluyen aislamiento y propagación en cultivos celulares, test de inhibición de la hemaglutinina, o la transcriptasa inversa RT-PCR, entre otros. Aunque estos métodos son efectivos, generalmente utilizan mano de obra cualificada y procedimientos largos. Por tanto, el desarrollo de biosensores permitiría el diagnóstico rápido y específico de la enfermedad, de manera que un 
especialista pudiera determinar inmediatamente la necesidad de tratamiento. Además, el empleo de la tecnología de disco compacto posibilita la detección simultánea de virus de distintas cepas, o bien de anticuerpos y virus en una misma muestra, facilitando el seguimiento de la enfermedad de manera efectiva.

Para la puesta a punto de los ensayos de detección de gripe aviaria se trabajó sobre la superficie de PC de DVDs comerciales, empleando la metodología descrita en el apartado 1.5.3, basada en la detección de la señal reflejada por el disco. Esta metodología utiliza el propio haz láser del lector como fuente de emisión y detector. Empleando DVDs como plataformas analíticas se trabaja a longitudes de onda más energéticas que con CDs, permitiendo un enfoque del láser mucho más preciso sobre la superficie y, por lo tanto, una mayor resolución óptica.

Para la detección de gripe aviaria en DVD, se desarrolló un inmunoensayo en formato sándwich (Figura 30) no competitivo, empleando un anticuerpo monoclonal de ratón $\left(\mathrm{mAb}\left(\mathrm{H}_{1} \mathrm{~N}_{1}\right)\right.$ y virus inactivos correspondientes a una vacuna antigripal de las correspondientes cepas. El anticuerpo monoclonal actúa tanto de elemento de captura, como de anticuerpo de detección, tras un marcaje con biotina siguiendo el protocolo de la casa comercial que suministró los reactivos. Ello es debido a que el virus de la gripe aviaria tiene la particularidad de ser multivalente y poseer más de un epítopo o zona de reconocimiento.

Los DVDs comerciales fueron funcionalizados según se describe en la ruta R.2 del apartado 4.1.1. para modificación química de PC, cuyo potencial ha sido demostrado en los estudios precedentes. Así, tras una etapa de nitración utilizando la mezlca $\mathrm{HNO}_{3} / \mathrm{H}_{2} \mathrm{SO}_{4}$ y una reducción con $\mathrm{NaBH}_{4}$, los discos fueron activados con grupos aldehído mediante tratamiento con glutaraldehído. Los ensayos en formato sandwich fueron llevados a cabo siguiendo el procedimiento descrito en el apartado 3.5.1. Para ello, los discos fueron divididos en ocho zonas y sobre cada una de ellas se inmovilizó una matriz $2 \times 8$ de $m A b\left(H_{1} N_{1}\right)$, además de una fila 
adicional de anticuerpo marcado con biotina $m A b\left(\mathrm{H}_{1} \mathrm{~N}_{1}\right)$-BT y otra de anticuerpo de cabra anti-conejo (GAR), como controles de revelado positivo y negativo, respectivamente. Sobre cada una de las zonas de trabajo se adicionaron diferentes concentraciones de virus inactivos, correspondientes a una vacuna antigripal de las cepas $\mathrm{H}_{1} \mathrm{~N}_{1}$, en el intervalo de 0 a $2 \mu \mathrm{g} / \mathrm{mL}$. Los DVDs se incubaron durante 15 minutos, y tras los lavados, se trataron con $\mathrm{mAb}\left(\mathrm{H}_{1} \mathrm{~N}_{1}\right)$ - $\mathrm{BT}$ y, posteriormente, con estreptavidina-HRP. Finalmente, tras un revelado con TMB, la aparición de un precipitado oscuro en aquellas matrices en las que se produce detección del virus, permite correlacionar la intensidad de la señal con la extensión de la reacción de reconocimiento biológico. Los DVDs fueron escaneados con el lector de CDs, generándose una imagen en escala de grises que, tras tratamiento, pudo ser cuantificada utilizando el programa Genepix 6.0.

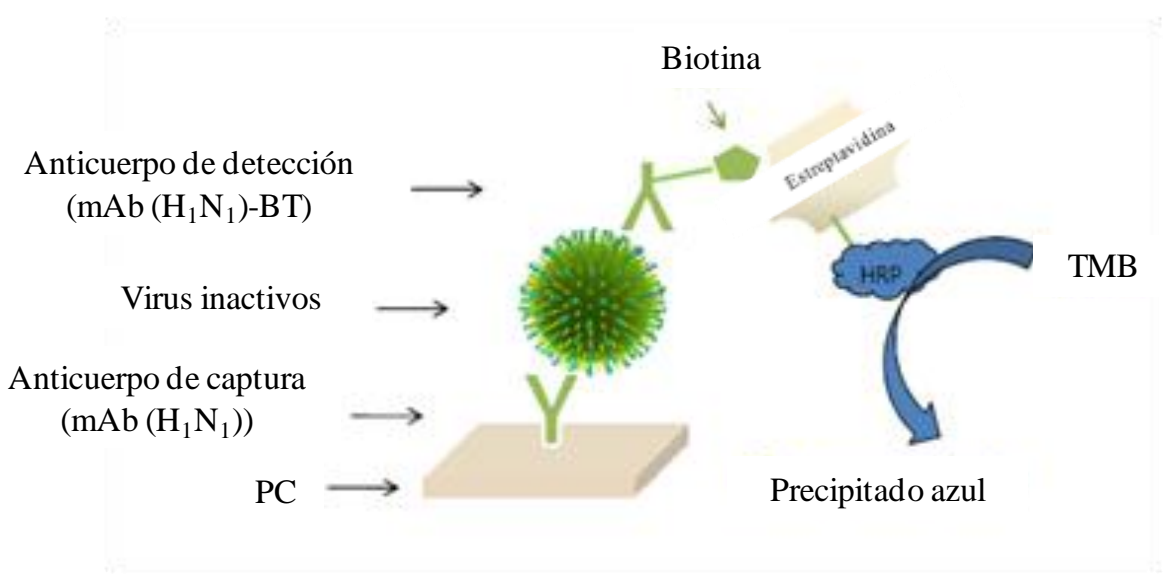

Figura 30. Esquema del inmunoensayo sandwich no competitivo para la detección para la gripe aviaria. 
Para la optimización del inmunoensayo se realizaron varias curvas de saturación del virus de la gripe a diferentes concentraciones de anticuerpo de captura mAb $\left(\mathrm{H}_{1} \mathrm{~N}_{1}\right)$. Para estos experimentos, las concentraciones de anticuerpo de detección $\mathrm{mAb}\left(\mathrm{H}_{1} \mathrm{~N}_{1}\right)$-BT y de estreptavidina-HRP fueron previamente optimizadas. De este modo, para una concentración de $\mathrm{mAb}\left(\mathrm{H}_{1} \mathrm{~N}_{1}\right)$ de $20 \mu \mathrm{g} / \mathrm{mL}$, y de virus inactivo de $250 \mu \mathrm{g} / \mathrm{mL}$, se estudió un amplio intervalo de concentraciones de $\mathrm{mAb}\left(\mathrm{H}_{1} \mathrm{~N}_{1}\right)$-BT $(0,5 ; 1 ; 5 ; 10 \mu \mathrm{g} / \mathrm{mL})$ y de estreptavidina-HRP $(0,1 ; 2,5 ; 5 ; 10 \mu \mathrm{g} / \mathrm{mL})$. De las dieciséis posibles combinaciones se seleccionaron aquellas que produjeron mayor intensidad de señal para valores $\mathrm{SNR}>25$. Los resultados obtenidos fueron: 5 $\mu \mathrm{g} / \mathrm{mL}$ de $\mathrm{mAb}\left(\mathrm{H}_{1} \mathrm{~N}_{1}\right)$-BT y $10 \mu \mathrm{g} / \mathrm{mL}$ para estreptavidina-HRP.

Para asegurar el correcto desarrollo de los ensayos y descartar posibles errores durante las etapas de análisis, se llevaron a cabo diferentes controles. En cada zona de ensayo se integró una fila de $\mathrm{mAb}\left(\mathrm{H}_{1} \mathrm{~N}_{1}\right)$-BT como control positivo, basándose en el reconocimiento específico estreptavidina-biotina como control cualitativo de revelado. Esta estrategia es útil para corregir la variabilidad del ensayo; por ejemplo, variaciones internas del disco pueden originar mayor o menor señal en la lectura de los controles, que tendrá el mismo efecto sobre la matriz de ensayo, proporcionando información cualitativa sobre el desarrollo del mismo y permitiéndo descartar puntos o concentraciones erróneas.

Para el intervalo de concentraciones de mAb $\left(\mathrm{H}_{1} \mathrm{~N}_{1}\right)$-BT estudiadas (de 1 a 10 $\mathrm{mg} / \mathrm{mL}$ ), la óptima para el control de revelado fue de $1 \mathrm{mg} / \mathrm{mL}$, tomando como criterio la intensidad de señal y su reproducibilidad. A fin de evaluar la variabilidad de las lecturas de los controles positivos, se prepararon tres discos, sobre los que se imprimieron ocho matrices $4 \times 2$ (total de 192 puntos de media). La desviación estándar relativa inter e intradisco obtenidas fueron del 5,2\% y del $2 \%$, respectivamente, lo que da una idea de la elevada fiabilidad del control de revelado. 
Para corroborar la selectividad de los ensayos, se integró como control negativo una fila de anticuerpo de cabra anticonejo GAR $(1 \mathrm{mg} / \mathrm{mL})$ en cada matriz de ensayo. La Figura 31a muestra los resultados de la detección del virus de la gripe $\left(\left[\mathrm{mAb}\left(\mathrm{H}_{1} \mathrm{~N}_{1}\right)\right] 40 \mathrm{ng} / \mathrm{mL}\right.$ y [virus] $\left.100 \mathrm{ng} / \mathrm{mL}\right)$ incluyendo los controles de revelado.

Por otro lado, se llevaron a cabo diferentes controles para comprobar la unión covalente de las sondas empleando DVDs sin tratar (PC), y activados con grupos nitro (PC1) y grupos amino (PC2). Trabajando en las condiciones de ensayo descritas, se observó que la señal obtenida en todos los controles fue inferior al $20 \%$ de la alcanzada en PC3, siendo las relaciones señal/ruido extremadamente bajas.

En la Figura 31b, se muestran las diferentes curvas de saturación del virus de la gripe obtenidas a distintas concentraciones de anticuerpo de captura, para una media de 6 réplicas leídas en diferentes días. En todas las curvas se observa el comportamiento característico de un formato no competitivo, mostrando una tendencia lineal al principio, cuando la mayoría de los receptores anclados están libres, y perdiendo la linealidad a medida que éstos se van saturando. Al estudiar el intervalo lineal de las curvas obtenidas, y calcular los parámetros de calibrado (Tabla 16), se observó que para las cuatro rectas se obtienen coeficientes de correlación cercanos a 1, lo que indica una buena linealidad. Considerando la sensibilidad de un método como la capacidad de respuesta del mismo frente a variaciones de concentración ( $\mathrm{k}$, pendiente de la recta de calibrado), la máxima sensibilidad se alcanzó para concentraciones de anticuerpo de captura de $40 \mu \mathrm{g} / \mathrm{mL}$. El límite de detección obtenido (30 ng/mL) es comparable a los encontrados en la literatura para kits comerciales de detección de gripe aviaria (serotipo $\mathrm{H}_{1} \mathrm{~N}_{1}$ ) en formato de tira reactiva, cuyos valores oscilan entre 20 y $100 \mathrm{ng} / \mathrm{mL}^{237,251-253}$. 
(a)

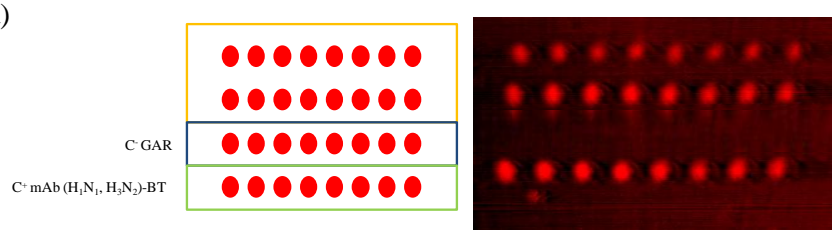

(b)

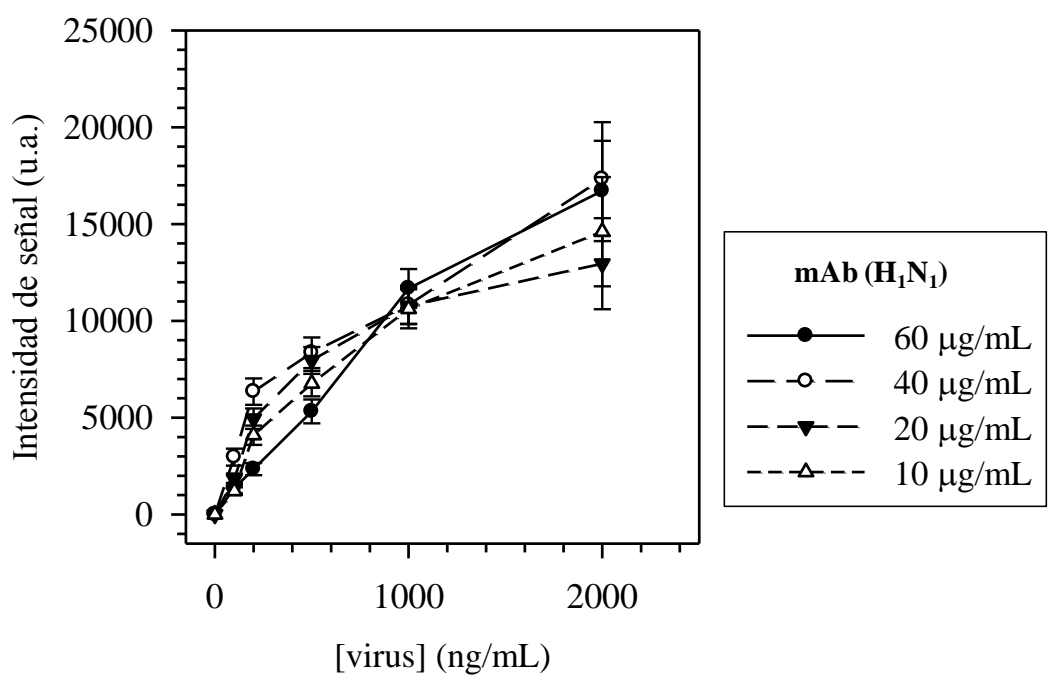

Figura 31. (a) Imagen de los resultados para la detección del virus de la gripe aviaria $\left(\left[\mathrm{mAb}\left(\mathrm{H}_{1} \mathrm{~N}_{1}\right)\right] 40 \mathrm{ng} / \mathrm{mL}\right.$; [virus] $100 \mathrm{ng} / \mathrm{mL} ; \mathrm{C}^{-}$control negativo; $\mathrm{C}^{+}$control positivo). (b) Curvas de saturación de virus a distintas concentraciones de anticuerpo de captura ([mAb(H1N1)-BT] 5 $\mu \mathrm{g} / \mathrm{mL}$; [Strep-HRP] $10 \mu \mathrm{g} / \mathrm{mL})$. 
Por otro lado, para evaluar la desviación estándar inter e intra disco se analizaron tres discos utilizando una concentración de $\mathrm{mAb}\left(\mathrm{H}_{1} \mathrm{~N}_{1}\right)$ de $40 \mu \mathrm{g} / \mathrm{mL}$ y $100 \mathrm{ng} / \mathrm{mL}$ de virus inactivo, analizándose un total de 128 puntos/disco. Se obtuvieron desviaciones estándar relativas intra e interdisco del 7 y 14\%, respectivamente, así como $\mathrm{SNR}>20$, lo que indica la robustez y buena reproducibilidad de la metodología desarrollada.

Tabla 16. Detección de virus de gripe aviaria. Variación de los parámetros de calibrado con la concentración de anticuerpo de captura.

\begin{tabular}{c|ccc}
\hline$\left[\boldsymbol{m} \boldsymbol{A b}\left(\mathrm{H}_{1} \boldsymbol{N}_{1}\right)\right]$ & $k$ & $\boldsymbol{R}^{2}$ & $\boldsymbol{L D D}$ \\
$(\boldsymbol{\mu g} / \mathbf{m L})$ & $(\boldsymbol{n g} / \mathbf{m L})^{-1} \times($ u.a $)$ & & $(\boldsymbol{n g} / \mathbf{m L})$ \\
\hline \hline 60 & 10,5 & 0,999 & 132 \\
40 & 31,7 & 0,998 & 30 \\
20 & 24,7 & 0,998 & 44 \\
10 & 20,5 & 0,950 & 50 \\
\hline
\end{tabular}

La Tabla 17 muestra algunas prestaciones del método desarrollado utilizando tecnología DVD, en comparación con otros ensayos de diagnóstico de gripe aviaria descritos en la bibliografía. Como puede observarse, aunque la sensibilidad es inferior a la alcanzada utilizando otras técnicas instrumentales, ofrece ventajas claras como elevada capacidad de trabajo, portabilidad y precio reducido. 
Tabla 17. Comparación entre diferentes tecnologías de diagnóstico de virus de gripe aviaria atendiendo a diferentes criterios, (EF) Electroforesis, (CF) Citometría de flujo, (IF) Interferometría (Mach-Zender), Kits comerciales y tecnología DVD.

\begin{tabular}{|c|c|c|c|c|c|}
\hline Parámetro & $(E F)^{254}$ & $(C F)^{255}$ & $(I F)^{256}$ & Kits $^{257}$ & $D V D$ \\
\hline $\begin{array}{l}\text { Personal } \\
\text { cualificado }\end{array}$ & Sí & Sí & Sí & No & No \\
\hline $\begin{array}{l}\text { Coste } \\
\text { aproximado }\end{array}$ & $35000 €$ & $40000 €$ & $20000 €$ & $50-500$ & $500-1000 €$ \\
\hline $\begin{array}{l}\text { Duración del } \\
\text { ensayo }\end{array}$ & $15^{\prime}$ & $75^{\prime}$ & $40^{\prime}$ & $15^{\prime}$ & $30^{\prime}$ \\
\hline $\begin{array}{l}\text { Capacidad de } \\
\text { trabajo }\end{array}$ & Media & Media & Media & Mínima & Muy Elevada \\
\hline Portabilidad & No & No & No & Sí & Sí \\
\hline Sensibilidad & 610 TICD50* & $0.016 \mathrm{ng} / \mathrm{mL}$ & $\begin{array}{l}0.0005 \mathrm{HA} \\
\text { units/mL* }\end{array}$ & $103 \mathrm{ng} / \mathrm{mL}$ & $30 \mathrm{ng} / \mathrm{mL}$ \\
\hline Detección visual & No & No & No & Sí & Sí \\
\hline Cuantificación & Sí & Sí & Sí & No & Sí \\
\hline
\end{tabular}

*Difícil comparación ya que las unidades utilizadas son diferentes. Según los resultados del kit comercial utilizado, $1 \mathrm{ng} / \mathrm{mL} \sim 5 \times 10^{-3} \mathrm{HA}$ units $/ \mathrm{mL}$ y 1 TCID50

\subsubsection{Análisis en muestras de saliva}

Una vez probada que la detección de gripe aviaria sobre DVD era posible, el siguiente paso fue demostrar su aplicabilidad a muestras reales de fluido oral. Para ello, las muestras se doparon a distintas concentraciones de virus dentro del intervalo lineal de trabajo. De este modo se evaluó la aplicación práctica de esta metodología en saliva, así como las posibles variaciones producidas por el efecto matriz.

La determinación de gripe aviaria en saliva se realizó en DVD, para lo cual fueron tomadas muestras de fluido oral de seis sujetos de los que se desconocía su exposición al virus de la gripe aviaria durante el último año. La toma de muestra se 148 
realizó según el protocolo establecido para detección de gripe A y B (Binax NOW Flu A, Flu B $)^{237}$, mediante un bastoncillo de algodón esterilizado que, una vez finalizada la toma de muestra, se introdujo $15 \mathrm{~min}$ en $0,5 \mathrm{~mL}$ de tampón PBS-T.

Los ensayos de detección del virus de la gripe se llevaron a cabo en las $24 \mathrm{~h}$ posteriores a la toma de muestra. Para la realización de los mismos, las muestras fueron dopadas con diferentes concentraciones de virus $(100-400 \mathrm{ng} / \mathrm{mL})$ dentro del intervalo lineal de la curva de saturación. Para la detección se realizaron 6 réplicas en diferentes días, con un total de 48 puntos $(2$ matrices $3 \times 8)$ de muestra por réplica. Paralelamente se realizó una réplica de ensayo con las muestras sin dopar para descartar la presencia de efecto matriz.

Finalmente, interpolando valores para la señal neta obtenida en la correspondiente curva de calibrado, se calcularon los coeficientes de recuperación. En la Tabla 18 se observa que estos valores están comprendidos entre 80 y 102\%, demostrando la capacidad de la metodología de disco compacto para la detección de virus $\mathrm{H}_{1} \mathrm{~N}_{1}$ en muestras de saliva, de una forma rápida, fiable y sin necesidad de etapas adicionales de pretratamiento de muestra. Además, esta metodología reúne las ventajas que proporciona el formato de disco compacto, como son la alta capacidad de trabajo y la posibilidad de desarrollar detección multianalito, que en el caso de la gripe aviaria permitiría trabajar simultáneamente con virus procedentes de distintas cepas lo que, teniendo en cuenta el alto índice de mutación de este virus, conllevaría una gran capacidad de diagnóstico de la enfermedad. 
Tabla 18. Determinación de virus de la gripe aviar en saliva. Porcentajes de recuperación para las distintas muestras de saliva.

\begin{tabular}{c|ccc}
\hline Muestra & Dopada & Determinada & \% Recuperación \\
\hline \hline M1 & 50 & 48 & 102 \\
M2 & 100 & 79 & 79 \\
M3 & 125 & 110 & 89 \\
M4 & 150 & 142 & 95 \\
M5 & 175 & 147 & 84 \\
M6 & 200 & 160 & 80 \\
\hline
\end{tabular}

[virus] en $\mathrm{ng} / \mathrm{mL}$

\section{Recapitulación}

En el apartado 4.1 se ha abordado el estudio de la modificación química de superficies de PC y PMMA para la inmovilización de material biológico, y el desarrollo de sistemas microanalíticos con detección óptica: fluorescencia y tecnología CD. Por otro lado, estos materiales químicamente modificados se han utilizado para la puesta a punto de biosensores selectivos y sencillos con los que se ha efectuado una prueba de concepto, como por ejemplo, discriminación de polimorfismos de una sola base y detección del virus de la gripe aviaria.

El empleo de materiales poliméricos, debido a la versatilidad en los formatos y prestaciones para su producción y su coste competitivo en comparación con los de vidrio, es un enfoque muy prometedor para el desarrollo de microarrays. En el presente trabajo se ha logrado la modificación química de PMMA y PC, en condiciones reproducibles y mediante procedimientos sencillos como: reducción de grupos éster, aminólisis del éster metílico o nitración de los anillos bencénicos del PC, introduciendo distintos grupos funcionales mediante la química de los 
organosilanos y la formación de siloxanos. Las diferentes superficies obtenidas fueron caracterizadas mediante técnicas de ángulo de contacto, ATR-FTIR, EDS, XPS y elipsometría, así como mediante la inmovilización de biomoléculas marcadas y detección fluorimétrica, corroborando la utilidad de las metodologías propuestas. Los resultados obtenidos indican que las modificaciones químicas investigadas no afectaran a las propiedades ópticas y mecánicas del polímero, aspectos indispensables para el desarrollo de los diferentes sistemas analíticos.

La unión covalente de biomoléculas de diferente naturaleza, como proteínas -a través de los grupos amino o carboxilo existentes en la estructura de las mismas-, o bien sondas de ADN activadas por el extremo de la cadena 3 'terminal -con grupos amino o tiol-, fue optimizada mediante la puesta a punto de protocolos de trabajo para la impresión de micromatrices de biorreceptores sobre las diferentes superficies activadas.

La viabilidad de las metodologías desarrolladas ha quedado demostrada mediante su aplicación para la detección polimorfismos de una sola base, empleando como sistema de detección un reproductor de CDs estándar. El empleo de discos compactos y de un lector de CDs convencional adaptado para la lectura de ensayos químicos, es una metodología novedosa desarrollada por nuestro grupo de investigación, que permite la detección de diferentes dianas moleculares con buena sensibilidad y tiempos de análisis cortos.

Los resultados obtenidos mostraron la aplicabilidad de nuestra propuesta. Así,en ensayos con ácidos nucleicos se alcanzaron valores de sensibilidad y eficiencia similares a las obtenidas con metodologías de inmovilización por adsorción y lectura del ensayo mediante detectores convencionales de fluorescencia. 
Otra aportación de gran interés fue la detección del virus de la gripe aviaria, enfermedad infecciosa vírica que afecta a las aves y que, ocasionalmente, puede transmitirse a mamíferos. Las ventajas de la metodología para detección de gripe aviaria sobre DVD comercial, frente a otros ensayos de diagnóstico, ofrece prestaciones competitivas en cuanto a sensibilidad, rendimiento, coste del proceso y tiempos de análisis, siendo comparable con otras técnicas bien establecidas. Los límites de detección obtenidos son del orden de los alcanzados con kits comerciales, lo que da una idea del gran potencial de los CDs como herramienta de análisis masivo.

En resumen, la metodología desarrollada basada en el empleo de tecnología CD y dispositivos de disco compacto como plataformas analíticas es sensible, portátil, de bajo coste y fácil de operar. Además ha mostrado ser un sistema muy versátil en ensayos in situ simultáneos y multianalito, como ha quedado demostrado en su aplicación a la detección de virus y discriminación de organismos géneticamente modificados. 


\subsection{Dispositivos ópticos basados en guías de ondas 3D}

Tras el estudio realizado con los soportes tipo CD/DVD, constituidos por materiales poliméricos 2D, se abordó el desarrollo de dispositivos Lab on a Chip, basados en materiales silíceos 3D, que integran etapas de reconocimiento biológico, lavado, detección y transducción de la señal de manera automatizada en un mismo dispositivo.

En esta investigación, enmarcada en el proyecto europeo SABIO (ultrahigh sensitivity Slot- wAveguide BIOsensor on a highly integrated chip for simultaneous diagnosis of multiple disases), se ha desarrollado un dispositivo fotónico integrado basado en microanillos de guías slot de nitruro de silicio sobre una plataforma de óxido de silicio ${ }^{187,188,258}$ (Figura 32a). Estas guías fueron desarrolladas hace algunos años en la Universidad de Cornell (Nueva York) por el grupo de Michal Lipson $^{259,260}$; a diferencia de las guías de onda convencionales (strip) en las que la luz es guiada a través de un material de alto índice de refracción (Figura 32b (1)), la luz es guiada por una ranura de bajo índice de refracción de un tamaño determinado (aprox. $200 \mathrm{~nm}$ ) comprendida entre dos guías de alto índice de refracción (Figura $32 \mathrm{~b}$ (2)). Como consecuencia de ello, las guías slot son extremadamente sensibles, pudiendo duplicar la sensibilidad del dispositivo respecto a las guías de onda convencionales. El dispositivo en estudio, tal y como se detalla en la Figura 32c, se compone de una estructura fotónica, un sistema de microfluídica ensamblado en un soporte rígido, una fuente láser y un fotodiodo como sistema de detección. 
La estructura fotónica está formada por un conjunto de ocho anillos resonadores (ver apartado 1.6.1.) que tienen la capacidad de incrementar el campo evanescente generado como efecto de la recirculación de la luz guiada en el anillo a una determinada frecuencia de radiación ( $v_{\text {resonancia }}$ ). Seis de los microanillos están diseñados para detección de muestras (permitiendo la detección multianalito del sistema), y el resto como guías de referencia. Este sistema integrado puede operar como biosensor si se inmoviliza sobre la guía de ensayo un biorreceptor adecuado.

(a)

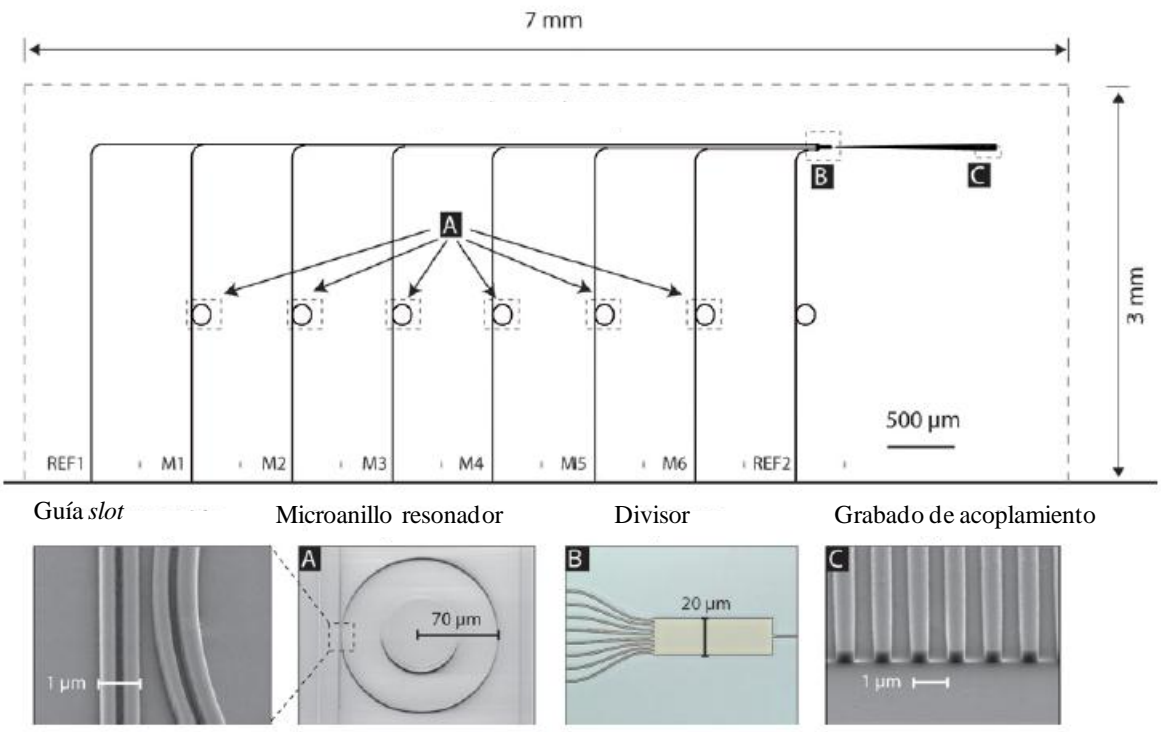


(b)

(1)

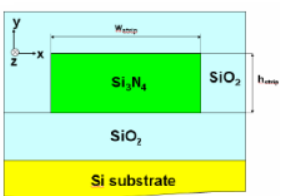

(2)

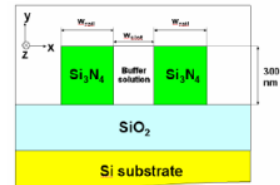

(c)

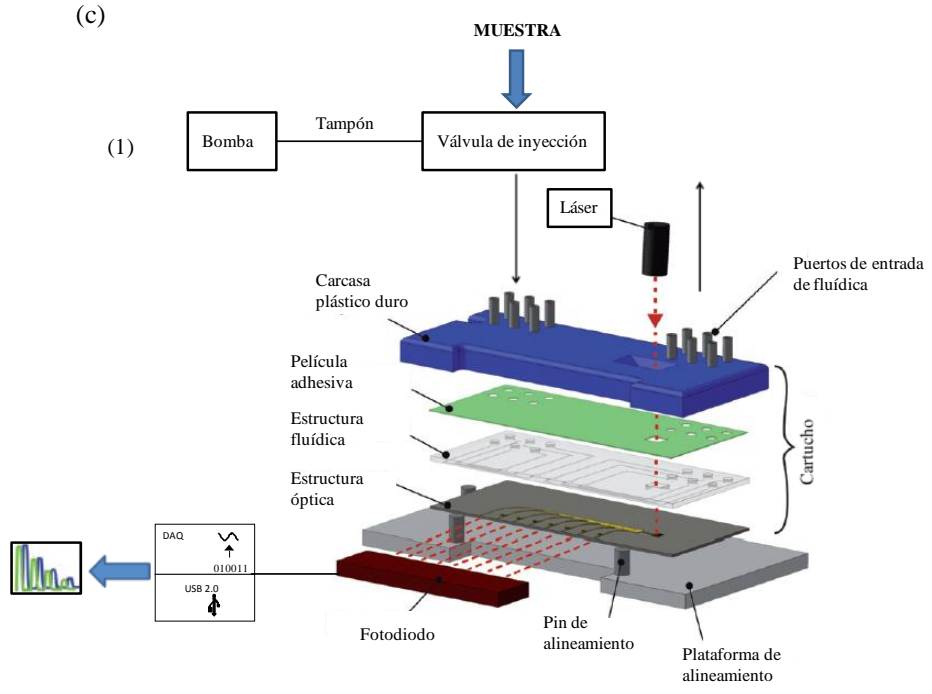

(2)

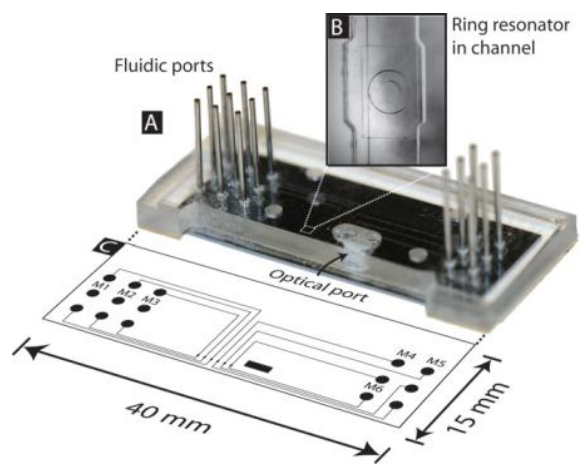

Figura 32. (a) Estructura fotónica de microanillos de guía de ondas slot integrada en el dispositivo. (b) Esquema de guía de ondas tipo strip (1) y tipo slot (2). (c) Dispositivo de trabajo: (1) Esquema, (2) imagen real. 
La puesta a punto de este tipo de sistemas requiere la inmovilización selectiva del elemento biorreceptor únicamente en la guía de nitruro, ya que toda la materia inmovilizada de forma no selectiva en el sustrato de óxido de silicio no será detectada, lo que conllevaría la pérdida de sensibilidad del dispositivo. Se persiguió también la aproximación a una estructura ideal ordenada con el fin de minimizar el espesor de la capa biomolecular, debido a que al disminuir la distancia a la guía la intensidad de campo es mayor y, por tanto, aumentará la sensibilidad del dispositivo.

Con tal finalidad, el trabajo consistió en llevar a cabo una modificación química selectiva que permitiese la inmovilización de las sondas exclusivamente en la superficie de la guía slot, maximizando sus prestaciones. Para ello se plantearon diversas estrategias de modificación química de los materiales que componen la estructura fotónica: nitruro, óxido y oxinitruro de silicio. En primer lugar, se estudió la funcionalización química selectiva en superficies mixtas planas, la mitad de $\mathrm{Si}_{3} \mathrm{~N}_{4}$ y la otra mitad de $\mathrm{SiO}_{2}$ (Chips $\mathbf{S i}_{3} \mathbf{N}_{4} / \mathbf{S i O} \mathbf{O}_{2}$ ). Las superficies derivatizadas obtenidas se caracterizaron mediante técnicas de ángulo de contacto, infrarrojo de reflectancia total atenuada con transformada de Fourier (ATR-FTIR) y espectroscopia fotoelectrónica de rayos $\mathrm{X}$. Posteriormente, se estudió la inmovilización covalente de micromatrices de biorreceptores sobre estas mismas superficies activadas y se determinó el espesor de las capas de biomoléculas mediante elipsometría.

Tras la optimización del proceso en superficies planas (2D), la metodología que proporcionó los mejores resultados se aplicó a las nanoestructuras que conforman las guías de ondas (3D). Utilizando inmunosistemas modelo se estudió la inmovilización de biomoléculas marcadas y su bioactividad, empleando técnicas de microscopia confocal de fluorescencia (MCF) y microscopia de barrido electrónico (SEM) para la caracterización. 
Finalmente, se realizó la caracterización optoquímica de la estructura fotónica de anillos resonadores mediante detección sin marcaje, empleando el sistema BSAantiBSA como modelo.

\subsubsection{Modificación química selectiva de $\mathrm{Si}_{3} \mathrm{~N}_{4}$ sobre superficies planas}

Para llevar a cabo una modificación química selectiva y eficaz sobre nitruro de silicio frente a óxido, se ensayaron diferentes estrategias. El objetivo principal era lograr la unión covalente de los elementos de reconocimiento sobre la guía de nitruro, zona de detección del dispositivo. Si tenemos en cuenta que el área correspondiente a la superficie del óxido de silicio representa un $98 \%$ de la superficie total del dispostivo, frente al $2 \%$ que representa la guía de nitruro, el anclaje de biorreceptores en el dispositivo de manera no selectiva implicaría que la mayoria de los analitos serían reconocidos fuera del área de detección, lo que conllevaría una disminución drástica de la sensibilidad del dispositivo. Así pues, desde el punto de vista de la modificación química, el sistema ideal sería aquel en el que el biorreceptor se encontrará anclado únicamente en la superficie de la guía y no sobre el sustrato de óxido de silicio.

Con tal finalidad fueron diseñadas y estudiadas tres estrategias, la primera (Ruta 1) basada en la reactividad del enlace $\mathrm{Si}-\mathrm{H}$ generado sobre la superficie de nitruro tras un tratamiento con HF y reacción (bien por vía fotoquímica, o bien térmica) de hidrosilación con un grupo alqueno terminal. Dicho alqueno posee un derivado de ácido en un extremo de la cadena, de modo que tras un tratamiento de hidrólisis, permite la obtención de una superficie de nitruro activada con grupos ácido carboxílico. Esta metodología estaba descrita en la literatura para superficies de silicio $^{203-206,261}$, pero su aplicación a nitruro de silicio es escasa. ${ }^{221,222}$ 
En la segunda estrategia (Ruta 2), se optó por utilizar un proceso de selectividad física. Para ello, se uso un estámper diseñado con unas dimensiones que permitiese (mediante contacto) el bloqueo únicamente del óxido de silicio, utilizando para ello un alcoxisilano derivado de polietilenglicol (-PEG), inerte frente a los principales grupos activos de las proteínas (- $\left.\mathrm{NH}_{2},-\mathrm{COOH},-\mathrm{SH}\right)^{262}$ (Figura 33). A continuación se efectuó la unión química sobre la capa de óxido de silicio nativa remanente en las superficies de nitruro de silicio, empleando otro alcoxisilano con un grupo isocianato terminal, de modo que permitiera la unión directa y selectiva sobre la guía de nitruro de silicio de las biomoléculas a través de sus grupos amino.

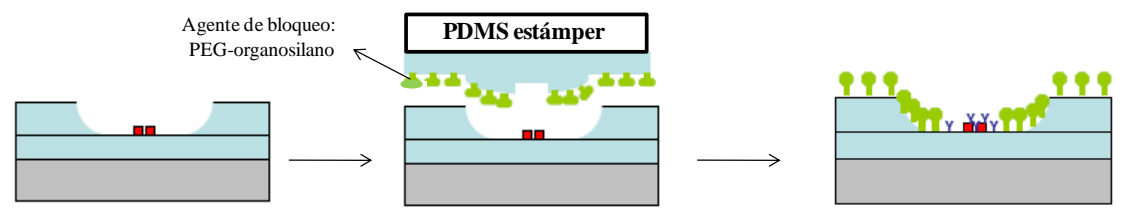

Figura 33. Esquema de la modificación química mediante el uso de un estámper (Ruta 2).

Finalmente, la tercera estrategia (Ruta 3) se basó en aprovechar los grupos amino presentes únicamente en la superficie de nitruro de silicio. Para ello, fue necesario realizar un tratamiento previo de la superficie con HF -para eliminar la capa de oxido nativo remanente en las superficies de óxido de silicio-, así como llevar a cabo el proceso en atmósfera inerte para evitar la oxidación del nitruro de silicio. Se empleó ácido 11-bromoundecanoico, que se une mediante una reacción de sustitución nucleofílica a la superficie de nitruro, obteniéndose una superficie activada con grupos ácidos que permite la conjugación de las proteínas y ácidos nucleicos a través de sus grupos amino libres. Posteriormente, se probó el empleo de un crosslinker bifuncional, glutaraldehído, que reacciona con los grupos amino, permitiendo tanto la unión al nitruro de silicio del soporte como el posterior 
acoplamiento directo con los grupos amino libres de las proteínas. Esta estrategia aportaba la ventaja de aprovechar la química del nitrógeno, presente únicamente en el nitruro de silicio, pudiendo prescindir de etapas de bloqueo para el óxido de silicio.

\subsubsection{Estrategia de modificación química selectiva a través de la química del enlace Si-H (Ruta 1)}

Para la modificación selectiva de la superficie de nitruro de silicio a través de la química del enlace Si-H se siguió la estrategia detallada en la Figura 34, que incluye los siguientes pasos: 1) Síntesis de 10-undecenoato de 2,2,2, trifluoroetilo; 2) Bloqueo del $\mathrm{SiO}_{2}$; 3) Unión del derivado éster a la superficie de nitruro de silicio por vía fotoquímica o térmica; 4) Hidrólisis del derivado éster del trifluoroetanol para la obtención de una superficie carboxilada.

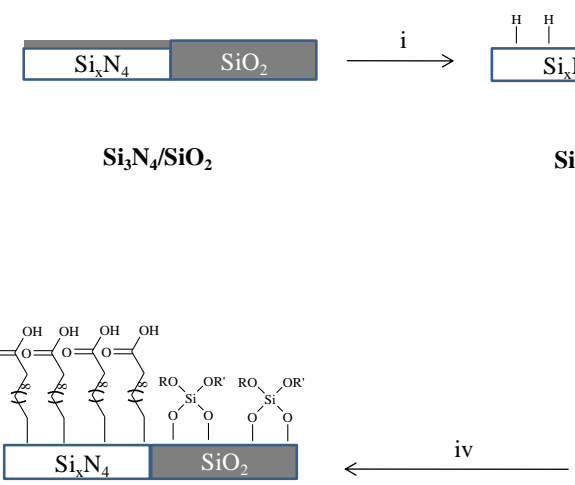

$\mathrm{Si}_{3} \mathrm{~N}_{4}(-\mathrm{COOH}) / \mathrm{SiO}_{2}(-\mathrm{PEG})$

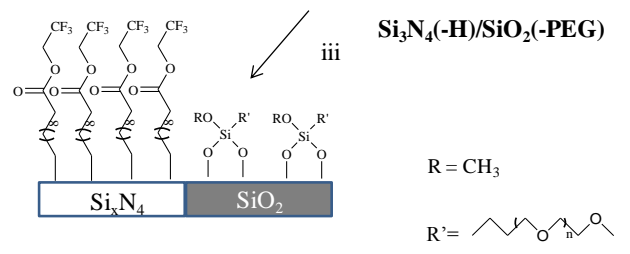

$\mathrm{Si}_{3} \mathrm{~N}_{4}\left(-\mathrm{CF}_{3}\right) / \mathrm{SiO}_{2}(-\mathrm{PEG})$

Figura 34. Modificación química selectiva de $\mathrm{Si}_{3} \mathrm{~N}_{4}$ (Ruta 1). i. $\mathrm{HF}\left(1 \% \mathrm{H}_{2} \mathrm{O}\right), 2$ min; ii. $\left(\mathrm{CH}_{3} \mathrm{O}\right)_{3}-\mathrm{Si}-\left(\mathrm{C}_{10} \mathrm{H}_{18} \mathrm{O}_{4}\right)(2 \%$ en disolución metanólica de $\mathrm{AcOH} 0,15 \mathrm{M}), 30$ min; iiia. $\mathrm{CH}_{2}=\mathrm{CH}-(\mathrm{CH})_{8}-\mathrm{COO}-\mathrm{CH}_{2}-\mathrm{CF}_{3}(0,1 \mathrm{M}$ en mesitileno), $254 \mathrm{~nm}, 48 \mathrm{~h}$; iiib. $\mathrm{CH}_{2}=\mathrm{CH}-(\mathrm{CH})_{8}-\mathrm{COO}-\mathrm{CH}_{2}-\mathrm{CF}_{3}(0,2 \mathrm{M}$ en mesitileno $), 165^{\circ} \mathrm{C}, 24 \mathrm{~h}$; iv. ${ }^{t} \mathrm{BuO}^{-} \mathrm{K}^{+}$ (0,26 M en DMSO), 10 min; $\mathrm{HCl}\left(0,1 \mathrm{M}\right.$ en $\left.\mathrm{H}_{2} \mathrm{O}\right), 10 \mathrm{~min}$. 
La síntesis de 10-undecenoato de 2,2,2, trifluoroetilo (etapa 1) se llevó a cabo mediante una reacción de esterificación empleando 2,2,2, trifuoetanol y ácido 10undecilénico, con una relación molar (1:1,3), llevando a reflujo durante $5 \mathrm{~h}$ en tolueno. Tras purificación por cromatografía en columna, se obtuvo el producto en forma de aceite incoloro, que se caracterizó por ${ }^{1} \mathrm{H}-\mathrm{RMN}$ (Figura 35).

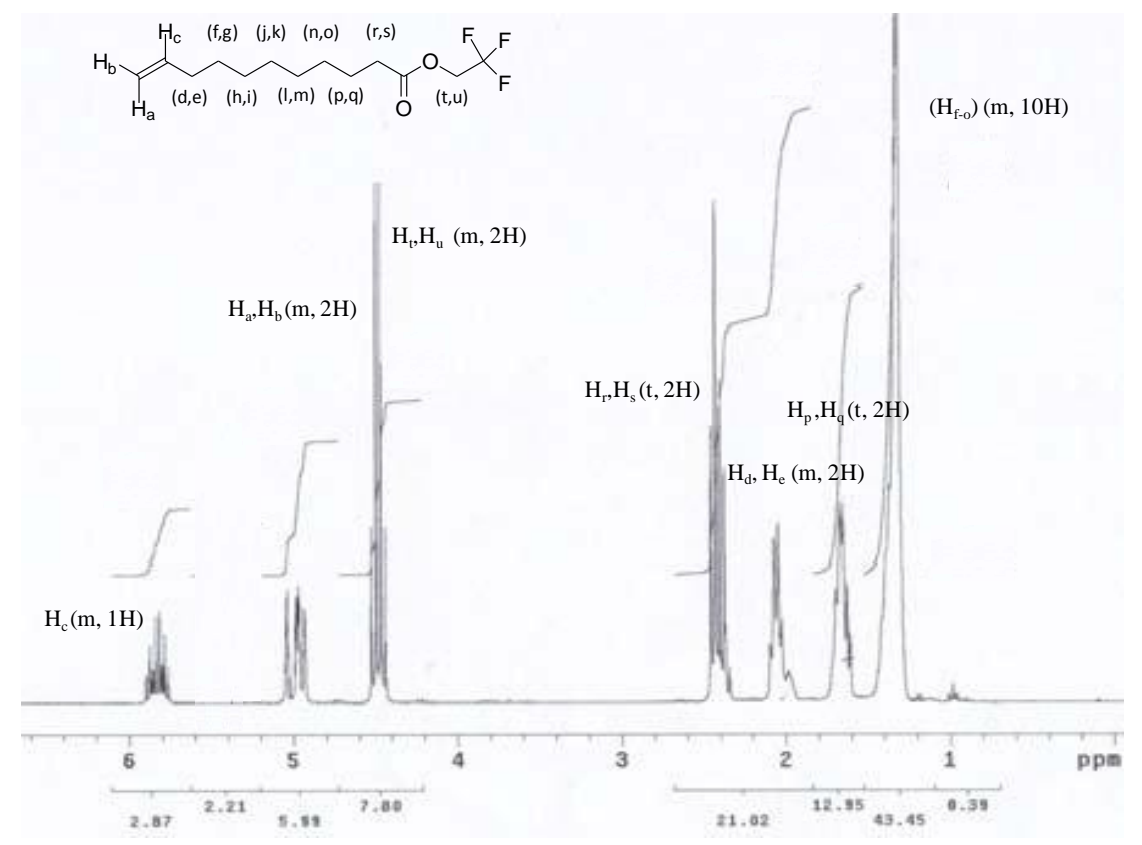

Figura 35. Espectro $\mathrm{RMN}-{ }^{1} \mathrm{H}$ de 10 -undecenoato de 2,2,2, trifluoroetilo.

Para la unión química del derivado éster sobre la superficie de nitruro de silicio se realizó, en primer lugar, un tratamiento con HF a fin de eliminar la capa de óxido nativo del nitruro y generar una superficie hidrogenada que permitiese la unión del 10-undecenoato de 2,2,2, trifluoroetilo a través de un mecanismo de hidrosilación con el grupo alqueno terminal. Se ensayaron distintas concentraciones $(0,1-10 \%)$ y 
tiempos de tratamiento (0,5-10 min), observando que el tratamiento con $\mathrm{HF}$ al $1 \%$ en agua durante 2 min producía los resultados más satisfactorios sin dañar las superficies. El proceso se realizó en atmósfera de argon, con la finalidad de evitar la presencia de oxígeno que produciría de nuevo la oxidación del nitruro de silicio.

Tras la activación del nitruro de silicio $\left(\mathbf{S i}_{3} \mathbf{N}_{\mathbf{4}}(\mathbf{- H})\right)$, se llevó a cabo el bloqueo de la superficie de $\mathrm{SiO}_{2}$ (etapa 2), mediante tratamiento con un organosilano derivado del PEG (2\% en metanol 0, $15 \mathrm{M} \mathrm{AcOH})$ durante $30 \mathrm{~min}\left(\mathbf{S i O}_{2}\right.$ (-PEG)). Esta etapa se realizó con el fin de minimizar la adsorción inespecífica durante la inmovilización de biorreceptores y el reconocimiento biológico. La alta adsorción sobre las superficies de $\mathrm{SiO}_{2}$ se debe a la ionización de los grupos silanol en agua a pH neutro, lo que da lugar a una superficie cargada negativamente, favoreciendo la unión de biomoléculas mediante fuerzas electrostáticas de carácter débil. En este sentido, el empleo de PEG permitió reducir considerablemente las interacciones debido a que su estructura posee un alto contenido en grupos $(-\mathrm{CH})$ que actúan a modo de capa protectora entre la biomolécula y los grupos cargados negativamente de la superficie. La disolución PEG-organosilano fue previamente desoxigenada y se trabajó bajo atmósfera de argón para evitar la oxidación del nitruro.

Finalmente se procedió a la unión del 10-undecenoato de 2,2,2, trifluoroetilo, por hidrosilación a través del grupo alqueno terminal y los grupos $\mathrm{Si}-\mathrm{H}$ en la superficie del nitruro. Para ello, se estudió la activación por vía fotoquímica y térmica (etapa 3). En la primera de las vías, el chip mixto $\mathrm{Si}_{3} \mathrm{~N}_{4} / \mathrm{SiO}_{2}$ se introdujo en una cubeta de cuarzo que contenía el alqueno-éster a una concentración 0,1 $\mathrm{M}$ en mesitileno, y se irradió durante 48 h con una lámpara UV (Vilber Lourmat, VL-4 LC, $4 \mathrm{~W})$ a $254 \mathrm{~nm}\left(\mathbf{S i}_{\mathbf{3}} \mathbf{N}_{\mathbf{4}}\left(\mathbf{-}-\mathbf{C F}_{\mathbf{3}}\right)^{\mathbf{a}}\right)$. Para la activación por vía térmica, los chips se introdujeron en una disolución 0,2 M del derivado éster del 2,2,2, trifluoroetanol en mesitileno, y se calentó durante $24 \mathrm{~h}$ a $165^{\circ} \mathrm{C}\left(\mathbf{S i}_{\mathbf{3}} \mathbf{N}_{\mathbf{4}}\left(-\mathbf{C} \mathbf{F}_{\mathbf{3}}\right)^{\mathbf{b}}\right)$ 
Una vez anclado el éster, para la activación con grupos carboxilo que permitan la posterior conjugación de las biomoléculas a través de sus grupos amino, se realizó una hidrólisis básica con tert-butóxido potásico (0,26 M) en DMSO durante 10 min. Posteriormente se acidificó con $\mathrm{HCl}$ 0,1 M durante diez minutos para obtener la forma protonada (etapa 4).

La caracterización de la superficie de nitruro de silicio modificada se llevó a cabo mediante el empleo de técnicas de ángulo de contacto, ATR-FTIR y XPS.

\section{Ángulo de contacto}

Las medidas fueron realizadas empleando agua como disolvente. Los ángulos de contacto proporcionan información acerca de la hidrofilia de las superficies, pudiendo correlacionar las variaciones de los ángulos con la introducción de determinadas cadenas y grupos funcionales. En la Tabla 19, se muestran los resultados obtenidos sobre cada uno de los sustratos de la Ruta 1, como media de cinco medidas y el error relativo.

Tabla 19. Medidas de ángulo de contacto $(\theta)$.

\begin{tabular}{|c|c|}
\hline Superficie & $\theta_{\text {agua }}$ \\
\hline $\mathrm{SiO}_{2}$ & $35,6 \pm 1,3$ \\
\hline $\mathrm{SiO}_{2}(-\mathrm{PEG})$ & $64,3 \pm 3,6$ \\
\hline $\mathrm{Si}_{3} \mathrm{~N}_{4}$ & $47,1 \pm 1,7$ \\
\hline $\mathrm{Si}_{3} \mathrm{~N}_{4}(-\mathrm{H})$ & $61,7 \pm 1,6$ \\
\hline$S i_{3} N_{4}\left(-C F_{3}\right)$ & $79,6 \pm 2,4$ \\
\hline $\mathrm{Si}_{3} \mathrm{~N}_{4}(-\mathrm{COOH})^{a}$ & $55,9 \pm 2,7$ \\
\hline $\mathrm{Si}_{3} \mathrm{~N}_{4}(-\mathrm{COOH})^{b}$ & $58,3 \pm 2,4$ \\
\hline
\end{tabular}


El ángulo de contacto de la superficie de óxido de silicio aumenta tras la etapa de bloqueo con PEG-organosilano, como consecuencia de la introducción de una capa orgánica que genera un incremento de la hidrofobia de las superficies.

En el caso de las superficies de nitruro de silicio, se observa un aumento del ángulo de contacto tras el tratamiento con $\mathrm{HF}\left(\mathbf{S i}_{3} \mathbf{N}_{4}(-\mathbf{H})\right)$ y la introducción del derivado éster del trifluoroetanol $\left(\mathbf{S i}_{\mathbf{3}} \mathbf{N}_{\mathbf{4}}\left(\mathbf{-}-\mathbf{C F}_{3}\right)\right)$. Este hecho concuerda con el aumento de la hidrofobicidad de la superficie tras la eliminación de la capa de óxido nativo remanente y el aumento de la proporción de enlaces tipo $\mathrm{Si}-\mathrm{H}$, así como tras la introducción de una capa orgánica. Por otro lado, se observa una disminución de estos valores tras la etapa de hidrólisis $\left(\mathbf{S i}_{3} \mathbf{N}_{\mathbf{4}}(\mathbf{-} \mathbf{C O O H})\right.$ ), consecuencia del aumento de la hidrofilia de la superficie carboxilada frente a los grupos éster.

Los resultados obtenidos para $\mathbf{S i}_{3} \mathbf{N}_{\mathbf{4}}-\mathbf{C F} \mathbf{F}_{\mathbf{3}}$ permitieron concluir que las dos metodologías ensayadas son viables, y que los rendimientos alcanzados por activación fotoquímica (a) y térmica (b) son similares.

\section{Espectroscopía infrarroja de reflectancia total atenuada con transformada de Fourier (ATR-FTIR)}

Los espectros de infrarrojo con transfomada de Fourier (Figura 36) permitieron corroborar la presencia de grupos carbonilo $\left(v=1750 \mathrm{~cm}^{-1}\right)$ introducidos tras la modificación química del nitruro de silicio con 10-undecenoato de 2,2,2, trifluoroetilo $\left(\mathbf{S i}_{3} \mathbf{N}_{4}-\left(\mathbf{C F}_{3}\right)\right)$. 


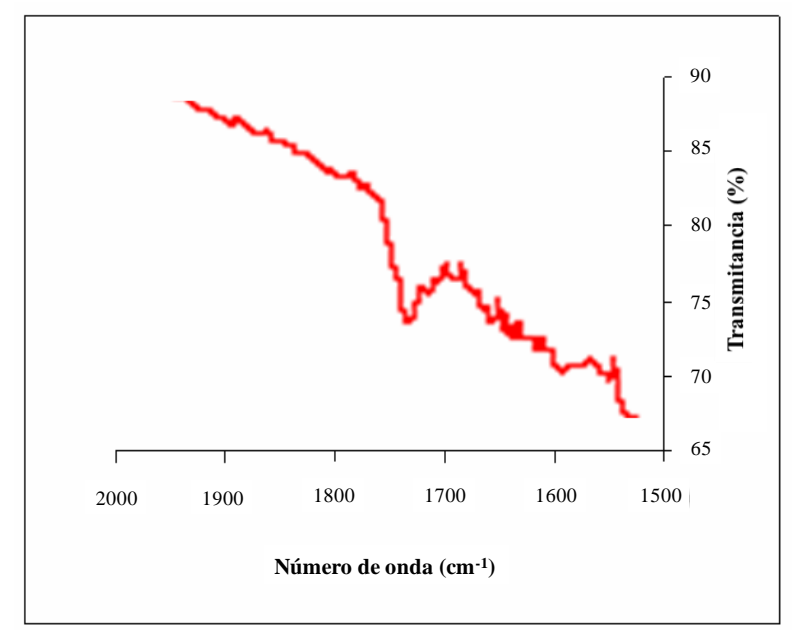

Figura 36. Región ATR-FTIR correspondiente al estiramiento del carbonilo en el espectro del $\mathbf{S i}_{3} \mathbf{N}_{\mathbf{4}}-\left(\mathbf{C F}_{3}\right)$.

\section{Espectroscopía fotoelectrónica de rayos X (XPS)}

La técnica de microscopía electrónica, basada en la excitación de los niveles energéticos más internos de los átomos mediante un haz de rayos $\mathrm{X}$, proporciona información sobre la energía de cada nivel y, por tanto, sobre la naturaleza de cada átomo emisor, permitiendo hacer un seguimiento de los distintos pasos del proceso.

En la Figura 37 se muestran los espectros obtenidos para la caracterización de las diferentes superficies intermedias de reacción. En los espectros de la Figura 37a, se comparan los picos correspondientes al nitrógeno $\left(\mathrm{N}_{1 \mathrm{~s}}\right)$ y al oxígeno $\left(\mathrm{O}_{1 \mathrm{~s}}\right)$, antes y después del tratamiento con $\mathrm{HF}\left(1 \%\right.$ en $\left.\mathrm{H}_{2} \mathrm{O}\right)$. La disminución del pico correspondiente al oxígeno corrobora la eliminación casi total del óxido de silicio existente sobre el nitruro. 
(a)

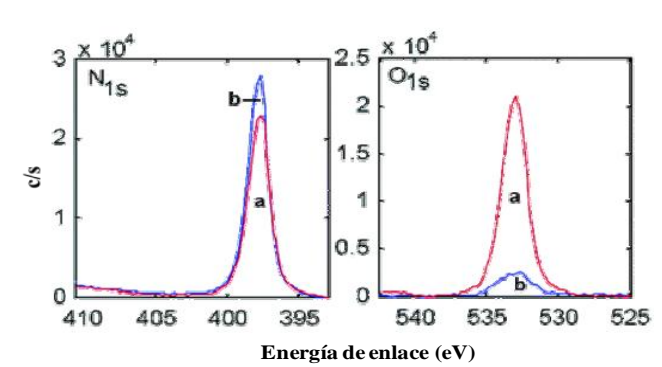

(b)

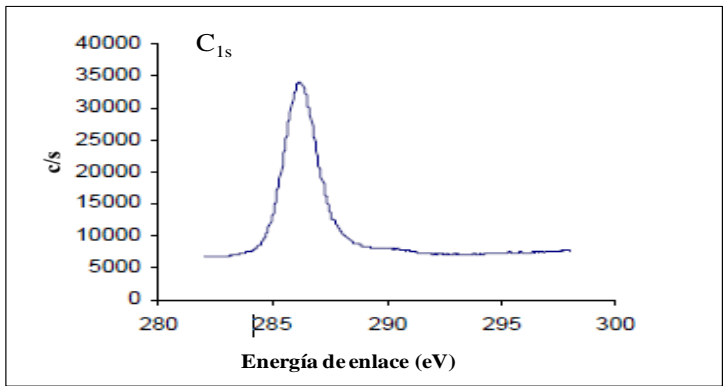

(c)

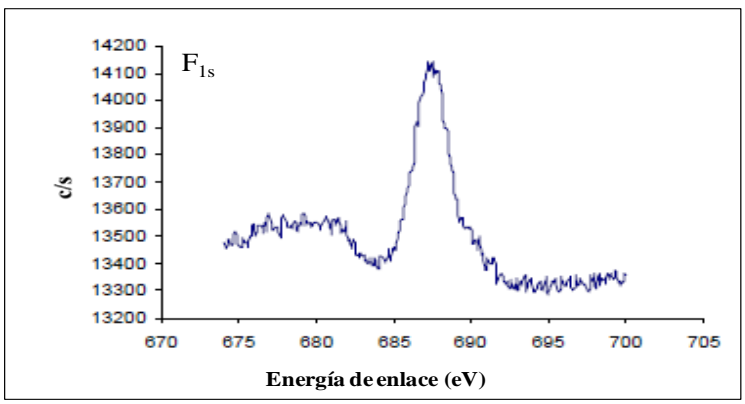

(d)

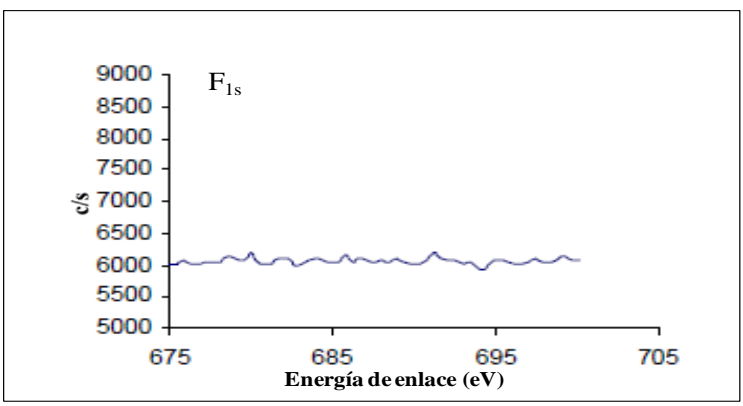

Figura 37. Espectro XPS $\mathrm{N}_{1 \mathrm{~s}}$ y $\mathrm{O}_{1 \mathrm{~s}}$ de $\mathrm{Si}_{3} \mathrm{~N}_{4}$ antes (rosa), y después (azul) del tratamiento con HF; (b) y (c) $\mathrm{C}_{1 \mathrm{~s}}$ y $\mathrm{F}_{1 \mathrm{~s}}$ de $\mathbf{S i}_{\mathbf{3}} \mathbf{N}_{\mathbf{4}}-\left(\mathbf{C O O}-\mathbf{C F}_{\mathbf{3}}\right)^{\mathbf{a}}$, (d) $\mathrm{F}_{1 \mathrm{~s}}$ de $\mathbf{S i}_{3} \mathbf{N}_{\mathbf{4}}-(\mathbf{C O O H})^{\mathrm{a}}$. a -activación fotoquímica 
Por otro lado, los espectros de la Figura 37b y c, correspondientes al nitruro de silicio tratado con 10-undecenoato de 2,2,2, trifluoroetilo $\left(\mathbf{S i}_{\mathbf{3}} \mathbf{N}_{\mathbf{4}}\left(-\mathbf{C} \mathbf{F}_{3}\right)^{\mathbf{a}}\right)$, muestran los picos correspondientes al fluor $\left(\mathrm{F}_{1 \mathrm{~s}}\right)$ y al carbono $\left(\mathrm{C}_{1 \mathrm{~s}}\right)$, confirmando la presencia del derivado éster del trifluoetanol.

Finalmente, la Figura 37d muestra el espectro tras la etapa de hidrólisis $\left(\mathbf{S i}_{\mathbf{3}} \mathbf{N}_{\mathbf{4}}(-\right.$ $\mathbf{C O O H})^{\text {a }}$ ) en la que se observa la desaparición total del pico correspondiente al flúor. En el caso de las superficies activadas según la vía fotoquímica los resultados fueron similares.

\section{Elipsometría}

Las medidas elipsométricas permiten la caracterización de películas superficiales a partir de las variaciones de la luz polarizada incidente, proporcionando información sobre el grosor y densidad de la mismas. Tal y como se justificó anteriormente, la generación de una capa de biomoléculas captoras de bajo espesor es de gran interés en este tipo de sistemas; durante la etapa de reconocimiento biológico a mayor proximidad del analito a la superficie de trabajo mayor efecto del campo, lo que influirá muy favorablemente en la sensibilidad.

Las medidas de elipsometría se llevaron a cabo sobre superficies de nitruro de silicio carboxiladas $\mathbf{S i}_{3} \mathbf{N}_{4}-\mathbf{C O O H}$, sobre las que se inmovilizó una capa proteíca (BSA) mediante reacción con EDC $(2,5 \mu \mathrm{M})$ y NHS $(5 \mu \mathrm{M})$ en PBS1x.

Previo al tratamiento al anclaje de la BSA, las muestras de $\mathbf{S i}_{3} \mathbf{N}_{4}-\mathbf{C O O H}$ fueron caracterizadas utilizando un modelo de dos capas $\left(\mathrm{Si}_{3} \mathrm{~N}_{4} /\right.$ capa orgánica). El grosor de capa orgánica correspondiente al ácido undecanoico se estimó en 3,7 nm, con un índice de refracción de 1,5. Estos resultados, corroboran la presencia de una capa orgánica sobre el nitruro de silicio, tanto para las muestras obtenidas mediante tratamiento fotoquímico $\left(\mathbf{S i}_{3} \mathbf{N}_{4}(-\mathbf{C O O H})^{\mathbf{a}}\right)$ como térmico $\left(\mathbf{S i}_{3} \mathbf{N}_{4}-(\mathbf{C O O H})^{\mathbf{b}}\right)$. 
Por otro lado se realizaron medidas para superficies de $\mathbf{S i}_{\mathbf{3}} \mathbf{N}_{\mathbf{4}}-\mathbf{C O O H}$ sobre las que se había introducido una capa de proteínas tras tratamiento con BSA. Para este caso, se empleó un modelo de tres capas $\left(\mathrm{Si}_{3} \mathrm{~N}_{4} /\right.$ ácido undecanoico $(3,7 \mathrm{~nm}$, índice de refracción 1,5)/ BSA). Las medidas indicaron que la capa de proteína presentaba un grosor medio de $8 \mathrm{~nm}$ y un índice de refracción de 1,2, valores que se correlacionan con el tamaño de la BSA.

Las resultados obtenidos permiten concluir la formación de una capa de proteína de bajo espesor sobre la superficie de nitruro de silicio activada con ácidos carboxílicos.

\subsubsection{Estrategia de modificación selectiva a través de la química del enlace Si-OH (Ruta 2)}

En esta vía de modificación química se optó por aprovechar la capa nativa de óxido de silicio presente sobre el nitruro. En la Figura 38 se muestra la estrategia propuesta, que consta de dos etapas: 1) Bloqueo de la superficie de óxido de silicio mediante un organosilano con un grupo polietilenglicol terminal (PEGorganosilano) y 2) Activación del nitruro de silicio mediante un organosilano con un grupo isocianato terminal que permite la unión directa de las proteínas a través de los grupos amino. 


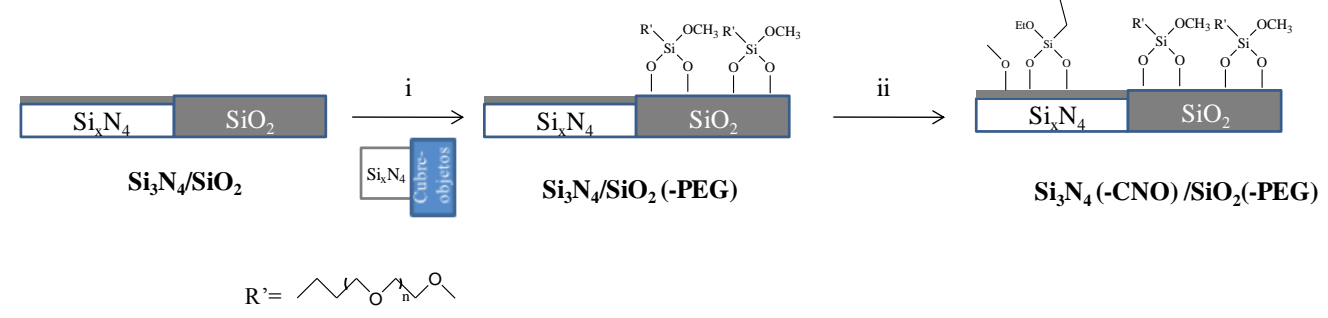

Figura 38. Vía de modificación química selectiva de $\mathrm{Si}_{3} \mathrm{~N}_{4}$ (Ruta 2). i. $\left(\mathrm{CH}_{3} \mathrm{O}\right)_{3}$ $\mathrm{Si}-\left(\mathrm{C}_{10} \mathrm{H}_{18} \mathrm{O}_{4}\right)(2 \%$ en $\mathrm{MeOH}(0,15 \mathrm{M} \mathrm{AcOH})), 30 \mathrm{~min}$; ii. $\left(\mathrm{CH}_{3} \mathrm{CH}_{2} \mathrm{O}\right)_{3}$-Si$\left(\left(\mathrm{CH}_{2}\right)_{3} \mathrm{CNO}\right)$ (2\% en disolución metanólica 0,15 M de AcOH), 30 min.

Para el bloqueo del óxido de silicio se empleó PEG-organosilano (etapa 1), que con ayuda de un cubreobjetos fue depositado, exclusivamente, sobre el óxido de silicio de la superficie mixta $\left(\mathbf{S i}_{3} \mathbf{N}_{4} / \mathbf{S i O}_{2}\right)$. Para comprobar la eficacia del bloqueo, matrices $(3 \times 3)$ del anticuerpo marcado GAR-Cy5 $(1-200 \mu \mathrm{g} / \mathrm{mL}$ en PBS $1 \times)$ se depositaron utilizando un sistema de impresión manual por contacto. Tras $2 \mathrm{~h}$ de incubación, y varios lavados con tampón MES y agua, se registró la fluorescencia tras cada lavado mediante LFS. En la Figura 39 se observa que no existe señal residual de fluorescencia después de lavar y, por tanto, que no se produce adsorción inespecífica sobre las superficies de ( $\mathbf{S i O}_{2}$-PEG), lo que indica que el PEGorganosilano genera un bloqueo efectivo y reduce la adsorción inespecífica.

Para la optimización del tratamiento se ensayaron diferentes concentraciones de PEG-organosilano (de 0,1-10\%) y tiempos de reacción (0,5-2 h), obteniéndose un señal despreciable y por tanto un bloqueo más efectivo para 30 min de PEGorganosilano $2 \%$ en una disolución metanólica $0,15 \mathrm{M}$ de $\mathrm{AcOH}$.

Una vez bloqueada la superficie de $\mathrm{SiO}_{2}$, se procedió a la activación del $\mathrm{Si}_{3} \mathrm{~N}_{4}$ para el anclaje covalente de biorreceptores (etapa 2). Para ello, los chips mixtos 
$\mathbf{S i}_{3} \mathbf{N}_{4} / \mathbf{S i O}_{2}$ (-PEG) fueron activados por inmersión en una disolución al $2 \%$ de ICPTS en metanol (0,15 M AcOH), durante $30 \mathrm{~min}$.

Para el seguimiento de las etapas de reacción de la Ruta 2 se emplearon técnicas de elipsometría y ángulo de contacto.

(a)

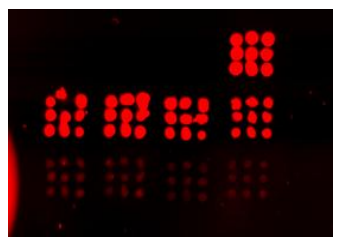

(b)

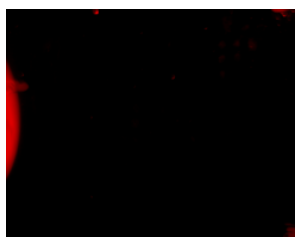

(c)

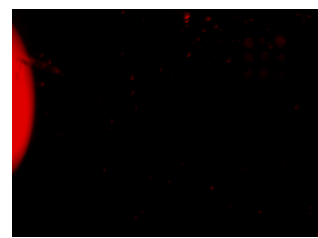

Figura 39. GAR-Cy5 inmovilizado sobre $\mathrm{SiO}_{2}-\mathrm{PEG}$ (a) sin lavar, (b) lavado con tampón MES, (c) lavado con agua.

\section{Elipsometría}

La Figura 40 muestra el mapa bidimensional de la capa de organosilano, obtenido mediante elipsometría empleando un modelo de dos capas $\left(\mathrm{SiO}_{2}\right.$ ó $\mathrm{Si}_{3} \mathrm{~N}_{4} /$ capa orgánica) para superficies de $\mathbf{S i O} \mathbf{O}_{2}$-PEG (a) y $\mathbf{S i}_{3} \mathbf{N}_{4}$-CNO (b). En ellas se observa la homogeneidad de la película de organosilano depositada, con un espesor medio de $3 \mathrm{~nm}$.

Posteriormente, para caracterizar el espesor de la capa de biomoléculas sobre las superficies de $\mathbf{S i O}_{2}$-PEG y $\mathbf{S i}_{3} \mathbf{N}_{4}$-CNO, se realizó un tratamiento con BSA al $2 \%$ en PBS1× y se midieron los resultados por elipsometría, empleando un modelo de tres capas $\left(\mathrm{SiO}_{2} /\right.$ capa orgánica (organosilano)/proteína). Los espesores promedio estimados para $\mathbf{S i}_{3} \mathbf{N}_{4}-\mathbf{C N O}$ oscilaron entre 8 y $12 \mathrm{~nm}$, lo que teniendo en cuenta el tamaño molecula de BSA $(4 \times 4 \times 14 \mathrm{~nm})$, permite confirmar la formación de una capa de bajo espesor. Los resultados para $\mathbf{S i O}_{2}$-PEG descartan la presencia de una capa proteíca sobre su superficie. 
(a)

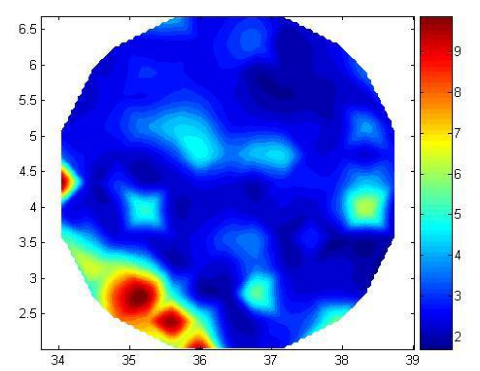

(b)

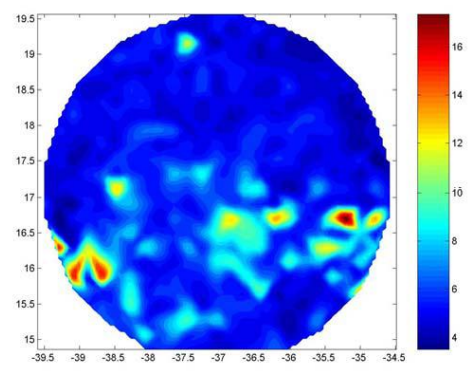

Figura 40. Mapa 2D para la capa de $\mathbf{S i O}_{2}$-PEG (a) y $\mathbf{S i}_{3} \mathbf{N}_{4}-\mathbf{C N O}$ (b).

\section{Ángulo de contacto}

Los valores promedio de ángulo de contacto obtenidos empleando agua como disolvente (Tabla 20), muestran un aumento para $\mathrm{SiO}_{2}$ tras la etapa de bloqueo con PEG-organosilano, consecuencia de la introducción de una capa orgánica que provoca un incremento de la hidrofobia de las superficies.

Tabla 20. Medidas de ángulo de contacto $(\theta)$.

\begin{tabular}{l|l}
\hline Superficie & $\boldsymbol{\theta}_{\text {agua }}$ \\
\hline \hline $\mathrm{SiO}_{2}$ & $35,6 \pm 1,6$ \\
$\mathrm{SiO}_{2}(-\mathrm{PEG})$ & $64,3 \pm 3,6$ \\
$\mathrm{Si}_{3} \mathrm{~N}_{4}$ & $47,1 \pm 1,7$ \\
$\mathrm{Si}_{3} \mathrm{~N}_{4}(-\mathrm{CNO})$ & $51,7 \pm 2,2$ \\
\hline
\end{tabular}


En las superficie de nitruro de silicio, se observa también un aumento del ángulo de contacto tras la introducción del alcoxisilano ( $\mathbf{S i}_{\mathbf{3}} \mathbf{N}_{\mathbf{4}}$ (-CNO)), aunque de menor magnitud, debido a la menor longitud de la cadena para el ICPTS y mayor polaridad del grupo isocianato.

\subsubsection{Estudios de la modificación química selectiva a través de la química del enlace Si-N (Ruta 3)}

Respecto a las estrategias que aprovechan la reactividad de los grupos amino presentes en el nitruro, deben tenerse en cuenta tres consideraciones. En primer lugar, el paso previo para la pasivación de óxido de silicio no es necesario, ya que las reacciones se producen a través de los grupos amino que no están presentes en óxido de silicio. En segundo lugar, la etapa de etching con HF es necesaria para eliminar el óxido de silicio nativo en nitruro de silicio, aumentando así la concentración de los grupos amino en la superficie. Por último, la reacción posterior al tratamiento con HF debe llevarse a cabo en atmósfera inerte para evitar la oxidación del nitruro de silicio. En esta línea, se estudiaron dos opciones (Figura 41). La primera de ellas (Ruta 3.1) se basó en la reacción con ácido 11bromoundecanoico, que se une a los grupos amino de la superficie mediante un mecanismo de sustitución nucleofílica de tipo SN1, obteniendo los mejores resultados para una concentración $0,16 \mathrm{M}$ de bromoácido. Este tratamiento se llevó a cabo en caliente durante $5 \mathrm{~h}$.

En la segunda aproximación propuesta (Ruta 3.2.) se optó por el acoplamiento directo de glutaraldehído al amino del nitruro a través de la formación de una base de Schiff. A priori, esta vía puede parecer poco fiable debido a la inestabilidad de los enlaces imina; sin embargo, en realidad se dispone de una mezcla de derivados poliméricos de glutaraldehído en disolución, que contienen grupos aldehído $\alpha$, $\beta$ insaturados. Los aminos de las proteínas enlazan a través del $\mathrm{C}_{\beta}$, formandose un 
enlace tipo amino, que confiere estabilidad al derivado obtenido. Las condiciones óptimas de reacción se alcanzaron para un tratamiento con glutaraldehído $0,53 \mathrm{M}$ durante $2 \mathrm{~h}$, en atmósfera de argon y a temperatura ambiente.

Los diferentes productos de reacción obtenidos para las estrategias propuestas a través de la química del enlace $\mathrm{N}-\mathrm{H}$, se caracterizaron por técnicas de ángulo de contacto, XPS y elipsometría.

$\mathrm{Si}_{\mathrm{x}} \mathrm{N}_{4}$

$\mathrm{SiO}_{2}$
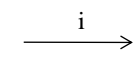

$\mathrm{Si}_{3} \mathrm{~N}_{4}(-\mathrm{H}) / \mathrm{SiO}_{2}$

$\mathrm{Si}_{3} \mathrm{~N}_{4} / \mathrm{SiO}_{2}$

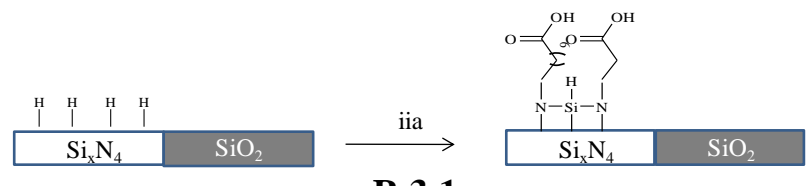

R.3.1

$\mathrm{Si}_{3} \mathrm{~N}_{4}(-\mathrm{COOH}) / \mathrm{SiO}_{2}$
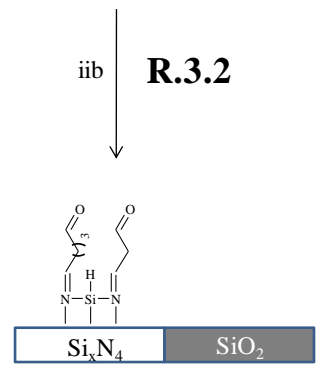

$\mathrm{Si}_{3} \mathrm{~N}_{4}(-\mathrm{CHO}) / \mathrm{SiO}_{2}$

Figura 41. Modificación química selectiva de $\mathrm{Si}_{3} \mathrm{~N}_{4}$ (Ruta 3). i.HF $\left(1 \% \mathrm{H}_{2} \mathrm{O}\right), 2$ min; iia. $\mathrm{BrCH}_{2}-\left(\mathrm{CH}_{2}\right)_{9}-\mathrm{COOH}\left(0,16 \mathrm{M}\right.$ tolueno), $5 \mathrm{~h}$ (Ruta 3.1); iib. HOC- $\left(\mathrm{CH}_{2}\right)_{3}{ }^{-}$ CHO (0,53 M en PBS 0,01×), 2 h (Ruta 3.2). 


\section{Ángulos de contacto}

Los resultados obtenidos, empleando agua como disolvente, mostraron que tanto para $\mathbf{S i}_{3} \mathbf{N}_{4}(-\mathbf{C O O H})$, resultado de la reacción de nitruro de silicio con ácido bromoundecanoico, como para $\mathbf{S i}_{3} \mathbf{N}_{4}$ (-CHO), derivado de la reacción con glutaraldehído, se produce un incremento de los ángulos de contacto respecto al material original $\left(\mathbf{S i}_{3} \mathbf{N}_{4}\right)$, consecuencia del aumento de la hidrofobia de la superficie tras la introducción de cadenas alquiladas (Tabla 21).

Tabla 21. Medidas de ángulo de contacto $(\theta)$.

\begin{tabular}{l|l}
\hline Superficie & $\theta_{\text {agua }}$ \\
\hline \hline $\mathbf{S i}_{3} \boldsymbol{N}_{4}$ & $47,1 \pm 1,7$ \\
$\mathbf{S i}_{3} \boldsymbol{N}_{4}(-\mathrm{COOH})$ & $59,2 \pm 4,1$ \\
$\mathbf{S i}_{3} \boldsymbol{N}_{4}(\mathbf{- C H O})$ & $56,1 \pm 3,4$ \\
\hline
\end{tabular}

\section{Espectroscopía fotoelectrónica de rayos X (XPS)}

Mediante XPS se analizó la composición química de las superficies de $\mathrm{Si}_{3} \mathrm{~N}_{4}$ y $\mathrm{SiO}_{2}$, antes y después de la modificación química con glutaraldehído. La Figura 42a muestra el espectro XPS del nitruro de silicio en el que se observa la presencia de los picos $\mathrm{Si} 2 \mathrm{p}$, Si $2 \mathrm{~s}$ y $\mathrm{N}$ 1s. Los registros del oxígeno pueden deberse a la oxidación parcial de la superficie durante la manipulación de la muestra, mientras que la presencia del pico de carbono se atribuyó a posibles impurezas orgánicas. 

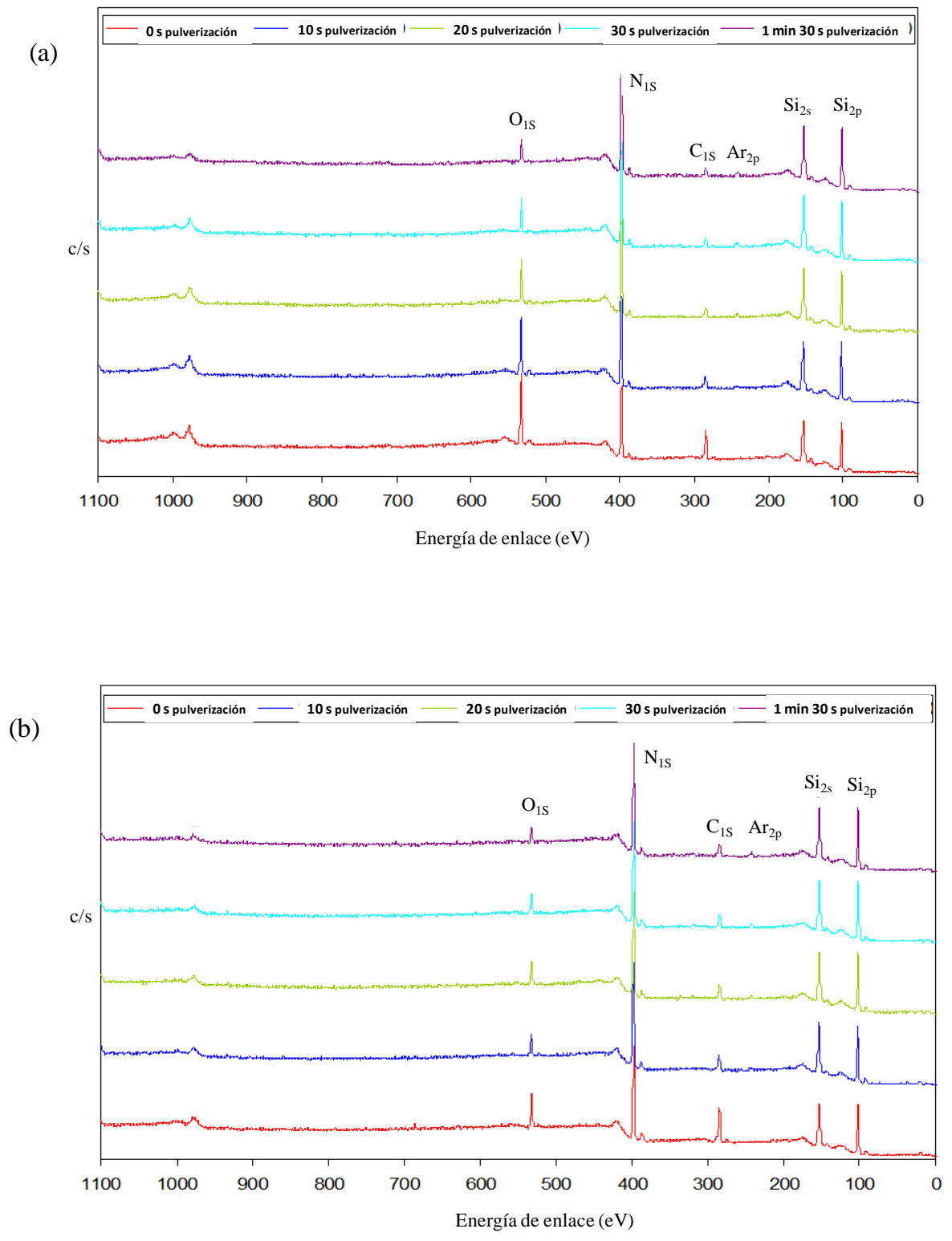
(c)

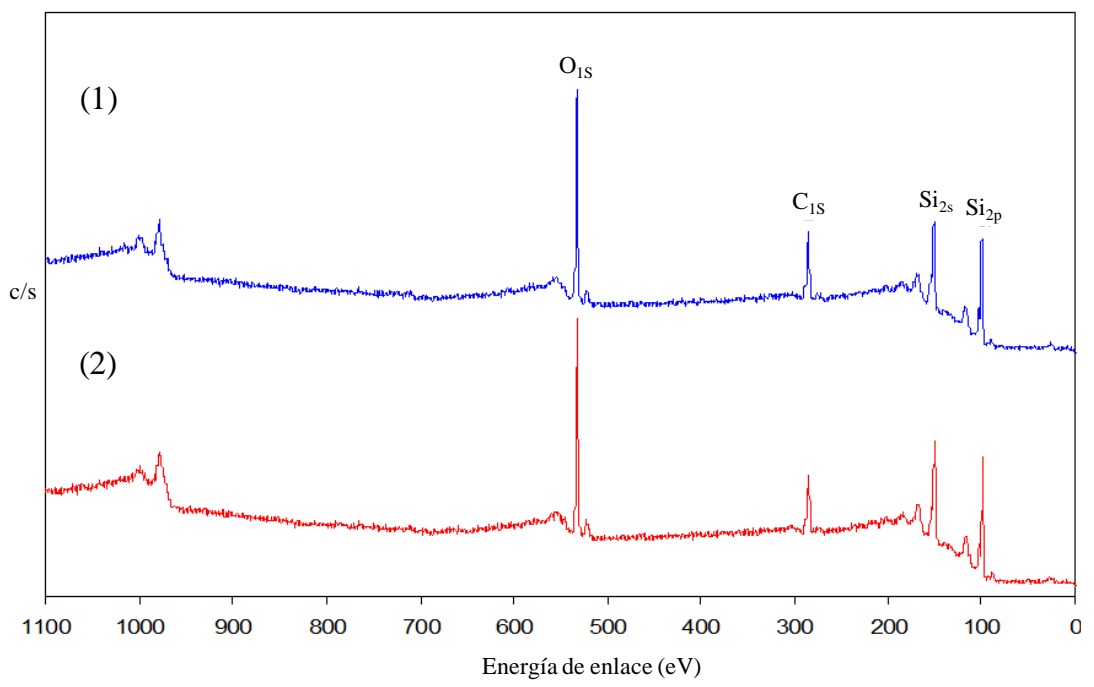

Figura 42. Espectro fotoelectrónico de rayos $X$, (a) $\mathrm{Si}_{3} \mathrm{~N}_{4}$; (b) $\mathbf{S i}_{3} \mathbf{N}_{4^{-}}$ (CHO) y (c) $\mathbf{S i O}_{2}$ tratado (1) y sin tratar (2).

Por otro lado, la Figura 42b muestra el espectro de XPS tras la funcionalización con glutaraldehído $\left(\mathbf{S i}_{3} \mathbf{N}_{4}\right.$ (-CHO)). Se observa un aumento del pico correspondiente al carbono C 1s, acorde con la formación de la capa orgánica en la superficie, así como la disminución en la señal correspondiente al oxígeno, ya que tras la etapa de etching se elimina el $\mathrm{SiO}_{2}$ nativo, siendo el oxígeno de la capa orgánica el único que prevalece en la superficie.

Otra evidencia que corrobora la formación de la capa orgánica es que, tras diferentes tiempos de sputtering, la relación entre los picos de carbono y oxígeno permanece constante para la superficie funcionalizada, pero no para el material sin modificar (ver Figuras $42 \mathrm{a} \mathrm{y} \mathrm{b).} \mathrm{Esto} \mathrm{sugiere} \mathrm{que} \mathrm{el} \mathrm{C}$ y el $\mathrm{O}$ presente pertenecen a la misma capa y se están eliminando de forma simultánea, mientras que para la muestra sin modificar los dos picos disminuyen sin relación alguna, lo que indica la independencia de ambos. 
Finalmente, la Figura 42c muestra los espectros de XPS para el óxido de silicio antes y después del tratamiento con glutaraldehído. En ellos no se observan diferencias significativas, concluyendo que el glutaraldehído no se ha unido a la superficie, demostrando la eficacia y selectividad de esta ruta.

\section{Elipsometría}

Para la caracterización mediante elipsometría, las superficies $\mathbf{S i}_{\mathbf{3}} \mathbf{N}_{\mathbf{4}} \mathbf{-} \mathbf{C H O}$ se trataron con BSA ( $2 \%$ en PBS1 $\times$ ). Utilizando un modelo de medida de tres capas los resultados obtenidos fueron: $\mathrm{Si}_{3} \mathrm{~N}_{4} /$ glutaraldehido ( $4 \mathrm{~nm}$, índice de refracción 1,5)/ BSA (10 nm, índice de refracción 1,5).

Los resultados demostraron la presencia de una capa de bajo grosor de proteína sobre la superficie de nitruro de silicio activada con grupos aldehído. Estas condiciones favorecen el bioreconocimiento en el sistema, incrementando considerablemente la sensibilidad del mismo.

\subsubsection{Estudios de inmovilización de biomoléculas sobre las superficies activadas}

Con el fin de analizar las prestaciones de las superficies modificadas según cada una de las vías desarrolladas, se estudió la capacidad de inmovilización de biorreceptores y la biodisponibilidad de los mismos. Para ello se llevaron a cabo estudios de inmovilización de biomoléculas marcadas con fluoróforos. Así, diferentes concentraciones de GAR-Cy5 $(5-200 \mu \mathrm{g} / \mathrm{mL})$ en PBS1× fueron depositadas sobre cada una de las superficies, creando matrices $3 \times 3$ con un tamaño medio de punto de $500 \mu \mathrm{m}$. La intensidad de fluorescencia se registró mediante LFS, con el fin de obtener la correspondiente curva de calibrado.

Tras un periodo de $2 \mathrm{~h}$ de incubación a temperatura ambiente en cámara húmeda, los chips fueron lavados con PBS-T y agua (5 min), y secados bajo flujo 176 
de aire, midiendo la fluorescencia a $635 \mathrm{~nm}$. La cantidad de anticuerpo inmovilizado fue cuantificado a partir de la curva de calibrado correspondiente.

En la Tabla 22, se presentan los resultados de inmovilización para una concentración de sonda depositada de $50 \mu \mathrm{g} / \mathrm{mL}$. En ellos se muestra la concentración de anticuerpo inmovilizado $\left(\mathrm{pmol} / \mathrm{cm}^{2}\right)$, el porcentaje de recubrimiento como cociente de inmovilización real frente al ideal de formación de monocapa $\left(2,1 \mathrm{pmol} / \mathrm{cm}^{2}\right)^{263}$ y la relación señal/ruido (señal de fluorescencia/ desviación estándar del blanco (fluorescencia de fondo), $\mathrm{SF} / \mathbf{s}_{\boldsymbol{b}}$. Adicionalmente, se incluyen parámetros relativos a las condiciones del proceso (temperatura y tiempo), con la finalidad de comparar las diferentes metodologías.

Los mejores porcentajes de recubrimiento ( 78 y $70 \%$ ) se alcanzaron para la Ruta 2 (química del enlace Si-OH) y 3.2 (reacción con el crosslinker glutaraldehído), respectivamente. Ambas metodologías presentan relaciones señal ruido superiores a 25, lo que da una idea de la bondad de la medida. Además, estas estrategias ofrecen ventajas en su procesado, ya que trabajan a temperatura ambiente y no requieren tiempos largos de preparación.

Sin embargo, dada la complejidad que presenta la Ruta 2, por la necesidad de diseñar y optimizar un estámper que permita la unión física selectiva de la biomolécula a la guía de nitruro, así como la dificultad del alineado del mismo con la de la superficiede la guía, se optó por aplicar la Ruta 3.2 sobre guías de onda. Esta metodología, basada en la unión selectiva y directa del glutaraldehído a la superficie de nitruro, es sencilla y reproducible, emplea condiciones de reacción suaves y permite la inmovilización eficiente de las biomoléculas en superficies planas. 
Tabla 22. Resultados de la inmovilización de GAR-Cy5 (50 $\mu \mathrm{g} / \mathrm{mL})$.

\begin{tabular}{|c|c|c|c|c|c|}
\hline Muestra & $\begin{array}{c}{[G A R-C y 5]} \\
\left(\mathrm{pmol} / \mathrm{cm}^{2}\right)\end{array}$ & $\begin{array}{c}\text { Recubrimiento } \\
\text { (\%) }\end{array}$ & $\begin{array}{r}S N R \\
\left(S F / s_{b}\right)\end{array}$ & $\begin{array}{l}T \\
\left({ }^{\circ} \mathrm{C}\right)\end{array}$ & $\begin{array}{l}t \\
(h)\end{array}$ \\
\hline $\begin{array}{c}\mathrm{Si}_{3} \mathrm{~N}_{4}(-\mathrm{COOH})^{a} \\
\quad(\text { RUTA 1) }\end{array}$ & 1,01 & 48 & $>15$ & 165 & 24 \\
\hline $\begin{array}{c}\mathrm{Si}_{3} \mathrm{~N}_{4}(-\mathrm{COOH})^{b} \\
\quad(\text { RUTA 1) }\end{array}$ & 0,88 & 42 & $>10$ & -- & 48 \\
\hline $\begin{array}{c}\mathrm{Si}_{3} \mathrm{~N}_{4}(-\mathrm{CNO}) \\
(\mathrm{RUTA} 2)\end{array}$ & 1,64 & 78 & $>25$ & 25 & 0,5 \\
\hline $\begin{array}{c}\mathrm{Si}_{3} \mathrm{~N}_{4}(-\mathrm{COOH}) \\
(\mathrm{RUTA} 3.1)\end{array}$ & 1,13 & 54 & $>20$ & 165 & 5 \\
\hline $\begin{array}{c}\mathrm{Si}_{3} \mathrm{~N}_{4}(-\mathrm{CHO}) \\
(\mathrm{RUTA} 3.2)\end{array}$ & 1,47 & 70 & $>25$ & 25 & 2 \\
\hline
\end{tabular}

a activación fotoquímica, ${ }^{\mathrm{b}}$ activación térmica

Una vez seleccionada la vía de modificación química, y previo a su aplicación en estructuras de guía de onda, se realizaron estudios de bioactividad para confirmar que tras la pérdida de grados de libertad que implica la inmovilización de la biomolécula sobre el soporte rígido, ésta mantiene su capacidad de reconocimiento. Para ello, se empleó el sistema modelo BSA-antiBSA, siguiendo el esquema de trabajo representado en la Figura 43. Para los estudios de biodisponibilidad en superficie plana mixta de nitruro y óxido de silicio, los anticuerpos antiBSA fueron inmovilizados en chips previamente activados con glutaraldehído, según el protocolo descrito en el apartado 3.4.2.3. Tras dos horas de incubación en cámara oscura y húmeda, fueron lavados con PBS-T y agua, y tratados con una disolución de OVA al $1 \%$, durante dos horas a $37^{\circ} \mathrm{C}$ con la finalidad de bloquear los grupos aldehído residuales de la superficie del nitruro. Por último, la BSA se marcó con 
Cy5 de acuerdo al procedimiento recomendado por el proveedor, y se aplicó con ayuda de un cubreobjetos sobre la superficie de ensayo, a una concentración de 100 $\mu \mathrm{g} / \mathrm{mL}$ en PBS-T. Tras un período de incubación de 1 h, el chip se lavó con PBS-T y agua, midiendo la fluorescencia a $635 \mathrm{~nm}$.

Los resultados (Figura 43), muestran que el anticuerpo anclado no pierde su actividad tras la unión al soporte. También queda demostrada la elevada la selectividad de la unión de las biomoléculas a las superficies de nitruro activadas frente a las de óxido, alcanzándose un coeficiente de selectividad $\left(\mathrm{SF}_{\mathrm{SiO} 2} / \mathrm{SF}_{\mathrm{Si3N} 4}\right)$ de 1:15. Por todo ello, se concluyó que la metodología propuesta para la modificación química selectiva del nitruro de silicio según la Ruta 3.2 es viable en estructuras planas $\mathrm{Si}_{3} \mathrm{~N}_{4} / \mathrm{SiO}_{2}$. El siguiente paso fue demostrar su aplicabilidad en estructuras de guía de ondas.

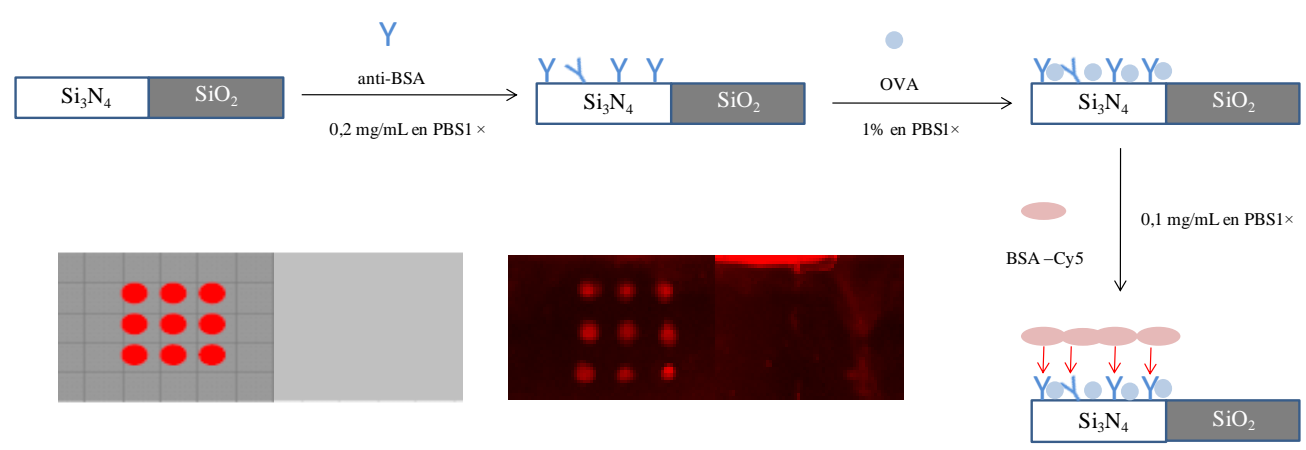

Figura 43. Esquema del inmunoensayo en formato directo sobre una superficie plana de $\mathrm{Si}_{3} \mathbf{N}_{4}$ (-CHO)/ $\mathrm{SiO}_{2}$ e imagen del chip tomada mediante LFS. 


\subsubsection{Aplicación en nanoestructuras (3D)}

\subsubsection{Estudio en estructuras patrón}

Los dos problemas principales relacionados con la aplicación del tratamiento químico optimizado para chips planos y la inmovilización de biorreceptores (proteínas, ácidos nucleicos, etc.) en nanoestructuras 3D fueron, en primer lugar, la inmovilización selectiva en la región slot y, en segundo lugar, la búsqueda de técnicas que dieran información sobre lo que ocurría en las nanoguías. Para ello, los experimentos de optimización fueron realizados empleando estructuras patrón integradas por diferentes tipos de guías, (A) guía tipo stripe, (B) guía tipo slot, (C) guía tipo channel, todas ellas con una longitud de $1 \mathrm{~mm}$ y diferenciadas en morfología y anchura de guía (ver el apartado de 3.1.2 de Material y Métodos).

La elección de técnicas de caracterización apropiadas presenta una dificultad inherente al pequeño tamaño de las estructuras. Así pues, se optó por microscopía confocal de fluorescencia (MCF) en el caso de moléculas fluorescentes (GAR-Cy5), y microscopía de barrido electrónico (SEM) para moléculas no marcadas.

Los resultados expuestos a continuación se han obtenido para los distintos tipos de guía que componen el chip patrón, aunque únicamente son mostrados los referentes a la guía slot debido al interés de la misma en el presente trabajo.

En primer lugar, se demostró la unión covalente del anticuerpo GAR-Cy5 al soporte, mediante MCF. Para ello, el chip fue tratado según la Ruta 3.2, inmovilizando posteriormente el anticuerpo marcado (GAR-Cy5) a una concentración de $50 \mu \mathrm{g} / \mathrm{mL}$, durante $1 \mathrm{~h}$ en cámara oscura y húmeda. La señal de fluorescencia fue detectada mediante MCF a $635 \mathrm{~nm}$, y comparada con un chip control sin tratamiento químico. En la Figura 44a, se observa la falta de homogeneidad de la señal de fluorescencia en el chip tratado, debida a la 
inmovilización del anticuerpo, mientras que el chip sin tratar mostró una señal de fluorescencia residual altamente homogénea, debida al fenómeno de reflexión del láser sobre la superficie del nitruro de silicio.

Por otro lado, mediante espectroscopia electrónica de barrido (SEM) se estudió la inmovilización de estreptavidina. En la Figura 44b se observa que la proteína quedaba unida a las nanoguías, penetrando en la región slot, sin llegar a anclarse en el área comprendida entre guías.

Por último, para demostrar la biodisponibilidad de la proteína anclada en la nanoguía, se diseñó el ensayo mostrado en la Figura 44c. En en primer lugar se inmovilizó covalentemente estreptavidina y tras bloqueo de los grupos aldehído activos con OVA, se adicionó un oligonucleótido biotinilado marcado con Cy5. Los resultados fueron analizados mediante SEM y MCF. Paralelamente, se realizaron dos controles, uno sin usar sonda biotinilada y otro sin tratamiento con glutaraldehído. Los resultados SEM mostraron que tanto en el ensayo como en el primer control se produce la inmovilización de la estreptavidina, no siendo así para el control sin tratamiento con glutaraldehído. Las medidas empleando MCF únicamente mostraron fluorescencia en el caso del ensayo completo. Estos ensayos demostraron que la inmovilización del anticuerpo sobre $\mathrm{Si}_{3} \mathrm{~N}_{4}$ es efectiva y selectiva, así como que las biomoléculas inmovilizadas mantienen su bioactividad, permitiendo la detección selectiva sobre la guía de ondas de las dianas moleculares de interés. 
(a)
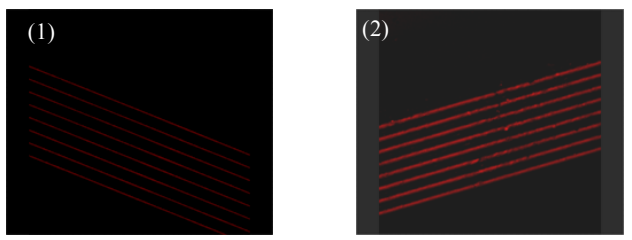

(b)
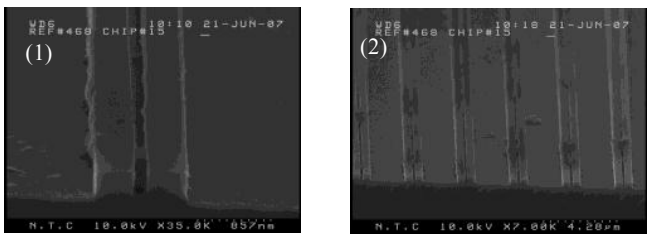

(c)

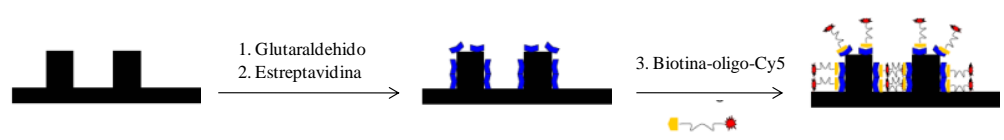

(d)
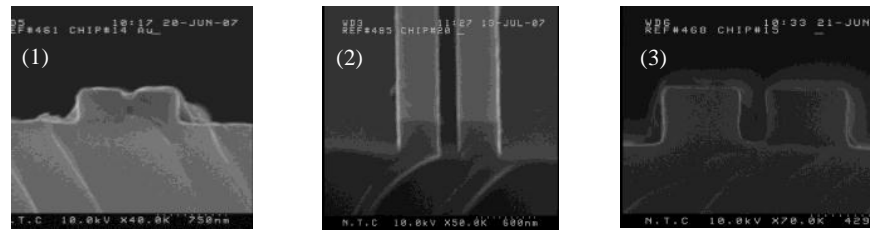

(e)
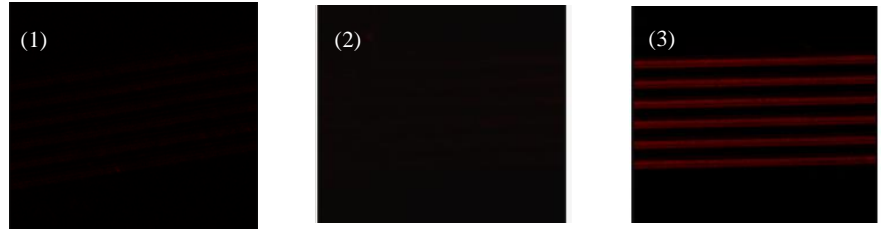

Figura 44. (a) Imágenes de MCF de la guía tipo grating para los chips patrón tratados con GAR-Cy5 (50 $\mu \mathrm{g} / \mathrm{mL}$ en PBS $1 \times$ ), sin modificar (1) y activados con glutaraldehído (2). (b) Imágenes de SEM de la guía tipo slot de los chips funcionalizados tratados con estrepavidina $(100 \mu \mathrm{g} / \mathrm{mL}$ en PBS $1 \times$ ). (c) Esquema del ensayo. Imágenes de SEM (d) y MCF (e) para guía slot tras el inmunoensayo, (1) control 1, sin oligo biotinilado, (2) control 2, sin glutaraldehído, (3) ensayo completo. 


\subsubsection{Estudio en estrucuras de microanillos resonadores: Detección sin marcaje}

Tras demostrar la viabilidad de la ruta R.2, que emplea el crosslinker glutaraldehído para la modificación química selectiva de nitruro de silicio, en estructuras de ensayo patrón constituídas por diferentes tipos de guía de ondas, el siguiente paso fue la aplicación del procedimiento optimizado en estructuras nanofotónicas biosensoras, y la correspondiente caracterización optoquímica sin marcaje (label-free), siendo este paso crucial para la posible integración del chip fotónico en un sistema biosensor tipo Lab-on-a-chip.

Para ensayar la detección sin marcaje se empleó la estructura fotónica descrita en el apartado 4.2, y el sistema modelo BSA-antiBSA en formato directo. Para ello, el chip de ensayo fue previamente tratado con disolución piraña $\left(\mathrm{H}_{2} \mathrm{SO}_{4}: \mathrm{H}_{2} \mathrm{O}_{2}\right.$ (3:1)), con la finalidad de eliminar la materia orgánica que hubiese en la superficie sensora. Después, los chips se trataron con disolución diluida de HF para eliminar la capa de óxido nativa del nitruro y permitir la unión directa del glutaraldehído a los grupos amino de la superficie del nitruro, tras un tratamiento con el crosslinker al $5 \%$ bajo atmosfera de argón, durante $2 \mathrm{~h}$. A continuación, las superficies fueron tratadas con concentraciones crecientes de antiBSA durante 20 min, lavadas con agua desionizada y, tras cada paso incubación/lavado, caracterizadas por un sistema óptico (SO) de temperatura controlada ${ }^{187}$, depositando una gota de agua sobre la superficie sensora durante la realización de cada medida. La materia inmovilizada sobre la guía de ondas produce una variación del índice de refracción que genera una alteración en las propiedades de resonancia del microanillo y, por tanto, en la longitud de onda de resonancia. El desplazamiento en la longitud de onda de resonancia puede determinarse monitorizando el espectro óptico a la salida de la nanoguía lineal, pudiendo ser relacionado con la concentración de materia inmovilizada por unidad de superficie. 
En la Figura 45a se muestra el espectro normalizado de la señal de transmisión monitorizada a la salida de la guía de onda, para concentraciones crecientes de antiBSA. En ella, se observa un desplazamiento hacia el rojo conforme aumenta la concentración de anticuerpo. Tras representar el desplazamiento de la longitud de onda de resonancia en función de las concentraciones de anti-BSA, se obtuvo la gráfica de la Figura 45b, en la que se observa que el desplazamiento de la longitud de onda de resonancia alcanza la saturación a una concentración de anti-BSA de $17,2 \mu \mathrm{g} / \mathrm{mL}$, indicando el recubrimiento total de la superficie de la guía de onda.

La sensibilidad del sistema para la captura de antiBSA se calculó como $\mathrm{S}_{\mathrm{B}}=$ $\left(\delta \lambda / \sigma_{\mathrm{p}}\right)$, donde $\delta \lambda$ es el desplazamiento espectral en el punto de saturación y $\sigma_{\mathrm{p}}$ equivale a la densidad de la monocapa de biomoléculas. Como se observa en Figura 45b, el desplazamiento espectral para la detección de anti-BSA cuando se alcanza la saturación fue de $3 \mathrm{~nm}$. La densidad de una monocapa de anti-BSA se calculó a partir del tamaño medio de una molécula de anti-BSA $\left(\mathrm{d}_{\text {antiBSA }}=12 \mathrm{~nm}\right)$, como $\sigma_{\mathrm{p}, \text { antiBSA }}=\left(\mathrm{M}_{\text {antiBSA }} / \mathrm{N}_{\mathrm{A}}\right) /\left(\mathrm{d}_{\text {antiBSA }}\right)^{2}=1,7 \mathrm{ng} / \mathrm{mm}^{2}$, donde $\mathrm{M}_{\text {antiBSA }}=147.000 \mathrm{Da}$ (masa molecular molecular de la antiBSA) y $\mathrm{N}_{\mathrm{A}}=6,02 \times 10^{23}$ (número de Avogadro). Los valores teóricos para $\sigma_{\mathrm{p}, \text { antiBSA }}$ correlacionan bien con los valores experimentales $\left(1,2 \mathrm{ng} / \mathrm{mm}^{2}\right)^{264}$, siendo por tanto la sensibilidad del sistema $\mathrm{S}_{\text {antiBSA }}=1,8 \mathrm{~nm} /\left(\mathrm{ng} / \mathrm{mm}^{2}\right)$.

Por otro lado, el límite de detección (LDD) se estimó como $\mathrm{R} / \mathrm{S}_{\mathrm{B}}$, donde $\mathrm{R}$ representa la resolución del sensor, que en el sistema óptico utilizado viene determinada por la resolución espectral $(\mathrm{R}=50 \mathrm{pm})$. Así pues, se obtuvo un límite de detección para antiBSA de $28 \mathrm{pg} / \mathrm{mm}^{2}$. 
(a)

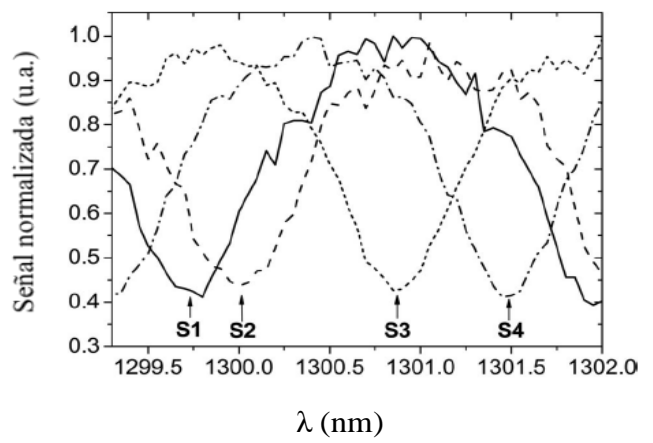

(b)

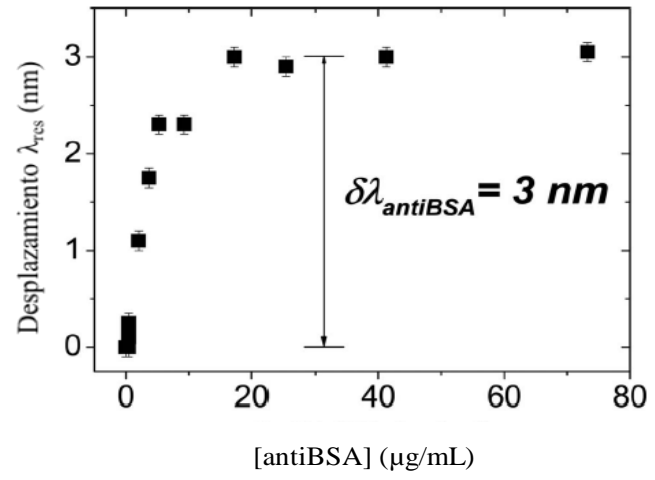

(c)

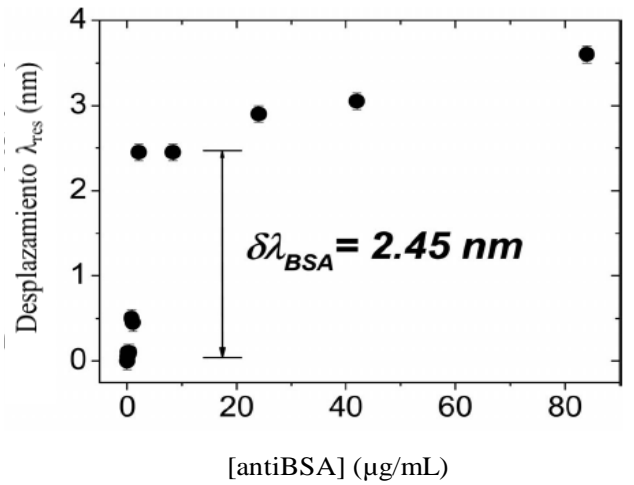

Figura 45. (a) Espectro normalizado de la señal de transmisión para concentraciones crecientes de anti-BSA. Curva de saturación del desplazamiento de la longitud de onda de resonancia para antiBSA (b) y BSA (c). 
Para la detección de BSA, tras la saturación del sistema con antiBSA, se llevó a cabo una etapa de bloqueo con etanolamina a fin de desactivar los grupos aldehído residuales en la superficie de la guía. A continuación, las superficies se incubaron con BSA a concentraciones crecientes durante $20 \mathrm{~min}$, y se lavaron con agua desionizada. Tras cada paso incubación/lavado, fueron caracterizadas del modo descrito para antiBSA, pudiendo correlacionar el desplazamiento de la longitud de onda de resonancia con la magnitud del reconocimiento biológico.

La Figura 45c, muestra el desplazamiento de la longitud de onda de resonancia para concentraciones crecientes de BSA. La gráfica muestra una curva de saturación, en la que se observa que los desplazamientos en la longitud de onda de resonancia empiezan a saturar a una concentración de $5 \mu \mathrm{g} / \mathrm{mL}$ de BSA. Ello sugiere que las biomoléculas se unen exclusivamente a la antiBSA anclada en la superficie de la guía, hasta que se produce la saturación de todos los sitios de reconocimiento, momento a partir del cual comienza a unirse de manera inespecífica. Como se observa en la gráfica, para concentraciones superiores a 5 $\mu \mathrm{g} / \mathrm{mL}$ los desplazamientos de la longitud de onda comienzan a diferir de la media espectral, aumentando más gradualmente como consecuencia de la adsorción inespecífica de la BSA. Para estimar la sensibilidad del sistema en la detección de BSA se asumió el mismo criterio tomado anteriormente para la antiBSA. Teniendo en cuenta la masa molecular de la BSA (66.399 Da) y que el desplazamiento espectral en el punto de saturación resulto ser 2,45 nm, se estimó una sensibilidad de $3,2 \mathrm{~nm} /\left(\mathrm{ng} / \mathrm{mm}^{2}\right)$ y un límite detección de $16 \mathrm{pg} / \mathrm{mm}^{2}$, considerando una resolución espectral de 50 pm.

Por otro lado, existen trabajos previos que estiman la sensibilidad del dispositivo mediante métodos numéricos ${ }^{265}$, utilizando el esquema modelo de medida mostrado en la Figura 46a y asumiendo la inmovilización selectiva de proteína exclusivamente en la guía de nitruro. La Figura 46b muestra la relación teórica 
entre el desplazamiento espectral y el grosor de la capa adyacente de proteína sobre el $\mathrm{Si}_{3} \mathrm{~N}_{4}$ en el sistema de microanillos resonadores. Teniendo en cuenta los desplazamientos espectrales tras la etapa de activación química con glutaraldehído (1 nm) y de inmovilización de antiBSA (3 nm), el grosor de la capa sobre la guía de $\mathrm{Si}_{3} \mathrm{~N}_{4}$, estimado mediante métodos numéricos (4 y $12 \mathrm{~nm}$, respectivamente) correlaciona con los obtenidos (ver apartado 4.2.1.3) mediante elipsometría (4 nm para la capa de glutaraldehído y $10 \mathrm{~nm}$ para antiBSA).

(a)

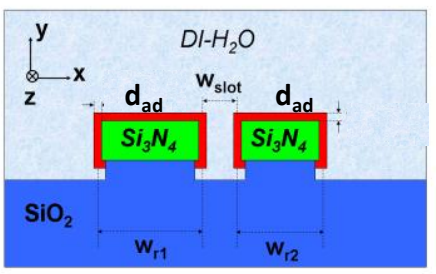

(b)

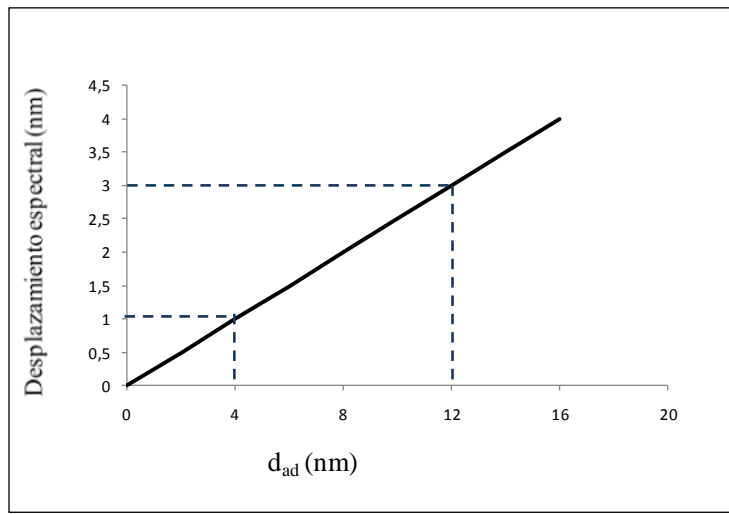

Figura 46. a) Esquema de la guía slot. $\mathrm{w}_{\mathrm{r} 1}=540 \mathrm{~nm}, \mathrm{w}_{\mathrm{r} 2}=380 \mathrm{~nm}$ $\mathrm{y}_{\mathrm{slot}}=210 \mathrm{~nm}$. b) Desplazamiento de la longitud de onda de resonancia en función del grosor de la capa biomolecular sobre la guía de $\mathrm{Si}_{3} \mathrm{~N}_{4}$. 
Los resultados obtenidos para la detección de BSA son comparables a los encontrados en la bibliografía ${ }^{68,266}$ en sistemas ópticos de detección sin marcaje, un biosensor basado en microanillos poliméricos (LDD de $250 \mathrm{pg} / \mathrm{mm}^{2}$ ) y un interferómetro Mach-Zender $\left(5 \mathrm{pg} / \mathrm{mm}^{2}\right)$.

A modo de recapitulación, los resultados de este apartado se concretan en que se ha demostrado la modificación química selectiva de una plataforma analítica basada en microanillos resonadores de nitruro de silicio sobre un sustrato de silicio. También se ha demostrado la aplicabilidad de la superficie modificada para la detección sin marcaje de BSA, empleando el sistema modelo BSA/antiBSA en formato directo, obteniendo valores de sensibilidad y límites de detección comparables a los alcanzados con sistemas establecidos para la detección sin marcaje (interferómetros, SPR, etc.). Las aproximaciones químicas estudiadas son de gran interés para el desarrollo de biosensores integrados, con gran capacidad de trabajo y detección multianalito, aplicables en el campo agroalimentario y clínico, entre otros.

\subsection{Dispositivos basados en guía de ondas plana}

La tecnología de guía de ondas plana (PWG) hace uso de la excitación de un marcador fluorescente mediante el campo evanescente generado por el guiado de la luz a través de la película del material de mayor índice de refracción (guía de onda). La excitación y detección del fluoróforo se restringe a la superficie sensora, mientras que la señal debida a moléculas no ancladas o en disolución no es detectada. Esto se traduce en un incremento significativo de la relación señal/ruido en comparación con los métodos de detección óptica convencionales al aprovechar la alta intensidad del campo y su confinamiento en la proximidad de las guías de onda, lo que proporciona una detección altamente sensible y selectiva (Figura 47). 


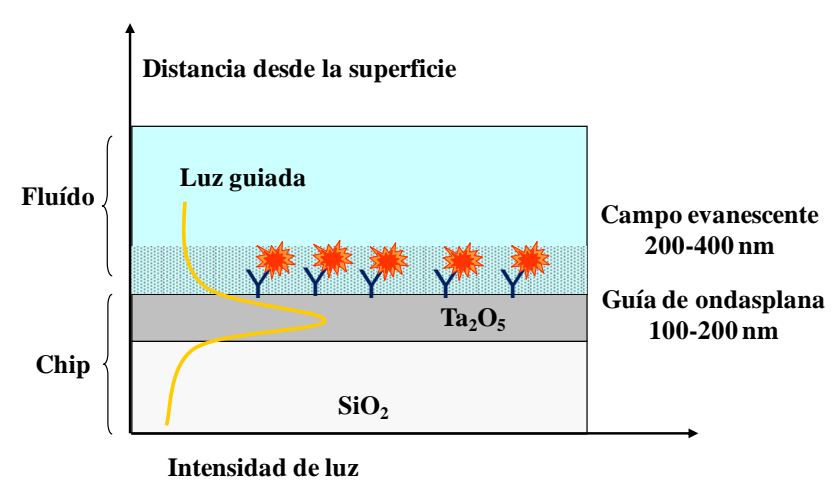

Figura 47. Diagrama del guiado de la luz en una superficie plana de $\mathrm{Ta}_{2} \mathrm{O}_{5}$.

En este sentido, el pentóxido de tántalo, además de ser un material poco explotado como sustrato para desarrollo de biosensores, presenta propiedades ópticas idóneas para la fabricación de guías de onda plana. Éstas se fabrican mediante la deposición de una película de un material con elevado índice de refracción $\left(\mathrm{Ta}_{2} \mathrm{O}_{5}, \mathrm{TiO}_{2}\right)$ sobre en un soporte transparente con bajo índice de refracción (como vidrio o determinados polímeros).

El desarrollo de soportes en base pentóxido de tántalo, fundamentados en la unión covalente de receptores moleculares -proteínas o ácidos nucleicos, principalmente-, pasa por la aplicación de una química de tratamiento de superficies para anclaje de biorreceptores bien caracterizada, simple y reproducible, que dote a estos materiales de la capacidad de anclaje de receptores específicos, sin modificar las propiedades físico-químicas del material y manteniendo inalterada la capacidad de reconocimiento del receptor.

Con este fin se propuso una metodología alternativa a las descritas en la bibliografía para la modificación de $\mathrm{Ta}_{2} \mathrm{O}_{5}$, basada en la introducción de capas orgánicas a través de la química de los organosilanos (estrategias ampliamente 
descritas para materiales silíceos ${ }^{210-212}$ ), pudiendo de este modo introducir grupos de interés para la conjugación de biomoléculas.

El trabajo desarrollado usando PWG consistió en poner a punto protocolos de impresión de micromatrices de biorreceptores sobre las superficies activadas y, posteriormente, demostrar la aplicabilidad de estos sistemas sensores a problemáticas reales mediante la puesta a punto de ensayos de detección de anticuerpos de hepatitis B en muestras de suero sanguíneo. Los resultados obtenidos fueron comparados con los de las metodologías de referencia, ampliamente establecidas, basadas en inmovilización de sondas por adsorción sobre sustratos de pentóxido de tántalo químicamente activados con compuestos derivados de alquilfosfonatos ${ }^{229,230}$.

\subsubsection{Modificación química de pentóxido de tántalo}

Para la modificación química de las superficies de pentóxido de tántalo se emplearon alcoxisilanos. Este tipo de compuestos, ampliamente utilizado para superficies de óxido de silicio, se unen a la superficie formando siloxanos con los grupos hidroxilo superficiales, ofreciendo una gran versatilidad debido al gran número de grupos funcionales disponibles para el anclaje de biomoléculas. Además presenta la ventaja de ser una metodología rápida y sencilla, aplicada en condiciones suaves de $\mathrm{pH}$, temperatura y fuerza iónica, sin alterar la estabilidad fisiológica y la actividad de los biorreceptores.

En la Figura 48 se muestran las diferentes vías de modificación superficial de pentóxido de tántalo ensayadas. 


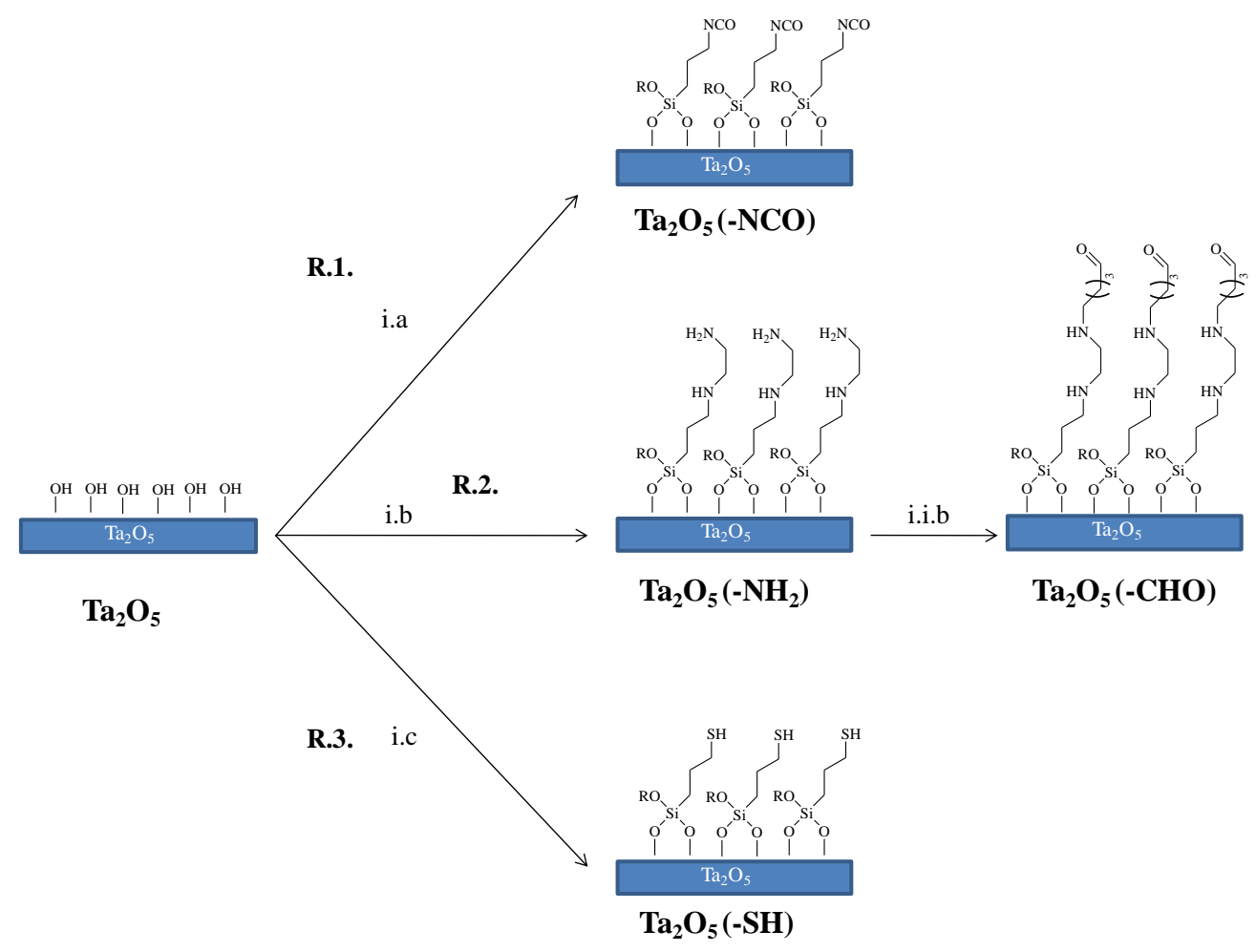

Figura 48. Vías de modificación química de $\mathrm{Ta}_{2} \mathrm{O}_{5}$. i. a. $\left(\mathrm{CH}_{3} \mathrm{CH}_{2} \mathrm{O}\right)_{3} \mathrm{Si}\left(\mathrm{CH}_{2}\right)_{3} \mathrm{NCO}$ (2,3\% en hexano; $0,5 \%$ agua), 1,5 h, (R1). i.b. $\left(\mathrm{CH}_{3} \mathrm{CH}_{2} \mathrm{O}\right)_{3} \mathrm{Si}\left(\mathrm{CH}_{2}\right)_{3} \mathrm{NH}\left(\mathrm{CH}_{2}\right)_{2} \mathrm{NH}_{2}$ (2,3\% en disolución metanólica; $0,15 \mathrm{M}$ AcOH con contenido 3,7\% en agua), 1,5 h; iib. $\mathrm{HOC}-\left(\mathrm{CH}_{2}\right)_{3}-\mathrm{CHO}(1 \%$ en $\mathrm{PBS} 1 \times), 2 \mathrm{~h}$, (R2); ic. $\left(\mathrm{CH}_{3} \mathrm{CH}_{2} \mathrm{O}\right)_{3} \mathrm{Si}\left(\mathrm{CH}_{2}\right)_{3} \mathrm{SH}$ ( $1,8 \%$ en disolución metanólica; $0,15 \mathrm{M}$ AcOH con contenido 3,7\% en agua).

En la Ruta 1 (R1), la superficie de $\mathrm{Ta}_{2} \mathrm{O}_{5}$ se modificó con grupos isocianato por tratamiento con 3-ICPTS al 2,3\% en agua/hexano (1:2000). En la Ruta 2 (R2), las superficies fueron funcionalizadas con grupos amino mediante un tratamiento con 4-TMSPED (3,7 \% en disolución metanólica 0,15 $\mathrm{M} \mathrm{AcOH})$, introduciendo a continuación grupos aldehído por tratamiento con glutaraldehido (1\% en PBS 1×, 
durante 2 h). En la Ruta 3 (R3) el chip de pentóxido de tántalo fue tratado con 2,3 $\%$ en una mezcla agua/ metanol (0,15 M ácido acético) (1:25), para obtener una superficie funcionalizada con grupos tiol.

En todos los casos se ensayaron distintos tiempos de reacción con cada uno de los alcoxisilanos, obteniendo los mejores resultados para tiempos de rección de 1,5 h.

Los diferentes sustratos e intermedios de reacción se caracterizaron mediante técnicas de ángulo de contacto y estudios de inmovilización de biomoléculas marcadas con Cy5.

\section{Ángulo de contacto}

En la Tabla 23, se muestran los resultados obtenidos tras el tratamiento de los chips de pentóxido de tántalo con diferentes alcoxisilanos.

Como cabía esperar, la tendencia observada en los resultados es un aumento de la hidrofobia de la superficie como consecuencia de la introducción de la cadena orgánica del organosilano. El incremento del ángulo de contacto dependerá de la longitud de la cadena orgánica introducida y de la mayor o menor hidrofilia del grupo terminal. Por ejemplo, los ángulos obtenidos para $\mathbf{T a}_{2} \mathbf{O}_{5}$ (-CNO) y $\mathbf{T a}_{2} \mathbf{O}_{5}$ (SH) son menores respecto a $\mathbf{T a}_{2} \mathbf{O}_{5}\left(-\mathbf{N H}_{2}\right)$, consecuencia de la menor longitud de la cadena alquílica; sin embargo, $\mathbf{T a}_{2} \mathbf{O}_{5}$ (-CHO) presenta un valor más bajo $\left(60,7^{\circ}\right.$ frente a $68,4^{\circ}$ de $\mathbf{T a}_{2} \mathbf{O}_{5}\left(-\mathbf{N H}_{2}\right)$ ) a pesar de contener una cadena de mayor longitud, consecuencia de la mayor polaridad de los grupos funcionales. 
Tabla 23. Ángulos de contacto $(\theta)$ para superficies de $\mathrm{Ta}_{2} \mathrm{O}_{5}$ derivatizadas

\begin{tabular}{|c|c|}
\hline Superficie & $\theta_{\text {agua }}$ \\
\hline $\mathrm{Ta}_{2} \mathrm{O}_{5}$ & $42,1 \pm 2,1$ \\
\hline $\mathrm{Ta}_{2} \mathrm{O}_{5}(-\mathrm{NCO})$ & $65,7 \pm 1,5$ \\
\hline $\mathrm{Ta}_{2} \mathrm{O}_{5}\left(-\mathrm{NH}_{2}\right)$ & $68,4 \pm 1,3$ \\
\hline $\mathrm{Ta}_{2} \mathrm{O}_{5}(-\mathrm{CHO})$ & $60,7 \pm 1,9$ \\
\hline $\mathrm{Ta}_{2} \mathrm{O}_{5}(-\mathrm{SH})$ & $66,2 \pm 1,8$ \\
\hline
\end{tabular}

\subsubsection{Inmovilización de biomoléculas marcadas con Cy5}

Para comprobar la eficacia de las estrategias de modificación química, se estudió la inmovilización del anticuerpo GAR-Cy5 en cada una de las superficies activadas. Para ello, se depositaron sobre las superficies activadas disoluciones de anticuerpo de diferente concentración $(5-50 \mu \mathrm{g} / \mathrm{mL})$. Se crearon matrices de 2x3 puntos, con un $90 \%$ de humedad ambiente, depositando aproximadamente $50 \mathrm{~nL}$ por punto. Tras 2 $\mathrm{h}$ de incubación a temperatura ambiente, en cámara oscura y húmeda, los chips se lavaron con PBS1x y secaron, leyendo la fluorescencia mediante LFS. Paralelamente, este mismo procedimiento se aplicó sobre chips control sin tratamiento químico con la finalidad de descartar la unión inespecífica.

La Figura 49 resume los principales resultados obtenidos, mostrando las gráficas comparativas de la señal neta media para las diferentes superficies activadas con sus respectivos controles. Se observa que, en todos los controles realizados, la señal de fluorescencia registrada corresponde a un valor menor del $20 \%$ de la fluorescencia obtenida en el ensayo completo. Además, las relaciones señal/ ruido (SNR) calculadas fueron significativamente mejores sobre las superficies activadas $(>20)$, que en los controles $(<5)$. 
Por otro lado, teniendo en cuenta el volumen $(50 \mathrm{~nL})$ y diámetro de gota, a partir de la fluorescencia registrada y por interpolación en la correspondiente curva de calibrado, se pudo estimar la densidad de inmovilización de proteína por unidad de superficie (Apéndice I). En la Tabla 24, se representan los resultados obtenidos para una concentración de sonda de $25 \mu \mathrm{g} / \mathrm{mL}$, mostrando la concentración de sonda inmovilizada $\left(\mathrm{pmol} / \mathrm{cm}^{2}\right)$ y el porcentaje de recubrimiento como cociente de inmovilización real frente al teórico de formación de una monocapa $(2,1$ $\left.\mathrm{pmol} / \mathrm{cm}^{2}\right)^{263}$.

Las medidas de ángulo de contacto, y los estudios de inmovilización de anticuerpos marcados con Cy5 permiten corroborar la formación de una capa de organosilano en todas las estrategias desarrolladas. Sin embargo, para abordar el estudio de sistemas de ensayo empleando tecnología de guía de ondas plana se seleccionó la superficie aldehizada $\mathbf{T a}_{2} \mathbf{O}_{5}$ (-CHO), ya que ofrecía los mejores rendimientos de inmovilización.

Tabla 24. Resultado de inmovilización de GAR-Cy5 $(25 \mu \mathrm{g} / \mathrm{mL})$.

\begin{tabular}{c|cc}
\hline Muestra & $\begin{array}{c}{[\text { GAR-Cy5] }} \\
\left(\mathrm{pmol} / \mathrm{cm}^{2}\right)\end{array}$ & $\begin{array}{c}\text { Recubrimiento } \\
(\%)\end{array}$ \\
\hline \hline $\mathrm{Ta}_{2} \mathrm{O}_{5}(-\mathrm{NCO})$ & 1,07 & 51 \\
$\mathrm{Ta}_{2} \mathrm{O}_{5}(\mathrm{CHO})$ & 1,54 & 73 \\
$\mathrm{Ta}_{2} \mathrm{O}_{5}(-\mathrm{SH})$ & 0,66 & 31 \\
\hline
\end{tabular}



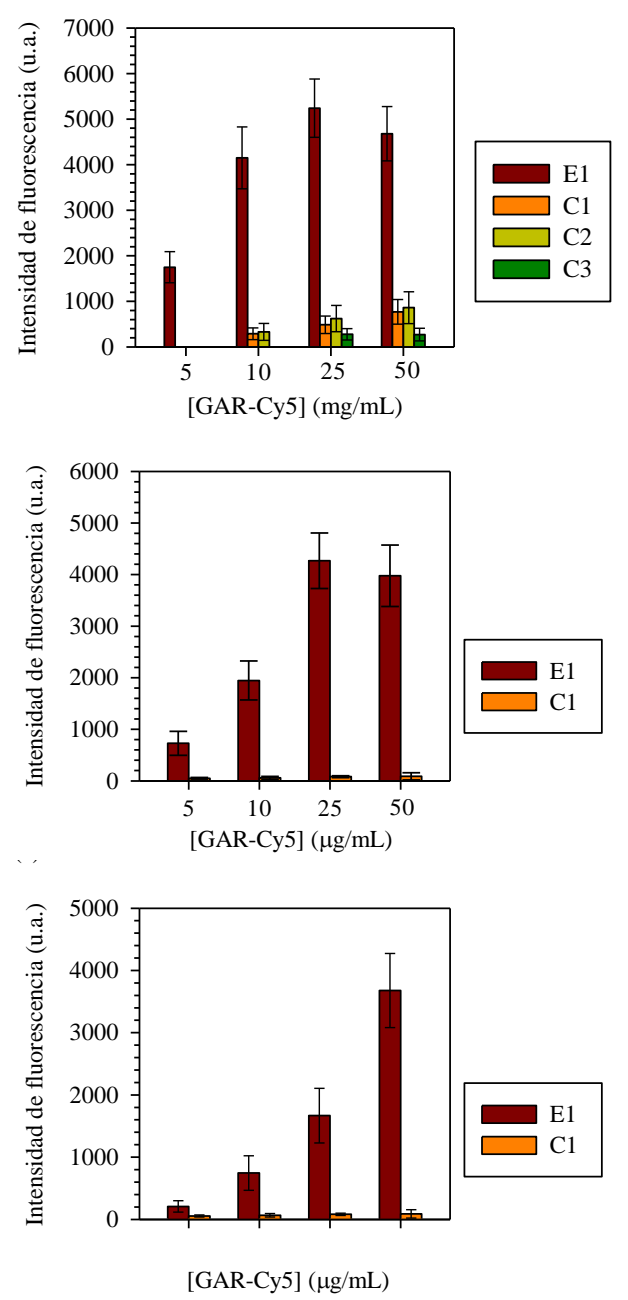

Figura 49. Intensidad de fluorescencia normalizada para concentraciones crecientes de GAR-Cy5, sobre superficies activadas con alcoxisilanos. (a) E1, $\mathbf{T a}_{2} \mathbf{O}_{5}$ (-CHO); C1, sin tratamiento; C2, sin 3-TMSPED; C3, sin glutaraldehído; (b) E1, $\mathbf{T a}_{2} \mathbf{O}_{5}$ (-NCO); C1, sin tratamiento, (c) E1, $\mathbf{T a}_{2} \mathbf{O}_{5}$ (-SH); C1, sin tratamiento. 


\subsubsection{Aplicación a estructuras de guía de ondas plana.}

Una vez optimizado el proceso de activación de las superficies e inmovilización de biorreceptores, se procedió a evaluar la compatibilidad de las superficies aldehizadas $\mathbf{T a}_{2} \mathbf{O}_{5}$ (-CHO), con técnicas de detección basadas en tecnología de guía de ondas plana, comparando los resultados con los obtenidos en superficies de referencia, basados en la unión por adsorción del elemento de biorreceptor sobre el sustrato de pentóxido de tántalo activado con cadenas alquilfosfatadas.

\subsubsection{Estudios de inmovilización de proteínas marcadas}

En este estudio se inmovilizaron disoluciones de BSA marcada con el fluoróforo Alexa-647, siguiendo el protocolo de trabajo Zeptosens (Figura 50). Para ello, las disoluciones seriadas de BSA-Alexa-647 a concentraciones comprendidas entre 312 y $0,15 \mathrm{ng} / \mathrm{mL}$, fueron impresas mediante un robot intercalando muestras de referencia para las que se utilizaron patrones. Tras la impresión, los chips fueron bloqueados con BSA y posteriormente ensamblados en el soporte de ensayo acoplado a un sistema de fluídica, que permitió la introducción de los tampones de ensayo. Finalmente, se registró la fluorescencia empleando el lector Zeptoreader.

Respecto a la detección, cuando el haz láser del equipo incide en dirección paralela a las guías de $\mathrm{Ta}_{2} \mathrm{O}_{5}$, se genera un campo evanescente perpendicular a la superficie que excita al fluoróforo situado sobre ella, discriminando al fluoróforo en disolución. La fluorescencia se registra usando una cámara CCD situada en la parte inferior del chip.

Paralelamente, los ensayos se realizaron también con chips comerciales derivatizados con alquilfosfatos $\mathbf{T a}_{2} \mathbf{O}_{\mathbf{5}}$ (-DDP), basados en la inmovilización del elemento biorreceptor por fuerzas electrostáticas débiles (adsorción) y de uso ampliamente extendido para tecnología de guía de ondas plana. 


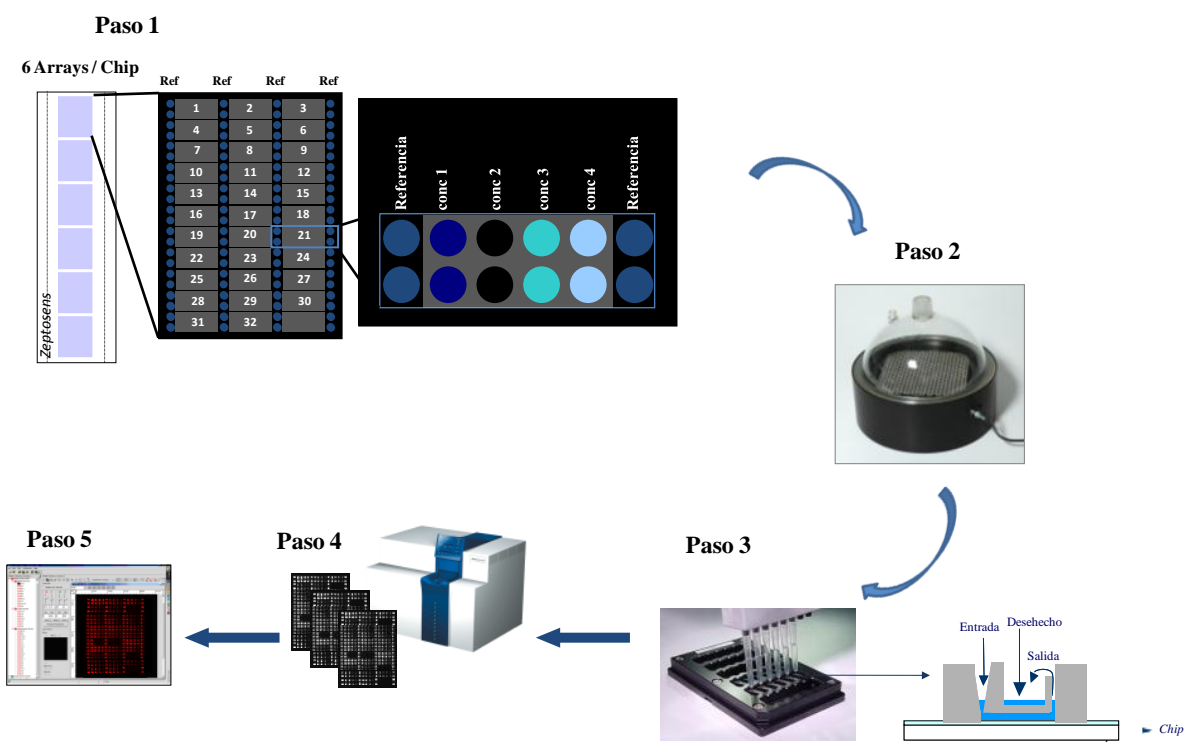

Figura 50. Protocolo de ensayo en chips de guía de ondas plana de $\mathrm{Ta}_{2} \mathrm{O}_{5}$ comercializado por Zeptosens.

Las imágenes de la Figura 51 muestran que la superficie aldehizada es compatible con la técnica de detección que utiliza guía de ondas plana, pudiendo detectar señales de fluorescencia hasta concentraciones de $0,3 \mathrm{ng} / \mathrm{mL}$ de sonda inmovilizada. Además, se observa que la capacidad de inmovilización de sondas para superficies activadas con grupos aldehído es comparable a la de chips de referencia, obteniéndose en ambos casos una baja fluorescencia de fondo. 


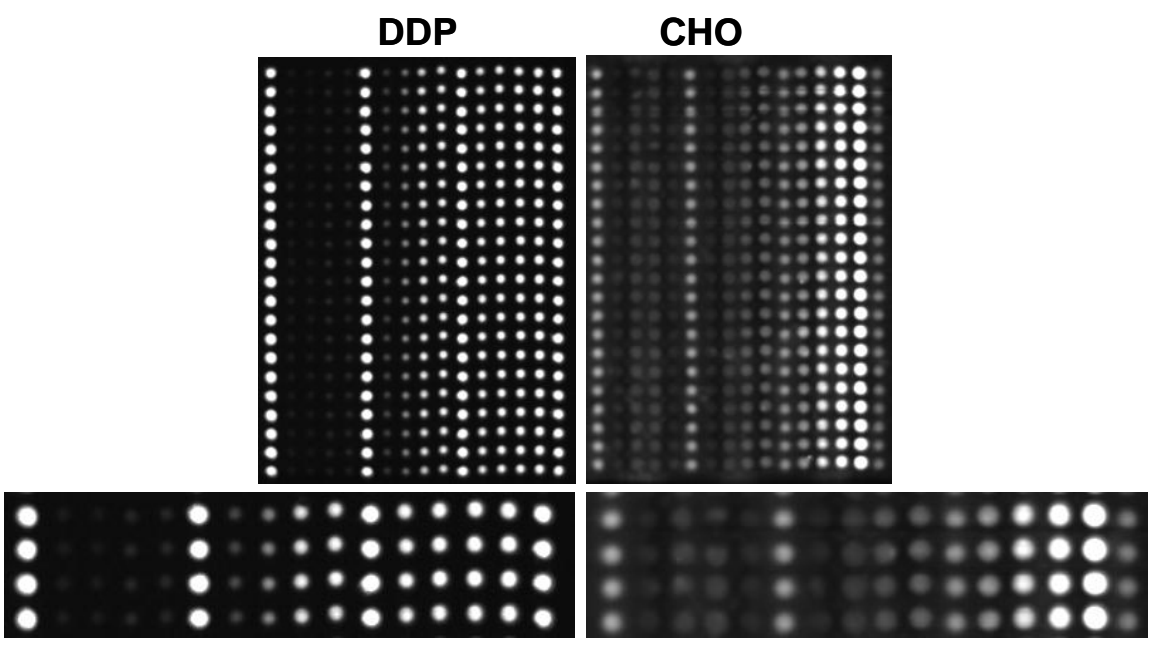

Figura 51. Resultados para diluciones seriadas de BSA-Alexa 647 sobre las superficies de $\mathrm{Ta}_{2} \mathrm{O}_{5}$ tratadas

Este estudio ha permitido demostrar que la modificación química del pentóxido de tántalo con alcoxisilanos es una alternativa viable y prometedora para el desarrollo de dispositivos sensores basados en tecnología de guía de ondas plana, dando lugar a superficies robustas. Además, ofrece las ventajas de una química rápida, sencilla y reproducible, que permite la activación de las superficies con diferentes grupos funcionales capaces de conjugarse a las biomoléculas de interés.

\subsubsection{Aplicación de la tecnología de guía de ondas plana para detección de hepatitis $B$}

La hepatitis B es causada por un virus del género Orthoepadnavirus, perteneciente a la familia Hepanaviridae. El virus tiene aproximadamente $42 \mathrm{~nm}$ de diámetro, con un ADN de doble cadena rodeado de una cápside, la cual a su vez 
está recubierta por una envoltura viral rodeada por lípidos y proteínas incrustadas en su superficie.

Ante un cuadro de hepatitis, los estudios serológicos -basados en la búsqueda de marcadores virales como antígenos y/o anticuerpos específicos- permiten hacer el diagnóstico diferencial del agente etiológico, tomar decisiones terapéuticas, efectuar el seguimiento, así como evaluar la persistencia, severidad y respuesta a la terapia. Así, la infección por el virus de la hepatitis B da lugar a la aparición en sangre de una serie de antígenos y anticuerpos, denominados marcadores serológicos, que varían en el curso de la infección y que sirven para caracterizar en qué etapa se encuentra ésta. En Tabla 25 se muestran el análisis serológico para diferentes cuadros frente al VHB.

Tabla 25. Ánalisis de los marcadores serológicos para diferentes cuadros clínicos de hepatitis $\mathrm{B}^{267}$

\begin{tabular}{l|ccccc}
\hline Estado Marcador & HBsAg & antiHBsAg & antiHBcAg & HBeAg & antiHBeAg \\
\hline \hline Fase aguda (p. ventana) & $(-)$ & $(-)$ & $(+) \operatorname{IgM}$ & $(+/-)$ & $(+/-)$ \\
Fase aguda & $(+)$ & $(-)$ & $(+) \operatorname{IgM}$ & $(+/-)$ & $(+/-)$ \\
Recuperación & $(-)$ & $(+)$ & $(+) \operatorname{IgG}$ & $(-)$ & $(+/-)$ \\
Postvacunación & $(-)$ & $(+)$ & $(-)$ & $(-)$ & $(-)$ \\
Crónica (muy contagiosa) & $(+)$ & $(-)$ & $(+) \operatorname{IgG}$ & $(+)$ & $(-)$ \\
Crónica (poco contagiosa) & $(+)$ & $(-)$ & $(+) \operatorname{IgG}$ & $(-)$ & $(+)$ \\
\hline
\end{tabular}

Marcador: HBsAg, antígeno de superficie; antiHBsAg, anticuerpo frente al antígeno de superficie; antiHBcAg, anticuerpo frente al antígeno core; $\mathrm{HBeAg}$, antígeno e; antiHBeAg, anticuerpo frente al antígeno e. 
De los diferentes marcadores virales de la hepatitis, el anticuerpo anti-HBs, con especificidad frente al antígeno de superficie HBsAg (proteína codificada en el ADN viral, localizada en la superficie del la envoltura del virus), es un marcador serológico que puede dar información del cuadro clínico de un paciente. A los 4-6 meses de infección, el antígeno de superficie HBsAg tiende a desaparecer y, simultáneamente, aparecen los anticuerpos específicos antiHBsAg, asociados a la recuperación de la infección por VHB y a la inmunidad frente a la reinfección por este virus. Por otro lado, aquellos individuos que hayan sido vacunados del VHB también darán positivo.

En la Tabla 26 se muestran las diferentes especies de antígenos y anticuerpos empleadas para la detección del anticuerpo antiHBs. Para la detección se utilizó un anticuerpo frente a proteína del antígeno de superficie de la hepatitis B, marcador serológico de la recuperación e inmunidad frente al VHB. Este marcador se une específicamente al antígeno de superficie del virus de la heptitis B, así como al virus recombinante (sintetizado mediante técnicas de ADN recombinante y de uso en vacunas). Para evaluar la especficidad del anticuerpo y la ausencia de reactividad cruzada, se utilizaron diferentes marcadores serológicos de la hepatitis B, por ejemplo, proteínas de antígeno core de la hepatitis, marcador que expresan los hepatocitos infectados y que es indicativo de la replicación viral que no se detecta en suero sanguíneo, así como especies víricas de hepatitis C. 
Tabla 26. Antígenos y anticuerpos empleados para los estudios de detección de anticuerpos de la hepatitis B

\begin{tabular}{l|l}
\hline Antígenos & Abreviatura \\
\hline \hline Virus hepatitis C proteína NS5 & HCV NS5 \\
Virus hepatitis B proteína del antígeno core & HBcAg \\
Virus hepatitis B proteína del antígeno de superficie & HBsAg \\
Virus hepatitis C recombinante proteína NS3 & rHCV-NS3 \\
Virus recombinante hepatitis B proteína del antígeno de & rHBsAg \\
superficie & mAbHBsAg \\
\hline Antícuerpos & antiratón-(Alexa-647) \\
\hline \hline Anticuerpo monoclonal de ratón anti-HBsAg & \\
Anticuerpo anti ratón marcado con Alexa-647 & \\
\hline
\end{tabular}

Utilizando chips activados con grupos aldehído, y las diferentes clases de antígenos descritos, se desarrollaron ensayos de biorreconocimiento empleando los sistemas sensores basados en tecnología de guía de ondas plana descritos anteriormente.

En los estudios llevados a cabo para la detección de antiHBsAg se empleó un formato de inmunoensayo indirecto, tal y como muestra la Figura 52a. Los diferentes antígenos de superficie utilizados fueron impresos en matrices $2 \times 3$ en el área de ensayo (Figura 52b), en un intervalo de concentraciones comprendido entre 0,5 y $1 \mu \mathrm{g} / \mathrm{mL}$. Tras un periodo de incubación de $2 \mathrm{~h}$, los chips se bloquearon con caseína y se introdujeron en el soporte de ensayo acoplado con un sistema de fluídica que permite la introducción de muestra. Sobre cada una de las zonas de trabajo en las que se dividió el chip, se introdujo la muestra de mAbHBsAg a 
diferentes concentraciones, en un intervalo $130-0,00013 \mu \mathrm{g} / \mathrm{mL}$ en suero humano diluido (1:300).

Posteriormente, las superficies se trataron con anticuerpo antiratón marcado con Alexa 647 y se procedió a leer la fluorescencia en aquellas matrices donde había reconocimiento, utilizando el lector Zeptoreader. Paralelamente, se llevó a cabo el mismo ensayo sobre chips $\mathbf{T a}_{2} \mathbf{O}_{5}$-DDP, con la finalidad de comparar los resultados para ambas metodologías.

Los resultados mostraron que para ambas superficies únicamente se produce reconocimiento en las matrices en las que previamente se inmovilizaron los virus HBsAg y rHBsAg. Se observó que el diámetro del punto era mayor en las superficies de $\mathrm{Ta}_{2} \mathrm{O}_{5}-(\mathrm{CHO})$, debido a la menor hidrofobidad de este recubrimiento, y que la fluorescencia de fondo fue baja para ambas superficies. Además no se producían reacciones inespecíficas con otros antígenos inmovilizados, demostrando la alta selectividad del reconocimiento biológico (Figura 52c).

Los límites de detección alcanzados para ambas superficies $\mathbf{T a}_{2} \mathbf{O}_{5}(-\mathbf{C H O})$ y $\mathbf{T a}_{2} \mathbf{O}_{5}$ (-DDP), fueron de $300 \mathrm{ng} / \mathrm{mL}$. Los valores de las desviaciones estándar relativas, intrachip e interchip, fueron menores al $20 \%$ en todos los casos, poniendo en evidencia la robustez y reproducibilidad de la aldehización de las superficies, comparable a las obtenidas con las metodologías de referencia.

Con todo ello, los resultados obtenidos mediante la tecnología PWG demuestran que las superficies derivatizadas con alcoxisilanos son compatibles con esta técnica de detección, alcanzando prestaciones comparabales a las de superficies comerciales de referencia $\left(\mathbf{T a}_{2} \mathbf{O}_{5}\right.$ (-DDP)). Así pues, la química de los alcoxisilanos es una alternativa con potencial para el desarrollo de biosensores ópticos de guía de ondas plana de $\mathrm{Ta}_{2} \mathrm{O}_{5}$ basados en microarrays de alta sensibilidad, que permite la realización de medidas automatizadas sin requerir etapas intermedias de lavado y en presencia de otros compuestos. 
(a)

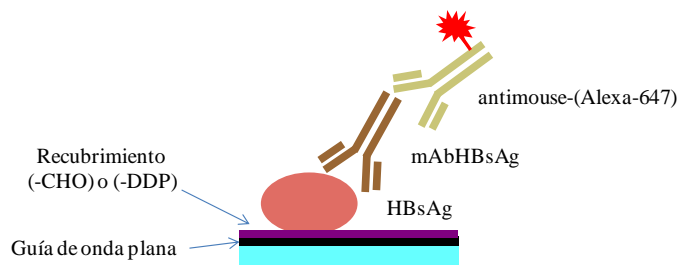

(b)

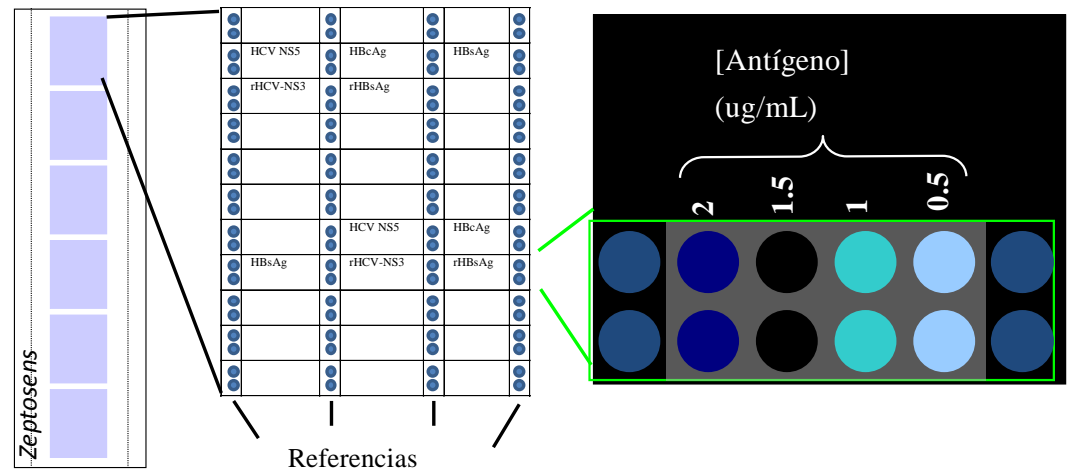

(c)

$\mathrm{Ta}_{2} \mathrm{O}_{5}(-\mathrm{DDP})$

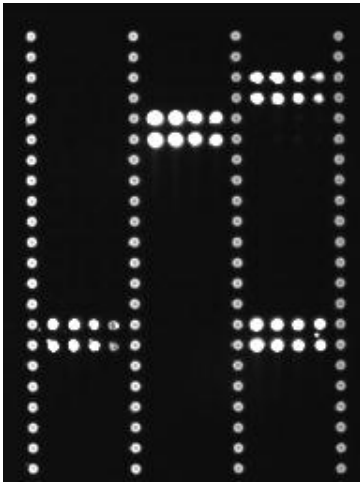

$\mathrm{Ta}_{2} \mathrm{O}_{5}$ (-CHO)

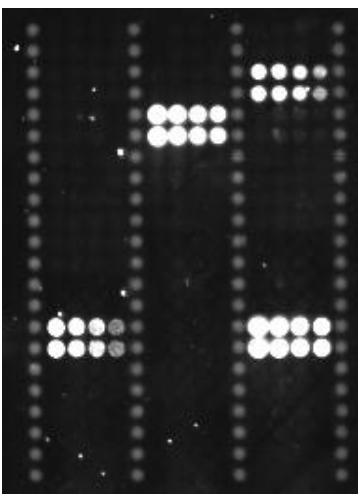

Figura 52. (a) Esquema del formato de ensayo indirecto. (b) Diagrama representativo de la impresión de las sondas en el área de ensayo. (c) Resultados para la detección de anti-HBsAg en $\mathbf{T a}_{2} \mathbf{O}_{5}$ (-DDP) y $\mathbf{T a}_{2} \mathbf{O}_{5}$ (CHO), [antiHBsAg]= $13 \mathrm{ng} / \mathrm{mL}$ en suero. 
Además, a las ventajas intrínsecas de la tecnología de guía de ondas plana, hay que añadir la utilización de protocolos de modificación química de $\mathrm{Ta}_{2} \mathrm{O}_{5}$ sencillos y reproducibles, que permiten la introducción de diferentes grupos funcionales para la inmovilización covalente del elemento de captura. A ello hay que añadir las ventajas del anclaje covalente de biomoléculas: tiempos de inmovilización cortos, sustratos inmovilizados estables frente a agentes externos y control de la orientación espacial de los receptores anclados.

\section{Recapitulación}

En este capítulo de la tesis se ha expuesto el desarrollo de dispositivos sensores basados en estructuras de guía de ondas. En un primer enfoque se trabajó con materiales silíceos debido a sus ideales propiedades ópticas, mecánicas y eléctricas, y a que son los materiales utilizados mayoritariamente como sustratos en sistemas micro-optoelectrónicos fabricados con técnicas ampliamente establecidas. Para ello se trabajó con una estructura fotónica integrada, con varios microanillos resonadores de guías de ondas slot, y se estudió la modificación química selectiva de la guía de nitruro y la fijación de biomoléculas exclusivamente en la misma superficie de detección del dispositivo propuesto. Las superficies fueron funcionalizadas mediante el empleo de glutaraldehído y caracterizadas con técnicas de microscopía (SEM y MCF).

Mediante el empleo de esta estructura fotónica, se consiguió la detección inmunoquímica, sin marcaje, empleando el sistema modelo (antiBSA/BSA) en formato directo. Los resultados indican que la respuesta del sistema sensor es selectiva, únicamente debida a la unión producida en la superficie de la guía de onda. El límite de detección estimado para BSA fue de $16 \mathrm{pg} / \mathrm{mm}^{2}$, resultado satisfactorio si los comparamos con otros sistemas integrados que empleen tecnología de guía de ondas. Esto da una idea del gran potencial de las guías de ondas slot para la detección de pequeñas variaciones de masa en la superficie 
debido a la unión molecular, así como del potencial de la estructura fotónica de microanilllos químicamente modificada, de cara al desarrollo de un sistema biosensor integrado con microfluídica, que permita la detección sin marcaje de distintos analitos de interés, en tiempos de análisis cortos y de manera automatizada, aprovechando las prestaciones de las guías slot.

Otras investigaciones se han centrado en la modificación química de superficies de pentóxido de tántalo, material con propiedades dieléctricas que lo hacen óptimo para el desarrollo de dispositivos optoelectrónicos basados en guía de ondas plana. En el presente trabajo se han desarrollado metodologías basadas en esta tecnología, que aporta ventajas en lo que respecta a la sensibilidad y selectivad del reconocimiento biológico.

En este estudio, se han desarrollado metodologías para la modificación química de pentóxido de tántalo con organosilanos terminados en distintos grupos funcionales (tiol, aldehído, isocianato). Esta metodología permite la activación de las superficies de pentóxido de tántalo con diferentes radicales y, por tanto, una gran versatilidad de cara al anclaje covalente de biomoléculas. Las metodologías propuestas además de no alterar las propiedades ópticas del polímero, condición necesaria para la detección de microarrays mediante tecnología de guía de ondas plana, han permitido la inmovilización eficiente de micromatrices de sondas.

Utilizando este material se han podido detectar anticuerpos de la hepatitis B en suero sanguíneo con límites de detección comparables a los alcanzados sobre superficies alquilfosfatadas e inmovilizadas por adsorción, dando una idea de las buenas prestaciones de nuestra propuesta, que auna ventajas como alta sensibilidad, discriminación entre la superficie y la matriz de la muestra, entre otras, con las correspondientes a la inmovilización covalente de sondas. 


\subsection{Estudio comparativo de los sistemas analíticos desarrollados}

Las investigaciones llevadas a cabo se han centrado en el estudio de la modificación química de diferentes materiales de naturaleza orgánica e inorgánica sobre los que fijar sondas para el desarrollo de biosensores. Todos los sistemas desarrollados tienen en común el empleo de soportes químicamente activados, sobre los que se inmoviliza una biomolécula que actúa como biorreceptor del analito que se pretende detectar y el empleo de un sistema de transducción óptico.

En la Tabla 27 se recogen los principales resultados obtenidos para los distintos sistemas desarrollados: (1) Sistema analítico de CD/DVD con lector de CDs; (2) Sistema fotónico de microanillos resonadores de guías de ondas slot de $\mathrm{Si}_{3} \mathrm{~N}_{4}$, depositadas sobre un sustrato de $\mathrm{SiO}_{2}$; y (3) Sistema de guías de onda plana de pentóxido de tántalo y detección fluorescente. En la Tabla 28 se han comparado las principales propiedades de los mismos.

En los sistemas microanalíticos que emplean materiales poliméricos, se distinguen dos estrategias. La que utiliza formato chip y detección fluorimétrica, y la que trabaja sobre disco compacto y utiliza el propio lector del CD como detector. Con dicho fin, se desarrollaron diferentes rutas para la modificación química de PMMA y PC. Sobre estas superficies se optimizaron ensayos de detección de polimorfismos de una sola base, y detección de gripe aviaria en muestras de saliva. Todos los resultados obtenidos, además de ser comparables con los encontrados en la literatura, demostraron robustez y reproducibilidad de las superficies modificadas, así como la aplicación de una tecnología prometedora, basada en dispositivos de audio-video, para el desarrollo de microarrays con buena sensibilidad y gran capacidad de trabajo. 


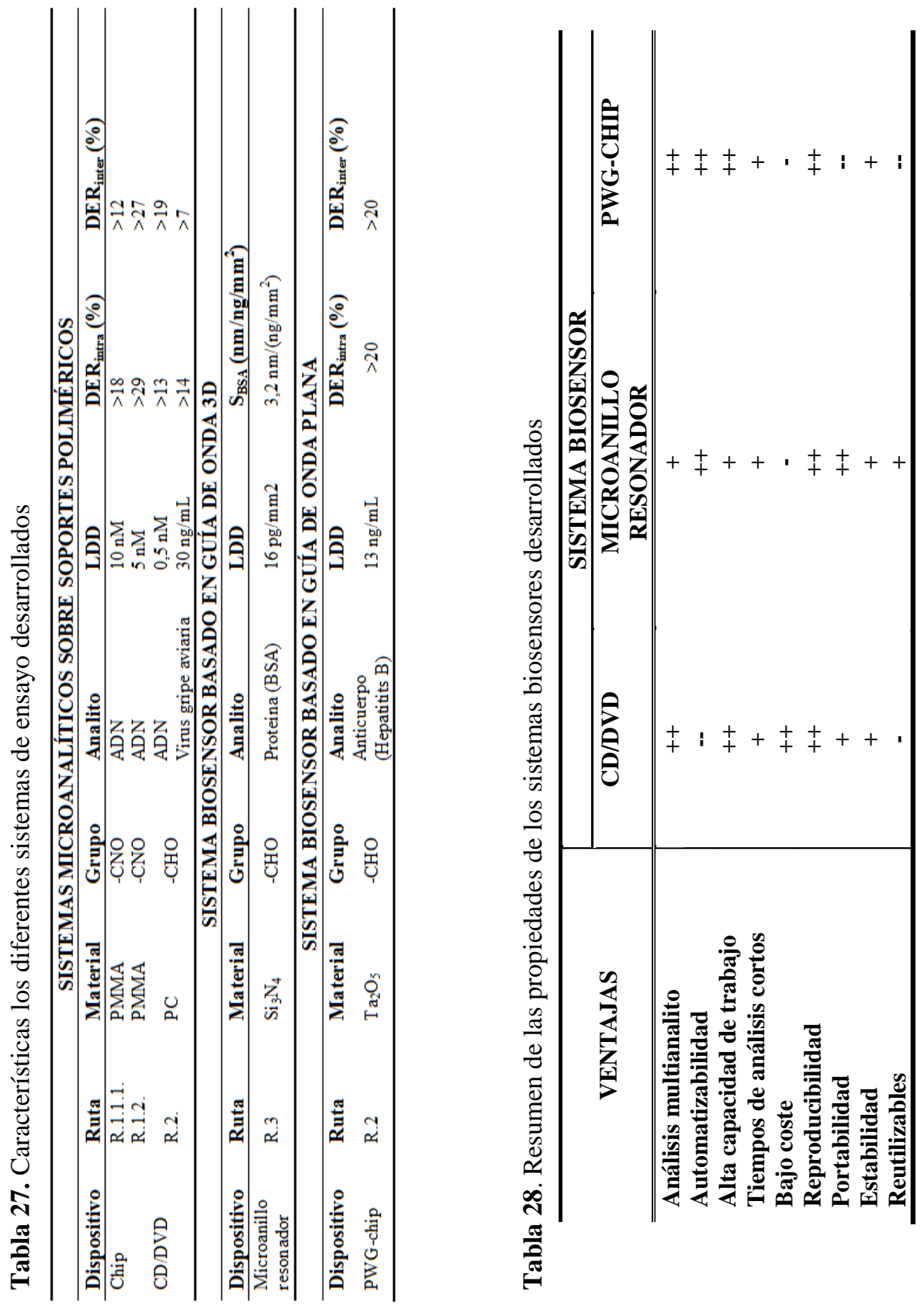


Por otro lado, los resultados obtenidos para los sistemas sensores propuestos basados en microanillo de guía de ondas slot, ponen de manifiesto la aplicabilidad de este tipo de sistemas para detección sin marcaje, con buena sensibilidad respecto a los resultados encontrados en la bibliografía. Además, el desarrollo de este tipo de estructura abre una prometedora área de trabajo de cara al desarrollo de un dispositivo final que integre la microfluídica, y la estructura fotónica, y permita la detección multianalito y sin marcaje.

Finalmente, para el desarrollo de los microarrays sobre superficies de $\mathrm{Ta}_{2} \mathrm{O}_{5}$ utilizando la tecnología de guía de ondas plana para la detección del reconocimiento biológico, se ensayaron diferentes rutas de activación a través de la química de los alcoxisilanos, alcanzando una sensibilidad competitiva respecto a la de las superficies establecidas e incorporando las ventajas de la unión covalente de biomoléculas. Ello ha permitido demostrar la utilidad de los estudios llevados a cabo mediante su aplicación en sistemas reales, tales como la detección del anticuerpo de la hepatitis B en suero. 

En la presente tesis se ha afrontado el estudio de estrategias de modificación química de soportes rígidos (polímeros orgánicos, derivados del silicio y pentóxido de tántalo) para anclaje covalente de receptores moleculares específicos, útiles en el desarrollo de micro y nanobiosensores. Para ello se trabajo en dos líneas diferenciadas.

En lo referente a la primera -metodologías de modificación química para PMMA y PC- han sido desarrolladas diferentes estrategias que introducen distintos grupos funcionales en la superficie $\left(\mathrm{NH}_{2}, \mathrm{CHO}, \mathrm{CNO}\right)$ que permiten la unión covalente de biomoléculas para la puesta a punto de sistemas microanalíticos sencillos, selectivos y versátiles. Los mejores resultados se obtuvieron para las superficies de PC aldehizadas, que se unen a los grupos amino de las biomoléculas a través de la formación de una base Schiff. Mediante esta metodología:

$\checkmark$ Por primera vez fue demostrada la utilización de discos químicamente modificados como platarforma analítica de ensayo usando un lector de CDs como detector. De esta manera, se detectaron sondas de oligonucleótidos hasta concentraciones 2,5 nM, con un alto grado de discriminación de polimorfismos de una sola base (SNPs).

$\checkmark$ Usando esta metodología se puso a punto un inmunoensayo en formato sándwich para detección de virus de gripe aviar sobre un DVD comercial, alcanzándose LDD de $30 \mathrm{ng} / \mathrm{mL}$.

En lo referente a la segunda línea de investigación -funcionalización de materiales inorgánicos para la puesta a punto de biosensores basados en guía de ondas- se ha demostrado la activación química de soportes que integran estructuras de onda bi o tridimensionales para desarrollar biosensores ópticos de alta sensibilidad. Las principales aportaciones en esta línea son: 
$\checkmark$ Los mejores resultados, respecto al trabajo realizado sobre dispositivos de guías de onda 3D, se obtuvieron para la activación selectiva del nitruro del $\mathrm{Si}_{3} \mathrm{~N}_{4}$ frente al $\mathrm{SiO}_{2}$.por tratamiento con glutaraldehído.

$\checkmark$ Esta estrategia permitió el empleo de una nanoestructura fotónica constituida por microanillos de guías de onda slot para la detección de proteína BSA sin necesidad de marcaje. Los LDD alcanzados fueron de $16 \mathrm{pg} / \mathrm{mm}^{2}$, resultados similares a los encontrados en la literatura.

$\checkmark$ En lo referente a los estudios realizados sobre guía de ondas plana, las superficies de $\mathrm{Ta}_{2} \mathrm{O}_{5}$ han sido activadas con distintos grupos funcionales (-SH, $\mathrm{CNO}, \mathrm{CHO})$, mediante el empleo de alcoxisilanos.

$\checkmark$ Usando las superficies de $\mathrm{Ta}_{2} \mathrm{O}_{5}$ aldehizadas se puso a punto un inmunoensayo para la detección de anticuerpos de hepatitis B en suero sanguíneo empleando tecnología de guía de onda plana para la lectura del ensayo. Se alcanzó un LDD de $300 \mathrm{ng} / \mathrm{mL}$ similar a las superficies de referencia basadas en inmovilización por adsorción. 

1. D.R. Thévenot, K. Toth, R.A. Durst, G.S. Wilson. Food Chemistry, 1996, 55, 201.

2. M. Borisov, O.S. Wolfbeis. Chem. Rev., 2008, 108, 423.

3. T. Vo-Dinh, B. Cullum. J. Anal. Chem., 2000, 366, 540.

4. D.R. Thevenot, K. Toth, R.A. Durst, G.S. Wilson. Biosens. Bioelectron., 2001,16,121.

5. L.C. Clark, C. Lyons. Ann. NY Acad. Sci., 1962, 102, 29.

6. http://www.ysilifesciences.com

7. http://www.abbottdiagnostics.com

8. http://www.roche-diagnostics.com

9. http://www.appliedbiosystems.com

10 http://www.novabiomedical.com

11. R. Bashir. Adv. Drug Deliv. Rev., 2004, 56, 1565.

12. L.J. Kricka. Clin. Chim., 2001, 307, 219.

13. B. Weigl, R.L. Bardell, C.R. Cabrera. Adv. Drug Deliv. Rev., 2003, 55, 349.

14. A.M.C. Grayson, R.S. Shawago, A.M. Johnson, N.T. Flynn, Y. Li, M.J. Cima, R. Langer. Proceeding of the IEEE, 2004, 92, 6.

15. W. Wang, S.A. Soper. "BioMEMs. Technologies and applications". Taylor and Francis (Ed), Boca Raton, FL, 2007.

16. Lecture of R. Feynman at Caltech during the APS meeting, December 1959, (http://www.zyvex.com/nanotech/feynman.html). 
17. www.affymetrix.com

18. E.G. Puffenberger, D. Hu-Lince, J.M. Parod, D.W. Craig, S.E. Dobrin, A.R. Conway, E.A. Donarum, K.A. Strauss, T. Dunckley, J.F. Cardenas, K.R. Melmed, C.A. Wright, W. Liang, P. Stafford, C.R. Flynn, D.H. Morton, D.S. Stephan. Proc. Natl. Acad. Sci., 2004, 101, 11689.

19. F.A. Middleton, M.T. Pato, K.L. Gentile, C.P. Morley, X. Zhao, A.F. Eisener, A. Brown, T.L. Petryshen, A.N. Kirby, H. Medeiros, C. Carvalho, A. Macedo, A. Dourado, I. Coelho, J. Valente, M.J. Soares, C.P. Ferreira, M. Lei, M.H. Azevedo, J.L. Kennedy, M.J. Daly, P. Sklar, C.N. Pato. J. Hum. Genet., 2004, 74, 886.

20. R.J. Klein, C. Zeiss, E.Y. Chew, J.Y. Tsai, R.S. Sackler, C. Haynes, A.K. Henning, J.P. Sangiovanni, S.M. Ane, S.T. Mayne, M.B. Bracken, F.L. Ferris, J.O.C. Barnstable, J. Hoh. Science, 2005, 308, 385.

21. S. Ko, S.A. Grant. Biosens. Bioelectron., 2006, 21, 1283.

22. S. Aoyagi, M. Kudo. Biosens. Bioelectron., 2005, 20, 1680.

23. R.G. Heideman, R.P.H. Kooyman, J. Greeve. Sens. Actuators B, 1991, 4, 297.

24. Ch. Stamm, W. Lukosz. Sens. Actuators B, 1996, 31, 203.

25. D. Clerc, W. Lukosz. Sens. Actuators B, 1997, 40, 53.

26. M. Zourob, J.J. Hawkes, W.T. Coakley, B.J.T. Brown, P.R. Fielden, M.B. McDonnell, N.J. Goddard. Anal. Chem., 2005, 77, 6163.

27. G.I. Lepesheva, T.N. Azeva, V.N. Knyukshto, V.L. Chashchin, S.A. Usanov. Sens. Actuators B, 2000, 68, 27.

28. H. A. Engstroem, P.O. Andersson; S. Ohlson. Anal. Biochem., 2006, 357, 159.

29. D.A. Stead. J. Chromatogr., 2000, B 747, 69. 
30. L.D. Mello, L.T. Kubota. Food Chemistry, 2002, 77, 237.

31. R.H. Hall. Microbes and infection, 2002, 4, 425.

32. M.A. González-Martinez, R. Puchades, A. Maquieira. Trends Anal. Chem., 1999, 3, 204.

33. J.P. Gosling. Clin. Chim., 1990, 36, 1408.

34. F.P. Anderson, W.G. Miller. Clin. Chim., 1988, 34, 1417.

35. C.M. Hanbury, W.G. Miller, R.B. Harris. Biosens. Bioelectron., 1996, 11, 1129.

36. J.R. Astles, W.G. Miller. Sens. Actuators B, 1993, 11, 73.

37. K.E. Sapsford, P.T. Charles, C.H. Paterson, F.S. Ligler. Anal. Chem., 2002, 74, 1061 .

38. I.B. Bakaltcheva, F.S. Ligler, C.H. Paterson, L. Shriver-Lake. Anal. Chim. Acta, 1999, 399, 13.

39. C.Q. Zhao, N.A. Anis, K.R. Rogers, R.H. Kline, J. Wright, A.T. Edelfrawi, M.E. Edelfrawi. J. Agric. Food Chem., 1995, 43, 2308.

40. K. Schult, A. Katerkamp, D. Trau, F. Grawe, K. Camman, M. Meusel. Anal. Chem., 1999, 71, 5430 .

41. D.B. Papkovsky, T.C. O’Riordan, G.G. Guilbault. Anal. Chem., 1999, 71, 1568.

42. T. McCormack, G. O’Keffe, B.D. McCraith, R. O’Kennedy. Sens. Actuators B, 1997, 41, 89 .

43. A.N. Sloper, J.K. Deacon, M.T. Flanagan. Sens. Actuators B, 1990, 1, 589.

44. C. Zhou, P. Pivarnik, S. Auger, A. Rand, S. Letcher. Sens. Actuators B, 1997, 42,169 . 
45. U. Narang, G.P. Anderson, F.S. Ligler, J. Burans. Biosens. Bioelectron., 1997, $12,937$.

46. K. King, G.P. Anderson, K.E. Bullock, M.J. Regina, E.W. Saaski, F.S. Ligler. Biosens. Bioelectron., 1999, 14,163.

47. D. Ivnitski, I. Abdel-Hamid, P. Atanasov, E. Wilkins. Biosens. Bioelectron., 1999, 14, 599.

48. S. Morais, R. Marco-Molés, R. Puchades, A. Maquieira. Chem. Comm., 2006, $22,2368$.

49. M.M. Ngundi, C.R. Taitt, S.A. McMurry, D. Kahne, F.S. Ligler. Biosens. Bioelectron., 2006, 21, 1195.

50. H.S. Dhadwal, P. Kemp, J. Aller, M.M. Dantzler. Anal. Chim. Acta, 2004, 501, 205.

51. S.D. Jayasena. Clin. Chem., 1999, 45, 1268.

52. J. Wang, X.J. Zhang, M. Prakash. Anal. Chim. Acta, 1999, 395, 11.

53. D.R. Thévenot, K. Toth, R.A. Durst, G.S. Wilson. Biosens. Bioelectron., 2001, $16,121$.

54. S.F. D’Souza. Biosens. Bioelectron., 2001, 16, 337.

55. B. Ling, Z. Zhang, Y. Jin. Biosens. Bioelectron., 2002, 17, 585.

56. T.T. Stenzel. Arch. Pathol. Lab. Med., 2003, 127, 1565.

57. P. Leonard, S. Hearty, J. Brennan, L. Dunne, J. Quinn, T. Chackraborty, R. O'Kennedy. Enzyme Microb. Technol., 2003, 32, 3.

58. M.P. Raphael, J.A. Christodoulides, S.A. Qadri, M.M. Miller, L.K. Kurihara, J.M. Byers. Biosens. Bioelectron., 2008, 24, 888. 
59. L. Wang, D.M. Sipe, Y. Xu, Q. Lin. J. Microelectromech., 2008, 17, 318.

60. J. Tamayo, M. Alvarez, L.M. Lechuga. Sens. Actuators B, 2003, 89, 33.

61. M. Alvarez, A. Calle, J. Tamayo, L.M. Lechuga, A.Y. Abad, A. Montoya. Biosens. Bioelectron., 2003, 18, 649.

62. B.M. Cullum, G.G. Griffin, T. Vo-Dihn. Anal. Biochem., 2000, 277, 25.

63. D. Diamond. "Chemical and Biological Sensors", John Wiley \& Sons, New York, 1998.

64. Z. Rosenzweig, R. Kopelman. Anal. Chem.,1996, 68, 1408.

65. E. Mallat, D. Barceló, C. Barzen, G. Gauglitz, R. Abuknesha. Trends Anal. Chem., 2001, 20, 124.

66. A. Ramachandran, S. Wang, J. Clarke, S.J. Ja, D. Goad, L. Wald, E.M. Flood, E. Knobbe, J. V. Hryniewicz, S.T. Chu, D. Gill, W. Chen, O. King, B.E. Little. Biosens. Bioelectron., 2008, 23, 939.

67. A. Yalcin, K.C. Popat, J.C. Aldridge, T.A. Desai, J. Hryniewicz, N. Chbouki, B.E. Little, K. Oliver, V. Van, C. Sai. J. Sel. Top. Quant. Electron., 2006, 12, 148.

68. C.Y. Chao, W. Fung, L.J. Guo. J. Sel. Top. Quant. Electron., 2006, 12, 134.

69. T.Vo-Dihn, T. Nolan, Y.F. Chen, M.J. Sepaniak, J.P. Alarie. Appl. Spectrosc., 1990, 44, 128.

70. R. Koncki, G.J. Mohr, O.S. Wolfbeis. Biosens. Bioelectron., 1995, 10, 635.

71. W.R. Seitz. Crit. Rev. Anal. Chem., 1988, 19, 135.

72. E.K. Pye, L.B. Wingard. "Enzyme Engineering", Plenum Press, New York, 2008. 
73. R.F. Taylor. "Protein immobilization: Fundamentals and applications", Marcel Dekker, New York, 1991.

74. W. Hartmeier. Trends Biotechnol., 1985, 3, 149.

75. K. Martinek, V.V. Mozhaev. Adv. Enzymol., 1987, 57, 179.

76. J.H.T. Luong, A. Mulchandani, G.G. Guilbault. Trends Biotechnol., 1988, 6, 310.

77. V. González-Rumayor, E. García-Iglesia, O. Ruiz-Galán. Aplicaciones de biosensores en la industria agroalimentaria. CEIM/Dirección General de Universidades e Investigación, 2005.

78. G.Wagner, G.G. Gibault. "Food Biosensors Analysis". G.G. Gibault (Ed.), Marcell Decker, New York, 1994.

79. S. Zhang, G.Wright, Y. Yang. Biosens. Bioelectron., 2000, 15(5-6), 273.

80. P.N. Barlett, S. Booth, D.J. Caruana, J.D. Kilburn, C. Santamaría. Anal. Chem., 1997, 69, 734 .

81. E. Oosterbroek. Lab-on-a-chip: "Miniaturized Systems for Biochemical Analysis and Synthesis". E. van den Berg (Ed.), Elsevier Science, Amsterdam, 2003.

82. P. Najmabadi, J.J. Laclair, M.D. Burkart. J. Org. Biomol. Chem., 2007, 5, 214.

83. J.J. la Clair, M.D. Burkart. J. Org. Biomol. Chem., 2003, 1, 3244.

84. J.J. LaClair, Eur. Pat Appl. Number 00120417.1. 2002.

85. B. D. Hammock, H. Kido, A. Maquieira. U.S. Patent. Number US20026342395B1. 2002.

86. J. Virtanen. U.S. Patent. Number 20006030581. 2000. 
87. S. Iimura, H. Ogawa. U.S. Patent. Number 20030169677A1. 2003.

88. C. Liu. Adv. Mater., 2007, 19, 3783.

89. J. Frechette, R. Maboudian, C. Carraro. J. Microelectromech. Syst., 2007, 15,737 .

90. S.A. Soper, S.M. Ford, R.L. McCarley, K. Kelly, M.C. Murphy. Anal. Chem., 2000, 72, 642 .

91. J. Rossier, F. Reymond, P.E. Michel. Electrophoresis, 2002, 23, 858.

92. W.N. Sharpe, Jr., K.M. Jackson, K.J. Hemker, Z. Xie. J. Microelectromech. Syst., 2001, 10, 317.

93. W.N. Sharpe, J. Bagdahn. Mech. Mater., 2004, 36, 3.

94. Z.H. Fan, J.D. Harrison. Anal. Chem., 1994, 66, 177.

95. J.P. Landers. "Handbook of Capillary and Microchip Electrophoresis and Associated Microtechniques”, J.P. Landers (Ed.), CRC Press, Boca Raton, FL, 2008.

96. X. J. Shen, L.W. Pan, L. Lin. Sens. Actuators A, 2002, 428, 97.

97. T. Cui, J. Wang. J. Microelectromech. Syst., 2005, 14, 895.

98. N. Fang, C. Sun, X. Zhang. Appl. Phys., 2004, 79, 1839.

99. D.J. Beebe, J.S. Moore, J.M. Bauer, Q. Yu, R.H. Liu, C. Devadoss, B.H. Jo. Nature, 2000, 404, 588.

100. M.W. Rowell, M.A. Topinka, M.D. McGehee, H.J. Prall, G. Dennler, N.S. Saricifci, L. Hu, G. Gruner. Appl. Phys. Lett., 2006, 88, 233.

101. J.H. Ahn, H.S. Kim, K.J. Lee, S. Jeon, S.J. Kang, Y. Sun, R.G. Nuzzo, J.A. Rogers. Science, 2006, 314, 1754. 
102. Standard IEC60908, International Electrotechnical Comission, 1999.

103. http://electronics.howstuffworks.com

104. N. Hayashida, T. Kazushi. U.S. Patent. Number US20050095432A1. 2005.

105. N. Hayashida, K. Yoniyama, T. Kazushi. U.S. Patent. Number US 20050123741 A 1.2005.

106. N. Hayashida, T. Kazushi. U.S. Patent. Number US20050248881A1. 2005.

107. M. Madou, J. Zoval, G. Jia, H. Kido, J. Kim. Annu. Rev. Biomed. Eng., 2006, 8,601 .

108. H. Kido, M. Micic, D. Smith, J. Zoval, J. Norton, M. Madou. Colloids and Surfaces:Biointerfases, 2007, 58, 44.

109. H. Kido, J. Zoval, M. Madou. Curr. Opin. Chem. Biol., 2008, 305.

110. N. Kim, C.M. Dempsey, J. Zoval, J.Y. Sze, M. Madou. Sens. Actuators B, 2007, $122(2), 511$.

111. http://gyros.com

112. http://gamera.informatik.hsnr.de

113. I. Alexandre, Y. Houbion, J. Collet, J. Demarteau, J.L. Gala, J. Remacle. Biotechniques, 2002, 33, 435.

114. J. Remacle, I. Alexandre, Y. Houbion. U.S. Patent. Number US 2002177144A1, 2005.

115. R.A. Potyrailo, W.G. Morris, A.M. Leach, T.M. Sivavec, M.B. Wisnudel, S. Boyette. Anal. Chem., 2006, 78 (16), 5893.

116. R. A. Potyrailo, W.G. Morrisa, R. Wroczynskia, L. Hassiba, P. Millera, B. Dworkena, A. M. Leacha, S. Boyetteb, C. Xiao. Sens. Actuators B, 2009, 136, 203. 
117. S.A. Lange, G. Roth, S. Wittermann, T. Lacoste, A. Vetter, J. Graslse, S. Kopta, M. Kolleck, B. Breitinger, M. Wick, J.K.H. Horber, S. Dubel, A. Bernard. Angew. Chem., 2006, 45, 270.

118. X. Wang, M. Zhao, D.D. Nolte. Anal. Bioanal. Chem., 2009, 393 (4), 1151.

119. X. Wang, M. Zhao, D.D. Nolte. Appl. Phys. Lett., 2008, 93, 2239.

120. D.D. Nolte, F.E. Regnier. Opt. Phot. News, 2004, 15, 48.

121. X. Wang, M. Zhao, D.D. Nolte. Appl. Optics, 2008, 47 (15), 2779.

122. M.M. Varma, L. Peng, F.E. Regnier, D.D. Nolte. Proc. of SPIE, 2005, 5699, 503.

123. B. Singh, A.C. Hillier. Anal. Chem., 2006, 78, 2009.

124. H. Kido, A. Maquieira, B.D. Hammock. Anal. Chim. Acta, 2000, 411, 1.

125. J. Tamarit-López, S. Morais, R. Puchades, A. Maquieira. Anal. Chim. Acta, 2008, 609 (1), 120.

126. S. Morais, J. Tamarit-López, J. Carrascosa, R. Puchades, A. Maquieira. Anal. Bioanal. Chem., 2008, 391 (8), 2837.

127. S. Morais, J. Carrascosa, D. Mira, R. Puchades, A. Maquieira. Anal. Chem., 2007, 79 (20), 7628.

128. S. Morais, L.A. Tortajada-Genaro, T. Arnandis-Chover, R. Puchades, A. Maquieira. Anal. Chem., 2009, 81, 5646.

129. M.J. Bañuls, M.V. González-Pedro, R. Puchades, A. Maquieira. Bioconjugate Chem., 2007, 18, 1408.

130. D.R. Reyes, D. Iossifidis, P.A. Auroux, A. Manz. Anal. Chem., 2002, 74, 2623. 
131. K. Norman, A. Ghanbari-Siahkali, N.B. Larsen. Annu. Rep. Prog. Chem. C, 2005, 101, 174.

132. A. C. Henry, R.L. McCarley. J. Phys. Chem., 2001, 105, 8755.

133. A.C. Henry, T.T. Tutt, C.S. Mcwharter, Y.Y. Davidson, M. Galloway, S.A. Soper, R.L. McCarley. Anal. Chem., 2000, 72, 5331.

134. S.A. Soper, A.C. Henry, B. Vaidya, M. Galloway, M. Wabuyele, R.L. McCarley. Anal. Chim. Acta, 2002, 470 (1), 87.

135. E. Waddell, Y. Wang, W. Stryjewski, S. McWhorter, A.C. Henry, D. Evans, R.L. McCarley, S.A. Soper. Anal. Chem., 2000, 72, 5907.

136. F. Fixe, M. Dufva, P. Telleman, B.V. Christensen. Nucleic Acids Res., 2004, $32,1,9$.

137. V. Bulmus, H. Ayhan, E. Piskin. Chem. Eng. J., 1997, 65, 71.

138. G.A. Díaz-Quijada, R. Peytavi, A. Nantel, E.R. Roy, M.G. Bergeron, M.M. Dumoulin, T. Veres. Lab. Chip, 2007, 7, 856.

139. F. Xu, P. Datta, H. Wang, S. Gurung, M. Hashimoto, S. Wei, J. Goettert, R.L. McCarley, S.A. Soper. Anal. Chem., 2007, 79, 9007.

140. Y. Li, Z. Wang, L.M.L. Ou, H.Y. Yu. Anal. Chem., 2007, 79, 426.

141. M. Pallapa, L.M.L. Ou, M. Parameswaran, H.Z. Yu. Sens. Actuators B, 2010, 148,620 .

142. R.A. Soref. Proc. of IEEE, 1993, 81, 1687.

143. W. Menz, J. Mohr, O. Paul. "Microsystems Technology", Wiley-VCH, New York, 2001. 
144. G. T. A. Kovacs. "Micromachined Transducers Sourcebook", McGraw-Hill, New York, 1998.

145. M. Madou. "Fundamentals of Microfabrication", CRC Boca Raton, FL, New York, 1997.

146. J. Voldma, M.L. Gray, M.A. Schmidt. Ann. Rev. Biomed. Eng., 1999, 1, 401.

147. P. Patnaik. "Handbook of Inorganic Chemicals", McGraw-Hill, New York, 2002.

148. E. Mauriz, A. Calle, A. Abad, A. Montoya, A. Hildebrandt, D. Barceló, L.M. Lechuga. Biosensors. Bioelectron., 2006, 21, 2129.

149. E. Mauriz, A. Calle, L.M. Lechuga, J. Quintana, A. Montoya, J.J. Manclús. Anal. Chim. Acta, 2006, 561, 40.

150. B. Sepulveda, A. Calle, L.M. Lechuga, G. Armelles. Opt. Lett., 2006, 31, 1085.

151. R. Slavík, J. Homola, J. Cytyroky, E. Brynda. Sens. Actuators B, 2001, 74, 106.

152. R. Slavík, J. Homola. Sens. Actuators B, 2007, 123, 10.

153. M. Piliarik, J. Homola, Z. Maníkova, J. C. Tyroky. Sens. Actuators B, 2003, 90, 236.

154. M. Piliarik, H. Vaisocherová, J. Homola. Biosens. Bioelectron., 2005, 20, 2104.

155. H.J. Lee, D. Nedelkov, R.M. Corn. Anal. Chem., 2006, 78, 6504.

156. B.P. Nelson, T.E. Grimsrud, M.R. Liles, R.M. Goodman, R.M. Corn. Anal. Chem., 2001, 73, 1. 
157. R.G. Heideman, P.V. Lambeck. Sens. Actuators B, 1999, 10, 109.

158. A. Ymeti, J.S. Kanger, J. Greve, P.V. Lambeck, R. Wijn, R.G. Heideman. Appl. Opt., 2003, 42, 5649.

159. A. Ymeti, J. Greve, P.V. Lambeck, T. Wink, S.W.F.M.V. Hovell, T.A.M.

Beumer, R.R. Wijn, R.G. Heideman, V. Subramaniam, J.S. Kanger. Nano Lett., 2007, 7, 394.

160. B.H. Schneider, J.G. Edwards, N.F. Hartman. Clin. Chem., 1997, 43, 1757.

161. B.H.Schneider, E.L. Dickinson, M.D. Vach, J.V. Hoijer, L.V. Howard. Biosens. Bioelectron., 2000, 15, 13.

162. B.H. Schneider, E.L. Dickinson, M.D. Vach, J.V. Hoijer, L.V. Howard. Biosens. Bioelectron., 2000, 15, 597.

163. http://www.farfield-scientific.com/.

164. V.S.Y. Lin, K. Motesharei, K.-P.S. Dancil, M.J. Sailor, M.R. Ghadiri. Science, 1997, 278, 840 .

165. M.M. Varma, H.D. Inerowicz, F.E. Regnier, D.D. Nolte. Biosens. Bioelectron., 2004, 19, 1371.

166. M. Zhao, D.D. Nolte, W. Cho, F. Regnier, M. Varma, G. Lawrence, J. Pasqua. Clin. Chem., 2006, 52, 2135.

167. F.S. Tan, D.J.W. Klunder, H. Kelderman, H.J.W.M. Hoekstra, A. Driessen. Proc. of IEEE, 2002, 228.

168. Y. Teramura, H. Iwata. Anal. Biochem., 2007, 365, 201.

169. B.K. Oh, Y.K. Kim, K.W. Park, W.H. Lee, J.W. Choi. Biosens. Bioelectron., 2004, 19, 1497. 
170 . A.W. Wark, H.J. Lee, R.M. Corn. Anal. Chem., 2005, 3904.

171. http://www.biacore.com/lifesciences/index.html.

172. J.Q. Abraham, R.C. Bailey. Angew. Chem. Int., 2010, 49, 4608.

173. A. Ksendzov, M.L. Homer, A.M. Manfreda. Electron. Lett., 2004, 40, 152.

174. A. Ksendzov, Y. Lin. Opt. Lett., 2005, 30, 3344.

175 . K. de Vos, I. Bartolozzi, E. Schacht, P. Bienstman, R. Baets. Opt. Express, 2007, 15, 7610 .

176. N. Skivesen, A. Têtu, M. Kristensen, J. Kjems, L.H. Frandsen, P.I. Borel. Opt. Express, 2007, 15, 3169.

177. V. Toccafondo, J. García-Rupérez, M.J. Bañuls, J.G. Castelló, S. PeransíLlopis, A. Maquieira. Opt. Lett., 2010, 35, 3673.

178. T. Endo, S. Ozawa, N. Okuda, Y. Yanagida, S. Tanaka, T. Hatsuzawa. Sens. Actuators B, 2010, 148, 269.

179. C.Y. Chao, L.J. Guo. Appl. Phys. Lett., 2003, 83, 1527.

180. C.Y. Chao, L.J. Guo. J. Lightwave Technol., 2006, 1395.

181. M. Ehrat, G.M. Kresbach. Chimia, 2001, 55, 35.

182. M. Pawlak, E. Grell, E. Schick, D. Anselmetti, M. Ehrat. Faraday Discuss, 1998, 37, 27.

183. G.L. Duveneck, M. Pawlak, D. Neuschäfer, E. Bär, W. Budach, U. Pieles, M. Ehrat. Sens. Actuators B, 1997, 38, 88.

184. H.M. Grandin, B. Staedler, M. Textor, J. Vörös. Biosens. Bioelectron., 2006, $21,1476$. 
185. U. Weisenstein, M.J. Schneider, M. Pawlak, J. Cicenas, S. EppenbergerCastori, P. Oroszlan, S. Ehret, A. Geurts-Moespot, F.C.G.J. Sweep, U. Eppenberger. Proteomics, 2006, 6, 1427.

186. P. Francois, Y. Charbonnier, J. Jacquet, D. Utinger, M. Bento, D. Lew, G.M. Kresbach, M. Ehrat, W. Schlegel, J. Schrenzel. J. Microbiol. Methods, 2006, 65, 390.

187. C.A. Barrios, K.B. Gylfason, B. Sanchez, A. Griol, H. Sohlström, M. Holgado, R. Casquel. Opt. Lett., 2007, 32, 3080.

188. C.A. Barrios, B. Sanchez, K.B. Gylfason, A. Griol, H. Sohlstrom, M. Holgado, R. Casquel. Opt. Express, 2007, 15, 6846.

189. K. Schmitt, K. Oehse, G. Sulz, C. Hoffmann. Sensors, 2008, 8, 711.

190. A.P. Abel, W. Budach, G.L. Duveneck, M. Ehrat, G.M. Kresbach, D. Neuschäfer. Num. Patent WO/2000/075644. 2002.

191. A. Ulman. Chem. Rev., 1996, 1533-1554.

192. F. Davis, S.P.J. Higson. Biosens. Bioelectron., 2005, 21, 1.

193. E.A. McArthur, T. Ye, J.P. Cross, S. Retoud, E. Barguet. J. Am. Chem. Soc., 2004, 126, 2260.

194. D.K. Aswal, S. Lenfant, D. Guerin, J.V. Yakhmi, D. Vuillaume. Anal. Chim. Acta, 2006, 568, 84 .

195. S. Lau, M. Veiseh, M. Zhang. Biosens. Bioelectron., 2005, 20, 1697.

196. B.J. Larson, J.M. Helaren, S.O. Manolache, A.Y. Lau, M.G. Lagally, F.S. Denes. Biosens. Bioelectron., 2005, 21(5), 796. 
197. G.F. Cerofolini, G. Arena, C.M. Camarelli, C. Galati, S. Reina, L. Renna, D. Mascolo. Nanotech., 2005, 16, 1040.

198. B.X. Xia, S.J. Xiao, D.J. Streifer, J. Wang, J. Chao, H.B. Liu, J. Pei, Y.Q. Chen, Y.C. Tang, J.N. Lui. J. Mater. Chem., 2006, 16, 570.

199. J.A. Streifer, H. Kim, B.M. Nichols, R.J. Hamers. Nanotech., 2005, 16, 1868.

200. S.W. Metzger, M. Natesan, C. Yanavich, J. Schneider, G.U. Lee. J. Vac. Sci. Technol. A, 1999, 17(5), 2623.

201. B.J. Eves, Q.Y. Sun, G.P. Lopinski, H. Zuilhof. J. Am. Chem. Soc., 2004, 126, 14318.

202. T. Strother, W. Cai, X. Zhao, R.J. Hamers, L.M. Smith. J. Am. Chem. Soc., 2000, 122, 1205.

203. A.B. Sieval, A.L. Demirel, J.W. M. Nissink, M.R. Linford, J.H. van der Maas, W.H. de Jeu, H. Zuilhof, E.J.R. Sudhölter. Langmuir, 1998, 14, 1759.

204. A.B. Sieval, R. Linke, H. Zuilhof, E.J.R Sudhölter. Adv. Mater., 2000, 12, 1457.

205. A. Arafat, K. Schroen, L.C.P.M. de Smet, E.J.R. Sudhölter, H. Zuilhof. J. Am. Chem. Soc., 2004, 126, 8600.

206. A. Arafat, M. Gisebers, M. Rosso, E.J.R. Sudhölter, K. Schroën, R.G. White, L. Yang, M.R. Lindford, H. Zuilhof. Langmuir, 2007, 23, 6233.

207. L. Scheres, J. Mat, M. Giesbers, H. Zuilhof. Small, 2010, 5, 642.

208. G.J. Zhang, H.J., Chua, R.E. Chee, A. Agarwal, S.M. Wong, K.D. Buddharaju, N. Balasubramanian. Biosens. Bioelectron., 2008, 23, 1701. 
209. G.J. Zhang, L. Zhang, M.J. Huang, Z.H.H. Luo, G.K.I Tay, E.J.A. Lim, T.G. Kang, Y. Chem. Sens. Actuators B, 2010, 146, 138.

210. K.S. Midwood, M.D. Karolas, M.P. Danahy, J.E. Schwarzbauer, J.E. Schwartz. Langmuir, 2004, 20, 5501.

211. C. Chu-Jiang, S. Zhi-Gang, X. Yu-Shan, M. Shu-lin. J. Phys. Chem., 2006, 39, 4829.

212. S. Diegoli, P.M. Mendes, E.R. Baguley, S.J. Leigh, P.Iqbal, Y.R. Garcia-Diaz, S. Begum, K. Critchley, G.D. Hammond, S.D. Evans, D. Attwood, I.P. Jones, J.A. Preece. J. Exp. Nanosci., 2006, 1, 333.

213. A.E. Hooper, D. Werho, T. Hopson, O. Palmer. Surf. Interf. Anal., 2001, 31, 809.

214. P. Iqbal, K. Critchley, S. Begum, D. Attwood, S.D. Evans, I.P. Jones, J.A. Preece. J. Exp. Nanosci., 2006, 1, 143.

215. H. Takano, J.R. Kenseth, S.-S. Wong, J.C. O'Brien, M.D. Porter. Chem. Rev., 1999, 99, 2845.

216. M. Manning, S. Harvey, P. Galván, G. Redmond. Mat. Sci. Technol. C, 2003, 23,347 .

217. A. Tlili, M.A. Jarboui, A. Abdelghani, D.M. Fathallah, M.A. Maaref. Mat. Sci. Technol. C, 2005, 25, 490.

218. J. Diao, D. Ren, J.R. Engstrom, K.H. Lee. Anal. Biochem., 2005, 343, 322.

219. A. Wang, H. Tang, T. Cao, S.O. Salley, N.K.Y. Simon. J. Colloid Interface Sci., 2005, 291, 438.

220. A. Simon, T. Cohen-Bouhacina, M.C. Porte, J.P. Aime, C. Baquey. J. Colloid Interface Sci., 2002, 251, 278. 
221. B. Pignataro, G. Grasso, L. Renna, G. Marletta. Surf. Interface Anal., 2002, 33, 54.

222. A. Arafat, M.A. Daous. Sens. Actuators B, 2011, 152, 226.

223. Y. Coffinier, R. Boukherroub, X. Wallart, J-P Nys, J.O. Durand, D. Stiévenard, B. Granditier. Surface Sci., 2007, 601, 5492.

224. F. Cataruzza, A. Cricenti, A. Flamini, M. Girasole, G. Longo, A. Mezzi, T. Prosperi. J. Mater. Chem., 2004, 14, 1461.

225. M.A. Karymov, A.A. Kruchinin, Y.A. Tarantov, I.A. Balova, L.A. Remisova, Y.G. Vlasov. Sens. Actuators B, 1995, 29, 324.

226. A. Ulman. Avd. Mater., 1990, 2, 573.

227. R. Polzius, T. Schneider, F.F. Bier, E. Bilitewski. Biosens. Bioelectron., 1996, $11,503$.

228. R. de Palma, W. Laureyn, F. Frederix, K. Bonroy, J.J. Pireaux, G. Borghs, G. Maes. Langmuir, 2007, 23, 443.

229. M. Textor, L. Ruiz, R. Hofer, A. Rossi, K. Feldman, G. Haehner, N.D. Spencer. Langmuir, 2000, 16, 3257.

230. D. Brovelli, G. Haehner, L. Ruiz, R. Hofer, G. Kraus, A. Waldner, J. Schloesser, P. Oroszlan, N.D. Spencer. Langmuir, 1999, 15, 4324.

231. O.S. Wolfbeis. Trends Anal. Chem., 1996, 15, 225.

232. P.M. Nellen, W. Lukosz. Sens. Actuators B, 1990, 1, 592.

233. D. Mira, R. Llorente, S. Morais, R. Puchades, A. Maquieira, J. Marti. Proc. of the SPIE, 2004, 5617, 364. 
234. X. Cao, Y.F. Wang, C.F. Zhang, W.J. Gao. Biosens. Bioelectron., 2006, 22, 393.

235. www.gelifesciences.com

236. http://www.piercenet.com

237. http://www.binaxnow.com

238. www.zeptosens.com

239. M.O. Worthington, J.R. Norton, H. Kido, V.M. Ortiz. Eur. Pat. 2002047071A2. 2002.

240. H. Berney, K. Oliver. Biosens. Bioelectron., 2005, 21, 618.

241. B. Lillis, M. Mannings, H. Berney, E. Hurley, A. Mathewson, M.M. Sheehan. Biosens. Bioelectron., 2006, 21, 1459.

242. B.A. Stillman, J.L. Tonkinson. Anal. Biochem., 2001, 295, 149.

243. A.W. Peterson, R.J. Heaton, R.M. Georgiadis. Nucleic Acid Res., 2001, 29, 5163.

244. S.S. Wong. "Homobifunctional cross-linking reagents. In chemistry of protein conjugation and cross-linking”, CRC Press Inc., Boca Raton, FL, 1991.

245. D.T. Clark, W.J. Feast. "Polymer Surfaces", John Wiley \& Sons, New York, 1978.

246. Y. Li. Anal. Chem., 2007, 12, 426.

247. M. Schena. "Microarray biochip technology”, Eaton publishing, Natick, 2000.

248. M.J. Bañuls, F. García-Piñon, R. Puchades, A. Maquieira. Bioconjugate Chem. 2007, 18, 1408. 
249. G.U. Lee. Israel J. Chem., 1996, 36, 81.

250. R.B. Wallace; J. Shaffer, R.F. Murphy, J. Bonner, T. Hirose, K. Itakura. Nucleic Acids Res., 1979, 6, 3543.

251. http://www.certest.es/

252. http://www.quidel.com

253. http://www.jefrapidtest.com/

254. D.S. Reichmut, S. Wang, L.M. Barret, D.J. Throckmorton, W. Einfeld, A.K. Singh. Lab. Chip, 2008, 8, 1319.

255. X. Yan, W. Zhing, A. Tang, E.G. Schielke, W. Hang, J.P. Nolan. Anal. Chem., 2005, 77, 7673.

256. J. Xu, D. Suarez, D.S. Gottfried. Anal. Bioanal. Chem., 2007, 389, 1193

257. A. Weinberg, M.L. Walker. Clin. Diagn. Lab. Immunol., 2005, 12(3), 367.

258 . C. F. Carlborg, K. B. Gylfason, A. Kazmierczak, F. Dortu, M. J. Bañuls Polo,A. Maquieira,G. M. Kresbach,H. Sohlstrom, T. Moh, L. Vivien, J. Popplewell, G. Ronan, C. A. Barrios, G. Stemme,W. van der Wijngaart. Lab. Chip, 2010, 10, 281.

259. C.A. Barrios, M. Lipson. Opt. Express, 2005, 13(25), 1009.

260. C.A. Barrios, M. Lipson. Eur. Pat WO2007058919A1. 2007.

261. Q.Y. Sun, L.C.P.M. Smet, B. Lagen, M. Gierbers, P.C. Thüne, J. Egelenburg, F.A. Wolf, H., E.J.R. Sudhölter. J. Am. Chem. Soc., 2005, 127, 2514.

262. I. Choi, S.K. Kang, J. Lee, Y. Kim, J. Yi. Biomaterials, 2006, 27, 4655.

263. W. Liao, F. Wei, M.W. Qian, X.S. Zhao. Sens. Actuators B, 2004, 101, 361. 
264. H.J. Seok, M.Y. Hong, Y.J. Kim, M.K. Han, D. Lee, J.H. Leeb, J.S. Yoob, H.S. Kim. Anal. Biochem., 2005, 337, 294.

265. C.A. Barrios. Proc. SPIE, 2009, 73, 7356.

266. B.J. Luff, J.S. Wilkinson, J. Pielher, U. Hollenbach, J. Ingenhoff, N. Fabricius. J. Lightwave Technol., 1998, 16, 583.

267 . J.M. Echevarría, P. León . Enferm. Infecc. Microbiol. Clin., 1995,13, 22. 